Developing Adaptive Capacity in Times of Climate Change in Central Rural Vietnam: Exploring smallholders' learning and governance 


\section{Developing Adaptive Capacity in Times of \\ Climate Change in Central Rural Vietnam: \\ Exploring smallholders' learning and governance}

\section{Thesis committee}

\section{Promotor}

Prof. Dr Arjen E.J. Wals

Personal Chair at the Education and Competence Studies group,

Wageningen University \& Research

\section{Co-promotors}

Dr G. Robbert Biesbroek

Assistant professor, Public Administration and Policy group,

Wageningen University \& Research

Dr Le Thi Hoa Sen

Associate professor, Faculty of Extension and Rural Development University of Agriculture and Forestry, Hue University, Vietnam

\section{Other members}

Prof. Dr Simon R. Bush, Wageningen University \& Research

Dr Tran Duc Tuan, Hanoi National University of Education, Vietnam

Dr Annemarie Groot, Wageningen University \& Research

Dr Jeroen F. Warner, Wageningen University \& Research

This research was conducted under the auspices of the Graduate School,

Wageningen of Social Sciences (WASS)

\section{Le Thi Hong Phuong}

\section{Thesis}

submitted in fulfilment of the requirements for the degree of doctor

$$
\text { at Wageningen University }
$$

by the authority of the Rector Magnificus,

$$
\text { Prof. Dr. A.P.J. Mol, }
$$

in the presence of the

Thesis Committee appointed by the Academic Board

$$
\text { to be defended in public }
$$

on Wednesday 22 November 2017

$$
\text { at } 11 \text { a.m in the Aula. }
$$




\section{Abstract}

Climate change already affects Vietnam in virtually all sectors. Agriculture in small communities is particularly vulnerable to current and projected climate change impacts. Many of the smallholder farmers in Vietnam have limited adaptive capacity to deal with these impacts. Increasingly social learning is proposed as an important mechanism to build the adaptive capacity of local farming communities. However, little is known about the interplay between social learning and adaptive capacity and how adaptive capacity could be increased in a complex hierarchical governance setting that is typical in a country like Vietnam. The dissertation therefore aims to elicit and explore the ways through which social learning can increase the adaptive capacity of smallholder farmers in central Vietnam to respond to climate change impacts. Four research questions are addressed: (i) what insights does the existing body of climate change adaptation literature provide into the interplay between social learning and adaptive capacity?; (ii) what do smallholder farmers in Vietnam perceive as their current adaptive capacity and what enables or constrains them in increasing it?; (iii) how can social learning configurations strengthen the adaptive capacity of farming communities?; and (iv) how do different levels of government enable and constrain the process of building adaptive capacity and social learning of smallholder farmers to respond to impacts of climate change in Vietnam?

Overall, the dissertation shows that social learning offers many possibilities to help farmers adapt to climate change, but that climate change adaptation in developing countries creates specific contextual conditions that require an adaptive capacityfocused perspective. An adequate learning configuration that can successfully help farmers build their adaptive capacity, considers responsive design, facilitation, monitoring, and evaluation steps. Furthermore, efforts of increasing adaptive capacity should not only focus on technical, social and human dimensions, but also on market conditions. The critical importance in creating an environment that enables social learning is the role of government across different levels. In order for the Vietnamese government to be more actively involved in building adaptive capacity through social learning, investments in transparent legal institutions, efficient use of limited available resources, and enhancing capacity of local policy actors will be critical in helping smallholder farmers learn how to adapt to climate change impacts. 


\section{Acknowledgements}

This PhD thesis, with its hurdles as well as blissful moments, would never have been completed had it not been with the help of various individuals.

A PhD-project is a long journey with many opportunities and challenges. The first challenge and also the most difficult one, was that I had to live far from my beloved family, especially my little son. The second challenge for me was to live in a foreign country with a different language, culture, food, and weather. This was counterbalanced by the many opportunities that I received to educate myself. I developed an extensive network, travelled to many countries, and met many interesting people who encouraged and helped me build up my motivation. With their support, my PhD-journey came to a successful end and I would like to take this opportunity to acknowledge all for their mental, financial, and academic support.

I am grateful for financial support from the Ministry of Education and Training, Vietnam and NUFFIC/NICHE/VNM/105 project, The Netherlands, which has made it possible to complete my PhD study. In the same spirit, I am grateful to my employer, University of Agriculture and Forestry (HUAF), Hue University, for granting me the study-leave to pursue doctoral training at Wageningen University.

First and foremost, I am deeply grateful to my promotor, Prof. dr. ir. Arjen E.J. Wals. I must have been lucky to work with Arjen who passionately cared about me and showed great interest in what I did. It has been a pleasure discussing and learning from your experience. Thanks for your invaluable guidance; this has always been very helpful for my achievement today. Your meticulous and helpful comments and suggestions during the time I wrote a research proposa and while writing the manuscripts, are much appreciated. Several times, you spent a lot of time explaining to me "only one new term" or supporting my critical thinking to help me understand particular issues in my dissertation. I greatly appreciate that you have inspired me with creativity, challenged me with tough questions and provided me valuable suggestions for significantly improving the dissertation. I want also to thank you for your time from The Netherlands to visit me and my family in 2015. During your visit in Vietnam, you worked almost full-time to help me to finish the first survey of my PhD project. Your contribution to my success today has an inestimable value. I also would like to say many thanks to your wife Anne for her wonderful dinners and 
sharing interesting stories of life. I wish all the best to you and your lovely family.

Second, special thanks also go to Dr Robbert Biesbroek, the co-promotor of this PhD project and my daily supervisor, for his invaluable, ardent commitment, empathy, accessibility, and willingness to help me during the entire period of the project. Thank you for your guidance, patience, and optimism for my progress throughout my PhD project. I would like to say many thanks for taking your time to visit me in Vietnam in 2016 and for your support in collecting data to finish the second survey of my $\mathrm{PhD}$ project. I really appreciate your time to provide me with the critical comments and suggestions for the dissertation. Sometimes, your challenging questions made me a bit nervous during the meetings and sometimes our opinions did not match. However, this is the way that I have learnt to be a critical learner and I am grateful to you for that.

My sincere appreciation also goes to Assoc. Prof Le Thi Hoa Sen, the copromotor of this PhD project and my local supervisor, who favourably recommended me for consideration for the 911 scholarship. Thank you for your significant and continuous support since I have started working at HUAF. You have not only motivated me to pursue the PhD program but you also were present to guide me throughout the process and to support me during my fieldtrips in Vietnam. I am grateful to you for that.

I wouldlike to many thanks go to Prof. Martin Verstegen and Mariet Verstegen and their big family. I have no words which can fully express my feelings for you both. You have become my family in The Netherlands. At your lovely house, I can say whatever I want; I can request whatever I need. I will miss the English lessons and conversations about the research and life in general. Whenever I had trouble in my life and my health, you sat beside me, listened and helped me find the solutions. You are my opa, oma, my teachers, my dear friends! You are an excellent mirror for learning to be happy in life and for envisioning my future career. I would also like to say "Hartelijk dank" for your invaluable contributions to my success today. I wish you health and happiness forever.

I would like to thank Dr Roel Bosma for all his kindness and supporting me during my stay in The Netherlands. I also would like to thank Dr Phung, who has introduced me to several lovely people in Wageningen and supported me when I needed help. Thanks to Mr. Dung - my colleague at HUAF - who supported me in the design of leaflets and information panels for the research intervention. My deepest appreciation goes to the agricultural staff at Thua Thien Hue province, Quang Dien district, the local authority and the farmers at Quang Loi commune who provided the data for this dissertation. In a special way, I sincerely thank Mr. Hoa, Mr. Lu in Quang Dien district for all the supporting and interesting discussions during the field work. Without the local community and its special members this dissertation would not have been possible.

To all my colleagues at the Education and Competence Studies group, thank you for being so friendly, supportive, and making the working environment very pleasant during the time I was there. To Marja Boerrigter, Jolanda Hendriks-Ruisbroek, and Nicolette Tauecchio, thank you for all the administrative support, you have been great and wonderful people to work with.

To all my friends: Jifke, thank you for the true friendship and all the good times that will forever stay in my heart. Thank you, Angela, for all your help whenever I had issues with submitting papers to journals. Thank you to Misbah and George for being good friends and for the interesting chats we had. Thank you, my corridor-mates, Lugman, Gerard, Haifa, Bing for the company and inspiration you provided. To the Wageningen Vietnamese students, Việt, Huyền, Tú, Kim, Lộc, Yến, Nhung, Vân Anh, Quang, Liên,..., many thanks for helping out with the party, travelling together, sharing your experiences during the time I lived in Wageningen. Your presence at the defence was a great encouragement.

To my spouse, Tuan, I want to say, you are such a wonderful and great person. Your continuous sacrifice, sympathy and support helped me get through the hardship during the PhD-process. I dedicate this dissertation with deep appreciation to you. I would like to say thank you to the most important person - my son, Nhat Minh (Men): You are my biggest motivation, a source of energy and inspiration to complete my doctoral studies as soon as possible in order to spend more time with you.

Last, but not the least, I offer my appreciation to all those who helped me in one way or another to complete this dissertation. For those whose names, I may not have mentioned: it is not that your effort and contribution was not appreciated. I sincerely still have you at heart and in mind.

Mẹ yêu quý, con thật may mắn vì có mẹ. Luận án tiến sỹ này con dành riêng tặng mẹ. Mẹ luôn dõi theo từng bước đi của con. Không biết dùng từ ngữ gì để 
nói lời cảm ơn đến Mẹ, chỉ biết rằng thành công của con hôm nay, không thể không kể đến công lao to lớn của mẹ. Con cảm ơn mẹ rất nhiều đã chăm sóc Men để con vững tâm đi học xa nhà. Con cầu mong mẹ luôn khỏe mạnh và hạnh phúc bên con cháu.

Ba me yêu quý, con cũng thật may mắn vì được làm con ba mẹ. Cảm ơn ba mẹ thật nhiều đã tạo điều kiện và chăm sóc Men trong thời gian con xa nhà. Con chúc ba mẹ thật nhiều sức khỏe để sống vui cùng con cháu.

Cảm ơn gia đình o Bé đã luôn động viên và bên $B a$ Bi và Men mỗi lúc cần. Cảm ơn o Bé thật nhiều vì những chia sẽ trong cuộc sống và hỗ trợ gia đình bé nhỏ của em trong thời gian em học xa nhà.

Cảm ơn cô em gái thân yêu, Huda, đã động viên, khích lệ mỗi lúc chị buồn và chia sẽ những lúc chị vui. Cảm ơn em đã tạo cho Men nhiều niềm vui bất ngờ và dành nhiều thời gian cho Men.

Le Thi Hong Phuong,

Wageningen, 22 November 2017

\section{Table of Contents}

Abstract

Acknowledgements

Chapter 1 General introduction

1.1. Climatic changes in Vietnam

1.2. Problem background

1.3. Key concepts

1.4. Research questions

1.5. Methodology

1.6. Structures of the thesis

Chapter 2 The interplay between social learning and adaptive capacity in climate change adaptation: A systematic review

2.1. Introduction

2.2. Systematic review methodology

2.3. Results

2.4. Discussion

2.5. Conclusions

Chapter 3 Understanding smallholder farmers' capacity to respond to climate change: A case study in a coastal community, Central-Vietnam

3.1. Introduction

3.2. Methodology

3.3. Results

3.4. Discussion

3.5. Conclusion

Chapter 4 Increasing Vietnamese smallholder farmers' adaptive capacity to respond to climate change

4.1. Introduction

4.2. Theoretical framework: building adaptive capacity

through social learning configuration

4.3. Methodology

4.4. Brief introduction to the study area 


\subsection{Discussion and conclusions}

Chapter 5 Barriers and enablers to climate change adaptation in the hierarchical governance system in Vietnam

5.1. Introduction

5.2. Examining policy capacity in hierarchical multilevel government settings

5.3. Climate change adaptation in Vietnam

5.4. Methodology

5.5. Results

5.6. Discussion

5.7. Conclusion

\section{Chapter 6 General conclusions and reflections}

6.1. Introduction

6.2. Synthesis of the research

6.3. Theoretical contributions

6.4 . Methodological reflections

6.5. Directions for future research

6.6. Policy implications and recommendations

6.7. Overall conclusion

\section{References}

Supplementary material A

Supplementary material B

Supplementary material C

\section{Summary}

About the author

List of publications

Training and Supervision Plan

\section{List of tables}

Table 1.1. Summary of research design and methods

Table 2.1. Configuration for the search query

Table 2.2. Inclusion and exclusion criteria used to select articles with $S L$ and $A C$

Table 2.3. Examples of social learning definitions

Table 2.4. Examples of adaptive capacity definitions

Table 3.1. The impact of climate change on crop and livestock production

Table 3.2A. Adaptation strategies to drought in crop production and motivation for choice adaptation option

Table 3.2B. Adaptation strategies to drought in livestock production and motivation for choice adaptation option

Table 3.3. Stepwise multiple regression of the number of adaptation measures on the explanatory variables

Table 4.1. The key elements which need to be considered for each phase during applying the learning configuration in practice

Table 4.2. The steps and key elements of the three workshop-based interventions

Table 4.3. The contents, indicators, methods for data collection and data analysis

Table 4.4. The evaluation of social learning outcomes

\section{List of figures}

Figure 1.1. Structure of the dissertation

Figure 2.1. Data collection for the systematic review process

Figure 2.2. Distribution of papers of year for time period 1997-2016 (2.2a), regional focus (2.2b), thematic scope (2.2c), type of study (2.2d)

Figure 2.3. Three emerging perspectives on the interplay between $S L$ and $A C$ Figure 3.1. 1(a) TTH provincial map; 1(b) Map of the QD district and the QL commune

Figure 3.2. The research design for data collection

(a) and frequency (b) of climate change during the past 20 years in the QL

Figure 3.4. Perceived barriers to adaptation by farmers $(n=114)$

Figure 4.1. Framework for building adaptive capacity through a social learning configuration

Figure 4.2. The design, implementation, upscale, and evaluation of social learning configuration

Figure 4.3. Changes in different types of knowledge

Figure 5.1. The Vietnamese government organization structure based on the mandates of agencies and main CCA policy in Vietnam

Figure 6.1. Increasing adaptive capacity for smallholder farmers to respond to climate change 
Chapter 1

General introduction 
This chapter sets the context of the research (Section 1.1), identifies the key research problem central to this dissertation (Section 1.2) and introduces the key concepts used in this study (Section 1.3). Section 1.4 presents the objective and research questions, followed by a description of the overall methodological framework used in this dissertation (Section 1.5). This chapter ends with an outline of the structure of the dissertation in Section 1.6.

\subsection{Climatic changes in Vietnam}

Climate change is a reality. Despite the efforts of mitigation strategies to reduce greenhouse gas emissions, climate change continues to be one of the key risks affecting countries, regions, and vulnerable groups across the world. Recent data has revealed global greenhouse gas emissions have continued to rise (Burck et al., 2016) and, as a consequence, global temperatures are increasing, precipitation patterns are changing, and sealevels are rising, amongst others (EEA, 2017). According to a recent report by the European Environment Agency (EEA, 2017), the global average annual near-surface temperature in the period $2006-2015$ was $0.83^{\circ} \mathrm{C}$ to $0.89^{\circ} \mathrm{C}$ higher than the pre-industrial average. Globally, 2015 was the warmest year on record, about $1^{\circ} \mathrm{C}$ warmer than the pre-industrial temperature. The global average is projected to exceed $2^{\circ} \mathrm{C}$ by 2050 which is well above the agreed levels under the UNFCCC Paris Agreement (UNFCCC, 2015).

Climate change will significantly impact the agricultural sector (Yohannes, 2016). Agricultural production is crucial as it ensures food supply and represents an important source of income globally. Campbell et al. (2011) showed that in developing countries, the agricultural sector has contributed $29 \%$ of country GDP and provided employment for $65 \%$ of the population. Many of the countries with limited economic growth and high dependency on natural resources have a large share of their GDP depending on agricultural production (Awokuse \& Xie, 2015). In many parts of the world, agricultural production is highly dependent upon weather and climate for the level of food production necessary to ensure food security and sustainable livelihoods (Yohannes, 2016). Agriculture is thus a socio-economic activity particularly vulnerable to climate variability and change, and one of the major economic sectors where climate change can have significant and disruptive societal impacts (Georgopoulou et al., 2017), particularly in developing countries (Yohannes, 2016). Studies show that changes in variability of rainfall and temperature in recent decades have already negatively impacted food availability and food access as a result of reduced agricultural productivity, combined with commodity inflation pressure, reduction in household income and consumption (Solaymani, 2017). This is particularly the case in rural areas. Lobell et al. (2008), for example, show that climate change impacts could significantly affect agricultural production and smallholder farmers' livelihoods. Sub-Saharan Africa and parts of Asia are critically vulnerable due to extreme increases in climate variability (Crane et al., 2017).

Climatic changes are already dramatically affecting Vietnam. Located in the center of Southeast Asia, Vietnam is characterized by large geographic diversity, a 3,250 km long S-shaped coastline, and exceptional climatic variation (Le et al., 2013). Due to the long coastline and deltas in the coastal areas, the country is among the most vulnerable globally, as it faces climate related risks such as floods, salinity intrusion, drought and sea level rise (Dasgupta et al., 2011; Mendelsohn, 2014). Vietnam has already experienced changes in rainfall and temperature trends in the past decades, which mirror the rise of global temperatures ( $Y u$ et al., 2010). Climate change reports of the Vietnamese government show record high average temperatures for three recent years (2010, 2014, and 2015) and a significant increase in climate extreme events that occur more frequently and seriously (MONRE, 2012; MONRE, 2016). Increases in extreme variations in annual average temperatures have also been observed in this period. Since 2000, for example, droughts have increased sharply due to rising temperatures and changes in rainfall distribution. This had a particularly high impact in 2015 when the rainy season ended early, leading to severe water shortages for agricultural production. Climate projections show that climate change will occur more rapidly in Vietnam, with a projected temperature rise of $4^{\circ} \mathrm{C}$ and an increase in rainfall by $5-10 \%$ by the end of $21^{\text {st }}$ century. Moreover, precipitation tends to become more intense during the rainy seasons, whereas more droughts are expected during the dry season (MONRE, 2016).

These impacts are particularly influential for the central coastal provinces in Vietnam (Beckman, 2011; Phuong, 2010; Hanh, 2010), posing considerable risks to agricultural production in these regions (Government of Vietnam, 2011; Rubin, 2014; Tran, 2016). Agriculture and farming communities are already experiencing the effects of extreme climatic events and gradual climate change (Fortier, 2010; Phuong, 2010). For example, in 2010 alone, 
six storms and four extreme floods damaged over 300,000 hectares of crop production in Vietnam (Le et al., 2013). The General Organization Statistic (GOS) office of Vietnam shows that farmable land has decreased by 30 thousand hectares between 2015-2016 (GOS, 2016), which can largely be attributed to climate change. Crop yield projections suggest that if the minimum seasonal average temperature will increase by another $1{ }^{\circ} \mathrm{C}$, rice production yields will be reduced by $10 \%$ (Le, 2010). This is exacerbating the already unfavorable conditions in the provinces for farming, as hilly plots, short and narrow riverbeds, and poor soil conditions already put stress on the feasibility of agricultural production.

\subsection{Problem background}

\subsubsection{Developing adaptive capacity for smallholder farmers to adapt} to climate change

In the agriculture-based economy of Vietnam (Ha et al., 2016; Ha et al., 2017), $65.4 \%$ of the rural population depends mainly on agriculture for their livelihoods (GOS, 2016). Agricultural production contributed to $16.32 \%$ of the national GDP and provided jobs for $42.4 \%$ of the working population in 2016 (GOS, 2016). In 2013, there were 15 million agricultural households that cultivated 9 million hectares of farmable land, distributed over 70 million plots (Xuan \& Hien, 2013). On average, each household has 0.6 hectares, but this is usually scattered across four or five smaller plots. According to Hazell \& Rahman (2014), there were more than 10 million smallholder farms in rural areas, mainly located in the Northern mountains and the Central coastal region where biophysical conditions are not very favourable for farming. Typical smallholder farmer activities in Vietnam in these regions include small-scale rice-based production, and chicken and pig livestock production. These activities provide their main source of income (Ha, 2014; Ha et al., 2016).

Climate change is going to further exacerbate the vulnerable group of smallholder farmers in Vietnam unless they can strengthen their adaptive capacity to respond to climate change. Adaptive capacity to climate change is seen as an essential capacity in responding adequately to circumstance. Studies show that large parts of Vietnam do not have sufficient adaptive capacity to deal with existing climatic changes (Clemens et al., 2016; Le Dang et al., 2014c; Lien, 2015; Rubin, 2014). A growing number of studies have indicated that the adaptive capacity of these smallholder farmers is expected to be significantly reduced in the coming decades (Harvey et al., 2014; van Noordwijk et al., 2011; Yohannes, 2016). Smallholder farmers in Vietnam are already facing several other socio-economic challenges, for example poor access to capital, limited technical knowledge, varying production revenues, volatile market conditions, and limited processing facilities (Vinning \& Chinh, 2008). The percentage of trained and skilled laborers for agriculture is low: only $20.3 \%$ in 2016 of which the rural area accounts for less than $12 \%$ (GOS, 2016). In 2016, the percentage of poor households $(9.7 \%)$ and marginally poor households $(5.27 \%)$ who receive an average income of less than 1 USD/person/day is declining, but still high when compared globally (MOLISA, 2016). These socio-economic conditions further weaken the adaptive capacities of farmers to recover from, or to proactively shift to, alternative forms of livelihood (IFAD, 2014; Le Dang et al., 2014d).

Over the past decade many efforts have been implemented to increase smallholder farmers' adaptive capacity, but their effectiveness is limited. This is largely because of the complexities and interdependencies in the agriculture and rural development sectors in Vietnam (Ha et al., 2017). For example, poor understanding of local conditions by governments, and limited smallholder knowledge and capacity, has been reported as main causes that lead to various failures in technology transfer and livelihood development programs (Vien et al., 2006). The linear ways of technologies transfer, where new technology is made available to farmers, can also lead to unintended consequences for already vulnerable and resource-poor smallholder farmers (Minh et al., 2010; Paris \& Chi, 2005). Other systemic issues in the agricultural sector such as the vicious cycle of poverty, lack of knowledge and education, unsustainable livelihoods and unequal access to resources, also affect smallholders' capacity to deal with climate change impacts (Bosch et al., 2015).

The Vietnamese government has recognized the importance of building adaptive capacity and offers some support to smallholder farmers in implementing adaptation measures. Several governmental programs and policies on climate change adaptation have recently been adopted (MARD, 2011; MONRE, 2011). The Vietnamese approach to climate change adaptation is, however, state-centered and top-down (Rubin, 2014). Studies suggest that national adaptation policies are communicated to local levels without clear plans and guidelines to support building adaptive capacity (Asian Management and Development Institute, 2011; Nguyen et al., 2013). 
Providing guidelines and directly collaborating with local farmers is considered important, however, several constraints are created by the ways farmers are actually doing things and therefore they require unlearning, or the relearning of better practices (Ho et al., 2012; Le Dang et al., 2014c; Rubin, 2014; Tran, 2016; Waibel, 2008).

The process of designing national adaptation policy to support implementation at local levels is weak at best (Bosma et al., 2016; Clemens et al., 2016; Le Dang et al., 2014b; Waibel, 2008). Ensuring connectivity across scales is considered as the critical step needed to reduce the loss and damages in agricultural production (Tompkins et al., 2010) and to help famers reach their food, income, and livelihood security objectives in the face of changing climatic and socio-economic conditions (Kandlikar \& Risbey, 2000). In addition, creating an environment to help smallholder farmers develop the ability to learn in a variety of ways, in different contexts, and under changing circumstances, is vital for increasing the adaptive capacity to respond to climate change impacts (Eakin et al., 2011).

Ideally, building adaptive capacity results from combinations of top-down and bottom-up initiatives that encourage continuous learning of smallholder farmers to change their practices and be better prepared (Butler et al., 2015). However, the governance process of trying to build adaptive capacity amongst farmers in Vietnam suffers from several problems caused by the lack of stakeholders' participation, combined with rigid planning procedures, and short-sighted proposed solutions (Clemens et al., 2016; Nguyen et al., 2017). It has proven difficult for farmers to learn and change their behaviors to be better equipped to deal with climate change. There is limited understanding of why this is the case. A question is whether this can be resolved through designing social learning configurations to improve the adaptive capacity of smallholder farmers.

\subsubsection{Challenges to use social learning for building adaptive capacity to adapt to climate change}

Specific challenges to build adaptive capacity become apparent when considering climate change as a wicked problem that is characterised by an unclear problem structure, as well as by contested knowledge, norms and values (Termeer et al., 2013). Such wicked problems are hard to define; they are complex, intractable, open-ended, and unpredictable (Alford \& Head, 2016), and will not be solved by the same tools and processes that created them in the first place (FitzGibbon \& Mensah, 2012). The solutions to this type of problem are not simply right or wrong, but instead they are "better or worse" and depend to a large extent on continuous learning. Understanding social learning to deal with wicked problems and develop a social learning approach is, however, no easy task as there are critical issues to be addressed.

The first challenge is how to connect the ideas and principles of social learning to practices that can increase the adaptive capacity of smallholder farmers. Although theories on iterative learning suggest social learning plays an important role in sharing knowledge and understanding the world (Marx et al., 2007), it remains unclear how social learning and adaptive capacity are linked. For example, most of the literature on adaptive capacity and social learning refers to similar characteristics: social learning requires some level of capacity to adapt, whereas adaptive capacity requires some level of social learning (Christmann \& Aw-Hassan, 2015; Henly-Shepard et al., 2015; Leys \& Vanclay, 2011).

The second challenge is that designing, implementing, and evaluating social learning configurations and assessing their effectiveness has proven to be rather cumbersome. Most research on social learning evaluates social learning configurations empirically by focussing mostly on processes and output (Cundill \& Rodela, 2012), and conceptually with a focus on the methodological underpinnings of social learning approaches (Rodela et al., 2012). However, two critical questions exist for evaluating the influence of social learning on adaptive capacity in the context of the "wicked" problem of climate change (Förch et al., 2014). The first critical question is which indicators to use and why to choose these. The literature on social learning has proposed a myriad of indicators and it is difficult to determine which of these is relevant to use. Second, there is limited understanding of how to attribute the impacts of social learning configurations to changes in outcomes or whether adaptive capacity has increased because of social learning (Bos et al., 2013; Duru et al., 2012; Henly-Shepard et al., 2015; Webler et al., 2016). It has proven to be particularly challenging to assess social learning in terms of improvements in relationships and levels of participation in a governance system (Egunyu \& Reed, 2015). Although various approaches and configurations to study and evaluate social learning and adaptive capacity already exist in the context of climate change, these tend to be rather incomplete, fragmented and provide a limited overview of how different types of social learning can increase adaptive capacity. Overall 
these studies are rather weak in including contextual factors in explaining outcomes (Bardsley, 2015; Mishra et al., 2013; Shaw \& Kristjanson, 2014).

The third challenge is that efforts to build adaptive capacity are not easily implemented in practice. The framing of building adaptive capacity as a mean to respond to climate change impacts is often done from the perspective of the state, with a strong bias towards making better policies, plans, directives, and resources to manage climate change adaptation. In such a view, the state has often been portrayed as both the main constrainer and enabler in building adaptive capacity and creating a social learning environment. Other studies focus on how local people are dealing with climate change impacts and how they might do this better (Christoplos et al., 2017). Emphasis in this perspective is placed on engaging local stakeholders in collective learning and knowledge exchange as this leads to flexibility and restructuring of norms, values, and practices (Blackmore et al., 2016; Folke et al., 2005; Pahl-Wostl, 2009). A review of the literature shows that these two perspectives are hardly considered together when studying social learning and adaptive capacity. This means that potential trade-offs are overlooked. Very few insights exist, for example, on how authority is shared between different governmental organizations and the impact on the process of social learning at the local level (Gupta, 2007). Moreover, critical questions about how social learning principles are integrated in hierarchical, post-communist states that are characterized by rigid bureaucracies with little or no accountability or transparency, weak institutions, and tight controls of information (Cooper \& Wheeler, 2015), is a black box that is yet to be opened. One way to do this is by connecting state and society perspectives on climate change adaptation.

\subsection{Key concepts}

There are three central concepts to this dissertation: social learning, adaptive capacity, and multilevel governance. This section briefly introduces these main concepts with each consecutive chapter discussing them in greater detail.

\subsubsection{Social learning}

Learning is a multifaceted phenomenon that includes seeking information and increasing knowledge, memorizing, acquiring facts, skills, and methods, making sense or abstracting meaning, and interpreting and understanding reality in a different way by reinterpreting knowledge (Saljo, 1979). Learning potentially facilitates "new understanding of the kinds of role, relationship, practice, and sense of purpose" required for changing a socio-technical system towards more adaptive systems (Collins \& Ison, 2009, p.354). The outcomes of learning are important to improve decision-making processes that are underpinned by a growing awareness of human-environment interactions, better relationships, and improving problem-solving capacities for participants (Cundill \& Rodela, 2012). Therefore, learning may lead to changes in perception, knowledge, and behavior of individuals, organizations, or community groups (Sol et al., 2013). Three interrelated learning theories are frequently used in recent academic literature: experiential learning (Kolb, 1984), transformative learning (Mezirow, 1997), and social learning (Keen et al., 2005; Wals, 2007). They have in common that they are: explorative (experience and discovery oriented), emergent and iterative (both the trajectory and the outcomes are not fixed ahead of time, the process tends to be cyclical rather than linear) and change-oriented (some more focusing on changes in the individual, some more on changes in collectives).

This dissertation uses social learning pragmatically to include features of experiential learning and transformative learning, as does much of the recent literature in natural resource management and environmental management, but also, in the context of climate change. Furthermore, this dissertation considers the changes in smallholder farmers' adaptive capacity and social learning outcomes in terms of changing/adjusting skills, practices, and actions of actors, changing values and policies, and changes in governance. Social learning is considered as a key approach to develop adaptive capacity to respond to climate change impacts because it allows for the exploration of imperfectly understood system and allows for mutual learning by the researcher, stakeholders, and their organizations (Keen et al., 2005; PahlWostl et al., 2007a; Wals, 2007).

Social learning theory has its roots in different learning theories and social science disciplines (Muro \& Jeffrey, 2008). It is increasingly becoming a normative goal in natural resource management (Keen et al., 2005) and sustainability research and practice (Wals, 2007). This type of learning seems quite suitable for fostering adaptive management and stakeholder engagement in the context of "wicked" problems such as climate change (Collins \& Ison, 2009; Wilder et al., 2010; Ensor \& Harvey, 2015). In early 
work, social learning was conceptualized as individual learning that takes place in a social context and is influenced by social norms (Bandura, 1977). In contrast, more recent literature defines social learning as a process of social change in which people learn from each other in ways that can benefit wider social-ecological systems (Keen et al., 2005; Mostert et al., 2007; PahlWostl, 2006; Pahl-Wostl et al., 2007a; Pahl-Wostl et al., 2007b; Pahl-Wostl et al., 2008; Reed et al., 2010; Wals et al., 2007). This is especially the case when there is a certain degree of diversity, trust, and commitment among those participating in addressing a challenge (Sol et al., 2013).

Currently there are many definitions of social learning, and the concept generally reflects the engagement of interdependent stakeholders in collective learning and knowledge sharing (Hurlbert, 2015), leading to the eventual transformation of routines, values, beliefs and innovative governance protocols and norms (Cooper \& Wheeler, 2015). Reed et al., (2010) define social learning "as a change in understanding that goes beyond the individual to become situated within wider social units or communities of practice through social interactions between actors within social networks" (Reed et al., 2010, p.r).

Interest in social learning as a part of the response to climate change has grown significantly in recent years (Ensor \& Harvey, 2015). Several researchers indicated that adopting a social learning approach is particularly relevant for climate change adaptation, as it allows stakeholders to deal with highly uncertain conditions (e.g. Pelling et al., 2008). As a starting point in this dissertation, social learning is broadly understood as "the process by which societal actors interact and develop alternative perspectives on a societal issue" (Bos et al., 2013, p.339). Social learning is considered an important process to increase adaptive capacity for implementing adaptation strategies where people need to jointly address challenges of the collective actions and engage with one another by sharing diverse perspectives and experience to develop a common framework of understanding (Schusler et al., 2003; Yuen et al., 2013). People need to have the capacity to learn to cope with climate change impacts because this will support them in building new knowledge, relationships, and practices in response to climate change (Ensor \& Harvey, 2015). In addition, the availability, access, and interpretation of information to provide feedback within a governance system is considered an essential part of the adaptation processes (Engle, 2012). Hence, social learning is not only enabling the participation of community actors, but also that of researchers and decision-makers across different sectors and levels, including actors active within an government system (Bardsley, 2015).

Social learning is often conceptualized as multi-loop learning (Argyris \& Schon, 1974). Multi-loop learning includes a series of learning cycles - often referred to single-, double- and triple- loop learning (Keen et al., 2005; Leeuwis \& Pyburn, 2002; Medema et al., 2014). Single-loop learning refers to re-adjusting or refining actions to improve current performance and can be considered a first step to improve adaptive capacity and to make and implement collective decisions. Double-loop learning refers to changes in a frame of reference and to critical reflection on goals that can be achieved. Triple-loop learning refers to transformation of the structural context and the factors that determine the frame of reference. A recent systematic review concluded that the key outcome of triple loop learning should improve decision making as it ensured growing awareness of human-environment interactions, encouraged better relationships and improved problem-solving capacities of participants (Cundill \& Rodela, 2012). In order to achieve these outcomes the actual interplay between the different components of a social learning configuration - the content, context, process and individual attributes of those participating - need to be in sync (Medema et al., 2014). Therefore, evaluation of learning not only focuses on the outcomes and processes of social learning (Cundill \& Rodela, 2012), but also on the other components and factors involved to ensure success of social learning (Wals et al., 2007).

\subsubsection{Adaptive capacity}

Adaptive capacity is not a new concept but in recent years it has gained considerable popularity, particularly in environmental governance studies (Gupta et al., 2010; Pahl-Wostl, 2009). Put simply, adaptive capacity means the ability human or biophysical systems have to adapt to change (Engle, 2011). Smit et al. (2001) define adaptive capacity in the context of sustainable development as the ability of a system to prepare for coping with stresses and changes proactively. One pivotal understanding of adaptive capacity is offered by the IPCC, namely "the ability of systems, institutions, humans, and other organisms to adjust to potential damage, to take advantage of opportunities, or to respond to consequences" (IPCC, 2014). In 
most instances, however, the definition of adaptive capacity is adjusted or modified depending on the specific context of the study.

The adaptive capacity literature emphasizes the role of different kinds of determinants including financial, human, social, technological, and political resources for increasing the ability of different individuals and groups to prepare for, respond to, and recover from climate-related impacts (Smit \& Wandel, 2006). However, these determinants are too general, and hardly useful for specific contexts, as people and systems often require specific determinants to cope with specific issues (Eakin \& Lemos, 2006). Thus, in order to building adaptive capacity in least developed countries, Lemos et al. (2013) suggest that there are two kinds of capacities that play a role in adaptive capacity: generic capacities and specific capacities. Generic capacities refer to the ability to respond to basic human development needs, while specific capacities refer to the ability to respond to specific issues such as climate change impacts (Eakin et al., 2014; Lemos et al., 2013; Lemos et al., 2016). Both capacities must be addressed explicitly, simultaneously and iteratively if sustainable adaptation to climate change goals are to be attained (Eakin et al., 2014).

Building adaptive capacity is best described as a dynamic social process (Raymond \& Cleary, 2013). Key conditions for adaptive capacity discussed in the scholarly literature include the presence of social learning and knowledge exchange, empowerment of actors and the bridging of social networks that link stakeholders and their resources across administrative levels and spatial scales (Plummer \& Armitage, 2010). Given the earlier described features of social learning it is no surprise that adaptive capacity is considered a critical component that needs to be enhanced at individual and institutional levels though social learning (Pahl-Wostl, 2009; Reed et al., 2010). Jones et al. (2010) argue that "at the heart of any local-level adaptation intervention is the need to increase the individual or community's adaptive capacity" (p.2).

Several frameworks to assess adaptive capacity have recently been presented (Below et al., 2012). A key component of these frameworks is ensuring that individuals, communities, and societies are actively involved in processes of change (Pettengell, 2010). The fact that farmers have to build their adaptive capacity to respond to external and internal drivers of change-through active engagement is well accepted (Milestad et al., 2012). Such engagement is considered critical to increase overall adaptive capacity of individuals and communities by promoting and creating more informed interactions among participants, resolve conflicts, and empower previously disadvantaged groups so as to become more effective adapters and managers in the long term (Egunyu \& Reed, 2015).

\subsubsection{Multilevel governance}

As discussed in Section 1.2. building adaptive capacity for climate change adaptation is often framed as an issue of either (inter)national or local responsibility. However, climate change adaptation is an issue requiring integrated action at multiple levels of governance and within the spheres of politics, economics and society (Schreurs, 2010). This means that national, regional, and local level public and private actors have critical roles in developing policies and strategies to respond to climate change impacts, build adaptive capacity, and ensure social learning. Multilevel governance is therefore a useful concept in gaining understanding of the different levels that are involved in social learning and adaptive capacity building of smallholder farmers (Amundsen et al., 2010; Nilsson et al., 2012; Rantala et al., 2014).

The concept of multilevel governance was first introduced by Marks in the early 1990 s and has gained in popularity since. Multi-level governance initially was described as a "system of continuous negotiation among nested governments at several territorial tiers - supranational, national, regional and local" (Marks, 1993, p.392). In their seminal work, Hooghe \& Marks (2003) identify two main types of multilevel governance based on power diffusion between the embedded actors and institutions. Type 1 refers to vertical multilevel governance, containing actors and institutions operating across levels based on human or territorial communities - mirroring bureaucratic or hierarchical forms of governance. Type 2 refers to inter-connection of multiple actors or institutions with more lean and flexible structure based on functional demands of the governance process - mirroring network and, to some extent, market based forms of governance.

In essence, multilevel governance is a political decision-making process in which governments engage and link with a wider range of stakeholders at different levels to pursue collaborative solutions to complex or wicked problems (Alcantara \& Nelles, 2014). Mickwitz et al. (2009) argue that multilevel governance is of importance for successful climate change policy and for creating opportunities to share, learn, and connect with different stakeholders at different levels, as well as for opening up spaces for innovation that can help develop and implement adaptation policies and actions at every level of government. 
Despite the popular use of multilevel governance, there still exists a considerable degree of ambiguity as to its exact meaning (Tortola, 2017) and as to how it should be organized (Termeer et al., 2010). Despite this ambiguity there is agreement that within multilevel governance the state usually plays an important role (Wals \& Jickling, 2002) and has responsibilities in collaborating with different actors, and across different scales, and levels (Alcantara \& Nelles, 2014).

Key aspects of multilevel governance thus include not only the structure of multilevel administrative governments, but also the patterns of interaction and the coordination systems within and between levels (Rantala et al., 2014). The essence of multilevel governance is, however, time and space bound as it depends on transforming roles of the state, increasing participation of non-state actors, involvement of complex networks and negotiations, and challenging conventional notions of the accountability of democratic institutions (Pahl-Wostl, 2009; Painter \& Pierre, 2004). Crosslevel and horizontal networks create new opportunities for diverse actors to participate in decision making and to engage in mutual learning (Pahl-Wostl, 2009). Social learning may thus inform approaches aimed at reinforcing multilevel governance in places where governance is emergent (Faysse et al., 2014), as is the case in Vietnam.

\subsection{Research questions}

The previous sections discussed the need for increasing adaptive capacity for smallholder farmers in Vietnam, and the potential role of social learning in this process. The three challenges demonstrate the need to advance scholarly debates further, both in theoretical explorations as well as through empirical research. The central aim of this dissertation is therefore to elicit and explore the ways through which social learning can increase the adaptive capacity of smallholder farmers in central coastal Vietnam to respond to climate change impacts. To achieve this overarching objective, four specific research questions (RQ) are defined.

RQ1. What insights does the existing body of climate change adaptation literature provide into the interplay between social learning and adaptive capacity?

This research question responds directly to the first challenge identified in Section 1.2. To be able to empirically investigate the link between social learning and adaptive capacity in the next steps of the research, it is first necessary to understand more deeply and critically what social learning and adaptive capacity mean, and how they (could) interact with each other. These insights help determine the validity of the conceptualization of social learning and adaptive capacity in the context of climate change adaptation.

RQ2. What do smallholder farmers in Vietnam perceive as their current adaptive capacity and what enables or constrains them in increasing their it?

This research question responds to the need to develop adaptive capacity for smallholder farmers to a respond adequately to climate change impacts. Using the insights from RQ1, this research question allows for identifying specific conditions and processes that explain what smallholder farmers currently perceive as being their adaptive capacity to respond to climate change. This question is critical as very few comprehensive studies have tried to address this question. Answering the question is likely to provide further insights into the interplay between adaptive capacity and social learning, which could further inform the next stages of the research.

RQ3. How can social learning configurations strengthen the adaptive capacity of farming communities?

This research question responds directly to the second challenge identified in Section 1.2. Answers to this research question can provide a deeper understanding of how to design, implement and evaluate specific social learning configurations. Such understandings are crucial for strengthening efforts to increase adaptive capacity to respond to climate change impacts, and for providing meaningful policy recommendations.

RQ4. How do different levels of government enable and constrain the process of building adaptive capacity and social learning of smallholder farmers to respond to impacts of climate change in Vietnam?

This research question responds directly to the third challenge identified in Section 1.2. Given that relatively few studies have addressed the question of how social learning is enabled or constrained by the features of the hierarchical governance system in Vietnam, answers to this question are vital to better understand the state-society relationship in building adaptive capacity in developing countries. It allows for better understanding of the policy capacity of different administrative levels in implementing climate change adaptation and to support smallholder farmers in their quest for building adaptive capacity. Answering this research question can enhance the various ways farmers can overcome the challenges they experience (RQ2), create meaningful social learning configurations (RQ3), and stimulate policy orientation learning in Vietnam. 


\subsection{Methodology}

This section describes the methodological perspective I adopted, the research approach designed to answer the four research questions and the methods used to collect data. The specific methods used for each study are presented and elaborated on in table 1.1 .

\subsubsection{Research perspective}

Obtaining rich answers to the questions raised about the ill-defined concepts of adaptive capacity, social learning, and multilevel governance can best be achieved by adopting a research perspective which allows for a combination of pragmatism and eclecticism. Pragmatic researchers recognize there are many different ways of interpreting the world and undertaking research, that no single point of view can ever give the entire picture and that there may be multiple realities (Saunders et al., 2012). Pragmatism seeks to establish knowledge claims with reference to human action in, and experience of, the complex world (Dousa, 2010).

This means that good science does not only require respect for scientific theories and hypotheses from, for example, a positivist stance, but also interpretation of findings from a social-constructivist stance, where knowledge is constructed through interaction and becomes a social construct. Pragmatism - sometimes referred to as realism - is therefore seen as the middle-ground between positivism and social-constructivism research philosophies and as necessary for finding answers to the diverse set of research questions central to this dissertation (Wilson, 2010). It uses the strengths of social-constructivism to address the weaknesses of positivism and vice versa. Adopting a pragmatism perspective puts the research question, rather than the epistemology, central to the research. Pragmatism stresses the value of theoretical and methodological eclecticism, in other words there is no predefined and rigid approach as is common in positivist research, but the research starts from a general objective and adopt theories and methods that are most appropriate for answering the question. I therefore use whatever combination of methods I consider necessary to find answers to the research questions (Moon \& Blackman, 2014). The outcomes of one question can inform the course of the research, leading it to new directions (Creswell, 2009).

\subsubsection{Research design}

In this dissertation I combine the pragmatism perspective with an exploratory approach, where a number of things remain open to allow for the findings of previous steps to guide the ones that follow the next one. It allows the research to iteratively evolve in a direction that is most meaningful and relevant. Exploratory research is generally applied in cases for which no or only sparse systematic knowledge exists (Kummar, 2011), and is often combined with pragmatic perspective. It is an approach that can be used to gain greater familiarity with a particular topic that is not clear or developed sufficiently enough to enable conceptual distinctions or posit explanatory relationships prior to the start of the research (Shields \& Rangarajan, 2013). This approach is chosen here as it fits well with the explorative ambition to better understand the interplay between social learning and adaptive capacity in climate change adaptation. The adoption of an exploratory research design does not mean that the research lacks theoretical points of departure or theoretical ambitions. This is where the research in this dissertation differs from purely inductive or grounded theory (Charmaz, 2006; Glaser \& Strauss, 1967). Instead, for each of the research questions, a theoretical approach from different strands in the literature has been carefully selected as seemed most appropriate and potentially insightful.

\subsubsection{Research methods}

For this dissertation I adopt a multi-methods approach which combines different research methods to address a particular research problem (McKendrick, 1999). The multi-method research design involves collecting and analysing both quantitative and qualitative data in a single study, in an attempt to investigate a research problem more comprehensively (Creswell, 2009). There are various reasons why multi-method research is employed by researchers (Greene et al., 1989; McKendrick, 1999), for example because certain methods do not provide sufficient answers to the research questions, particularly in cases with weak and unreliable data sources. This approach is a variation of the principle of triangulation, where supporting evidence is derived from independent sources. In each chapter, I have included a description of the specific methods adopted for the specific study, and discuss how these multiple methods were used to collect, analyse and interpret the data. Section 6.4 I reflect on the implications of adopting a multimethod approach. Table 1.1 provides an overview of the research design and methods. 


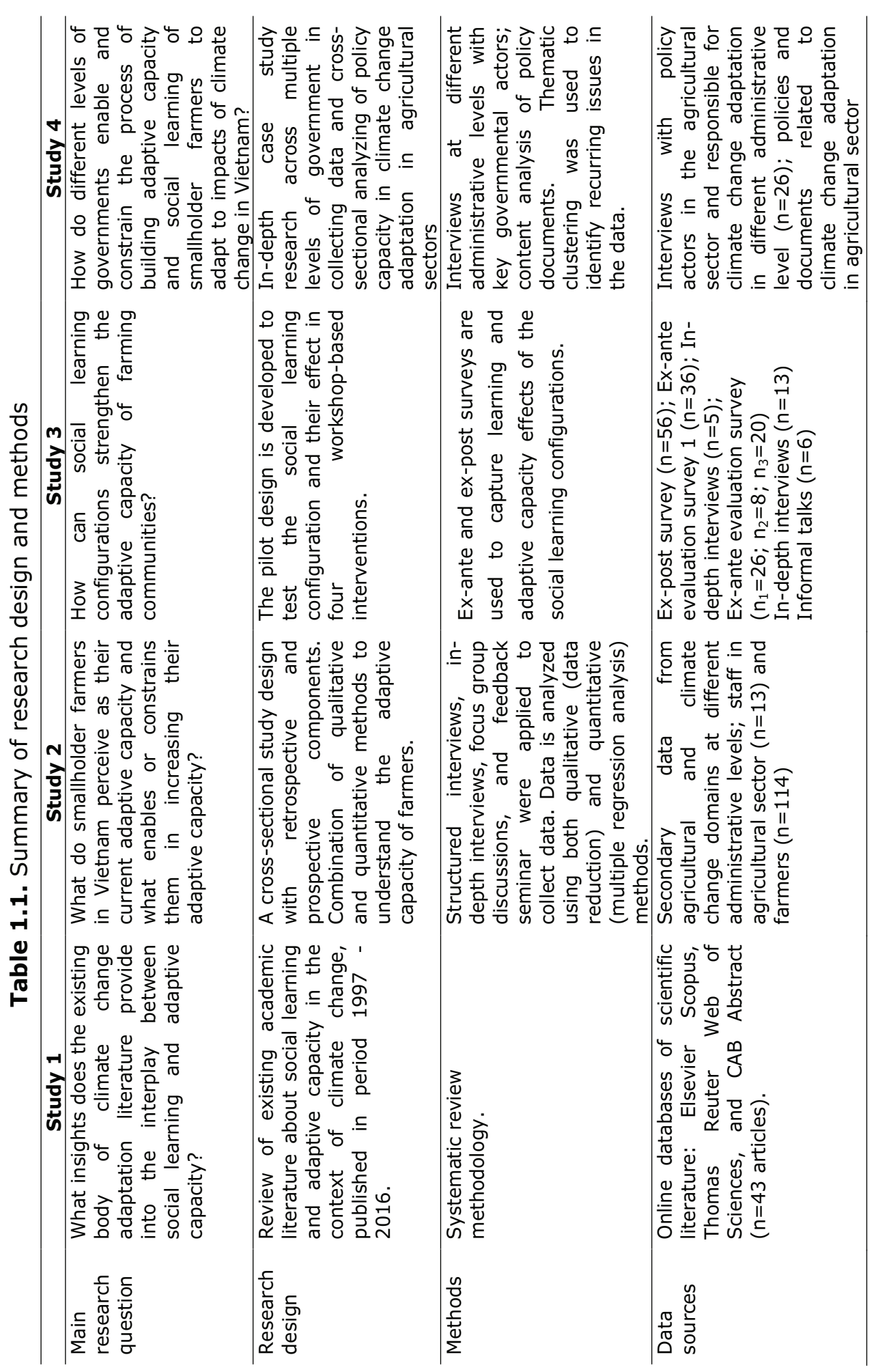

\subsection{Structure of the dissertation}

After the introduction (Chapter 1), the body of the dissertation is presented in four chapters that correspond directly to the four research questions (Chapters $2-5)$. These chapters are submitted to or published in scientific journals. The final discussion chapter (Chapter 6) reviews the main results, discusses the broader implications of findings of the dissertation, reflects on the strengths and limitations of the dissertation, and proposes ways to further study this topic. Moreover, it presents theoretical and practical implications of the dissertation's findings for building adaptive capacity of smallholder farmers through social learning. Figure 1.1 presents an overview of the six chapters.

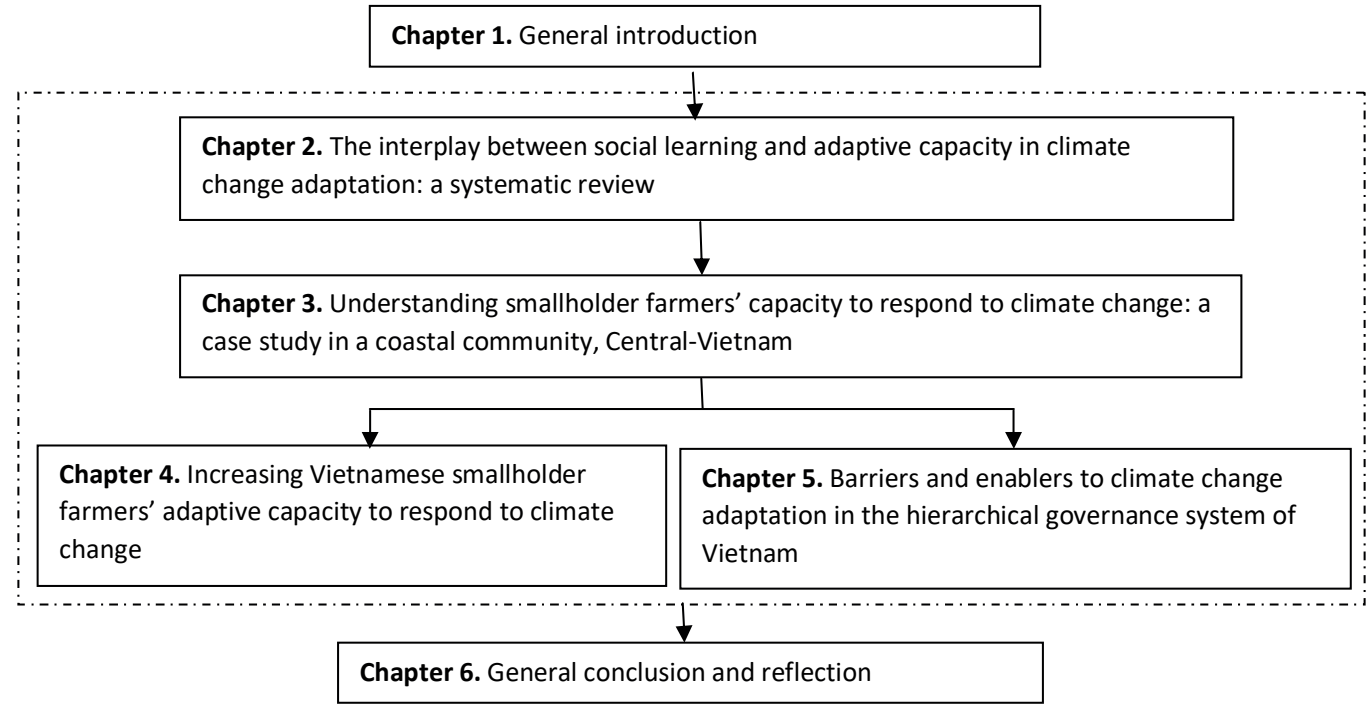

Figure 1.1. Structure of the dissertation 
Chapter 2

The interplay between social learning and adaptive capacity in climate change adaptation: A systematic review adaptation: A systematic review. NJAS - Wageningen Journal of Life

Sciences, 82, 1-9. 


\subsection{Introduction}

In both the world of policy and academia there is an increased recognition that adaptive capacity (AC) is crucial for societies to prepare for the adverse impacts of anthropogenic climate change (Williams et al., 2015). An integral part of the resilience of human systems is the $A C$ of individuals, organizations, and communities to deal with stress. AC can be broadly understood as the ability of people and institutional systems to cope with incremental and rapidly changing conditions (Smit \& Wandel, 2006). AC shapes, for example, actors' abilities to plan and to implement adaptation, as well as their capacities to overcome various types of socio-political constraints (Biesbroek et al., 2013). Successful implementation of adaptation depends heavily on the AC of individuals and of a community as a whole (Adger et al., 2005). Several authors, including Pahl-Wostl (2009), argue that improving AC requires first and foremost the engagement of stakeholders at multiple levels and in different contexts to learn how to improve their AC.

Processes of social learning (SL) have been intensively studied in the natura resource management literature, particularly in relation to collective action problems (Keen et al., 2005; Pahl-Wostl, 2007; Wals \& Rodela, 2014). Fo example, Christmann et al. (2015) showed that SL is crucial for facilitating and building community capacity. Because collective action problems require the involvement of multiple stakeholders with a diversity of values and perceptions across scales (Ostrom, 2007), the emphasis is often on forms of collective learning rather than on individual types of learning. We can broadly define SL as "...the process by which societal actors interact and develop alternative perspectives on a societal issue" (Bos et al., 2013, p.399).Various related concepts used in the literature, such as collective learning, joint learning, or group learning, refer to similar mechanisms for helping multiple stakeholders understand and utilize one another's viewpoints, values, resources, and ideals with regard to collective actions. Ison (2010) argues that SL at the collective level is considered particularly suitable for situations where the issues at hand are dynamically complex and about which there is systemic uncertainty. This is certainly true for efforts to adapt to the impacts of climate change.

There is a general consensus and convincing empirical evidence that $A C$ and SL are intricately linked (Raymond \& Cleary, 2013; Yuen et al., 2013). However the current knowledge about the nature and influence of the interplay between $\mathrm{AC}$ and $\mathrm{SL}$ is fragmented across academic scholarship. Several studies have 
already demonstrated that increasing $A C$ in practice is limited by knowledge gaps (e.g. Williams et al., 2015), and the lack of a sound conceptual base to understand learning in multilevel governance regimes complicates theoretical and practical advancements (e.g. Medema et al., 2014). A better understanding of the interplay between $\mathrm{SL}$ and $\mathrm{AC}$ can help to strengthen both. This is of particular importance in low and middle income countries where levels of both $A C$ and $S L$ tend to be low but are needed most, as many such countries are severely affected by climate change (Adger, 2010; Pelling et al., 2008).

This study therefore aims to critically examine the interplay between SL and AC in the context of climate change adaptation (CCA). A better understanding of this interplay in a practical sense can help determine whether emphasis needs to be placed on $\mathrm{SL}, \mathrm{AC}$, or both simultaneously. Understanding this interplay can also help to elucidate how CCA takes place in practice and to advance theoretical debates on adaptation issues (Swart et al., 2014). Three research questions (RQs) are central in our review of the literature:

a) How are the concepts of SL and AC understood in the literature on CCA?

b) How is the interplay between SL and AC conceptualized in this literature?

c) Are there conditions which favour a particular type of interplay?

A systematic review method is used to explore the interplay between $S L$ and $A C$ as well as to find the implications of different types of interplay to help communities to respond to climate change. The paper is organized as follows. Section 2.2 outlines the methodology of our systematic literature review and illustrates the different steps in implementing the review of scientific peerreviewed articles. Section 2.3 presents the key findings. This is followed by a discussion in Section 2.4. The paper ends with a conclusion (2.5) and highlights implications for future research and practice.

\subsection{Systematic review methodology}

Systematic literature reviews are common in many fields of inquiry, most noticeably in health research, and have increasingly been used in environmental studies on issues such as water policy (Gallego-Ayala, 2013), CCA (Berrang-Ford et al., 2015), and food security (Candel, 2014). Compared to traditional methods, systematic reviews allow for more transparency and reduce reviewers' selection and interpretation bias (Petticrew \& Roberts,
2006). We have drawn on the methodologies of (e.g., Biesbroek et al., 2013; Candel, 2014; Ford et al., 2011) to construct our systematic review methodology. Figure 2.1 shows the different steps undertaken in this review; these are briefly discussed below. More details of the review methodology can be found in the supplementary material A (SM).

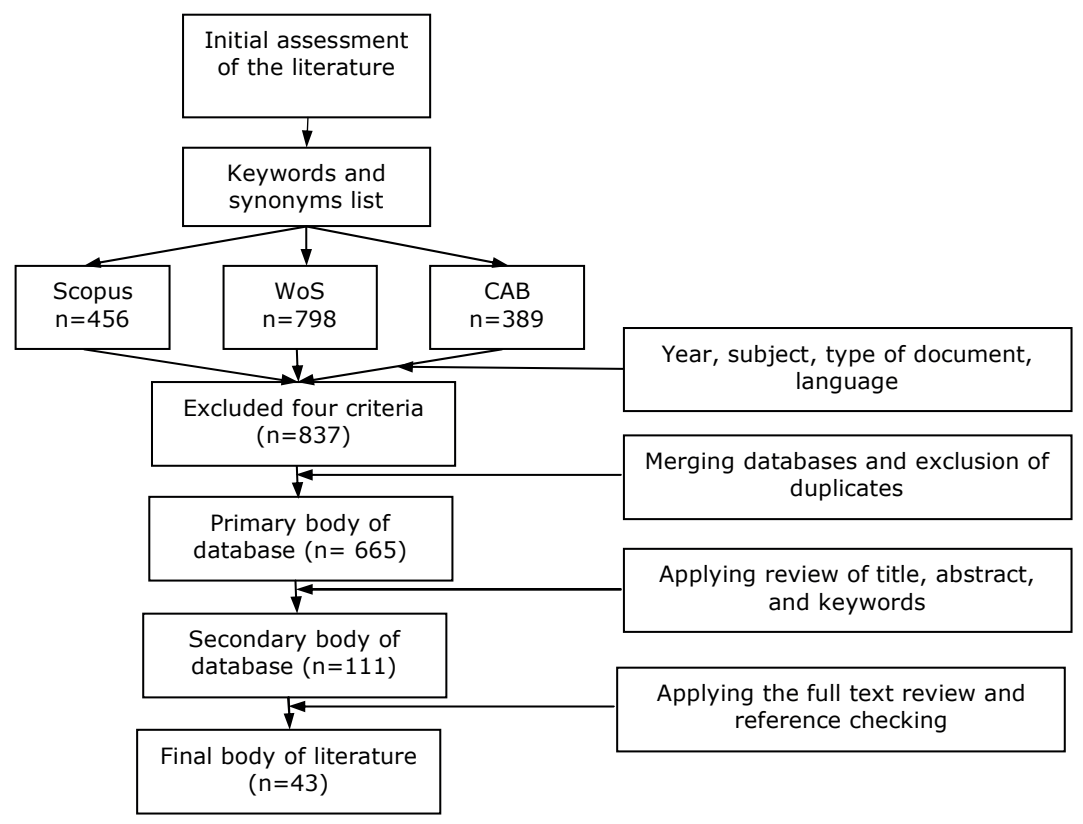

Figure 2.1. Data collection for the systematic review process

\subsubsection{Selection of search terms and databases}

To identify the key search terms, we carried out an initial search for publications that mentioned both SL and AC. From this, we identified a number of concepts that are strongly related to $\mathrm{SL}, \mathrm{AC}$, and climate change (see $\mathrm{SM}$ A1). The academic literature was searched using combinations of these search terms in the databases of Elsevier Scopus, Thomas Reuter Web of Science (WoS), and CAB Abstract. These databases were included because of their coverage across the subjects and to prevent either European (Scopus) or American (WoS) bias in the selection of reviewed articles (Biesbroek et al., 2013). The search configurations were designed on the basis of specific database characteristics (table 2.1). 
Table 2.1. Configuration for search query

\begin{tabular}{|c|c|}
\hline & \\
\hline $\begin{array}{l}\text { Scopus } \\
(n=456)\end{array}$ & $\begin{array}{l}\text { TITLE-ABS-KEY ("social learn*" OR "collective learn*" OR "collaborative learn*" } \\
\text { OR learn* OR "policy learn*" OR "configuration learn*" OR "learn* platform" OR } \\
\text { "learn* partnership" OR "co-learn*" OR "group learn*") AND ("adaptive capacity" } \\
\text { OR Capabilit* OR Abilit* OR Potential) AND ("climat* chang*" OR "climat* } \\
\text { variability" OR "climat* extrem* event*" OR "global warming" OR "climat* risk*" } \\
\text { OR "climat* chang*" W/4 adapt* OR "climat* uncertainty") }\end{array}$ \\
\hline $\begin{array}{l}\text { WoS } \\
(n=789)\end{array}$ & $\begin{array}{l}\text { TS=((social-learn* OR collective-learn* OR collaborative-learn* OR learn* OR } \\
\text { policy-learn* OR configuration-learn* OR learn*-platform OR learn*-partnership } \\
\text { OR co-learn* OR group-learn*) AND (adaptive-capacity OR Capabilit* OR Abilit* } \\
\text { OR Potential) AND (climat*-chang* OR climat*-variability OR climat- extrem*- } \\
\text { event* OR global-warming OR climat* risk* OR (climat*-chang*) W/4 adapt* OR } \\
\text { climat*-uncertainty)) }\end{array}$ \\
\hline $\begin{array}{l}\text { CAB } \\
(n=389)\end{array}$ & $\begin{array}{l}\text { ((social learn* OR collective learn* OR collaborative learn* OR learn* OR policy } \\
\text { learn* OR configuration learn* OR learn* platform* OR learn* partnership OR co- } \\
\text { learn* OR group learn*) AND (adaptive capacity OR Capabilit* OR Abilit* OR } \\
\text { Potential) AND (climat* chang* OR climat* variability OR climat* extrem* event* } \\
\text { OR global warming OR climat* risk* OR climat* chang* adapt* OR climat* } \\
\text { uncertainty)).ti,mh,ab. }\end{array}$ \\
\hline
\end{tabular}

\subsubsection{Inclusion and exclusion criteria}

Several inclusion and exclusion criteria were used to limit the scope of the search. Firstly, the inclusion of eligible papers was limited to the period between 1997 and 2016. The year 1997 was selected as the starting point because the Kyoto protocol was adopted that year, and around that time, some of the first articles using $S L$ and $A C$ building in the context of natural resource management appeared. Secondly, subject areas included only environmental and social sciences. Thirdly, only peer-reviewed and electronically available journal articles written in English were selected. This means that articles in other languages or in the form of books, book chapters, or grey literature were in principle not included. When the results from the searches in the three databases were merged and overlaps between Scopus, WoS, and CAB Abstract were excluded, the database contained 665 articles.

In the next step, manual scanning of titles, abstracts, and keywords allowed us to progressively focus. Articles relating to $S L$ and $A C$ in the context of CCA were included. Articles not relating to CCA were excluded, for example papers on mitigation, REDD, energy, tourism, industry, health, or environmental modelling (table 2.2). This resulted in 111 possibly eligible articles, of which the full texts were downloaded and read. We then narrowed down the sample size some more by including only papers that focused on $\mathrm{SL}$ at the collective level: articles that targeted the individual level, such as formal learning, individual learning, or cognitive learning, were removed. These criteria resulted in 33 relevant articles. To ensure that our search included all key papers, we applied forward and backward reference checking (Candel, 2014), and this led to 10 more articles. Therefore, the final selection yielded 43 articles for this review. This was a time-intensive process, but it ensured a rigorous step-bystep analysis of the literature.

Table 2.2. Inclusion and exclusion criteria used to select articles with $S L$ and $A C$ Inclusion criteria used for screening titles, abstracts, and keywords Adaptation with social learning and adaptive capacity

Understanding learning and/or adaptive capacity should be the main aim of the paper, not a side observation

Exclusion criteria used for screening titles, abstracts, and keywords

Not relevant topic: mitigation, REDD, energy; climate change and

gender/tourism/health/maritime/industry

(tearning

Resilience and vulnerability to climate change

Modelling and impacts of climate change

Adaptation of techniques

\subsubsection{Data extraction and evaluation of review findings}

The full texts of the resulting 43 articles were re-read and hand-coded using a data extraction protocol (see supplemantary material A2): 1) each article was classified in terms of general information (author, year of publication, regional focus, thematic scope, level of research, orientation of research); 2) the dimensions of SL and AC (definition, key influential factors reported); and 3) the way of presenting the interplay between $S L$ and $A C$, as well as the enabling and constraining conditions. The data extraction table (see SM A3) presents the results literally to ensure that all the summary descriptions of the reviewed articles can be traced (to one single document source) in an easily accessible manner (Candel, 2014).

The data extraction table was used to interpret the review findings and to discuss the state of the field based on the three research questions. Thematic synthesis (Gough et al., 2012) was applied, using an inductive approach, to analyse the data from the extraction table. We evaluated the important trends and thematic scope of the literature; this was followed by an analysis of the ways $S L$ and $A C$ are conceptualized in the literature and an analysis of the conditions that favour a particular interplay. This allowed us to examine 
systematically the interplay between $\mathrm{SL}$ and $\mathrm{AC}$ in the CCA context. We made a note of articles that provided good examples of how SL and $A C$ are characterized. Subsequently, we referred again to the original articles as a way to examine more carefully how these theories were used and in what ways they might have succeeded in advancing the conceptual understanding of the interplay between SL and AC.

\subsubsection{Limitations}

This study has limitations in terms of both the adopted methodology and the application of the methodology. Firstly, it focused on published peer-reviewed articles only. The so-called grey literature (e.g. non-peer reviewed academic work as well as policy documents and reports) was not included. This could exclude reports that, for example, provide empirical and anecdotal evidence of the interplay between SL and AC in practice. Secondly, although we included precautionary steps in our research design to include all relevant keywords and search strings; a number of articles in the searched databases might still have been excluded because they used different keywords to refer to similar phenomena. Thirdly; the review only included three scientific databases; other databases might have provided additional articles. A finally and widely recognized limitation is the inclusion only of articles written in the English language; because a number of low income countries tend to publish in their national language.

\subsection{Results}

\subsubsection{Descriptive results: trends and thematic scope of the literature}

Figure 2.2a-d presents a descriptive overview of our systematic review results for the 43 articles. It shows that the number of studies on SL and AC has increased significantly since 2007 (figure 2.2a). This is in line with other studies that found a similar pattern in the CCA literature more broadly (Ford et al., 2011). Articles' distribution by region indicates that the majority of studies are focused on developed countries $(n=20)$, whereas fewer articles focus on developing countries $(n=5)$. In terms of thematic scope, the majority of studies focus on $S L$ and $A C$ in water management $(n=12)$, environment $(n=8)$, natural resource management $(n=7)$, and agriculture $(n=7)$. The majority of articles are case studies to adopt insights from $S L$ and $A C$ in specific contexts $(n=19)$ or syntheses from difference cases $(n=17)$, with relatively few comparative studies being conducted to assess the interplay between SL and $A C$ in different contexts $(n=7)$. Several articles are focused on the conceptualization of $A C$ or SL or aim to synthesize the literature $(n=17)$.
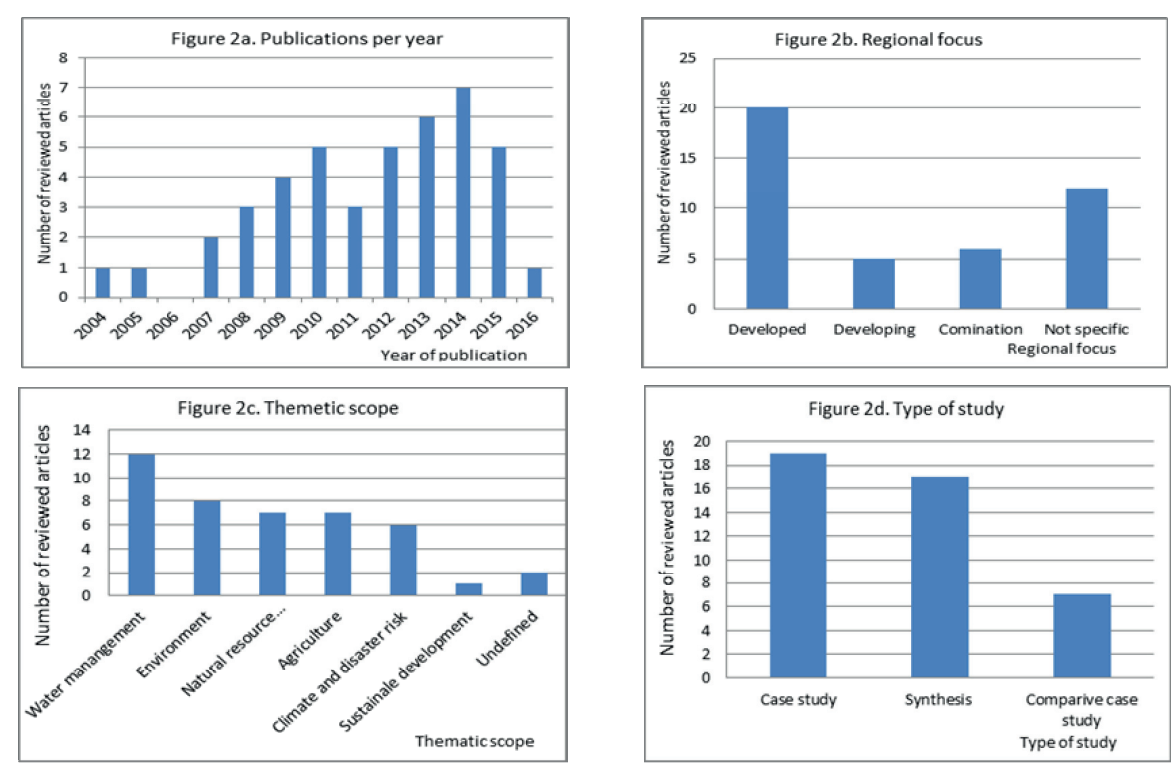

Figure 2.2. Distribution of papers by year for time period 1997-2016 (2.2a), regional focus $(2.2 \mathrm{~b})$, thematic scope $(2.2 \mathrm{c})$, type of study $(2.2 \mathrm{~d})$

\subsubsection{RQ1: how are the concepts of $S L$ and $A C$ understood in the literature on CCA?}

The definitions of SL and $A C$ are not discussed in equal depth in the reviewed articles. There appears to be much more variation in perspectives on SL than on AC.

The review shows that, in the vast majority of articles $(n=35)$, authors discuss, refer to, or operationalize the concept of $\mathrm{SL}$, with the remaining eight articles not making clear how SL was conceptualized. Our results show that different learning theories (e.g. experimental learning or transformative learning) and social science disciplines have been used by the authors to define and conceptualize SL (see also Muro \& Jeffrey, 2008). Consequently, SL is understood and defined across the studies differently; placing emphasis on different elements of SL. Table 2.3 presents some illustrative examples of different SL definitions used in the reviewed articles. These examples focus on the meaning or interpretations of these concepts, using exemplary definitions or descriptions to illustrate both convergence and divergence. Despite differences in definitions used, there is some convergence towards certain 
elements across our sample: there appears to be a general consensus on understanding learning as a process of (inter) action between (key) stakeholders in order to change actors' understanding of an issue so as to influence their future actions regarding the issue (Boyd et al., 2014; Hurlbert \& Diaz, 2013).

Table 2.3. Examples of social learning definitions

\begin{tabular}{|c|c|}
\hline Definition of social learning & Reference \\
\hline $\begin{array}{l}\text { "SL refers to the process by which societal actors interact and develop } \\
\text { alternative perspectives on a societal issue." (p. 399) }\end{array}$ & (Bos et al., 2013) \\
\hline $\begin{array}{l}\text { "SL processes are a natural occurring phenomenon whenever } \\
\text { stakeholders come together to deal with their differences but require } \\
\text { the nurturing of learning opportunities." (p. 339) }\end{array}$ & $\begin{array}{l}\text { (Muro \& Jeffrey, } \\
2008 \text { ) }\end{array}$ \\
\hline $\begin{array}{l}\text { "SL is an iterative and ongoing process that comprises several loops } \\
\text { and enhances the flexibility of a social-ecological system and its ability } \\
\text { to respond to change." (p. 486) }\end{array}$ & $\begin{array}{l}\text { (Pahl-Wostl et al., } \\
\text { 2008) }\end{array}$ \\
\hline $\begin{array}{l}\text { "SL is a process that refers to the development of common conceptual } \\
\text { understandings of climate challenges and regional vulnerability } \\
\text { integrated over multiple institutional scales, from individuals and local } \\
\text { agencies to state, federal, and binational actors and authorities." (p. } \\
919)\end{array}$ & $\begin{array}{l}\text { (Wilder et al., } \\
\text { 2010) }\end{array}$ \\
\hline $\begin{array}{l}\text { "SL which is ongoing in the professional day-to-day deliberations 'on } \\
\text { the job' arguably in stable contexts." (p. 373) }\end{array}$ & $\begin{array}{l}\text { (Johannessen \& } \\
\text { Hahn, 2013) }\end{array}$ \\
\hline $\begin{array}{l}\text { "SL broadly, as emerging through practices that facilitate knowledge } \\
\text { sharing, joint learning, and co-creation of experiences between } \\
\text { stakeholders around a shared purpose in ways that: } \\
\text { 1. Take learning and change beyond the individual to communities, } \\
\text { networks, or systems; and } \\
\text { 2. Enable new shared ways of knowing to emerge that lead to changes } \\
\text { in practice." (p. } 510 \text { ) }\end{array}$ & $\begin{array}{l}\text { (Ensor \& Harvey, } \\
2015 \text { ) }\end{array}$ \\
\hline
\end{tabular}

Several articles $(n=15)$ understand SL as the process by which actors develop shared meanings, values, and understanding through interaction that provides the basis for joint future action (e.g. Pahl-Wostl et al., 2007a). These articles argue that SL is increasingly conceptualized as a multilevel governance process seeking to involve participation of all stakeholders in discussions (e.g. Mishra et al., 2013), negotiations (e.g. Lemos, 2015), sharing (e.g. Thomsen, 2008), decision- making (e.g. Boyd et al., 2014), implementation (e.g. Albert et al. 2012), and monitoring and evaluation (e.g. Huntjens et al., 2012). A number of papers $(n=6)$ emphasize that $S L$ is the result of social interactions between actors within social networks that lead to a change in understanding that goes beyond the individual to become situated in groups of actors or communities of practice (e.g. Armitage et al., 2011). Moreover, more than a quarter of the reviewed articles $(n=12)$, mostly in natural resource management, clearly refer to SL as a collective action through community learning (e.g. Baird et al. 2014). SL can also be understood as learning from and with others; this comprises an important element and may lead to the development of shared understandings, providing a basis for collective action and decision-making (e.g. Keys et al., 2014). These articles explain that SL in the context of collective action focuses on the system of rules (e.g. Blackstock et al., 2009), decision-making procedures and programmes (e.g. Huntjens et al., 2012), and the participation of individuals in social practices. These rules, procedures, and programmes guide multi-stakeholder interactions. Breaking through existing routines, rules, and practices is considered a key principle of SL. Two articles showed how SL is conceived of as multi-loop learning to share participants experiences and ideas with others through an iterative process of reflection (Cooper \& Wheeler, 2015; Pahl-Wostl et al., 2008).

The review shows that in 32 articles the authors discuss and/or operationalize the concept of AC. Table 2.4 presents some examples of the various definitions of AC used in the reviewed articles. What is clear from the table is that AC has many different dimensions, but there seems to be consensus on the ability of a system, institutions, groups, or actors to cope and adjust to changing circumstances. The definitions of AC provided by the IPCC in their various reports are the most frequently used definitions in the papers analysed (IPCC 2014).

Within the literature reviewed, how AC is understood depends on the level of analysis. At the socio-ecological system level $(n=7)$, seven reviewed articles identify the abilities and qualities of systems that help create $A C$ and capture how these systems that enable adaptation have become a growing research area in the last decade (e.g. Tschakert, 2007). Studies focusing on the community level $(n=15)$ have tailored their definition to refer to the ability of individuals, groups, or organizations to adapt to changes and implement adaptation decisions (e.g. Eakin et al., 2011). However, these definitions do not specify what ability means in concrete dimensions. Another set of papers refer to the institutional level $(n=5)$, where $A C$ is understood as a dynamic process based on SL between and within institutions (e.g. Wilder et al., 2010) or is portrayed as the inherent ability of an institution to strengthen the responsiveness of a particular system to build AC (e.g. Gupta et al., 2010). Five articles define AC at the individual level (e.g. Armitage et al., 2011). In these articles the definition of $A C$ refers to one or a combination of the following features: individuals' societal knowledge and technical skills (e.g. Bos 
et al., 2013), their ability to adapt to changing conditions in agricultural production (e.g. Mishra et al., 2013) and their ability to harness and combine system attributes in adaptation processes.

Table 2.4. Examples of adaptive capacity definitions

Definition of adaptive capacity Reference example

"AC is an ability of a system to adjust to climate change, including (Janjua et al., 2010)

climate variability and extremes, to moderate potential dangers, to

take advantage of opportunities or to cope with the consequence

(p. 284)

"AC is an ability of an individual or group (community) to cope

with, prepare for and/or adapt to disturbance and uncertain social

ecological conditions." (p. 996)

"AC is the inherent characteristics of institutions that empower

social actors to respond to short and long-term impacts whether

through planned measures or through allowing and encouraging

creative responses from society both ex ante and ex post." (p. 461)

"AC is the ability of stakeholders to self-organise, share knowledge, (Cooper \& Wheeler, promote strong leadership, encourage shadow networks and 2015)

facilitate polycentric decision-making over multi-scales." (p. 96)

\subsubsection{RQ2: how is the interplay between SL and AC conceptualized in this literature?}

When analysing the literature, we looked at the presence of $S L$ and $A C$ components (see SM A4 and SM A5). Common SL components referred to in the CCA literature are: education and knowledge creation, social capital building, and active design and facilitation (Bos et al., 2013; Shaw \& Kristjanson., 2014; Pelling et al., 2008). Common components referred to in the general literature on AC are: human, social, financial, political, and institutional capital building (Armitage et al., 2011; Carien De Villiers et al., 2014; Huntjens et al., 2012). Papers that considered SL as one among other factors, while seeing $A C$ as an overarching theme, were classified as ACfocused. Papers on the other hand that considered AC as one among other factors, while considering SL as an overarching theme, were classified as SLfocused. Papers that did not fit in either category because they focused primarily on institutional development using both SL and AC were classified as hybrid. The finding suggests three possible conceptualizations of the interplay between SL and AC: 1) the AC-focused perspective, 2) the SL-focused perspective, and 3) the hybrid perspective. Figure 2.3 graphically represents these different conceptualizations. We discuss all three below.
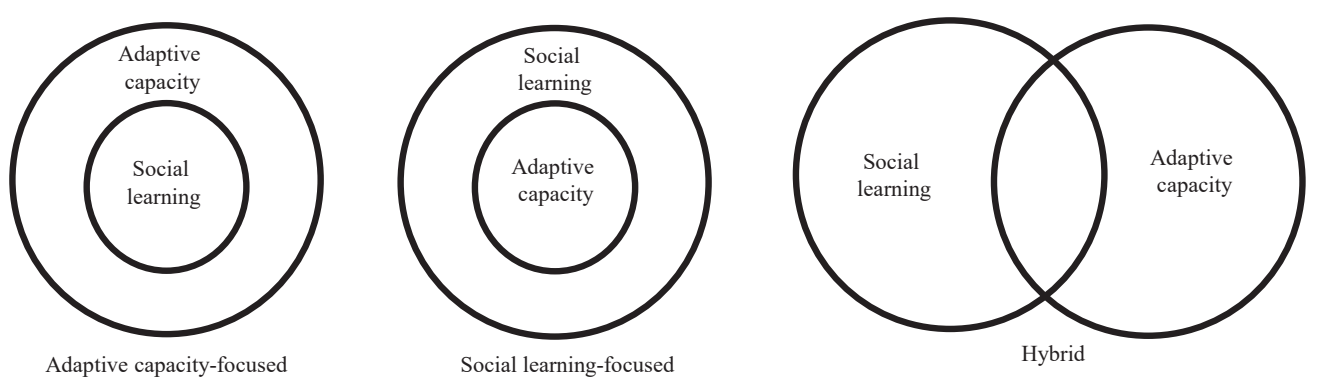

Figure 2.3. Three emerging perspectives on the interplay between $S L$ and $A C$

i) The adaptive capacity-focused perspective $(n=25)$

The AC-focused perspective suggests that $S L$ is an important component of AC. $\mathrm{SL}$ is viewed as one mechanism among others (e.g. collaborative learning, experiential learning, and scaffolding) that can help develop AC. Of the 43 reviewed articles, 25 seem to correspond with this perspective, and it is therefore by far the most prevalent perspective. A key assumption here is that capacity to learn is the most important element and always has a positive effect on increasing AC (e.g. Eakin et al., 2011). These articles argue that SL enhances participants' AC because SL itself is seen primarily as a process of adaptation (e.g. Baird et al., 2014), and it is the internalization of information about climate change and its relation to the other development factors (e.g. Hagemeier-Klose et al., 2014). SL is considered essential in building AC and by default constitutes an adaptation strategy (e.g. Ensor \& Hrvey, 2015) that opens up opportunities for future learning (Johannessen \& Hahn, 2013). The role of learning is central to effective adaptation in which $S L$ is necessary to improve AC. SL consists of a series of learning steps and contributes to increasing AC through changes in common understanding, mutual agreement, and collective action.

ii) The social learning-focused perspective $(n=9)$

The SL-focused perspective assumes that AC building is a component of SL. AC building is strengthened through $\mathrm{SL}$, as are other capacities (e.g. reflexivity, conflict management). Nine of the reviewed papers adhere to this perspective. Here, AC is one of the necessary conditions for enabling SL (e.g. knowledge co-production, co-management, sharing knowledge and skills, changing attitudes/behaviour) (e.g. Bos et al., 2013). SL is considered a social development process that depends first and foremost on the general 
capabilities of individuals in society and on their social relations (e.g. Chaffin et al., 2016). These capabilities relate to a range of characteristics of the individual such as age, gender, education, experience, perceived influence on learning, and the ability to share knowledge, but also to the quality of the interaction between actors. Several articles within this category maintain that the availability of a diversity of actors can increase the quality of social networks and can trigger SL within the community and between the community and partners or groups peripheral to the community (e.g. Keys et al., 2014).

iii) The hybrid perspective $(n=9)$

The hybrid perspective suggests that the relationship between $S L$ and $A C$ is that of a chicken and an egg: one cannot live without the other and they cannot be understood and developed separately. Nine of the reviewed articles express this perspective. Here, SL is one of the components necessary for developing the capacity to adapt and to build socio-ecological resilience (Lemos, 2015), and AC is one of the components necessary to become responsive to change and diversity (Keys et al., 2014). Building AC is assumed to encourage a diversity of learning processes to support CCA. Authors conclude that collective action will occur in adaptive management when stakeholders are fully engaged in developing management strategies and believe they understand the consequences of making a decision (e.g. PahlWostl, 2009).

\subsubsection{RQ3: are there conditions which favour a particular type of interplay?}

i) The adaptive capacity-focused perspective $(n=25)$

The AC-focused perspective seems to be used most in conditions where relationships and engagements among stakeholders are close and strong (e.g. Serrat-Capdevila et al., 2009), and it is particularly useful when knowledge is incomplete or dispersed amongst different stakeholders (e.g. Lebel et al., 2010). Articles starting from the AC-focused perspective explain that a high level of participation in groups with diverse knowledge, values, and expertise is fundamental to effective capacity to adapt to climate change (e.g. Johnson et al., 2012). Moreover, some of the articles claim that, in order to improve the AC of stakeholders and the local community, it is important to involve them in a SL process (e.g. Henly-Shepard et al., 2015).
SL helps establish social networks by involving participants, facilitating knowledge sharing, and creating partnerships between all stakeholders (e.g. Mapfumo et al., 2013).

SL depends very much on social networks, trust, and relationships as vita conditions for collaboration and collective action (e.g. Boyd et al., 2014). The building of trust and social networks can make the diversity among the participants a positive force for learning and can result in more open communication (e.g. Ensor \& Hrvey, 2015). Especially in the context of CCA, $\mathrm{SL}$ is considered a vital component of an adaptation framework for action at the local level (e.g. Shaw \& Kristjanson., 2014). However, lack of trust (e.g. Tompkins \& Adger, 2004), time (e.g. Munaretto \& Klostermann, 2011), and social influence (e.g. Baird et al., 2014) are reported as specific factors negatively affecting $S L$ in enhancing the $A C$ of communities or institutions. Although there are different constraining factors, it is most likely that lack of social influence will emerge as a key constraint (e.g. Collins \& Ison, 2009). Social influence provides measures of the structure and processes of interaction among participants and with the broader community. Many of the articles that share an AC-focused perspective suggest that maintaining social networks and cohesion in the community is a necessary condition for the development of AC (e.g. Johnson et al., 2012).

ii) The social learning-focused perspective $(n=9)$

Nine articles with an SL-focused perspective often drew empirically from situations where both the relationships and engagements among stakeholders have been historically limited (e.g. Huntjens et al., 2012). Butler et al. (2015) provide an example of this in a building-adaptive-planning situation where the community had the capacity to learn and see the value of knowledge exchange but never got going due to ineffective coordination (see also Chaffin et al., 2016). Several of the articles in this vein suggest that organizing a multistakeholder dialogue requires space, time, and support for groups to interact with other actors (e.g. Bos et al., 2013). AC might be a valuable outcome of such dialogue and interaction.

Not surprisingly, some of the key factors influencing SL reported in these articles include social capital and the design and facilitation of informa environments conducive to learning and sharing (e.g. Butler et al., 2015). The design and facilitation of a learning process influences the motivation (Bos et al., 2013), the participation (Butler et al., 2015), and ultimately the learning capacity of participants (e.g. Grothmann et al., 2013). When studies report a 
clear and transparent learning design that makes learning progress and outcomes visible, the core actors demonstrate high awareness of how the different project design elements are interlinked (e.g. Huntjens et al., 2012). Participants' knowledge about the SL process, and the availability or creation of learning spaces that allow for open and equitable communication among participants also enables SL processes.

Some articles explain that awareness about sharing and co-creating knowledge is the main factor influencing the success of learning (e.g. Tschakert, 2007). Learning and knowledge are expected to raise awareness, spur resourcefulness, and provide a sense of agency that will help actors to pursue future options. Active learning and sharing as well as readiness to engage with members of a community are very dependent on participants' knowledge level (Butler et al., 2015). Therefore, lack of awareness and lack of knowledge about climate change are generally considered as root causes of unsuccessfu implementation.

iii) The hybrid perspective $(n=9)$

Viewing the interplay between SL and AC seems particularly suitable under conditions where the community already has some $A C$, and $S L$ is already occurring. For example, in some cases (e.g. Huntjens et al., 2011), the community already has a high degree of $\mathrm{SL}$, and different types of knowledge exist. Nine studies show that this hybrid perspective is most effective when governance and institutions are developed simultaneously. For example, Emerson \& Gerlak (2014) show that governance structure and institutional mechanisms are increasingly seen as central determinants of AC and are necessary to help stakeholders face climatic changes and associated uncertainties.

In this hybrid perspective, SL and AC building are understood as the result of bringing diverse stakeholders together in order to reach a consensus position on the strength and importance of, and confidence in, a variety of solutions for carrying out adaptation activities (Huntjens et al., 2011; Storbjork, 2010). $A C$ is needed for institutions to retain their relevance and efficacy in their attempt to respond to and anticipate changing external conditions and the diversification of networks (Pelling et al., 2008). Multilevel interactions and sharing knowledge are factors that increase the capacity of organizations to respond to feedback in the environment and to ensure adaptation actions (Pahl-Wostl, 2009). Some of the articles with this hybrid perspective point out that weak governance leads to difficulties in establishing an adequate SL process and in enhancing a community's AC (e.g. Lemos, 2015).

In this perspective, we cannot say that either $S L$ or $A C$ is the main component in CCA processes. On the one hand, human factors, such as ability and willingness to collaborate and learn, are important for gathering, sharing, integrating, and applying adaptation strategies (e.g. Emerson \& Gerlak, 2014). On the other hand, social networks related to SL can support or hinder the capacity of individuals and communities to adapt to climate change (Pelling et al., 2008). Moreover, climate change may be a catalyst for the transition from technical to SL approaches and could increase opportunities for SL within adaptation processes by enhancing AC (Baird et al., 2014). Therefore, the hybrid perspective seems particularly useful in cases where the focus is on polycentric structures for implementing CCA (e.g. Pahl-Wostl, 2007).

\subsection{Discussion}

With respect to the first question this review set out to answer, concerning the manifestations of social learning and adaptive capacity in the literature analysed, our review shows that SL generally is understood as a process of social change in which a diverse group of people learn from one another in ways that can benefit a wider socioecological system (Reed et al., 2010). However, as Reed et al. (2010) indicate, in practice, there are three key problems with the term SL: 1 ) confusion about the conditions or methods to facilitate SL, such as stakeholder participation; 2) confusion between the concept itself and its potential outcomes; and 3) the lack of distinction between individual learning and SL in the wider context. Without clarity about the meaning of $\mathrm{SL}$, it becomes very difficult for practitioners to facilitate SL processes. From our review, we conclude that SL can be understood as: a process where learning occurs at multiple governance levels, bringing together stakeholders with diverging initial perceptions with the intention to learn together and form a common understanding with respect to taking a planned course of action that they jointly implement by working in iterative cycles of action and reflection. Thus, SL can increase a community's AC for responding to climate-change-related challenges. However, some of the reviewed papers show that SL does not necessarily lead to improved natural resource management or to better environment governance (e.g. Nykvist, 2014). 
Turning to AC in the context of climate change, the review shows, that many of the analysed articles use the IPCC report (Cooper \& Wheeler, 2015) as their starting point, defining $A C$ as the ability of individuals, communities, organizations, nations, and other actors to adapt to the current and likely future effects of changes in the global climate. Although the current review did not look systematically at the indicators used by the different studies to assess $A C$, we did observe various general variables that relate to financial capital, social capital, or political capital (e.g. knowledge, income, age, kind of labour, trust, norms) and that correspond to these indicators.

With respect to the second question of this review - concerning the interplay between $A C$ and $S L$ - our findings show that, depending on the climate change adaptation context, this interplay can be characterized by three perspectives: 1) the AC-focused perspective, 2) the SL-focused perspective, and 3) the hybrid perspective. Our results show a dominance of the AC-focused perspective and fewer examples of the SL-focused and the hybrid perspective. We find that, depending on the context, specific interplays between SL and AC can be applied to increase a community's responsiveness to climate change. The SL-focused perspective is more suitable when individual or community capacities exist and there is a need to develop polycentric governance structures, whereas the AC-focused perspective seems to work better in situations where formal social ties are weak and local people have limited knowledge. The hybrid perspective seems to work best in conditions where some AC already exists and SL is already taking place. Usually, this is the case when an enabling governance arrangement, social capital, and a favourable institutional environment are already in place and are being developed simultaneously. Within the hybrid perspective, $S L$ and $A C$ building are an outcome of what we might call "generative plurality": people with different backgrounds from different levels come together in a friendly environment where they respect each other and can reach a consensus with confidence about the co-created solutions for carrying out adaptation activities.

Typically, in developing countries, where local people tend have low levels of $A C$ to respond adequately to climate change, there is more trust in (informal) social networks. Hence, adaptation planning should focus on developing SL to involve and engage stakeholder participation to improve AC. The AC-focused perspective indicates that the $S L$ process is essential for improving the $A C$ needed to respond to climate change. Hence, we suggest that, in contexts where people need to improve individual capacity first (for example in low income contexts in South-East Asia), this perspective is particularly suitable. However, in situations where AC is high, yet governance and institutions are weak and/or outdated, adaptation planning should focus on the promotion and development of good governance and institutional design. The SL-focused perspective is perhaps more suitable for this. In situations characterized by a dominance of polycentric structures needing to combine top-down and bottomup approaches to carry out strategies to respond to climate change, the hybrid perspective appears to be most fruitful.

When the focus lies primarily on $S L$, as in the $S L$-focused perspective, there is a risk of the learning remaining limited to single-loop learning that seeks to optimize existing routines and actions (how can we improve what are we doing?) but fails to interrogate and transform the assumptions and principles underlying these routines and actions. To prevent this, emphasis needs to be placed on establishing governance processes that can promote collective understanding and social interaction on a sufficiently broad scale to open up possibilities for deepening the SL to the level of double-loop learning (are we doing the right things?) and even triple-loop learning (how do we decide what is right?) (Argyris \& Schon, 1974). Thus, in order for the individual to be actively involved, governance-supported and community-based activities are needed to ensure that SL can take place at high levels of interaction between stakeholders (Argyris \& Schon, 1974). Only then will it be possible to have a deeper understanding of the context, power dynamics, and values that influence the ability of people and organizations to engage meaningfully in CCA.

With respect to the third question this review addresses - regarding conditions that might favour a particular interplay between $\mathrm{SL}$ and $\mathrm{AC}$ - it is clear that the context in which polycentric governance is needed to help communities respond to climate change needs to be considered when determining whether emphasis needs to be placed on $\mathrm{SL}, \mathrm{AC}$, or on both simultaneously. The review shows that the factors and conditions that enable or constrain adaptation to climate change are very context specific, dynamic, and not easily captured (Faysse et al., 2014). In many Western democracies, climate change is seen as the key driver of vulnerability, and policy intervention strategies are mostly intended to deal with projected climate change impacts. However, in many low and middle income countries, the impacts of climate change are accelerating some of the existing problems of lack of AC to deal with socio-environmental system changes in general. This demands a rather different understanding of 
what is important to consider in understanding the interplay between $\mathrm{SL}$ and $A C$. The hybrid perspective on the interplay between $S L$ and $A C$ has been explored mostly in so-called developed countries. What is needed now is the development and analysis of cases that use such a perspective to strengthen both $A C$ and $S L$ in those parts of the world that are, or will be, most affected by the impacts of climate change.

Moser \& Ekstrom (2010) conclude that institutional design and polycentric governance processes are necessary for effective problem detection, information gathering, assessment of adaptation options, transmission, and, finally, communication of information to increase awareness and understanding and the engagement of key stakeholders. Increasing 'democratic legitimacy' and 'empowered participation' were referred to in most studies as key factors influencing $S L$ and $A C$ - something that was also stressed in the most recent IPCC report (IPCC, 2014).

\subsection{Conclusions}

From our studies, the following conclusions can be drawn: (1) the SL concept is increasingly becoming a normative goal but more so in natural resource management contexts than in CCA contexts; (2) the understanding of AC in CCA mirrors those that can be found in the most recent IPCC report which distinguished several possible levels of AC: socio-ecological system level, community level, institution level, and individual level; and (3) there are three emerging perspectives on the interplay between $S L$ and $A C$ : an AC-focused perspective, a SL-focused perspective, and a hybrid perspective. The findings reveal that the interrelationship between $S L$ and $A C$ is not singular or uniform but can take on different manifestations (SL-focused, AC-focused, and hybrid) depending on the context and the complexity of the issue at stake. Each conceptualization can be helpful, depending on the circumstances under which communities seek to respond to climate change. These conclusions further explicate for knowing the implications for governance and other forms of interventions that seek to help communities respond to climate change.

Although community-based SL was deemed important, it is and by itself does not provide enough AC to respond to climate change. The quality of available governance and institutional systems presents serious limitations in enabling the interplay between AC and SL. Hence, the recent call for open system approaches in the study of SL allows for a better connection to the ideas of AC from socio-ecological systems theory in which governance arrangements and institutional mechanisms are considered key catalysts (Biesbroek et al., 2015). Adequate institutional structures as well as the presence of CCA policies and legal frameworks seem to play an important enabling role.

Further reflection on what we currently know about the interplay between SL and $A C$ in the context of CCA prompts a final critical note. Identifying the most relevant conditions for these interplays allows for more effective strategies to increase AC. In addition, the strong inductive orientation of the first generation of 'small- $n$ ' descriptive case studies has provided some empirical leverage but has been of limited influence in advancing scientific debates about these interplays. Quantitative 'large-n' studies and longitudinal studies of the application of these interplays in practice over time will be needed to advance these debates.

\section{Acknowledgements}

We are grateful for the comments and suggestions by Prof. Martin Verstegen on an earlier version of the paper and the feedback by Dr. Peter Tamas on the systematic review methods. We also would like to thank Mrs Anne Gutenkunst for reading and editing English for this paper. 
Chapter 3

Understanding smallholder farmers' capacity to respond to climate change: A case study in a coastal community,

Central-Vietnam 


\subsection{Introduction}

Agriculture is a major economic, social and, cultural activity which is the main source of national income and sustains livelihoods in many countries, especially in the developing countries in Asia and Africa (Howden et al., 2007). While the relative contribution of agriculture has declined in recent years due to the rapid growth of the industry and service sector in Vietnam, agriculture still plays an important role in the national economy, contributing to more than $21 \%$ of the GDP of the nation ${ }^{1}$ and providing employment for $47 \%$ of the working population ${ }^{2}$. Vietnam is currently ranked among the ten most climatevulnerable countries in the world and it is without adequate capacity to respond to future climatic disasters (Bruun, 2012; Maplecroft, 2011). Several studies provide evidence that Central Vietnam is increasingly affected by the unpredictable weather connected to climate change (Hanh, 2010; Phuong, 2010; Sen \& Phuong, 2011). Climate change impacts are likely to be severe for coastal smallholder farmers whose livelihoods depend largely on natural conditions (Beckman, 2010). The agricultural sector is considered to be particularly vulnerable to current and future climate risks because of low adaptive capacity of farming communities such as; lack of education and technical skills, poverty, and lack of assets and capital to recover or to shift to alternative livelihoods (Government of Vietnam, 2011; IFAD, 2014; Le Dang et al., 2014d; Oyekale \& Ibadan, 2009).

Early on the adaptation literature characterized adaptive capacity as a dynamic concept (e.g. Eakin \& Bojorquez-Tapia, 2008; Vincent, 2007). Lemos et al. (2016) consider adaptive capacity to include specific capacities and associated tools and skills that enable actors to anticipate and effectively respond to specific threats (e.g. the ability to respond to and manage identified climate hazards). These specific capacities need to be complemented by, what they refer to as, generic capacities that address the deficiencies in basic human development needs (e.g. the ability to respond to more general social, economic, political, and ecological stressors). They conclude that higher levels of generic capacity are associated with higher levels of specific capacities. The combination of specific and generic capacities is important to identify and assess the adaptive capacity of an individual, community or institution to respond to climate change impacts (Eakin et al., 2014; Lemos et al., 2016).

Recent literature on smallholder farmer climate change adaptation decisions shows that adaptation is driven by multiple stressors (Burnham \& Ma, 2016). 
Climate change adaptation decisions depend on the perceptions of adopters and on contextual factors such as; culture, education, gender, age, resource endowments and institutional factors (Prager \& Posthumus, 2010). A review of farmers' awareness and adaptation strategies in developing countries shows that smallholder farmers adopt adaptation strategies to respond to climate change impacts at the farm level based on objective determinants of adaptive capacity such as; financial responses, agricultural changes, religious and cultural strategies, the use of local, and prevalence of wider support networks (Harmer \& Rahman, 2014). Frank et al. (2011) indicate that the lack of resources and socio-economic limitations can impair farmers' adaptation decision-making even when they perceive high risks. In addition, smallholders' adaptation decision-making is also based on subjective determinants of adaptive capacity such as; as farmers' perception of climate risks and selfperceived adaptive capacity (Grothmann \& Patt, 2005; Kuruppu \& Liverman, 2011). Thus, in order to respond to climate change impacts, researchers may consider both objective determinants (e.g. financial or physical capital) (Burnham \& Ma, 2016) and subjective determinants (e.g. how individuals and communities perceive the process of adaptation and their self-efficacy) (Wolf et al., 2013) of adaptive capacity in future climate change adaptation programs and policies to facilitate adaptive actions (Burnham \& Ma, 2017).

Phuong et al. (2017) show that, common components of adaptive capacity referred to in the adaptation literature in the context of climate change responsiveness and natural resource management are: human, social, financial, political, and institutional capital building. Previous studies in the context of smallholder farmers' capacity indicate that adaptive capacity components should refer to the earlier mentioned objective determinants (Brooks \& Adger, 2005; Smit \& Pilifosova, 2003; Yohe \& Tol, 2002). However, Grothmann \& Patt (2005) developed a Model of Private Proactive Adaptation to Climate Change (MPPACC) based on Protection Motivation Theory (PMT) (Rogers, 1983) that posited that subjective determinants of adaptive capacity are at least as important in determining a person's ability to adapt. The model suggests that understanding smallholders' adaptive capacity is based on two important bottlenecks: risk perception (risk appraisal) and perceived adaptive capacity (adaptation appraisal). Here risk appraisal refers to a person who assesses a risk's probability and damage potential of a chosen course of action, while adaptation appraisal refers to a person's self-evaluated ability to cope with these risks and of the costs of taking a particular course of action.
A substantial volume of scholarly work has been devoted to understanding the adaptive behaviour of farmers (Below et al., 2010; Below et al., 2012; Bryan et al., 2009; Deressa et al., 2009; Hassan \& Nhemachena, 2008). These studies show that any attempt to elicit adaptive behaviour patterns should follow from understanding how climate variability is perceived by stakeholders and what shapes their perceptions (Maddison, 2007; Mertz et al., 2009; Shisanya \& Khayesi, 2007; Weber, 2010). Understanding perceptions of climate risks, adaptive capacity, and experiences in handling climate change is crucial for further strengthening of smallholder farmers' activities to manage the impacts of climatic risk and their social vulnerability, both at the individual and collective levels (Mtambanengwe et al., 2012).

Understanding existing farm-level adaptation strategies and farmers perceptions of possible future adaptation strategies, provides important input for the formulation of additional adaptation initiatives and strengthens farmers' social learning to deal with future climate risks (Mengistu, 2011). The link between farmers' perceptions, their learning processes, and their decisions to adopt adaptation strategies in agriculture remains a contested issue in the literature (Harmer \& Rahman, 2014), and little empirical research has been done to explore both understanding farmers' adaptive capacity and their motivations to act or not to act in response to climate change. To address this shortcoming, the aim of this study is to explore smallholder farmers' capacity and drivers to respond to climate change in current and future agricultural production. The study addressed the following research questions:

1. How do farmers perceive current and future climate change and how might impact it their agricultural production?

2. What are current and future measures farmers use to adapt to climate change and what explains their choices?

3. How do farmers perceive their capacities to deal with climate changes?

In this paper, we applied the MPPACC to understand smallholder farmers' capacity to respond to climate change impacts (Grothmann \& Patt, 2005) recognising three critical important determinants of adaptive capacity: learning capacity (information, feedbacks and transparency), decision-making capacity (participation, collaboration and power) and acting capacity (leadership, networks and flexible governance) (Bettini et al., 2015).

Research linking perception of climate variability and adaptation has been conducted in several low-income countries, especially in Africa (Bryan et al., 
2009; Gbetibouo, 2009; Hassan \& Nhemachena, 2008; Prager \& Posthumus, 2010; Shisanya \& Khayesi, 2007). However, a much smaller body of research has explored how smallholder farmers adapt in Southeast Asia. In Vietnam most research related to farmers' experience with and adaptation to climate risks in agriculture is concentrated in the Mekong Delta (Le Dang et al., 2014a; Le Dang et al., 2014c) with hardly any research in the coastal region of Central Vietnam. Thus, identifying how farmers perceive their capacity and understanding how they can enable adaptive capacity, are critical in climate change adaptation research and policy.

The paper is organized as follows. Section 3.2 describes the methodology of the study. The findings of this study are presented in section 3.3. In section 3.4 , we discuss our findings followed by our conclusions and recommendations for policymakers (3.5)

\subsection{Methodology}

\subsubsection{Selecting the study site}

The study was carried out in Thua Thien Hue (TTH) province. $\mathrm{TTH}$ is located in the Central coastal region in Vietnam. TTH is thought to be one of the most climate vulnerable areas in Vietnam (TTH Provincial People Committee, 2014) and people are highly vulnerable to more frequent and more intense weather extremes (Fortier, 2010). Several studies show that during the past ten years, drought was the main climate extreme event in the TTH province (e.g. Lien, 2015; Suong, 2011). While the annual average temperature has decreased in the last two decades, the temperature recorded by the TTH Meteorological Stations from 1956 to 2005 show an increase in extremes, with the hottest months in June and July and the coldest in December and January. Similarly, meteorological data from the TTH show a changed pattern in monthly rainfall, with an increase during the rainy season and a decrease during the dry period.

To select the most appropriate district and commune for this study we conducted an in-depth interview with the leader of the TTH provincial Department of Agriculture and Rural Development (DARD). The Quang Dien (QD) district was selected because of its large share of agricultural production in terms of area and productivity. It is very vulnerable to climate change. Indepth interviews with leaders of DARD at the district level resulted in selecting the QL commune for four reasons: (1) the livelihood of the people strongly depends on agricultural production; (2) it is the most vulnerable commune to climate change and especially drought in the QD district (Lien, 2015; Suong 2011); (3) the ecological conditions and agricultural production practice in the QL have representative characteristics for the coastal area; (4) most of the farmers in this commune have participated in the agricultural cooperative before.

Quang Loi (QL) is a coastal commune ("Bai ngang" commune) which has high poverty rates and a strong dependency on farming income. The total area cultivated for agricultural production was 1,456 ha (QL Commune People Committee, 2014). However, due to an increase in extreme droughts, the areawhich is used in Winter-Spring season for agriculture has dropped to around 734 ha in 2014. Popular crops for this season include rice, several kinds of beans, peanut, corn, sweet potatoes, cassava, and several kinds of vegetables. In Summer-Autumn season, around $39 \%$ of agricultural land could not be cultivated because of lack of water during the dry season (QL Commune People Committee, 2014). Popular crops in this season include rice, watermelon, and local onion. The most recent data from 2014 show that the livelihood of the QL's residents depended significantly on agricultural income $(54.5 \%)$, of which the main agricultural activities included crop (49\%) and livestock production (30\%), aquaculture and fishery (21\%).

In the $\mathrm{QL}$, the infrastructure for agricultural production (e.g. irrigation systems, inter-field roads and dams) is very poor. Before 2010, there were no irrigation systems for agricultural production and no dams to prevent salt water intrusion. Since 2011, irrigation systems have been built; however, these irrigation systems can serve only about $55 \%$ of the farmable lands (QL Commune People Committee, 2012). The type of irrigation system implemented mainly consists of pumping water from local streams and rivers of which there are not many in the region. Hence, farming practices remain very sensitive to drought and changes in temperature. The climatic impact seems to become more severe each year due to the lack of investments in infrastructure improvement (QD District People Committee, 2014).

When it comes to local governance, not unlike in other communes in Vietnam, local officials in the QL are obliged to provide detailed information about a broad range of issues including climate change. Any new initiative requires public discussion prior to being decided by the commune's councils and committees This form of local governance is important in the context of socio-economic planning, land use planning and the mobilization of residents' contributions to infrastructure construction as well as to the implementation of national plans on 
environmental protection, health and water. Normally, the local government has responsibilities for agricultural development in rural communes (Mattner, 2004). However, in the QL, these responsibilities reside with the agricultural cooperatives that play an important role in the planning, management and support of agricultural production. Unsurprisingly, almost all smallholder farmers participate in activities organised by agricultural cooperatives.
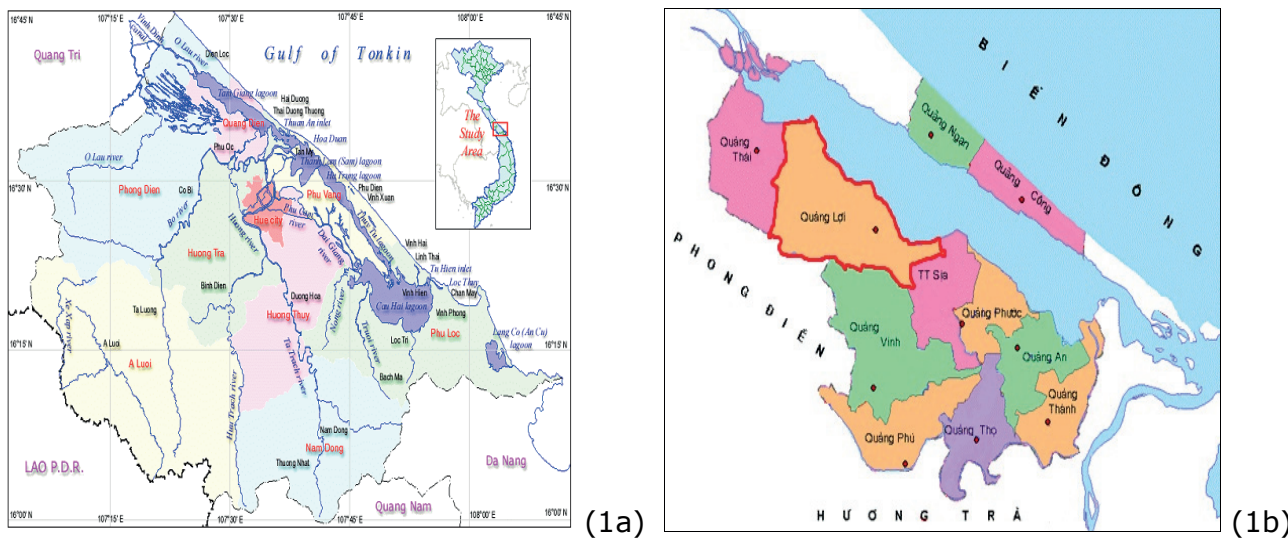

Figure 3.1. 1(a) TTH provincial map; 1(b) Map of the QD district and the QL commune (Source: Lien, 2015).

\subsubsection{Research methods}

This research used both qualitative and quantitative methods for collecting data in the period of March - August, 2015. Data collection started with a rapid rural appraisal to gain an overview of the significant social and physical features of the selected villages (Chambers, 1994). A mixture of participatory methods including open, in-depth key informant interviews $(n=13)$, focus group discussions (FGDs) and structured interviews $(n=114)$ were used, allowing farmers to participate by sharing their perceptions, their experiences and knowledge in various ways (see figure 3.2).

Open, in-depth interviews were used to explore various topics related to climate-related agricultural production, climate risks and their impacts, farmer capacities to deal with climate change and current and planned adaptation measures (AMs) in agriculture. The respondents at the district and commune level were selected based on their roles in the community, agricultural production, and climate change adaptation. In addition, three representatives of the three agricultural cooperatives were selected for open, in-depth interviews. In total, thirteen respondents were interviewed. The face-to-face interviews (Kummar, 2011) were conducted using a structured guide and each interview took between 45 minutes to an 1 hour.

Step 1: Selected the study site: in-
depth interview of 2 staff at provincia

district levels (March, 2015)

\section{Step 2: Prepare checklist for in-depth
interview and FGDs; design \\ questionnaire: literature review (March,}

Step 3: Secondary data collection at DPC and CPC and pre-analyse of these documents (the begin of April, 2015) farmers (March, 2015)

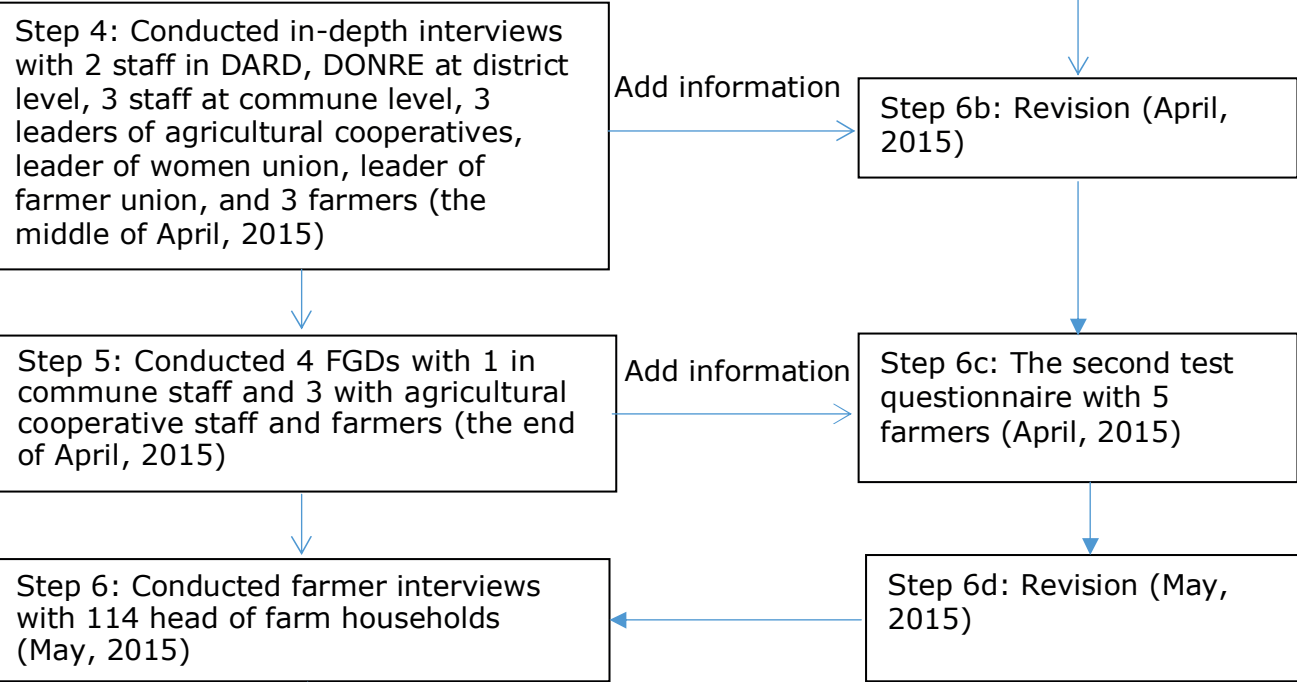
(May, 2015)

Step 7: Synthesized data from

secondary data, in-depth interviews,

ews (June, 2015)

Step 8: Organized final feedback to
present preliminary findings and get present preliminary findings and get participants in the fieldwork (AL

eldwork (August

Figure 3.2. The research design for data collection 
The four focus group discussions (FGDs) were conducted with 6-10 key informants, both men and women, to explore the perceptions, experiences, and understandings of the trends in climate risk during the past 5 years, 10 years, and 20 years. The impacts of climate risk and the AMs in agriculture, the learning process for adaptation decisions, the barriers in adaptation, and the adaptive capacity of local community in agricultural development also were collected. One FGD with commune staff and three FGDs with agricultural cooperative staff and experienced farmers were organized for discussions about climate change, its impacts and $A M s$ in their agricultural production (table 1 in SMB). On average a FGD lasted around 2 hours. FGD reports were written and condensed using data reduction methods and thematic analysis (Morse et al., 2001).

Structured interviews: after collecting and classifying information and data from the in-depth interviews, FGDs and an earlier conducted systematic review on social learning and adaptive capacity (Phuong et al., 2017), a structured questionnaire was designed and implemented (see figure 3.2). The majority of questions were closed; however, we included a few open-questions to allow interviewees to explain in greater detail. All interviewees received the official invitation for the interviewing from the leader of the agricultural cooperative. The invitation mentioned the contents and purpose for the interview. Each participant received around 30,000 VND ( 1.3 US Dollars) and some tea. In total, 120 households ( $10 \%$ of all agricultural households in the region) were randomly selected to send the invitation for interviews of which 114 households (head of household) in the end participated. Six households did not participate because they had no time or were not interested in participating. The interviews were conducted during April and May of 2015. Respondents were selected when they had at least 10 years of experience in crop or livestock production. Each interview took between 45 minutes and 1 hour. The interview captured the following topics: characterization of the household, perceptions of climate risks, climate risk impact, climate change AMs, barriers in adaptation implementation, adaptive capacity of household, the capacity to access information and networks, participation in climate change activities and participation in training courses. The English version of the interview can be found in semi-questionnaire form (see in SMB). Data from the interviews were collected, synthesised and analysed using SPSS 22. Descriptive statistics were used to present farmer's perceptions of changes in long-term temperature, rainfall and climate risks as well as various AMs being used by famers. Multiple regression analysis was used to explore which of the variables explain choices in the diversification of AMs. Forward stepwise multiple regression analysis was used to determine the predictive power of the explanatory variables associated with the diversification of their AMs.

A Feedback seminar was organized to verify the preliminary result of the structured interviews $(n=29)$. We presented the main results from the interviews to share and discuss the data. Colour cards and voting systems were used to collect additional opinions from participants about climate change risks and their AMs. The feedback was used to fine-tune findings and increase the research validity.

\subsection{Results}

\subsubsection{Farmers' perceptions of climate risks}

When asked about their experience of climate change in the past 20 years, almost all farmers reported that, in contradiction with the data provided by the Meteorological station $\mathrm{TTH}$ which reports annual tendencies without zooming in on seasonal differences, if we considered the year tendency. When also factoring in seasonal trends, the average temperature in the QL as well as temperature extremes are increasing, both in terms of intensity and frequency see figure 3.3. Less than $5 \%$ of the respondents did not experience any change. Similarly, most farmers responded that they perceived more and more extreme droughts and less extreme coldness during the last 20 years. Farmers were unaware of the impact of salinization on their farming activities. Out of the 114 respondents, almost all $(97.4 \%)$ experienced a decrease or a significant decrease in the frequency of precipitation in the last two decades.

The main observed changes are prolonged dry spells, longer intra-season dry spells and a general delay in on-set of rains and an abrupt end of the season (TTH Provincial People Committee, 2014). Floods and storms seem to have decreased in both frequency and intensity. Results from in-depth interviews reported, on average about 2-3 storms and 2 floods occurred per year over the last 20 years but during the last 7 years the average dropped to less than 1 storm and 1 flood a year. 

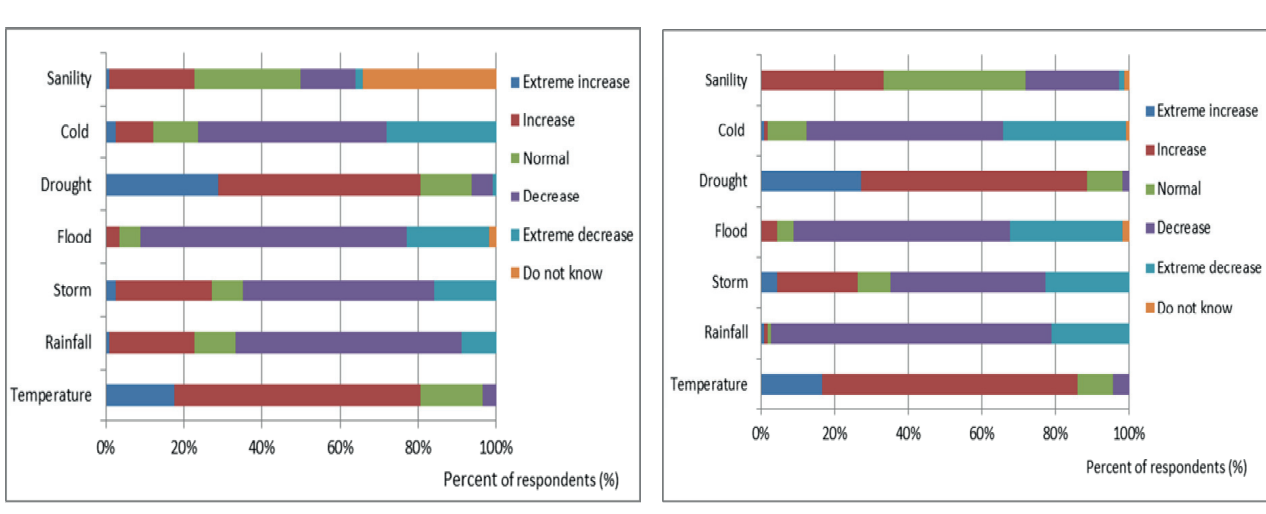

Figure 3.3. Farmers' perception of intensity (a) and frequency (b) of climate change during the past 20 years in the QL

\subsubsection{Farmers' perceptions of current and future climatic impacts on agricultural production}

Farmers were asked to assess and score the impact of climate risks on their crop and livestock production, ranging from having significant impact (5) to no impact (1). Results show that farmers have a diverging experience of climate impact on their agricultural practices, ranging from serious and very serious impact $(48.2 \%, \mathrm{n}=55)$ to almost no impact $(48.2 \%, \mathrm{n}=55)$. The most frequently identified climate impact for crops are: decrease in crop yield, increase in farming investment cost, increase in crop pests and diseases, decrease in the farmable land and lack of water for cultivation, see table 3.1. For livestock production, the main impacts are: increase in investment cost for farming, increase in number and frequency of livestock diseases, decrease in the number of healthy livestock, increase in numbers of livestock that died because of climate change related impacts, and lack of food to ensure livestock farming.

Table 3.1. The impact of climate change on crop and livestock production (" $n$ " is number of respondents in the survey, multiple options could be selected)

\begin{tabular}{lllc}
\hline Crop impact & Ranking & Livestock impact & Ranking \\
\hline Decrease yield & $1(n=91)$ & Increase investment cost & $1(n=79)$ \\
Increase investment cost & $2(n=63)$ & Increase livestock diseases & $2(n=78)$ \\
Increase pests \& diseases & $3(n=47)$ & Decrease livestock health \& production & $3(n=38)$ \\
Fallow land, dry land & $4(n=26)$ & Livestock died (chicken and duck) & $4(n=34)$ \\
Lack of water & $5(n=7)$ & Lack of food for livestock & $5(n=6)$ \\
\hline
\end{tabular}

During the in-depth interviews and Focus Group Discussions (FGDs), a farmer from the Thang Loi agricultural cooperative explained that "...long periods of sunshine and extremely high temperatures result in high evaporation, especially for the sandy soils. Consequently, the size of the dry area increased over the past years. Rice and sweet potato are the two crops that were most affected by the drought spells because these crops need more water and are more sensitive to air temperature". Furthermore, the leader of the Tin Loi agricultural cooperative stated that "...there were several reasons explaining the increase of pests and diseases in crop production; however drought and high temperature were the major ones. Previously, farmers sprayed pesticides only two or three times per crop season, but recently they had to spray up to seven times per crop season". Respondents also indicated that in recent years, pests and diseases developed in unpredictable ways and became more difficult to control. For livestock production, a farmer from the My Thanh agricultural cooperative argued that "...we have to use more medicine for disease control and more investment is necessary to regulate air temperature for the livestock". In addition, main feed sources for livestock including wild grass and agricultural by-products such as sweet potato leaves and roots, have been under pressure due to high temperatures and shortage of water. Farmers noted that their knowledge in determining the manifestation of livestock diseases was very limited leading to an increase of diseases and death rates.

When asked about the future climate impact on agricultural production, $94 \%$ of respondents expected that drought will be the most serious climate extreme that would threaten their farm. The variation of temperature both in frequency and intensity as well as the shortage of water will lead to more challenges for cultivation and livestock production, though irrigation systems might be improved in the future. The crop yield and livestock productivity are expected to continue to decrease and could even lead to total losses. The production cost will also increase. The result is that the farmers will face more constraints in their production if they fail to expand their adaptive capacity.

\subsubsection{Current adaptation measures of farmers in the QL commune}

The results from FGDs and in-depth interviews showed that at least 21 different adaptation measures (AMs) are most commonly used in or advocated for this region of which twelve are for crop production and nine are for livestock production (see table 2 and 3 in SMB). We selected a mixture of 
household levels and community level AMs in the interviews and asked farmers to identify which measures they already used or were planning to use.

\section{Adaptation measures for crop production}

All respondents indicated they adopted the changed crop seasonal calendar (AM1) that was developed by the government at the province and district level and promoted by agricultural cooperatives. In addition, farmers had made other changes in production techniques to adapt to climate change such as; change of quantity and timing of applying chemical fertilizer and pesticides (AM2); use of more manure (AM3); change in crop density (AM4); and use of mulching (AM6). Farmers also used more drought-tolerant, pest-tolerant, and disease-tolerant crop varieties (AM8) from DARD since 2004; the agricultural cooperatives encouraged farmers to adapt their rice production areas either in using new rice varieties or in using alternative crops. All farmers adopted tolerated drought varieties for sweet potato and $65.8 \%$ of the farmers switched to new rice varieties. Other crops that require less fresh water and are suitable to grow on sandy soil have been cultivated, including; cassava, watermelon, chili, onion, and all sorts of beans. As an alternative to the change in the seasonal calendar, farmers applied the intercropping model (AM5) and the rotation model (AM9). Crop diversification (AM7) is considered a feasible 'no-regret adaptation strategy' for farmers in this area because of low production risks, high source of income, reduction of production costs, and high resilience to drought. Interestingly, three AMs where hardly implemented: improvement of the irrigation system (AM10), improvement of the inter-field roads (AM11), and adoption of the integrated VAC model (V-garden; A-pond; C-cage) (AM12). During the FGDs, farmers argued that these measures were considered to be the responsibility of the government and/or cooperatives.

Adaptation measures for livestock production

Farmers adopted a range of AMs to reduce the impacts of climate change on their livestock production. The most frequently used measures included: increasing or changing the type and timing of vaccinations (AM13); using supplementary food for the livestock to reduce dependency on local grass and crop by-products (AM14); planting trees around the pig and cattle-shed to create shade (AM15) and changing the design in livestock stables and sheds to improve airflow (AM16). Farmers use local materials to build these sheds and change the shed's design. These changes allowed farmers to increase their poultry production as they could easily be combined with larger livestock animals. Over three-quarters of the farmers changed their livestock breeding programs to include animals that can cope well with changing environments (AM17). During the FGDs farmers indicated that using local breeds are a major AM in times of drought, especially in the case of chickens, ducks, and cattle. Crossbreeding has been promoted through government programs and is considered a feasible option for keeping up with changes in market demand.

However, farmers hardly made use of new livestock management techniques for climate change adaptation (AM18). Similarly, the percentage of farmers that changed their management of livestock health (AM19) and livestock diversification (AM20) were relatively low. Adjusting the seasonal calendar (AM21) for livestock production is a flexible adaptation option, but only $11.3 \%$ of the respondents used it. The in-depth interviews demonstrated that the capacity of farmers to invest in livestock management was considered low due to the lack of knowledge and the uncertainty of being able to sell livestock to the local market.

Reasons for selecting the adaptation measures

The results of FGDs and in-depth interviews show ten arguments of why farmers adopted particular AMs, see table 3.2A. The analysis ignored some AMs that were not used regularly and commonly at the study site, including AMs 10,11 , and 12 . For crop production, farmers responded that they mostly selected certain AMs because they are familiar. They learned from demonstrations of other farmers in the community. While there are multiple reasons for farmers to adopt a particular AM, some were selected for a single clear reason, for example the main reason to adopt crop diversification is the anticipated positive economic effect. Overall, farmers were most motivated by; cases documenting successful prior experiences support from their cooperative and governmental policies and availability of relevant information and new techniques. For livestock production, farmers were predominantly motivated by changes in market price, forcing them to adopt AMs such as changes in feed and breeding, to improve overall quality and quantity. Similar to crop production, farmers adopted AMs which they were already familiar with Legislation and policies were particularly influential for the application of vaccination for livestock production. Additionally, access to new information and the possibility to learn from other farmers also lead to change in livestock management, see table $3.2 \mathrm{~B}$.

In addition, in order to explore the factors associated with the diversification in applying AMs of farmers, we used the multiple regression analyse. We included seventeen variables in the structured interviews that could possibly explain 
diversification (table 7 in SMB), which we collected from earlier work and Pearson's correlational analysis (table 8 in SMB). The coefficients between the explanatory variables and the number of AMs are presented in table 9 in SUPPL. Twelve explanatory variables have positive coefficients and five variables have negative coefficients with the number of AMs. Five variables can explain the diversification of adaptation at the household level: 1- farmable land available during summer season $(P<0.05), 2$ - number of workers on the farm, 3- amount of farm income, 4- number of available information sources and 5 - access to these sources $(\mathrm{P}<0.01)$. A stepwise multiple regression analysis was conducted to identify which variables could best predict the number of AMs farmers adopted (table 3.3). Four variables were found to be significant predictors: amount of farm income; number of available information sources; number of workers on the farm; and farmable land available during summer season. These four variables jointly explained $33.6 \%$ of the variability in the number of AMs adopted. The $\mathrm{R}^{2}$ change indicates that amount of farm income among farmers contributes most in explaining the number of AMs in agriculture to climate change. The low variance of the variables included in this study may indicate that other variables, not included, could be important in explaining the diversification of adaptation in agriculture to climate change.

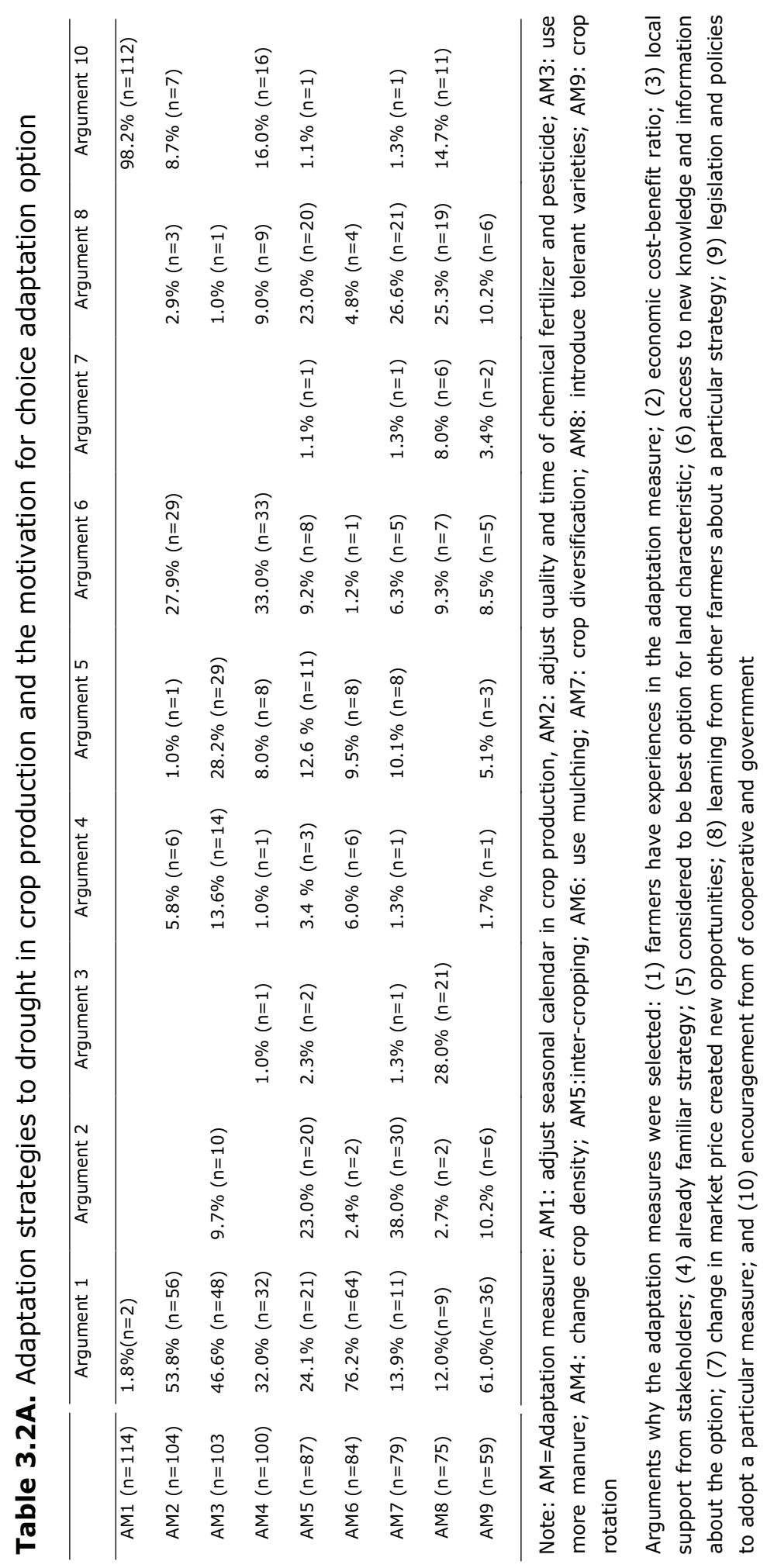


Table 3.3. Stepwise multiple regression of the number of adaptation measures on the explanatory variables

\begin{tabular}{lrrrr}
\hline \multicolumn{1}{c}{ Variables } & \multicolumn{1}{c}{$\mathrm{B}$} & \multicolumn{1}{c}{$\mathrm{R}^{2}$} & $\mathrm{R}^{2}$ change & Overall $\mathrm{F}$ \\
\hline Farm income & .040 & .174 & .174 & $23.571^{* *}$ \\
Number of available information & .509 & .266 & .092 & $13.949^{* *}$ \\
Number of workers on the farm & 1.943 & .325 & .059 & $9.620^{* *}$ \\
Farmable land available during & -.104 & .360 & .034 & $5.854^{*}$ \\
\hline * significant at 0.05 level; ** significant at 0.01 level & & & &
\end{tabular}

*Significant at 0.05 level; ** significant at 0.01 level

3.3.4. Future adaptation measures of farmers in the QL commune

When asked about whether or not farmers would consider the AMs identified in table 3.2A and 3.2B for future AMs most farmers were hesitant. Most of them only considered some routine AMs (see table 2 in SMB) such as: crop rotation; use of tolerant varieties of crops; crop diversification, or inter-cropping. These measures are most likely considered because other farmers already use these measures and therefore knowledge about the measure is more easily available. Several measures were not considered by farmers for future adaptation, particularly the VAC model, crop diversification, using mulching, and intercropping, partly because these options were already implemented extensively and partly because of lack of workers on the farm and appropriate irrigation systems. Improving irrigation systems and improving inter-field roads were not considered as important measures to farmers as they are considered the responsibility of the government. Ongoing improvements of the irrigation system means that crop rotation as an AM will become more feasible in the near future. According to the leader of the DARD and members of the commune, the government plans have improved and extended the irrigation system in the $\mathrm{QL}$, allowing enough fresh water to be available to the whole commune by the end of 2017.

Only a small percentage of respondents considered future AMs in livestock production (see table 3 in SMB), with the most frequently mentioned measures related to livestock diversification, change of breeds, change of the building design, and changing the seasonal calendar (7.5\%). The main reasons to adopt these measures are smallholder farmers' access to knowledge and information in relation to climate change and adaptation, access financial resources, and their perceived positive economic cost-benefit ratio. Farmers felt constrained by the lack of workers on the farm, lack of knowledge, and lack of financial resources to implement measures such as livestock diversification and change of the seasonal calendar. The interviewees from the 
DARD noted that the government has plans to change livestock breeding policies, especially for pig production and to develop new policies in supporting the development of vaccines for poultry production.

\subsubsection{How farmers perceive their capacities to deal with climate change}

As our results show farmers in QL commune have already started to adapt to their changing environments. We asked farmers to assess their capacities to deal with the impact of climate change. We cluster these capacities in three key features of adaptation: capacity to learn, capacity to decide and capacity to act.

"Capacity to learn" in the community was assessed through several questions in the structured interviews. We explicitly asked if farmers felt they have the capacity to learn from others: $43.0 \%$ of respondents considered that their capacity to learn was good to very good; $41.2 \%$ considered their learning capacity to be average; and only $15.8 \%$ perceived their learning capacity to be poor to very poor. Also, the diversification of information sources shows that famers collect their information on how to adapt to climate change through multiple information channels (see table 10 in SMB) mainly through mass media (93.9\%) (mass media in the QL includes: commune loudspeakers, bulletin boards, television, radio) and via other farmers in the community $(82.5 \%)$. However, there was an almost even split in how farmers perceived their capacity to access agricultural information and techniques in relation to climate change: $43.9 \%$ indicated this access was poor to very poor, $29.8 \%$ indicated that it was average, and $26.3 \%$ indicated that it was good to very good. Many respondents were unaware or at least uninformed about other potential AMs such as the VAC model $(72.8 \%)$, adjusting seasonal calendar in livestock production $(66 \%)$, management of livestock health $(60.4 \%)$ or new livestock management techniques $(58.5 \%)$. When asked what farmers could do to improve their learning capacity, the interviewed farmers suggested more training courses or learning programs for supporting them in adapting to climate change in livestock production (58 farmers) and crop production (29 farmers).

"Capacity to decide" refers to the possibility of farmers to be actively engaged in the planning and decision making process. A majority of respondents (75.4\%) participated in training courses in agriculture however, over half of these farmers felt that they were not actively involved in participation in planning agricultural production in cooperatives. Almost half of respondents perceived that their capacity to participate in cooperative activities and community activities was good to very good. However, during the FGDs, farmers explained that they were invited to meetings, training courses and community activities but were only informed about the results of the planning or were provided with information. For example, they were not given the opportunity to interact, ask questions or inform each other of their experiences. During the final feedback session, farmers concluded that their capacity to decide whether or not to adapt or to respond to climate change impacts in the community was low.

"Capacity to act" refers to the development of leadership and increased practical involvement in networks. Local authorities have played an important role in helping farmers adapt to climate change, according to the FGDs. However, almost three-quarters of the respondents indicated that the local authorities have just started implementing measures to increase awareness of climate change and to provide limited actionable support. Furthermore, $78.9 \%$ of the respondents stated that staff of the agricultural cooperatives introduced some innovative techniques, but these were only focussed on crop production and were often too late for given learning effectives. $43.0 \%$ of respondents perceived their capacity to have strong social networks with other actors to solve any adaptation problems as good to very good, $25.4 \%$ considered their networks to be average, and $31.6 \%$ to be bad to very bad. During the FGDs, the leader of cooperatives indicated that the capacity of the cooperative's staff and of the leaders of CBOs to facilitate and create new relationships, build partnerships and exploit opportunities to support farmers to act, is generally low.

The results indicate that the respondents experienced various barriers in adopting the above-mentioned AMs (figure 3.4). The most important barriers relate to difficulties in selling their products to local markets, making them more vulnerable to secure household income. Other reasons were also noted such as; a shortage of workers on the farm for applying AMs and the lack of information about climate change risks and appropriate adaptation responses. About half of the respondents mentioned the lack of opportunities to learn and to apply new techniques. Farmers noted that the poor irrigation system proved to be an important barrier to secure agricultural production. Less than one third of the respondents mentioned the lack of trust among farmers, as well as prevailing local norms and practices as keeping them from making changes. 
Although the assistance from the government and agricultural cooperatives was not mentioned as a main barrier to change, farmers expressed that the lack of institutional capacity to facilitate agricultural adaptation at the household level created an important barrier to future adaptation.

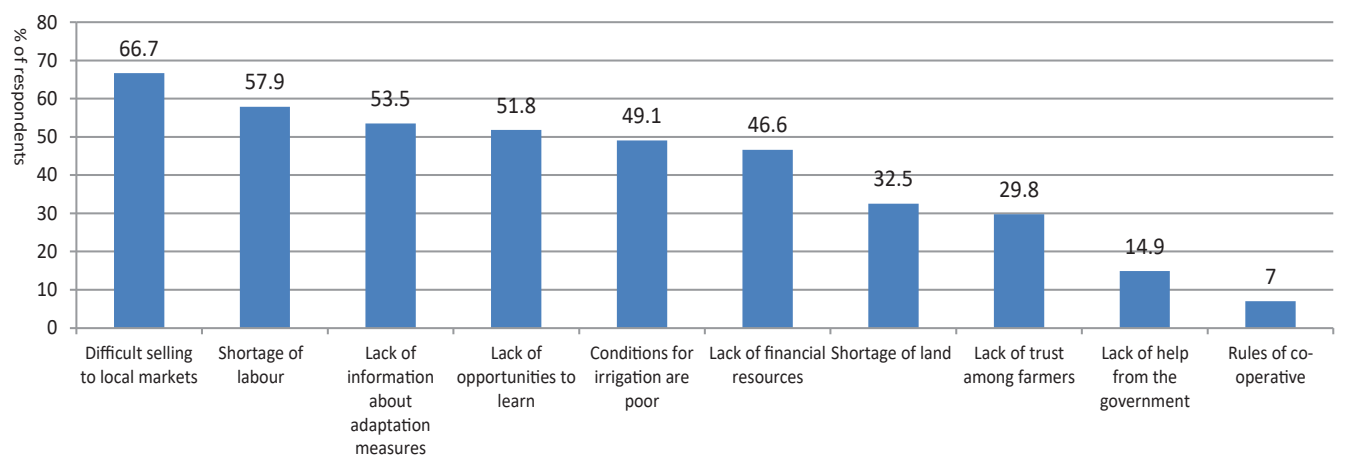

Figure 3.4. Perceived barriers to adaptation by famers $(n=114)$

\subsection{Discussion}

The findings of this study show that farmers are highly aware of climate risk and of how this impacts their livelihoods. Most of farmers are already adapting quite extensively but this likely remains rather conservative and dependent on the agricultural cooperative or local government. We showed that there are substantial differences between farmers engaged in crop production versus farmers engaged in livestock production, in terms of the number of adaptation measures considered and in terms of how farmers perceive their capacity to adapt to future changes. Farmers have faced several barriers in implementing adaptation measures. They are hampered by a lack of capacities with again some differences between crop production and livestock production.

Four key findings of this study warrant further discussion. First, awareness of climate change, climate variability and climate impacts has positively influenced the adoption of AMs in agriculture (Reidsma et al., 2010). We found that particularly crop producing farmers are very aware of climate change and variability and therefore they already have and are most willing to invest in AMs. This is consistent with the numerous earlier studies regarding the interplay between climate variability perception and AMs in agriculture in, for example, India (Dhanya \& Ramachandran, 2015; Vedwan, 2006), Nigeria (Apata et al., 2009), and the Mekong delta, Vietnam (Le Dang et al., 2014a).
Grothmann \& Patt (2005) concluded that the prevalent social discourse is a determinant of people's risk perception and their perceived adaptive capacity. In the past there have been ad-hoc or incidental trainings which contributed to overall awareness of climate risks. Our findings indicate that much more can be gained by sustaining a continuous process of social learning about the ways to increase adaptive capacity in QL. Most of farmers indicated that the lack of knowledge and disconnected social networks are major barriers to adaptation. Social networks in the community (Apata et al., 2009; Deressa et al., 2009), the participation in social activities in rural areas (Igodan et al., 1988) or access to agricultural services (Hassan \& Nhemachena, 2008; Maddison, 2007; Nhemachena \& Hassan, 2007) have proven to play an important role in enhancing social learning of farmers. As the community has experienced high vulnerability, the social networks are tightly coupled between stakeholders and farmers, providing them with some foundation to start to learn together. Our findings suggest that the provision of tailor-made courses and trainings, as well as the mediated communication between peers, friends, neighbours, cooperatives, etc. will increase social learning and likely will improve adaptive capacity and resilience. However, a word of caution is needed here for as (Berkes, 2009) shows, although learning is important, not all or any learning will lead to improved adaptation strategies or increased adaptive capacity: when poorly designed and/or supported it could even have opposite effects.

Second, most of the AMs explored in this paper are autonomously implemented by smallholder farmers. Past local and district level policies have already helped farmers prepare; even though it was not framed as adaptation policy at that time (see also Dupuis \& Biesbroek, 2013). For example, the agricultural staff in the QD district introduced new varieties of seeds and had policies for vaccination in livestock which was adopted unequivocally by almost all farmers. Although farmers and communities are familiar with and use some AMs, new practices and policies are required to enable them to become more proactive in adapting to the changing climate. Further efforts to integrate local adaptation strategies within local and district policy could increase local adaptive capacity in response to climate change, while also contributing to wider (sustainable) development goals in the region. Efforts to improve these practices often ignore social-economic conditions and other motivations of farmers (Reidsma et al., 2010). To improve the success of adaptation strategies in agriculture, the motivation of farmers should be the first consideration (Adger et al., 2005; Smit et al., 1996). 
Clearly, perception of climate risk has long been recognized as an important determinant of human responses to climate change (Grothmann \& Patt, 2005). In addition, Burnham \& Ma (2017) who applied the MPPACC model in practice, argue that perception of hazard risks is a critical determinant of adaptation decisions, but so are perceptions of self-efficacy, adaptation-efficacy, and adaptation cost. Frank et al. (2011) concluded that social identity may play important role in the process of adaptation. This study adds that to understand smallholder farmers' capacity to respond to climate change, the link between adaptation decision-making and farmers' motivations needs to be considered as well. Our study shows that different motivations strongly influence the successful application of AMs including personal, environmental, and policydriven ones. In addition, other factors such as market conditions, household composition, agricultural labour force, the available information sources and the main income sources of households also influence smallholder farmer's adaptation motivation and their capacity to learn, to decide and to act in responding to climate change impacts. As farmers do not adapt to only to climate change, it is paramount for these strategies to represent the aggregated result of multiple motivations, needs and aspirations operating over different time and spatial scales. Farmers typically respond rapidly and opportunistically to new incentives and tend to pursue a variety of activities simultaneously depending on their motivation in each adaptation measure (Below et al., 2010). Our findings therefore support the notion that a mixture of multiple motivational factors is paramount in transitioning towards more sustainable farming practices.

Third, as Rubin (2014) indicates, social vulnerability is understood as the inadequate capacity of individuals or groups to cope with and recover from the impact of hazards. Considering and addressing underlying social, economic and political conditions in reducing such vulnerability is crucial. Our findings seem to support this. Many farmers indicate strong concerns related to the economic situation, their ability to learn from other farmers and their familiarity with local knowledge and geography to adapt. Farmers' willingness to adapt to climate change and diversify adaptation strategies depended on their economic interests and their understanding of the market (Burnham \& Ma, 2016) as well as on the quality of their $r$ social network and social communication (Below et al., 2010). Farmers are also willing to change their choices and decisions based on the information they received (Grothmann \& Patt, 2005). Agricultural adaptation to climate change does not only depend on making changes in agronomic practices and attitudes but also on supportive functions provided by other farm enterprises and institutions both at micro and macro levels (Nyanga et al., 2011). Fourth and finally, many studies have ignored the fact that in the Vietnamese context in general and the QL in particular, workers in agriculture sector are older men and women. Young workers with higher education in rural areas have migrated to the big cities or to other countries to find jobs. This explains why most farmers mentioned that lack of workers in agriculture one of the foremost reasons for not applying forward looking adaptation strategies. Evidence from various sources indicates there is a positive relationship between education level of the household head (Maddison, 2007; Obayelu et al., 2014); age of head of household (Bayard et al., 2007) and diversification of adaptation to climate change (Igodan et al., 1988; Maddison, 2007). This implies that farmers with higher levels of education and more farming experiences are more likely to adapt better to climate change. However, the result from this research shows the reverse is taking place as the education level of the older people in rural area is low. We also found a positive association with the number of workers on the farm and the numbers of adaptation measures considered, see also Apata et al. (2009) and Burnham \& Ma (2017).

\subsection{Conclusion}

People in rural Vietnam still are poor, especially in the QL commune, with a large part of their income depending on agriculture. The QL commune has already started to adapt to climate change in both crop and livestock production. While a lack of local knowledge in times of rapid global change can promote the depletion of natural resources, local knowledge also may serve as an important asset in the design and implementation of adaptation practices (Below et al., 2010). For this purpose and to achieve long-terms benefits, planned adaptation should be combined with autonomous adaptation and should be co-created and carried out by state government in their development planning. Farm income, number of workers on the farm, the number of available information sources, and farmable land available in the summer season are all major factors associated with the availability of climate change adaptation strategies in agriculture. The majority of farmers used adaptation strategies that not only deal with climate change, but also the changes in market and household-related economic conditions. Previous studies concluded that understanding adaptive capacity requires the consideration of risk perception, perceived adaptive capacity (Grothmann \& 
Patt, 2005), social identity (Frank et al., 2011), perceived self-efficacy and adaptation intent (Burnham \& Ma, 2017). Our study adds the importance of farmers' motivation to engage in adaptation decision-making. This factor might enrich Grothmann \& Patt's (2005) Model of Private Proactive Adaptation to Climate Change (MPPACC). Moreover, in the rural culture of Vietnam, the social networks and social capital are critically important in the adoption of agricultural activities. This requires more understanding of the processes of decision-making in agricultural adaptation. Besides that, the government will need to support research and development in the agricultural sector, disseminate appropriate technologies, ensure that cheap technologies are available to smallholder farmers and promote market development. More specifically, increasing the roles of stakeholders in the community through, for example, community-based organizations will be critical in increasing farmers capacity and promoting continuous social learning to adapt to climate change.

\section{Notes}

1. FAO Vietnam Country Profile: http://www.fao.org/countries/55528/en/vnm/

2. Vietnam Employment Trends 2010, ILO (2011)

\section{Acknowledgements:}

This research is funded through the Nuffic project (NICHE/VNM/105). We are grateful for the comments, suggestions and feedback by Prof. Martin Verstegen on an earlier version of the paper. We acknowledge the helpful support by Dr Tobi Hilde on the statistics and interpretation of the data. We especially thank Miss Lien and Mr Hoa who supported us during data collection. We would like to thank the Quang Loi commune authorities, their staff, agricultural cooperatives and all farmers who provide invaluable information for this research. 


\subsection{Introduction}

Vietnam is currently ranked among the ten most climate-vulnerable countries in the world and without adequate responses the country will be even more vulnerable to future climatic disasters (Bruun, 2012; Maplecroft, 2011). Several studies show that Central Vietnam is increasingly affected by the unpredictable weather conditions and influenced by ongoing climate change (Hanh, 2010; Phuong, 2010). Particularly the coastal provinces are hotpots of natural disasters and climate change impacts are likely to be severe for coastal smallholder farmers whose livelihoods depend largely on favourable natural conditions (Beckman, 2010; Rubin, 2014). Smallholder farmers are considered to be particularly vulnerable to current and future climate risks because of low societal capacities, lack of education and technical skills, poverty and lack of assets and capital to recover or to shift to alternative livelihoods (IPCC, 2014), and this is particularly true for Vietnam (IFAD, 2014; Le Dang et al., 2014d).

Adapting to the impacts of climate change is thus of utmost importance. Adaptation can be considered an on-going learning process and therefore is a vital component of any adaptation framework for action at the local level (Janjua et al., 2010). Developing the ability to learn in a variety of ways, contexts and circumstances, is an important element of developing adaptive capacity (Fazey et al., 2007). Previous studies showed that social learning is an important process to deal with climate change, particularly in situations where people need to jointly address challenges of the common good and for which there are no tailor-made solutions that can be easily transferred or prescribed (Albert et al., 2012; Bradbury \& Middlemiss, 2015; Orderud \& Winsvold, 2012). Therefore, interest in social learning as a part of the response to the challenges of climate change adaptation has grown significantly in recent years (Ensor \& Harvey, 2015). Many social and technical interventions have been designed to support and increase farmer's adaptive capacity to deal with climate change (Bloch et al., 2016; Duru et al., 2012; Johnson et al., 2012; Mishra et al., 2013; Raymond \& Cleary, 2013). For example, introducing agronomic crop management has increased local farmers' capacity to adapt to drought in Thailand through enhancing crop and water productivity along with soil fertility with relatively low input-use (Mishra et al., 2013). Traditionally, interventions to adapt to climate change in Vietnam are orchestrated top-down where local farmers are selected by the village leaders or the leaders of agricultural cooperatives to participate in training programs (Sen, 2014). NGOs 
are implementing learning-based interventions to help smallholder farmers, but proper monitoring and evaluation is often lacking (Butler et al., 2015).

This study aims to critically reflect on the design, implementation, evaluation and upscaling of a social learning based intervention to address the key climatic problems for local smallholder farmers who work in poultry production in Central Vietnam. In the case under investigation here stakeholders are actively engaged in the design, implementation, evaluation, and upscaling of the learning configuration. We are particularly interested in how their involvement in the design choices and implementation practices of the intervention enables social learning and actually increases the adaptive capacity and agency of farmers.

In the next section, we propose a theoretical framework for the design implementation evaluation, and upscaling of social learning configurations by reviewing existing social learning and adaptive capacity literature. Subsequently we justify our methods for data collection and analysis. We then present our results by exploring the different dimensions of the social learning configuration. The final section presents the discussion and conclusion.

\subsection{Theoretical framework: building adaptive capacity through socia learning configuration}

Social learning is understood as "a multi-level learning process bringing together stakeholders with diverging initial perceptions with the intention to learn together and form a common understanding with respect to taking a planned course of action that they jointly implement by working in iterative cycles of action and refection" (Phuong et al., 2017). Social learning is nurtured through the process of specific interventions particularly in stable and difficult to change socio-technical systems (Van der Brugge \& Rotmans, 2007). Many different ways of organizing social learning and knowledge for production processes have been documented and crucial lessons have been reported. Mostly, it is evidenced that active involvement of the stakeholders throughout the learning process increases successful outcomes (Jakku \& Thorburn, 2010). Moreover, social learning processes are highly dependent on contextual circumstances such as location, historical experiences, and associated cultures (Ison \& Watson, 2007). Clearly, social learning requires conscious design and facilitation as it does not happen by accident (Woodhill, 2010).
Wals et al. (2012) suggest four interdependent phases in social learning configurations: a preparatory and design phase, an implementation phase, an evaluation phase, and an upscaling phase. Based on our reading of the rapidly growing body of social learning literature we added two additional phases to arrive at a total of six phases that can be distinguished in a dynamic social learning configuration (Collins \& Ison, 2009; Daniels \& Walker, 2001; Mostert et al., 2007; Muro \& Jeffrey, 2008; Schusler et al., 2003; Wals et al., 2012): (1) needs assessment - exploring the underlying needs, values and norms of the stakeholders to appropriately address the problem, (2) design ideas based on scientific and practice-based theories and experiences, (3) co-creation of the learning configuration between scientist and core groups in loca community, (4) implementation of the configuration through multiple interventions, (5) evaluation of the design, implementation and outcome of the social learning configuration, and (6) sharing and upscaling of the key lessons learned by participants and the learning facilitators. A framework of social learning configuration is presented in figure 4.1 which captures the six majo phases and table 4.1 reviews the key elements, which need to be considered for each of the phases.

In order to successfully apply a learning configuration in practice, the researcher and facilitators need to consider several elements in each phase. The most important motivation for farmers to participate in the learning process is their intrinsic motivation to improve their agricultural production and their livelihood (Defoer et al., 2009; Kristjanson et al., 2012; Vermeulen et al., 2013). To keep their motivation high, the contents and methods of learning need to support farmer's attempts to modify existing practices and there needs to be possibilities for them to share their experiences (Grothmann et al., 2013; Raymond \& Cleary, 2013).

Research has shown that in designing a learning configuration group composition, democratic structures, and facilitation requirements all need to be considered (Daniels \&Walker, 2001; Mostert et al., 2007; Johnson et al., 2012). In addition, active involvement of those to be engaged in designing the learning configuration is important as such involvement can already lay the ground work for increasing awareness, breaking down hierarchies and improve trust (Pringle \& Conway, 2012; Rist et al., 2006), as well as give room for collective action (Christmann et al., 2015; Collins \& Ison, 2009; Mapfumo et al., 2013). Finally, the relevance, legitimacy, and appropriateness of contents, 
process, facilitation, and methods need to be considered as well (Brydon-Miller et al., 2003; Shaw, 2005).

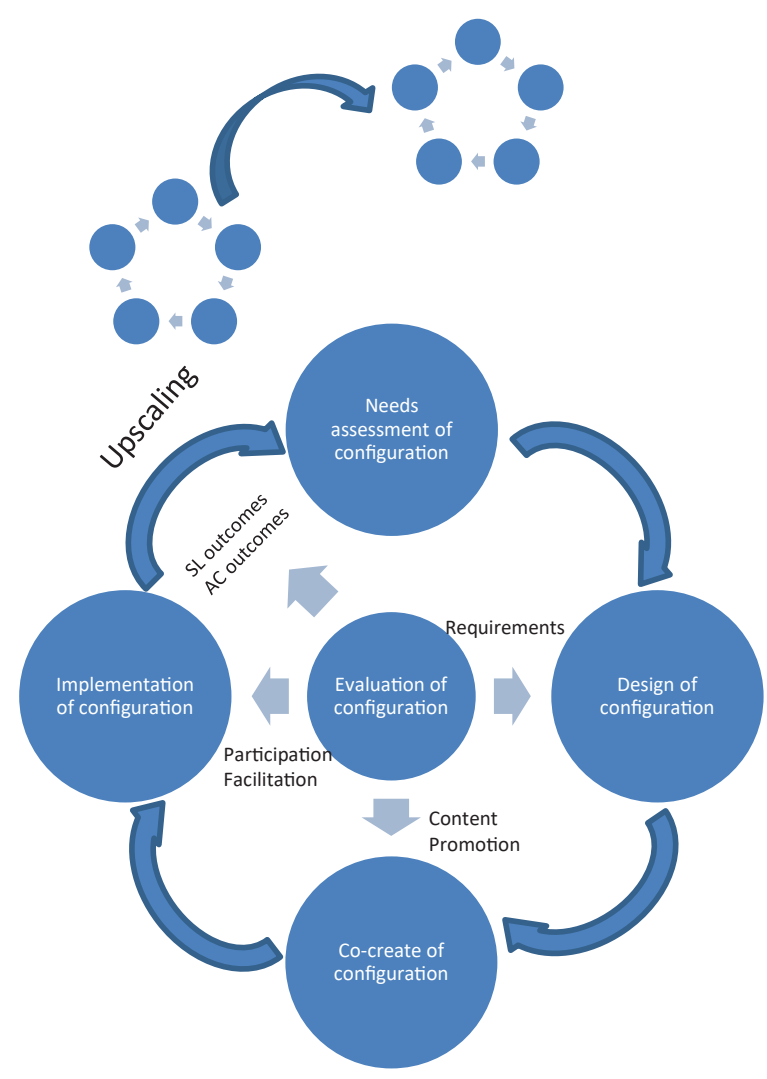

Figure 4.1. Framework for building adaptive capacity through a social learning configuration (based on Daniels \& Walker 2001; Schusler et al., 2003; Mostert et al., 2007; Muro \& Jeffrey 2008; Collins \& Ison 2009; Wals et al., 2012)

Crucial in the implementation phase is the appropriateness of the learning environment for all participants (Muro \& Jeffrey, 2008; Wals et al., 2012). In social learning-oriented interventions open communication, unrestrained thinking, diversity of knowledge, extended engagement and constrictive conflict, are critical (Muro \& Jeffrey, 2008; Johnson et al., 2012; Christmann et al., 2015). The evaluation component is necessary for finding out why a learning configuration works and which learning outcomes can improve adaptive capacity of participants (Akpo et al., 2015). The results of the evaluation phase can lead to improve learning outcomes (Ison \& Watson, 2007; Mostert et al., 2007; Sen, 2014; Sen, 2016), modify the implementation process, celebrate the achievements, achieve long term effectiveness, and can provide the input for the upscaling phase.
Table 4.1. The key elements which need to be considered for each phase while applying the learning configuration in practice

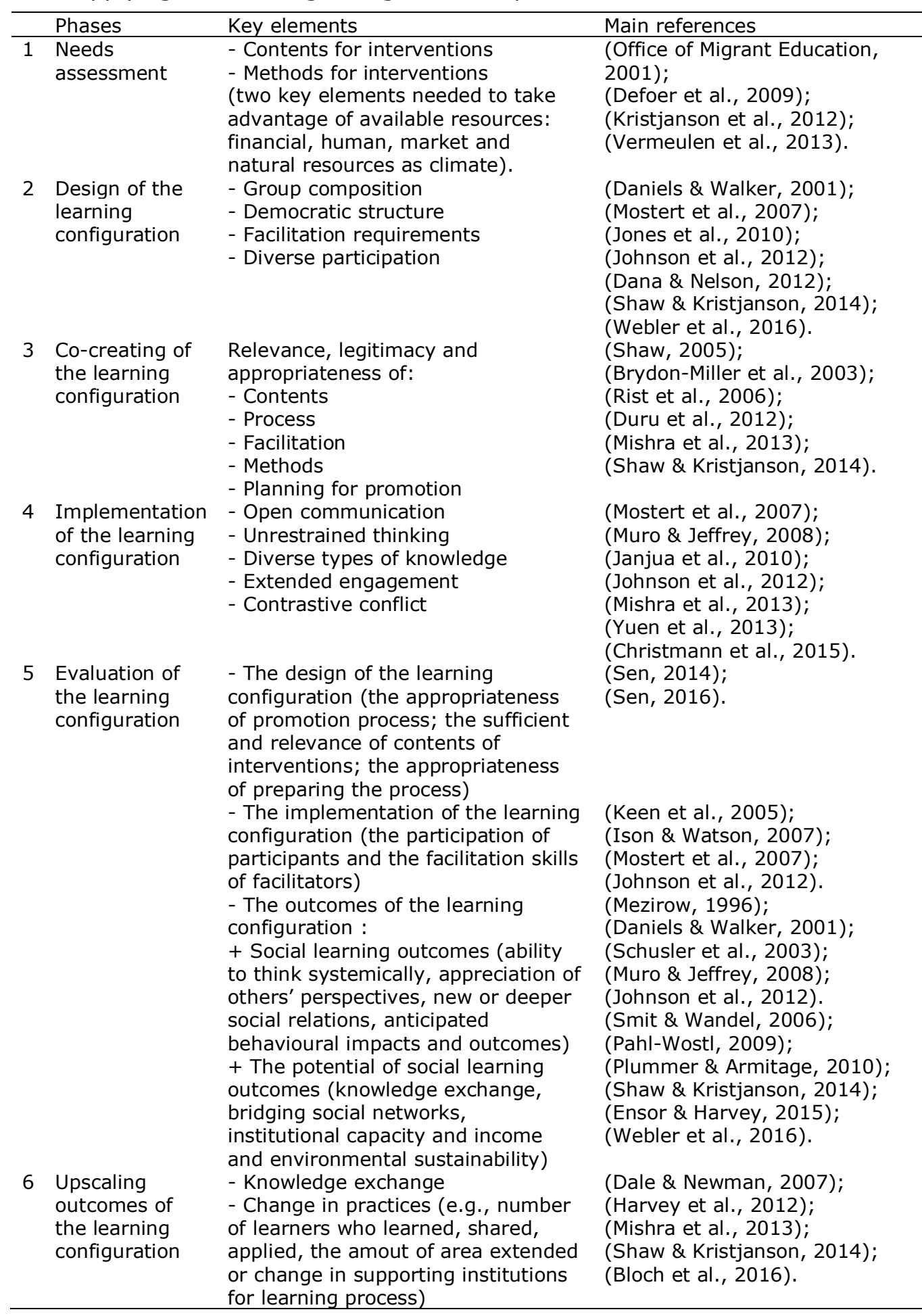




\subsection{Methodology}

We designed a social learning configuration to improve adaptive capacity of local farmers in Central-coastal Vietnam who all engage in small-scale poultry production as their main source of income. All six phases as outlined in the previous section were carried out during a six month period of needs assessment, designing, co-creating, implementing, evaluating, and upscaling (figure 4.2). Below we describe the key steps for data collection and analysis for each step.

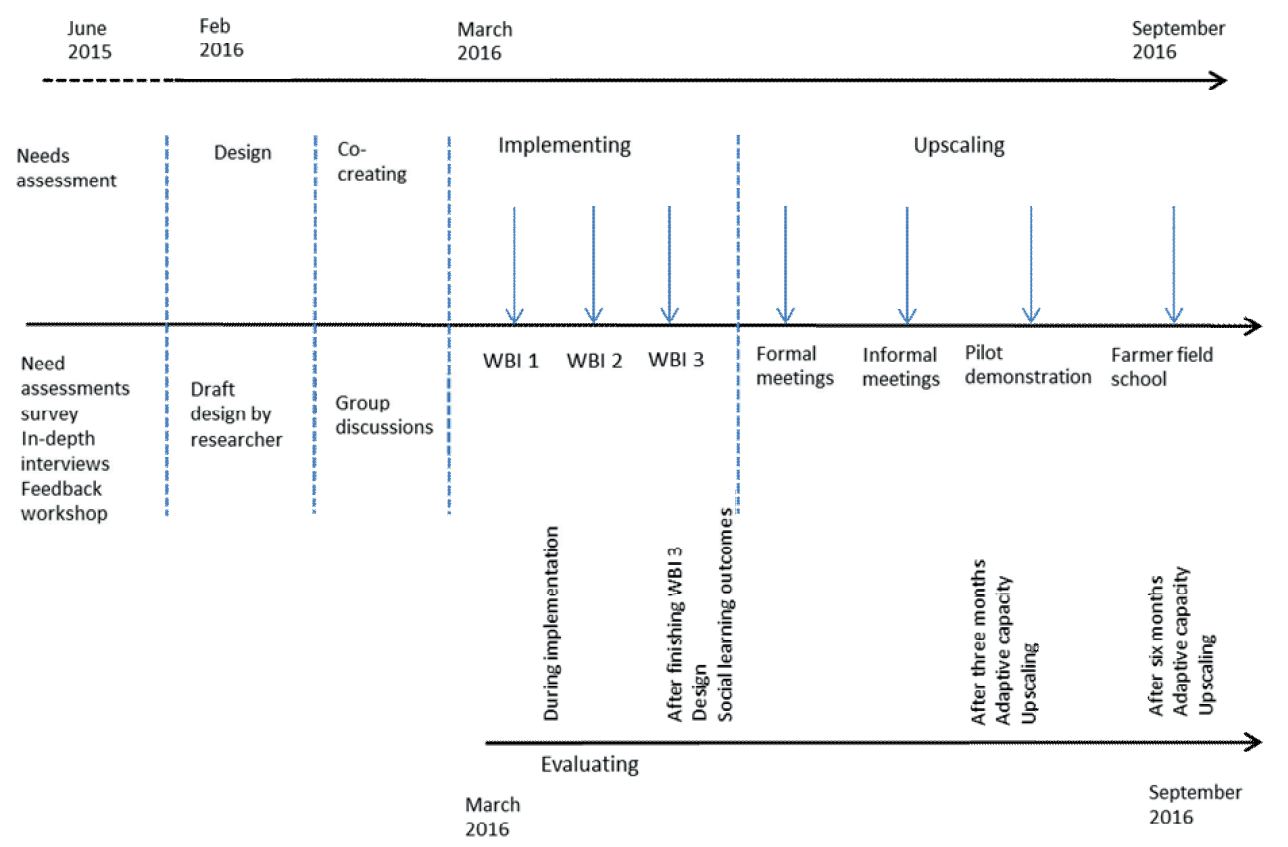

Figure 4.2. The design, implementation, upscale, and evaluation of social learning configuration

\section{Needs assessment phase}

To assess needs of local farmers the researcher and facilitators conducted a survey of 114 farmers to identify a problem social situation and the current attempts to improve the situation. A feedback workshop $(n=29)$ was organised to confirm the results from the needs assessments. Shortly thereafter we conducted several in-depth interviews $(n=7)$ with agricultural staff from the Department of Agriculture and Rural Development (DARD) and from the Department of Agricultural Extension (DAE) at the provincial, district and commune level to come to understand the different adaptation strategies for agricultural production.

\section{Design phase}

The design phase started with drafting the learning configuration based on a review of the scientific literature and an analysis of previous studies on farming interventions in Vietnam (Minh et al., 2010). Four meetings were organized with key actors including Hue University of Agriculture and Forestry (HUAF), DARD and DAE at the district level, commune authorities, community cooperatives and esteemed small-holder farmers (experienced, respected and communicative) as well as suppliers in and outside the community. A core group was created in which all stakeholders were represented to tailor the learning configuration and to maximize community engagement. This core group discussed and designed several ways to promote the learning configuration (using posters, banners, leaflets, and local radio newscasts). Then they also discussed how to adjust and modify the draft-learning configuration to be more congruent with the local context and the needs assessment outcomes.

\section{Implementation phase}

Three workshop-based interventions (WBI) were organized and implemented with a 10-day and 20-day time period in between to allow farmers to think, interact, and share their information with non-participating farmers. The WBIs were facilitated by experienced staff of the DARD, DAE, and HUAF. During the WBIs, tools such as farmer-to-farmer learning and participatory approaches were used to provide information and have interactive discussions with the farmers about the contents of learning.

Thanks to a number of promotion activities 56 participants registered for the workshops. Typically when traditional extension activities are organized and sponsored by the local government there is some form of payment as an incentive. In this case there was no budget for this: all of participants knew that they were not going to be paid for their participation. This suggests that participants had a high level of intrinsic motivation. There were 56 participants in the first workshop and 36 participants in the second one. Twenty participants did not continue mainly because of time constraints. In the third workshop, 27 participants (4 CBOs, 5 village leaders, 15 smallholder farmers from the two previous workshops, and 3 leaders of three agricultural cooperatives) participated to make the plans to increase the opportunities for other farmers' in accessing learning contents from two previous WBIs. 
Table 4.2 shows five steps for each of the three WBIs. In the first step, the WBI started with an introduction of the facilitators about the purposes, questions and output for the WBI. In the second step small group discussions with 4-5 participants were organized. During the third step the facilitators provided additional information and continued their discussions. Finally, the workshop ended with a discussion about the next WBI.

\section{Upscaling phase}

Based on the results of the third WBI, several ways to upscale and share the learning contents with other farmers in the community were proposed and executed. Firstly, the group contacted leaders of active organizations in the community such as: the women's association, the farmer's association, the production association, and the youth association to share lessons learnt in monthly meetings conducted jointly by researchers and facilitators. Secondly, 8 pilot demonstrations were conducted using a farmer field school approach combined with farmer-to-farmer videos sharing climate change information and new farming techniques. Thirdly, there were several small discussions and informal (oral) talks between farmers who conducted the pilot demonstration with other farmers to share and discuss the ways to apply new techniques in practice and ways to collaborate. Local media were utilised to inform introduce, share and upscale the key lessons and outcomes with other farmers in local and nearby communities.

\section{Evaluation phase}

To evaluate the learning outcomes, we used ex-ante and ex-post survey instruments. The survey instruments were designed to set a baseline and capture learned experiences after each WBI and the learning configuration as a whole (ex-post analysis). The evaluation phase was divided into three stages: before, during, and after each WBI and pilot demonstration models. The contents and methods for data collection and data analysis were used for evaluation of the design and the outcomes of social learning configuration were presented in table 3. Evaluation started before the first WBI to evaluate the level of knowledge about climate change, poultry production, and the understanding of current poultry production of participants. During implementation of the three WBIs, we evaluated the participation of participants activities and facilitation skills of facilitators in the WBIs by using participatory observations, note taking, and recording of discussion. After the third WBI, we conducted the first evaluation survey to evaluate the design phase including content design and promotion process. Additionally, we evaluated social learning outcomes with four indicators (table 4.3). After three months, we evaluated the results of pilot demonstrations and the adaptive capacity of participants and did upscaling of the level of information and of techniques. After six months, we evaluated the development capacity and extension of pilot demonstration through changes in practices.

Table 4.2. The steps and key elements of the three workshop-based interventions

\begin{tabular}{|c|c|c|c|}
\hline Steps & WBI $1(n=56)$ & WBI $2(n=36)$ & WBI $3(n=27)$ \\
\hline 1. Introduction & $\begin{array}{l}\text { Do research } \\
\text { presentation }\end{array}$ & $\begin{array}{l}\text { Summarize the } \\
\text { issues from the WSI } \\
1 \text { and have } \\
\text { reflection by } \\
\text { participants }\end{array}$ & $\begin{array}{l}\text { Summarize the issues } \\
\text { from the WSI } 2 \text { and } \\
\text { have reflection by } \\
\text { participants }\end{array}$ \\
\hline $\begin{array}{l}\text { 2. Key question } \\
\text { in group } \\
\text { discussion }\end{array}$ & $\begin{array}{l}\text { What do you think } \\
\text { about climate } \\
\text { change, impacts in } \\
\text { the future and in } \\
\text { poultry production? }\end{array}$ & $\begin{array}{l}\text { How do you raise } \\
\text { poultry production, } \\
\text { disease } \\
\text { management and } \\
\text { which constraints } \\
\text { are there in the } \\
\text { process of poultry } \\
\text { production? }\end{array}$ & $\begin{array}{l}\text { How to upscale social } \\
\text { learning processes and } \\
\text { outcomes to include } \\
\text { other farmers and } \\
\text { nearby communities? } \\
\text { How to get more people } \\
\text { to engage? }\end{array}$ \\
\hline $\begin{array}{l}\text { 3. Key contents } \\
\text { and follow-up } \\
\text { discussion }\end{array}$ & $\begin{array}{l}\text { - Information is given } \\
\text { or shared about } \\
\text { climate extreme } \\
\text { events, perception of } \\
\text { farmers about climate } \\
\text { risks in the } \\
\text { community, annual } \\
\text { and monthly } \\
\text { meteorological } \\
\text { summaries, and } \\
\text { future impact of CC } \\
\text { on poultry production } \\
\text { - Introduction of } \\
\text { some poultry } \\
\text { production forms } \\
\text { - Discussion on which } \\
\text { forms of poultry } \\
\text { production was } \\
\text { appropriate for the } \\
\text { community's } \\
\text { conditions? }\end{array}$ & $\begin{array}{l}\text { - Information is } \\
\text { given or shared } \\
\text { about adaptation } \\
\text { measures in } \\
\text { livestock production } \\
\text { in general and } \\
\text { detailed techniques } \\
\text { are given in poultry } \\
\text { production and } \\
\text { integrated disease } \\
\text { management: } \\
\text { - Discussion was } \\
\text { focused on the } \\
\text { integration of } \\
\text { disease } \\
\text { management in } \\
\text { poultry production, } \\
\text { especially } \\
\text { vaccination. }\end{array}$ & $\begin{array}{l}\text { - Presentation of the } \\
\text { approach and planning is } \\
\text { done to promote } \\
\text { information about tools } \\
\text { and techniques } \\
\text { - Provided detailed } \\
\text { information of input by } \\
\text { suppliers, detailed } \\
\text { contacts with facilitators } \\
\text { for conducting the pilot } \\
\text { demonstration } \\
\text { - Discussed the ways to } \\
\text { mainstream the } \\
\text { information of } \\
\text { techniques in the } \\
\text { community activities } \\
\text { - Discussed the process } \\
\text { and facilitation to } \\
\text { conduct the pilot } \\
\text { demonstration models. }\end{array}$ \\
\hline \multirow[t]{5}{*}{$\begin{array}{l}\text { 4. Final decision } \\
\text { for next WBI }\end{array}$} & \multirow{5}{*}{$\begin{array}{l}\text { Discussed use of } \\
\text { biological bedding } \\
\text { material in Poultry } \\
\text { production in } \\
\text { uncertain climate. }\end{array}$} & \multirow{5}{*}{$\begin{array}{l}\text { Identified the need } \\
\text { to have a workshop } \\
\text { to discuss and do } \\
\text { the planning to } \\
\text { promote techniques } \\
\text { and upscale the pilot } \\
\text { demonstration } \\
\text { models }\end{array}$} & $\begin{array}{l}\text { - Mainstreamed the } \\
\text { information of } \\
\text { techniques in the } \\
\text { community activities }\end{array}$ \\
\hline & & & $\begin{array}{l}\text { - Farmer-to-farmer } \\
\text { video }\end{array}$ \\
\hline & & & - Informal (oral) talking \\
\hline & & & - Using local media \\
\hline & & & $\begin{array}{l}\text { - Conducting the pilot } \\
\text { demonstration }\end{array}$ \\
\hline
\end{tabular}


Table 4.3: The contents, indicators, methods for data collection and data analysis

\begin{tabular}{|c|c|c|c|}
\hline Issues & Contents & Methods & Analysis \\
\hline $\begin{array}{l}\text { Knowledge } \\
\text { level (before } \\
\text { the first WBI) }\end{array}$ & Knowledge level & $\begin{array}{l}\text { Background survey } \\
(n=56)\end{array}$ & $\begin{array}{l}\text { - Data collection was } \\
\text { synthesised and } \\
\text { mainstreamed in the } \\
\text { design phases for the } \\
\text { implementation phase. } \\
\text { - The pre-evaluations were } \\
\text { synthesised to compare to } \\
\text { post-evaluation. }\end{array}$ \\
\hline $\begin{array}{l}\text { Design (after } \\
\text { the third WBI) } \\
\text { Implementation } \\
\text { (during WBIs } \\
\text { and after the } \\
\text { third WBI) }\end{array}$ & $\begin{array}{l}\text { Promotion process } \\
\text { Contents of the WBIs } \\
\text { Participation process } \\
\text { Facilitation skills }\end{array}$ & $\begin{array}{l}\text { The first evaluation } \\
\text { survey }(n=36) \\
\text { - Participatory } \\
\text { observations, note } \\
\text { taking, and recording } \\
\text { of discussion }\end{array}$ & $\begin{array}{l}\text { - Data collection was } \\
\text { synthesised } \\
\text { - Data was analysed and } \\
\text { synthesised, to adjust } \\
\text { contents and methods for } \\
\text { each WBI. - Information } \\
\text { was documented to } \\
\text { compare to post evaluation }\end{array}$ \\
\hline \multirow[t]{2}{*}{$\begin{array}{l}\text { Outcomes } \\
\text { - After the third } \\
\text { WBI } \\
\text { - After } 3 \text { and } 6 \\
\text { months since } \\
\text { the third WBI }\end{array}$} & $\begin{array}{l}\text { Social learning } \\
\text { outcomes } \\
\text { - Relationships } \\
\text { - Diverse } \\
\text { perspectives } \\
\text { - Systematic thinking } \\
\text { - New or changed } \\
\text { actions. }\end{array}$ & $\begin{array}{l}\text { - The first evaluation } \\
\text { survey }(n=36) \\
\text { - In-depth interview } \\
(n=5) \\
-3 \text { group discussions }\end{array}$ & $\begin{array}{l}\text { - Data were entered in } \\
\text { Excel and analysed for the } \\
\text { frequency of respondents. }\end{array}$ \\
\hline & $\begin{array}{l}\text { Adaptive capacity } \\
\text { outcomes } \\
\text { - Knowledge } \\
\text { - Bridging social } \\
\text { network } \\
\text { - Changes in practice } \\
\text { - Farmers' income }\end{array}$ & $\begin{array}{l}\text { - The second } \\
\text { evaluation survey } \\
\text { with semi-structured } \\
\text { questionnaire } \\
\left(n_{1}=26 ; n_{2}=8 ;\right. \\
\left.n_{3}=20\right) \\
\text { - In-depth interviews } \\
(n=13) \\
- \text { Informal talks } \\
(n=6) \\
\text { - Workshop }\end{array}$ & $\begin{array}{l}\text { - Data were input in Excel } \\
\text { and analysed for the } \\
\text { frequency of respondents. }\end{array}$ \\
\hline
\end{tabular}

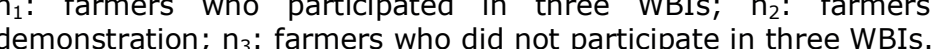

\subsection{Brief introduction to the study area}

The study was conducted in the Quang Loi commune, Quang Dien district, Thua Thien Hue (TTH) province in northern-Central Vietnam. Several studies show that during the past ten years, drought was the main climate extreme event in the TTH province (e.g., Suong, 2011; Lien, 2015). Temperatures recorded in the TTH Meteorological Stations from 1956 to 2005 showed a steady increase and several extremes, with the hottest months in June and July and the coldest on record in December and January of the next year. Similarly, meteorological data from the $\mathrm{TTH}$ shows a changed pattern in monthly rainfall, with an increase during the rainy season and a decrease during the dry period of March.

This district is characterised by coastal communities that are highly exposed to climate change and low levels of adaptive capacity among all stakeholders. The community has many vulnerable groups, particularly many older men and women, and children. According to Quang Dien district committee (2015), Quang Loi is one of the most vulnerable communes in the Quang Dien district because as it is a coastal community that is affected by not only climate change but also by severe ocean pollution, high poverty rates, and a strong dependency on farming income. Farmers' perceptions in the Quang Loi community indicated that temperatures have increased, the precipitation pattern has changed and that climate change extreme events give uncertainty (Phuong et al., under review). In 2014, the livelihood of the Quang Loi depended significantly on agricultural income $(54.5 \%)$, of which the main agricultural activities included crop (49\%) and livestock (30\%) production, aquaculture and fishery (21\%) (Phuong et al., under review). In the Quang Loi commune most households have kept poultry production however, they did not have any collaboration in production especially in disease management and in going to the market. In addition, the poultry grazing and traditional poultry production have negatively affected air quality. Other studies in the region reported farmers' difficulties in selling their products at local markets, their lack of information about climate change risks, and their inability to adapt to changing environmental and economic conditions. Finally, there is a lack of opportunity to learn and to apply new technologies to adapt to climate change in this commune (Jakku \& Thorburn, 2010; Mishra et al., 2013).

\subsection{Results}

Social learning can be observed by looking into the shifts in the ways of doing thinking and re-organizing the poultry production in the community. After finishing the third WBI, we evaluated the social learning outcomes in terms of four aspects: changed relationships, utilisation of different perspectives, improved systemic thinking, initiation of new or the optimization of existing actions (table 4.4).

In terms of relationships, the results from the first evaluation survey showed that the majority of participants $(97 \%, n=35)$ agreed or strongly agreed that 
participating in the three WBIs enhanced their relationships and helped them to create new ones as well. Participants indicated that they had not known many of the other individuals prior to the WBIs but that they became acquainted with new people very quickly. During the face-to-face discussions, participants stated that they expected to continue their relationships with new acquaintances after the WBIs. Strengthening relationships was considered important to exchange ideas/knowledge and seek collaborative opportunities. Additionally, there was (strong) agreement among survey participants $(n=36)$ that the WBIs increased their understanding that the impacts of climate change can be addressed collectively, which suggests the development of agency. During the evaluative discussion, the cooperative leader, one of the participants in WBIs, also indicated that "the WBIs had provided potential networking and relationship-building opportunities that will prove to be valuable over time". In the group discussions participants stated that they have started to connect, discuss, and agree on working together to prevent future diseases in poultry production. They explained that "working together was not only reducing the spread of disease, but also reducing production costs and time, because of the collective supporting and sharing of experiences and skills". They concluded that "nurturing connections among people and working together is extremely important for managing the impacts of climate change".

All participants agreed $(n=23)$ or strongly agreed $(n=13)$ that the WBIs improved their understanding of other's perspectives in climate change and disease management. Well over half the participants $(n=21)$ indicated that they enjoyed and appreciated the mix of participants. Participants observed that talking with others allowed them to understand other participants' perceptions of reality more clearly, therefore preventing future disputes. Five participants also stated that the WBIs were more inclusive of participants opinions than other training courses about climate change and livestock production, in which they had participated. They indicated that no-one was dominating the meetings and that all participants' experiences were highly valued in the process, which led to a rich picture of ideas, especially by including the opinions of women. Therefore, participants in the WBIs not only became better acquainted with one another, but also gained a better understanding of the opinions and perspectives of participants with different views about climate change, climate change impacts and especially about disease management in poultry production.
During the WBIs, emphasis was placed by the facilitators on the interdependency of the various components of climate change and human dimensions. $36 \%(n=13)$ of participants agreed that the WBIs increased their ability to think more systemically about connections between human activities and about climate change implications and 39\% $(n=14)$ of participants agreed that the WBIs increased their understanding about the connections between climate change scenarios and decisions in implementing climate change adaptation measures. Two participants noted that the WBIs allowed them to break free from normal short-term thinking. They explained that before the WBIs their decisions were only based on the current and short-term situation, but after discussions with other participants they were more willing to have a long(er)-term perspective. Of the 36 farmers, 8 farmers were willing to apply the knowledge, tools, and techniques in their pilot demonstration model, to upscale the pilot demonstration, and to share experiences with the participants and other members of the community. However, more than half of participants stated that there were no differences in their systemic thinking - that is they did not see new connections, relations or (inter)dependencies) - before and after participation the WBIs. Most of them explained that they understood climate change is occurring and will happen in the future and that it impacts their poultry production, but that they needed time to experience and explore these issues in practice.

In terms of new or changed actions, the majority of participants agreed that the WBIs influenced their personal lives $(80.6 \%, n=29)$ and professional work $(58.3 \%, \mathrm{n}=21)$. Just under half the participants strongly agreed that the WBIs influenced their professional work $(41.7 \%, n=15)$. During the group discussions participants explained that the WBIs has improved their skills and that they gained more experience in poultry production to deal with the uncertainty of planning for climate change impacts. Another participant stated that she now feels differently about priorities and regards short-term economic aspects (income) to be as equally important as long-term considerations in poultry production. Some other participants claimed that they have made changes in some lifestyle (culture) such as seeking more community life, becoming more open minded and sociable with people, sharing information with people instead of keeping it to themselves. Several participants claimed that they changed their farming practises, for example by keeping their chickens in contained spaces and by improving their housing and nutrition but also by avoiding conflict with their neighbours, and by paying more attention to 
hygiene, cleaning the trays for chickens on a daily basis which reduces the likely-hood of diseases and the spreading of diseases. Other participants have started applying techniques by using biological bedding material in poultry production which significantly reduced odors and improved air quality for their family and their neighbours.

Table 4.4. The evaluation of social learning outcomes (scale 1- do not agree to 5 - fully agree)*

\begin{tabular}{|c|c|c|c|}
\hline Social learning outcomes & $\begin{array}{l}\text { Strongly } \\
\text { agree } \\
\%(n)\end{array}$ & $\begin{array}{l}\text { Agree } \\
(\%, n)\end{array}$ & $\begin{array}{l}\text { No } \\
\text { difference } \\
\%(n)\end{array}$ \\
\hline \multicolumn{4}{|l|}{ Relationships: These interventions have } \\
\hline ...strengthened my relationships with other participants & $27.8(10)$ & $69.4(25)$ & $2.8(1)$ \\
\hline $\begin{array}{l}\text {...give me the belief that difficulties in a climate change } \\
\text { context can be addressed collectively }\end{array}$ & $22.2(8)$ & $77.8(28)$ & - \\
\hline \multicolumn{4}{|l|}{ Appreciation of other's perceptive: These interventions have } \\
\hline $\begin{array}{l}\text {...improved my understanding of other participants' } \\
\text { perspectives }\end{array}$ & $36.1(13)$ & $63.9(23)$ & - \\
\hline \multicolumn{4}{|l|}{ Systems thinking : These interventions have } \\
\hline $\begin{array}{l}\text {...increased my ability to think systemically about } \\
\text { connections between humans and climate change }\end{array}$ & $2.8(1)$ & $36.1(13)$ & $61.1(22)$ \\
\hline $\begin{array}{l}\text {...increased my understanding of the connections } \\
\text { between climate change scenario and decisions in } \\
\text { implementation planned adaptation measures }\end{array}$ & $5.6(2)$ & $38.9(14)$ & $55.6(20)$ \\
\hline \multicolumn{4}{|l|}{ New or change actions: These interventions have } \\
\hline ....influenced my professional activities & $41.7(15)$ & $58.3(21)$ & - \\
\hline ...influenced my personal lifestyle & $19.4(7)$ & $80.6(29)$ & - \\
\hline
\end{tabular}

*none of the participants ticked 'do not agree' or 'strongly disagree'

The study evaluated the influence of the WBIs on local farmers' adaptive capacity (knowledge, changes in practice, bridging social network, and sustainability in farmers' income and environmental community) after six months since the first WBI. Overall, the results of the ex-post analysis showed that the social learning configuration has increased local farmers' adaptive capacity to deal with climate change in poultry production.

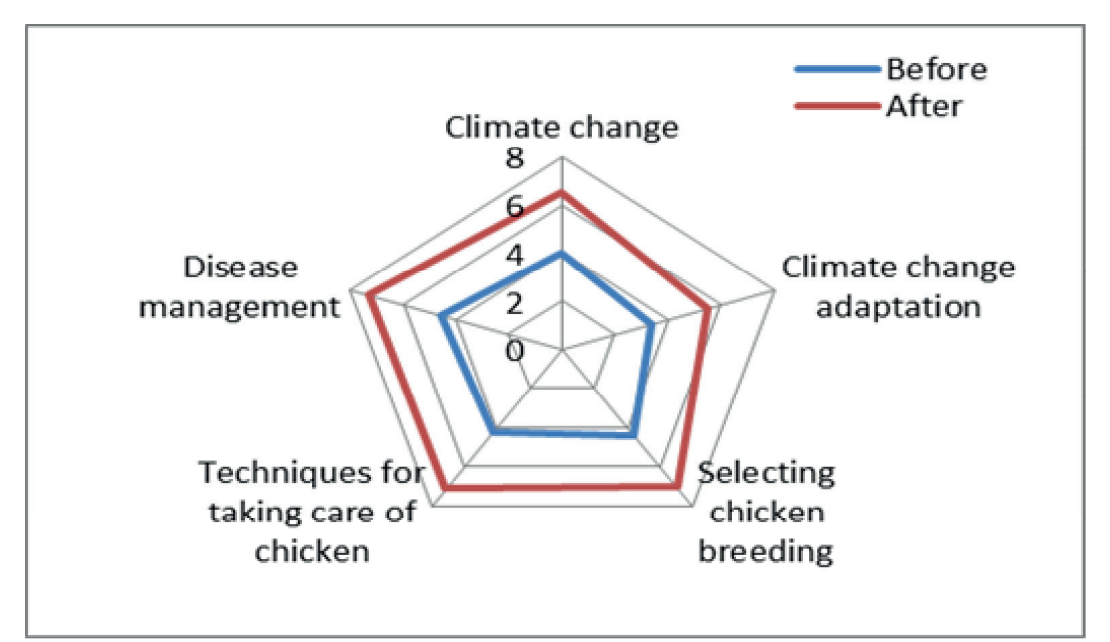

Figure 4.3. Changes in different types of knowledge (on a scale of 1 to 10 to consider before and after participating in WBIs and related activities with 1 indicating 'do not know' to 10 'deeply understand')

In terms of changes in farmers' knowledge (figure 4.3), the second evaluation survey showed that a great majority of participants reported having developed an increased understanding of causes and consequences of climate change (an increase from 4 to 6.5 ), added knowledge in how to adapt to climate change (an increase from 3.4 to 5.5), improved techniques to select for chicken breeding (an increase from 4.4 to 7 ), increased knowledge about techniques to adapt to the uncertainty of how to adapt chicken farming to climate change (an increase from 4.2 to 7.1), and increased knowledge in disease management techniques (an increase from 4.6 to 7.3 ). During the group discussions in the final evaluation workshop most of the participants confirmed that their overall understanding of climate change and poultry production had increased as a result of participation in the WBIs, the pilot demonstrations, and the upscaling activities after the WBIs.

When considering actual changes in practices $22 \%(n=8)$ of the individual farmers indicated they had already changed their production techniques and disease management in poultry production earlier, but $56 \%(n=20)$ of them had changed some of their production techniques again, for example the techniques in selecting for breeding or the process in feeding chicken, as a result of their participation. All of the participants $(n=36)$ indicated they had changed their disease management. In the past farmers did not collaborate or organize activities together. After WBIs and other upscaling activities in 
community, participants in one village organized different groups of 5-6 farmers who collaborated in buying breeding, feed, and vaccination. They were supported by the local veterinary, DARD, and DAE staff. They have also asked the local veterinary to vaccinate their chicken at the same time to reduce cost and risks.

In-depth interviews with farmers in the pilot demonstration $(n=8)$ revealed that their trust in governmental organizations had increased as result of the constructive, knowledgeable and open ways of communication employed by the DARD and DAE staff. Some farmers $(n=6)$ illustrated this by referring to how staff from these organizations had visited and advised farmers to help them solve some of their poultry issues. Therefore, it appeared that the relationship and the collaboration between these staff and farmers as well as other stakeholders (especially input suppliers and output collectors) had improved. A participant stated that "we are now more likely to communicate with DARD staff and the extension worker" and another stated that "the staff of DARD and DAE motivates me as we share ideas and have time to go and visit each other. We learn from each other's knowledge and experiences".

The in-depth interviews with the leaders of DARD and DAE revealed that they mainstreamed using biological bedding material as one of the main strategies to adapt to climate change to reduce risks in poultry production. They decided to have monthly department meetings as a strategic approach to train and upscale pilot demonstration activities and to revise the design of previous trainings. The vice-leader of Quang Dien District People Committee (DPC) stated "poultry production using biological bedding material has to be mainstreamed as a climate change adaptation strategy in the 2017 socialeconomic development plan of the Quang Dien district". The successful pilot demonstrations prompted the leader of Commune People Committee and viceleader of commune in agricultural production to promote and support the use of biological bedding material among more small-scale farmers, including farmers of pig production. Moreover, the DPC also established an incentive mechanism to encourage and promote using biological bedding material in livestock production by supporting loans from the agriculture and rural development bank or the social policy bank with a low interest.

In terms of bridging social networks, all of participants reported that they had more relationships with other farmers in the community and also connected to other networks (e.g. local veterinary, staff in district level, input suppliers). $75 \%(n=15 / 20)$ of non-participants reported that they had asked and talked with other farmers in the community about disease management in poultry production under uncertain climate. They also mentioned that through communication with other farmers they gained access to more information and new contacts for consultation to further improve their poultry production.

In terms of socio-economic and environmental sustainability the final workshop showed that the majority of farmers participating in the pilot agreed that the pilot had increased their income as it enabled them to produce higher quality, healthier chickens in shorter amounts of time against reduced cost. They stated that "We often raised chickens during 6 months, so the risks of disease and market fluctuations were very high. Besides that, it required more costs for food and labour thereby cutting the profits. When applying these techniques, the chickens were raised within three to four months, so input cost was reduced. We can now raise chickens three to four times per year instead of two times per year as before" (participant in the final workshop). Other participants explained that "when we apply this technique, the chickens were raised quickly so we can plan for high consumer demands in chicken meat, also during the wedding season, festivals, or Lunar New Year. This allowed us to sell chicken easily and also to get a high price. We can raise chicken the whole year, especially in the period we cannot cultivate crops, and the income from poultry production can guarantee a part of our financial security for our families". In addition, all farmers $(n=8)$ who participated in the pilot demonstration and the 17 farmers who adopted using biological bedding material in their poultry production stated that "they feel very happy because of there are no odors from poultry production around their house, suggesting that air quality improved as well". They also stated that the relationship with their neighbours also improved because their chickens were kept in one place and did not wonder off to neighbouring lots where they can be disruptive.

In terms of the results of upscaling activities, there were 8 farmers who volunteered to conduct the pilot demonstration in the beginning and another 17 farmers who also adopted the techniques of poultry production using biological bedding material. These upscaling activities, new forms of action, and engagement in community during monthly meetings have led to the active involvement of several other farmers in Thang Loi cooperative and other cooperatives. According to synthesis of agricultural cooperatives after 6 months, there were 130 farmers in the commune who adopted the poultry production using biological bedding material in their practice. 


\subsection{Discussion and conclusions}

Our findings show that a well-designed and supported social learning configuration can lead to a number of beneficial outcomes, including: increased problem ownership, enhanced local stakeholders knowledge, improved ability to see connections and interdependencies, enhanced relationships and social cohesion, and increased awareness of the existence of multiple perspectives. All these aspects are considered valuable for developing farmer's adaptive capacity as manifested in increased knowledge exchange, changes in farming practices, improved social networks, higher and more stable farmers' income, and improved environmental quality.

The understanding of the potential influence of development WBIs to increase adaptive capacity at local levels remains limited (Jones et al., 2010). In this study, we designed the WBIs which mainly applied the social learning approach to increase local adaptive capacity to climate change in poultry production. This study shows that is important that interactive methods used are adapted to the local situation, preferably by the participants themselves. Learning to make change seems to require the mobilization of a network that can support the process of the joint analysis and dialogue needed to motivate people to change their thinking and to take action to implement the preferred changes; and to empower those who are marginalised, deprived, or excluded, often women. This confirms recent findings of Togbé et al. (2015) that participatory approaches with a social learning orientation (e.g. seeking diversity and building social cohesion, trust and joint commitment) are better tailored to support learning and increase adaptive capacity of individuals and communities. Our findings also support other studies which have shown that brokering roles is important in facilitating linkages among various actors, as they try to respond to the needs of farmers and to emerging issues in a community (Minh et al., 2010; Duru et al., 2012; Johnson et al., 2012; Bartels et al., 2013; Bos et al., 2013).

Moreover, the inclusive design and management via different interfaces, the trust-building that took on different forms such as creating incentives (e.g. potential livelihood benefits from participation), attending to cultural norms (e.g. gender), moderating imbalances of power (e.g. through facilitated nonhierarchical exchange), and to a lesser but equally important extent, attenuating knowledge hierarchies (e.g. the role of the researcher and facilitators) were found to be added benefits of the research. Researcher and facilitators needed to move from "trainer" to "learner" roles among and amidst these interdependent actors, in effect, attenuating conventional knowledge hierarchies.

Monitoring and evaluation are important components for guiding the matching of demand for and supply of innovation support as part of dynamic learning processes (Kilelu et al., 2014). Our results show that supporting learning interventions are tied to linking the needs of actors, particularly farmers, to various resources and services that contribute dynamic application processes. At the farm level, the social learning configuration helped establish new and more sustainable partnerships between all stakeholders. It raised farmers' awareness of optimizing the input use and encouraged them to adapt the new techniques for addressing their specific problems such as disease management.

In many previous studies in Vietnam (e.g. Sen, 2016) also in other studies (e.g. Togbé et al., 2015), especially in the activities in the development project in rural areas, farmers receive a daily amount as a compensation for their time. Such a provision raises the costs of participatory research programmes (Togbé et al., 2015). However, in this study, we did not pay money for their time. We actively involved participants in the needs assessment and design of the WBIs which not only increased the farmers' ownership of and agency in the process, it also made them see potential economic, social and environmental benefits early on. Therefore, financial compensation might not be required when a social-learning based intervention is organized in a participatory way.

The findings showed that the social learning configuration and the pilot demonstration were successful. Based on the evaluation of social learning outcomes we can say that the social learning configuration was successful for a number of reasons: (1) the content of the process was appropriate for the local context (based on results of local stakeholder participation); (2) the frequency and intensity of the WBIs seemed adequate while the focus always connected to the farmers' interests (based on results of the needs assessment and local stakeholder participation); (3) there were excellent facilitators; (4) the learning environment was very flexible, open and utilised different ways to learn, share, and upscale. Clearly, understanding the context in which a social learning approach is being used is critical for ensuring the inclusion of all interdependent actors, their cultural and institutional practices, and their particular epistemologies and marginalized socially differentiated groups (Shaw \& Kristjanson, 2014). What our study adds to earlier studies (e.g. Mapfumo et al., 2013; Mishra et al., 2013; Akpo et al., 2015) is to show that there are 
continually emerging needs and demands triggered by new challenges and opportunities. Developing a better understanding of the context and perspectives, values and norms of socially differentiated groups can make researchers more sensitive to emergent agricultural and livelihood needs.

Muro \& Jeffrey (2008) suggest that successful social learning requires opportunities of interaction, openness, representativeness and facilitation that support the integration of multiple sources of knowledge. The world doesn't change one person at a time. It changes within networks of relationships among people who discover they share a common cause and vision of what's possible (Wheatley \& Frieze, 2015). Importantly for the work undertaken here is emphasising that social learning extends beyond the sharing of knowledge to supporting the mutual development of societal experiments through unique learning relationships (Bos et al., 2013).

Farmers were linked to other various support activities for improving their poultry production practices. First the project facilitated farmer-to-farmer visits and meetings, where lead farmers would share their experiences with the "new" farmers on various technical issues. The role of farmer-to-farmer learning processes is critical in this study and it fits with the research of Shaw \& Kristjanson (2014). The interface and learning environment in each of the projects created trust and legitimacy among interdependent actors. In many cases, the networks formed in the learning environment also acted as channels for knowledge mobilization.

During discussions farmers indicated that actual farm visits were important avenues for acquiring information. Such visits are less disruptive in the sense that they can continue to attend to their owneveryday work. Some famers missed group sessions because they had to work on their own farm, or were engaged in hiring workers or in off-farm activities. This suggests that before the experiment, farmers underestimated the amount of work involved in taking part. There are also seasonal influences that need to be considered: during the cropping season farmers are less likely to participate in social learning based interventions. Hoffmann et al. (2007) found that when farmers are engaged in extension programs or interventions, there is a tendency to revert to old routines when the return on investment is not as expected. It may be better to focus on a common emerging issue as this is more likely to create a common sense of purpose and solidarity that goes beyond a "return on investment" mentality" (Wheatley \& Frieze, 2015). Although the social learning configurations were evaluated successfully, the major lesson learned from the design and implementation of the social learning configuration in the Quang Lo commune context is that the process neglected the institutional capacities. Although there was much attention for learning in individuals, hardly any attention was paid to institutional learning and learning at multiple-governance levels. In order to develop and scale up the social learning configuration to other agricultural communities in Vietnam, it also needs to be considered as an institutional innovation. The starting point of this approach should be an assessment of the existing system's abilities, also considering the current climate change context, followed by the gradual introduction of the institutional innovation from simple to more comprehensive forms (Jakku \& Thorburn, 2010; Bartels et al., 2013). Therefore, systematically building up policy capacities at different levels should be planned for as well. Effective communication between participating stakeholders and policy makers is needed to facilitate positive changes. In particular, the participation of policy makers at crucial stages is essential. In this study, we did not involve policy makers at a sufficiently early stage of the process. We see it as an essential component that needs to be addressed in any future intervention on a similar theme. Moreover, enhancing capacity of individual farmers is not enough in developing social learning and increasing adaptive capacity in a climate change context. It also requires increased capacity of staff who has worked directly with farmers in agricultural production.

Finally, in the context of climate change and adaptive capacity development, in order to reach the most vulnerable individuals requires inclusive strategies and approaches aimed at understanding the needs of socially differentiated groups. To include socially differentiated groups in social learning requires that particular attention is paid to minimizing power imbalances, in order to enable a more equitable exchange of knowledge and ideas, and knowledge hierarchies. This ideally is done already in the design phase and includes a way that allows meaningful exchange while maintaining a somewhat level playing field. In the rural agricultural context, socially differentiated groups contribute substantive knowledge to the learning environment. The farmer-to-farmer learning processes combined with the external facilitation helps maximize the knowledge farmers get and minimize the knowledge hierarchy which is implicit when researcher and facilitators manage and facilitate learning processes. The benefits of applying a social learning design are multiple and include: increased farmers' participation, the greater adoption of appropriate technologies, expanded knowledge in relation to climate change, and better understanding of 
climate change adaptation strategies in the poultry production. All these benefits appear to contribute to an increase of farmers' adaptive capacity and agency. However, the impacts could be more profound and widespread when institutional learning and multi-level governance would be made an integral part of social learning-based interventions.

\section{Acknowledgements:}

This research is funded through the Nuffic project (NICHE/VNM/105). We acknowledge the helpful support by the staff in Department of Agriculture and Rural Development in Quang Dien district. We especially thank $\mathrm{Mr}$ Tan and $\mathrm{Mr}$ Lanh who supported us during conducted the interventions and data collection in community. We would like to thank the Quang Loi commune authorities, their staff, agricultural cooperatives and all farmers who provide invaluable information for this research.

Chapter 5

Barriers and enablers to climate change adaptation in the hierarchical governance system of Vietnam 


\section{Abstract}

Governments fulfil important roles in increasing the adaptive capacity of local communities to respond to climate change impacts, particularly in developing countries. There are existing studies on how governments enable and constrain the ways in which local level communities learn and build their adaptive capacity, however, they generally adopt network or market ideal types of governance. However, the most vulnerable regions to climate change impact in the world are generally governed through hierarchical governance models. This research aims to analyse how in the hierarchical governance system of Vietnam different levels of government enable or constrain the process of building adaptive capacity and social learning of smallholder farmers to adapto $t$ impacts of climate change. We conducted interviews $(n=26)$ with key actors at multiple levels of government. Our findings show the importance of clear legal institutions, available finance for implementing policies, and training of governmental staff, particularly at district and commune levels where the policy capacities are generally low to deal with climate change impacts. We conclude that any efforts of social learning and increasing adaptive capacity for smallholder farmers should include investments in policy capacity to ensure uptake and upscaling of adaptation actions.

\subsection{Introduction}

Communities across the globe are adapting to the impacts of climate change. Particularly in developing countries there is an important role ascribed to social learning to build the necessary adaptive capacity to help the most vulnerable social groups and regions to start adapting (Bardsley, 2015; Ensor \& Harvey, 2015). In these contexts, social learning is considered essential for developing and sustaining the capacity of different authorities, experts, interests groups, civil organizations or public organizations in reducing social vulnerability, particularly at the community level (Clemens et al., 2016; Lebel et al., 2010). Governments play an important role in creating such social learning environments for example by increasing knowledge exchange, creating training and educational programs, empowering the poorest and most vulnerable groups, enhancing social networks, and connecting administrative levels and scales (Armitage \& Plummer, 2010; Smit \& Wandel, 2006). However, planning for climate change adaptation (CCA) in developing countries is considered highly complex as this takes place in a setting of multiple socio-economic and political challenges including: poverty, gender inequality, illiteracy, corruption, rapid urbanization, food insecurity, and extensive extraction of natural resources for economic development (Mohabbat \& Shahriar, 2015). The immediacy of climatic impacts combined with the absence of dedicated state efforts to plan and implement adaptation measures has resulted in several cases in a mushrooming of NGO initiatives and internationally funded projects to help start local communities to adapt. This has in turn created a fragmented governance landscape of various government, NGO, and private sector driven adaptation initiatives.

Although the role of the state has been questioned in developing country contexts for not having the policy capacity to ensure timely implementation, there is still a potentially important role for the state in enabling the process of social learning and adaptation across levels of governance. Governments have unique constitutional tasks and responsibilities as well as policy instruments at their disposal - most explicitly the rule of law - that make them indispensable for ensuring timely CCA across scales (Araos et al., 2016; Jordan et al., 2015). Different policy systems such as network-, market-, and hierarchy-policy systems, however, impact the ways in which adaptation is being governed. These systems set the context for and directly shape local level implementation of those adaptation policies. Moreover, the state is (un)willingly creating constraining conditions that affect the capacity to adapt 
to climate change, such as creating conflicting tools and guidelines. Paradoxically, the state is also instrumental in removing these and other barriers to allow social learning to occur (Biesbroek et al., 2013). The state is expected to create a social learning environment that allows local stakeholders to build adaptive capacity. For example, Amundsen et al. (2010) find that without national authorities giving clear political signals through designing and facilitating adaptation policies, lower administrative levels will find it more difficult to develop effective adaptation policies and to implement them at local levels.

Although several studies on the ways in which governments enable and constrain how local level communities learn and build their adaptive capacity exist, they have focussed on network-oriented or market-oriented policy systems that exist in predominantly in high-income countries (Armitage et al., 2011; Nilsson et al., 2012). However, the most vulnerable regions in the world are often governed through hierarchical governance models. Studies on adaptation in developing countries often suggest improvements based on network and market orientated principles that do not necessarily fit with the existing hierarchical policy system context.

This research aims to understand how different levels of government in a hierarchical governance system enable or constrain the process of building adaptive capacity and social learning of smallholder farmers to respond to the impacts of climate change. To address this question, we focus on Vietnam - a highly vulnerable country with a hierarchical autocratic policy system. Over the past decades the Vietnamese government has already implemented several CCA activities, policies, and strategies (Hoang et al., 2014; Knaepen, 2014) in a formalized and top-down manner to ensure timely actions (Rubin, 2014).

\subsection{Examining policy capacity in hierarchical multilevel government settings}

We characterize climate change adaptation (CCA) as a societal issue that cross-cuts different spatial, temporal and administrative levels and scales, and requires involvement of different types of state and non-state actors. To study CCA adequately requires combining of different theoretical insights that can be captured under the umbrella concept of multilevel governance (Amundsen et al., 2010; Nilsson et al., 2012; Rantala et al., 2014). In its broadest sense, multilevel governance refers to a system of continuous negotiation of nested governments at several territorial tiers: supranational, national, regional, and local (Hooghe, 1996; Marks, 1993). Central to the notion of multilevel governance is the recognition that there are different ways in which power diffuses between the embedded actors and institutions and that different levels may have different tasks and responsibilities when it concerns adaptation (Araos et al., 2016). For example, in most contexts local governments are responsible for delivering basic services to their citizenry whereas the national government is responsible for creating an enabling environment. This environment allows this service delivery to take place, for example by implementing adaptation guidelines, building climate change awareness, establishing legal frameworks to support adaptation, and stimulating social learning processes. Studies find that in governing CCA cross-level and scale imbalances and even contradictions are inevitable (Bauer \& Steurer, 2014; Fröhlich \& Knieling, 2013). Multilevel governance studies therefore seek to identify the level at which the problem is manifested and the level at which the climate change impacts are being managed (Termeer et al., 2010), which are not necessarily in sync.

In the South-East Asian countries in general and Vietnam in particular, the policy systems are characterized as "bureaucratic hierarchies", "administrative states" or a "mono-centric modes of governance" (Schreurs, 2010). In these systems the focus is on the centre of political power and authority - the state that sets the agenda of societal problems, decides upon policy goals and means, and implements its policies at lower administrative levels in a top-down manner (Painter \& Peters, 2010). These systems are characterized by the specialization of functions, objective qualifications, civil servants who follow a fixed set of rules, and a hierarchy of authority (Thompson, 1991). Steering and controlling are key concepts within this system (Kooiman \& Jentoft, 2009) where the state does the steering rather than the rowing (Osborne \& Gaebler, 1992). The top-down institutional structures strongly influence the patterns of interaction and coordination within and between different jurisdictional levels and scales (McNeeley, 2012; Rubin, 2014).

Like any other system, hierarchical systems are operationalized by a set of shared rules, norms and practices that shape the implementation preferences of bureaucratic actors (Pahl-Wostl, 2009; Thompson, 1991). These policy system characteristics are difficult to change even in the face of major challenges such as climate change. This is because the political interest in retaining the status quo is often much stronger than efforts of changing existing institutions. Although many hierarchical systems are changing, for 
example due to globalization, such change usually goes very slow. Severa studies show that the ability of the state to respond to climate change is both enabled and constrained by the characteristics of the policy system (Craft \& Howlett, 2012; Wellstead \& Stedman, 2015), particularly the policy capacity of states to increase social learning and adaptive capacity across all levels of governance and support community action on adaptation.

\section{Understanding policy capacity in hierarchical system settings}

Many authors have listed different types of constraints, including cognitive, political, social, and institutional constraints (Biesbroek et al., 2013; Oberlack 2016; Walker et al., 2015). Especially in low income countries, socio-economic factors, resource constraints, societal hierarchies, and psychological factors have been widely identified as major constraints to CCA by smallholder farmers (Bayard et al., 2007; Deressa et al., 2009). Other frequently reported barriers include unfamiliarity of the local people with available data on climate change, lack of local expertise, lack of a clear role for local governments, and lack of focus on adaptation at the national level leading to a lack of attention to CCA at the local level (Biesbroek et al., 2013; Hughes et al., 2015).

To study the possible factors and processes that enable and constrain social learning at the local levels, we adopt the policy capacity framework to guide our analysis (Howlett, 2009; Howlett, 2015; Wu et al., 2015). Social learning in this study can be understood as: "a process where learning occurs at multiple governance levels, bringing together stakeholders with diverging initial perceptions with the intention to learn together and form a common understanding with respect to taking a planned course of action that they jointly implement by working in iterative cycles of action and reflection" (Phuong et al., 2017, p.6-7). Policy capacity is understood as the ability of governments to make intelligent collective decisions, to mobilise necessary resources, to produce robust evidence-based policy, to weave together different organisations and interests, to coordinate policy making across and external to government and to implement as well as formulate meaningful policy (Hughes et al., 2015; Oliphant \& Howlett, 2010; Wellstead et al., 2011). In the context of this paper, we operationalize policy capacity as: 1 ) the institutional characteristics of the policy and governance system; 2) the resources required and available in order to design and implement CCA, and 3 ) the policy analytic capacity of policy actors involved in CCA (Craft et al.
2013). We briefly discuss the three main elements of this policy capacity framework and how they enable or constrain social learning and adaptation at local levels.

The first element of policy capacity is the institutional characteristics of the system. Institutions are macro-level arrangements that are contrived of formal and informal rules, norms, cultures, and beliefs that influence for example the ways in which government is structured, how power and authority is being distributed within government and between government and society, and how the state interacts with society. Institutional arrangements have specific strengths (e.g. coercive power, clear division of tasks and responsibilities) and weaknesses (e.g. procedural restriction, fragmentation) that influence the ways in which governments (can) respond to climate change impacts (Doelle et al., 2012). Institutional characteristics are known to both empower and constrain societal and governmental actors. CCA studies in south Asia, for example, show that institutional fragmentation is considered a critical reason for governments not being able to respond to climate change impacts as there are many institutional gaps, coordination issues, bureaucratic separatism, conflicting responsibilities and objectives, as Lebel et al. (2011) show for Thailand. studies in Vietnam show that formal institutions have constrained collaborative governance processes by obstructing the participation of actors across levels and areas of expertise and weakening the roles and functions of local authorities in adapting to climate change (Ho et al., 2012).

The second element of policy capacity is governing resources. Governments have specific governing resources at their disposal such as financial, knowledge, legal, organizational, political, social or human related resources (Koch et al., 2007). Resources are the means through which governments can achieve particular policy goals (Henstra, 2016). As such, resources are critical to measure policy capacity and are considered crucial inputs for designing, recommending, and implementing policy decisions (Wellstead \& Stedman, 2015). Several studies show that lack of governing resources will limit local actions to CCA (Brown et al., 2010). Arguably, the most frequently reported constraint in low-income countries is the lack of governmental funding for designing and implementing adaptation measures as well as for hiring appropriate personal resources (Antwi-Agyei et al., 2015). Moreover, limited access to domestic and international financial resources were found to negatively influence analysis and implementation of adaptation, for instance in Ghana (Antwi-Agyei et al., 2015) and Bangladesh (Ahammad, 2011). 
The third element for studying policy capacity is related to so-called policy analytical capacity of civil servants. Policy analytical capacity refers to the capacities of actors, policy makers, and policy workers such as their competences, skills, attitudes, and knowledge (Howlett, 2015; Lodge \& Wegrich, 2014). Howlett (2015) argues that the capacities of individual policy actors are important as they determine, for example, the amount of research a government can conduct or access, the efficiency and effectiveness of policy implementation, the possibilities to create specific trainings for public and societal actors, and to provide recommendations to local people. These determinants are crucial as they allow governments to communicate about climate change policy and, vice versa, to incorporate insights from society into governmental decision-making (Howlett, 2009; Tiernan, 2011). However, several studies show that low skills and abilities of public sector actors seriously affect overall policy analytical capacity. The lack of knowledge and skills of governmental actors about climate change impacts and adaptation, for example, has proven to be a major constraint in Bangladesh to integrate adaptation (Ahammad, 2011). Low degrees of analytic capacity of policy actors explain the variation in how, within the same country or region, governmental responses of governments can vary greatly (Wellstead et al., 2011).

\subsection{Climate change adaptation in Vietnam}

We adopt this framework to study CCA in Vietnam. Vietnam has a long socialist and communist history with a strong role the Vietnamese Communist Party (Minh Chau, 1997), but recently there have been many socio-political reforms opening-up the country for international organizations and non-government stakeholders (Painter, 2003). Vietnam remains an autocratic one-party system where the Communist Party of Vietnam holds the monopoly of the political process and is the absolute leader of society (Desbarats, 1987). The Party implements its leadership through the state via the principle of democratic centralism which means unconditional implementation of the decisions taken at higher levels by the lower levels. The instrument of coordination between levels is through central planning (Minh Chau, 1997). When it comes to CCA, the government is responsible for building, steering, and implementing all policies, measures, and strategies. Figure 5.1 presents the hierarchical multilevel system for CCA in Vietnam.

At the national level, different ministries collaborate on CCA and each ministry has the authority to make decisions that should be implemented at lower levels of government. The Ministry of Natural Resource and Environment (MONRE) is responsible for and coordinates all CCA related activities, for example through the National Target Program to Respond to Climate Change (MONRE, 2008) and National Strategy on Climate Change (MONRE, 2011). When it comes to long-term CCA efforts in the agricultural sector, however, the Ministry of Agriculture and Rural Development (MARD) is the main ministry responsible. This ministry has developed several policies, most importantly the Action Plan Framework for Adaptation to Climate Change in the Agriculture and Rural Development for the period 2008-2020 (MARD, 2008), and a Climate Change Adaptation Vision to 2050 (MARD, 2011). The main objective of these policies is to improve the response capacities of the agriculture and rural development sector to better manage climate change impacts. In addition to MONRE and MARD, there are four main ministries with adaptation responsibilities: Ministry of Planning and Investment; Department of Public Finance of the Ministry of Finance; Department of Student Affairs of the Ministry of Education and Training; and the Ministry of Information and Communication.

The top-down governing structure means that the national level can force the Peoples' Committee at local levels to implement CCA policies. At the provincial and district levels, the institutions for CCA are structured the same as at the national level, see figure 5.1. There is an important role for the Provincial Peoples' Committee as this level is central in translating district (and sometimes commune) level requests, as well as converting proposals from sectoral departments and academic institutions into concrete project proposals that can be presented to international organizations. At the commune level, the lowest management level in the policy system, there are no institutions with an explicit responsibility for CCA issues. At the lower administrative levels (i.e. province, district, and commune), the Peoples' Committees approve and sign all legal documents which are used for day-today management and governance activities. The coordination between national level and other levels takes place via two routes: 1) top-down steering from national level to the local level through decisions and 2) decrees and resolutions and feedback from local level to national level through annual meetings, workshops and reports. 


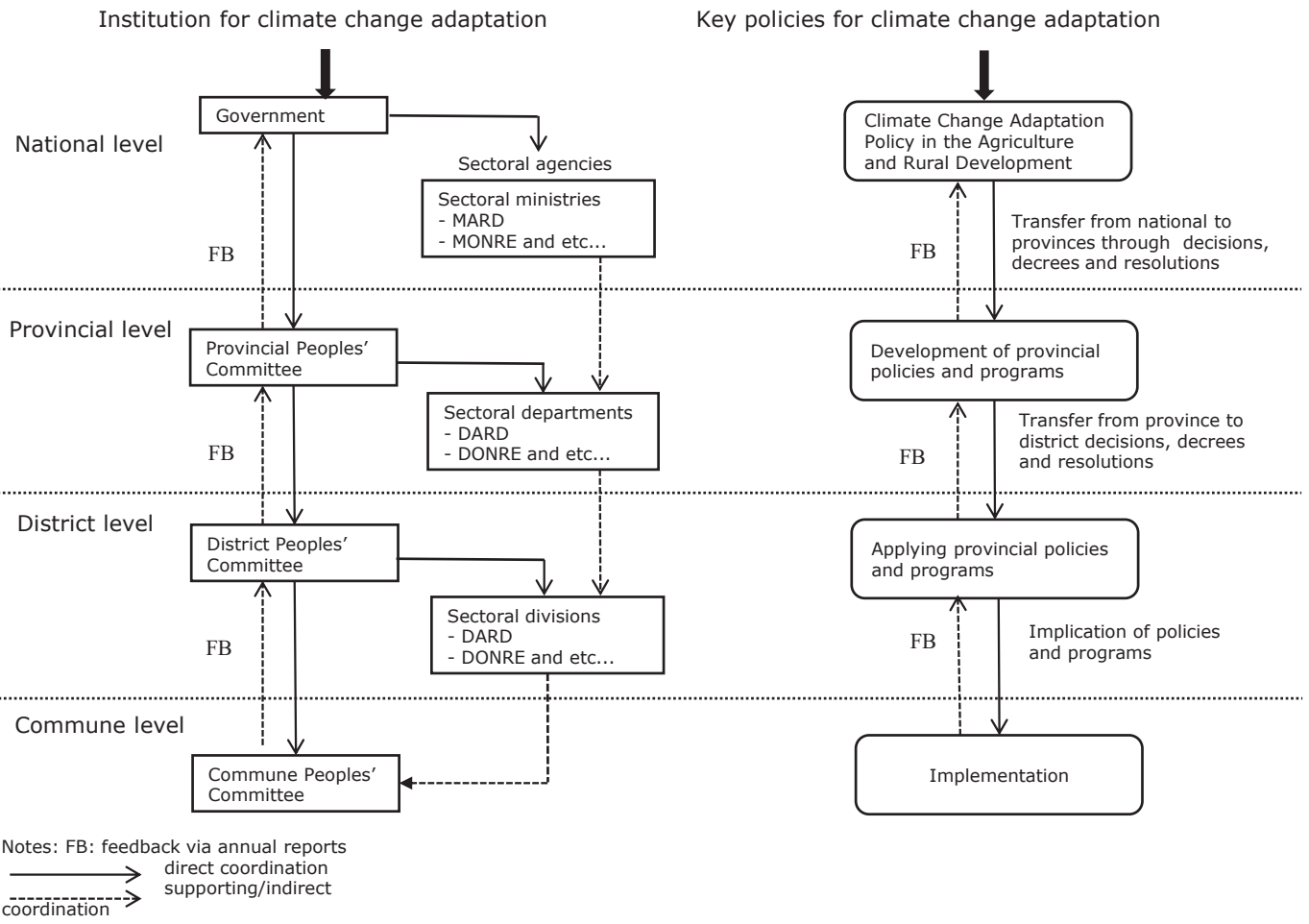

Figure 5.1. The Vietnamese government organization structure based on the mandates of agencies and main CCA policy in Vietnam (adapted from MONRE, 2008)

\subsection{Methodology}

To study the diverse perspectives about the enabling and constraining conditions we adopt an interpretive research design where we study and interpret our findings within the social and cultural context of the case (Cantrell, 1993).

\subsubsection{Selection of cases}

We used a qualitative nested case study approach (Keessen et al., 2016) to gain an in-depth understanding of how the four different levels in Vietnam (national, provincial, district, and commune levels) enabled or constrained social learning and increasing adaptive capacity of smallholder farmers to implement CCA. Vietnam is very vulnerable to climate change impacts (Bruun, 2012; Maplecroft, 2011), specifically agriculture and food security are under serious pressure. In Vietnam, agriculture is a major economic force contributing to more than $16.32 \%$ of the GDP of the nation and providing employment for $42.4 \%$ of the working population (GOS, 2016). Of the 63 subnational provinces we selected Thua Thien Hue province in the centre of Vietnam as it is considered one of the most vulnerable regions to extreme climate events (Beckman, 2010). The province is already recognizing the impacts of climate change and has started to invest in CCA. The third and fourth tiers of analysis are the Quang Dien district and Quang Loi commune, as they are thought to be one of the most climate vulnerable areas in Thua Thien Hue by the government with high poverty rate and farmers' livelihood strongly depending on income from agricultural production (TTH Provincial People Committee, 2014).

\subsubsection{Data collection methods}

We use interview and document analyse as main data sources. We conducted 26 in-depth interviews with actors from different levels: 4 at national level, 9 at provincial level, 5 at district level, and 4 at commune level. These were the policy actors most responsible for adaptation of the agricultural sector at the specific level. We also interviewed 2 households at farm level, one research organization and one non-government organization. Each interview lasted between 60-90 minutes during which interviewees were asked about specific themes: their current understanding and knowledge of climate change, their tasks, responsibilities and policy actions on adaptation, the other actors' involved, horizontal and vertical coordination between each level and between sectors, and the three dimensions of the policy capacity framework. Interviewees were also asked to critically reflect on the key factors they perceived as being enabling and constraining social learning and adaptive capacity of smallholder farmers to implement CCA strategies. We contacted several interviewees for follow-up questions. In addition, secondary data were collected including legal documents and governmental reports from all the four levels for the time period 2008-2016. This data allowed us to prepare the interviews and include specific questions that could not be distilled from the literature.

\subsubsection{Data analysis methods}

The data were analysed through several steps. First, the content of documents was analysed by identifying the main events, policies and 
(political) decisions to reconstruct the adaptation policy development at each of the four levels under analysis (2008-2016). Second, the interviews were recorded when allowed by the interviewee. In several instances, however, the interviewees did not agree to be recorded in which case detailed notes were taken by the two interviewers. The interviews were transcribed shortly after each interview. The data were then analysed using open coding to identify which enabling and constraining conditions were mentioned by the interviewees. We clustered and prioritized these using the three elements of policy capacity: institutions, resources, and individual policy actors. We used quotes to provide some examples from interviews clarify the findings. The quotes were selected that directly spoke to the key questions being asked in this study. The most frequently reported barriers were discussed and crosschecked with the secondary data. The findings of this analysis are reported in section 5 .

\subsubsection{Limitations}

This study has several methodological limitations. Firstly, the findings of this study were limited by the limited number of nested cases we studied. For analytical and pragmatic reasons, we focussed on one province, district, and commune rather than including multiple cases at each level. This will have consequences for the upscaling and generalizability of our findings, as we discuss in the final sections. Second, interviewing government officials in hierarchical systems are known to be a challenge for several reasons, including trustworthiness of the findings (Rubin, 2014). Whilst this could be a limitation in our study, we combined multiple interviews and document analysis to ensure the robustness of our findings. Finally, we mostly studied government officials, which is central to our analytical framework, but including more nongovernmental actors could have enriched allowed us to understand how other actors perceive the policy capacity of governments.

\subsection{Results}

Our analysis shows several enabling and constraining key conditions and processes across the different levels of government that impact on how social learning and adaptive capacity for smallholder farmers take place in Vietnam. We have clustered these through the three elements of policy capacity: institutions, resources, and individual policy actors.

\subsubsection{Policy capacity: Institutions \\ Key enabling institutional characteristics}

First, interviewees at national and province level argued that the existence of the NTPRCC and NSCC is helpful as it clarifies roles, tasks, and responsibilities of policy and societal actors. The fact that adaptation is not the sole responsibility of one ministry but rather shared across multiple ministries is considered to be strength, as it ensures that mainstreaming adaptation across vulnerable sectors is ensured. Consequently, at the national level, several policy networks and collaborations have emerged to share information and encourage policy learning for implementing across different sectors. Second, interviewees argued that because adaptation at subnational levels is mainstreamed in annual and five year social-economic development plans there is increasing institutionalized support for staff at province, district, and commune levels. This allows each level to gradually increase their governing resources and analytical capacity of their policy actors. Interviewees also reported that the hierarchical and structured approach ensured some degree of consistency and coherence between sectors (horizontal) and across all levels (vertical) in how to frame and address climate change impacts.

However, since adaptation is not fully institutionalized and mainstreamed across all levels, much of the adaptation taking place is still rather fragmented. The interviewees at the district and commune level did not consider this a key constraint, but rather argued that this creates plenty of opportunities for learning, participation, and experimentation by smallholder farmers.

"At district level, there are not yet specific CCA policies for agricultural development and adaptation. However, we are already organizing trainings, building pilot demonstrations, and conducting agricultural experiments in local communities. Mainstreaming of CCA in these activities increases the learning process and farmers' capacity to implement adaptation measures to respond to climate change impacts. Advanced climate models and new agricultural techniques are made available to us by the scientific and technological subdepartments which have increased farmers' knowledge and their capacity to adapt to climate change impacts", (interviewee of DARD at district level).

\section{Key constraining institutional characteristics}

However, interviewees also identified a number of key institutional constraints. First of all, much of the institutionalization of adaptation is still at the early stages. Although a lot has been realized at the national and provincial level, 
these are not yet dispersed to district and commune levels which mean that there is no legal basis for lower levels of government to start acting and making adaptation a central policy issue. Although several policies and plans for CCA in the agricultural sector have been adopted at the national level, these too have not yet been adopted and integrated at the lower levels. Consequently, all interviewees at the lower levels argued that their roles are unclear and tasks are very still limited. Thus, all decisions for building and implementing CCA strategies in the agricultural sector depend on the discretion of the Peoples' Committee at provincial and district level as they control the financial distribution for each department.

Because of the unclear roles and the lacking of a legal mandate, the question of who is held accountable for adaptation remains unclear, particularly at the lower levels. As one interviewee at the district level aptly notes:

"Although mainstreaming was mentioned in the provincial CCA policies, this strategy is not the main responsibility of the agricultural department. Given that these departments do not force us to engage with adaptation, we focus on the several other things that we [are legally required] to do", (interviewee of DARD at district (evel).

The second main institutional constraint was related to the top-down steering of implementing adaptation. Interviewees noted that it leads to mismatches between what the central government tells the lower levels to do and what the lower levels want to do given their specific contexts and vulnerabilities. So far, all existing policies, plans or guidelines are covering the whole country whereas large parts of the implementation are expected to be carried out at commune levels. This creates difficulties for lower levels if they want to adjust their adaptation measures to fit the appropriate climate change impacts. As one interviewee notes:

"All CCA strategies and measures have to follow the higher level provisions, so it is very difficulties for our departments to adjust or change these measures and make them more suitable to our specific context and needs. Departments such as DONRE and DARD at provincial level often select the techniques used in projects; smallholder farmers or commune authority do not have any opportunity to choose projects and measures they are interested in", (interviewee of DARD at district level).

Lower levels of government were also not involved in the design of these new adaptation policies, which means tensions are emerging between the new top- down designed adaptation policies, and the existing policies and practices at the lower levels. This is also affecting the policy actors (at lower levels) who mentioned that it is unclear how to coordinate across scales as there currently are no formal and informal mechanisms that allows them to 'do-not-harm' or to engage in positive coordination. During several projects, policy actors experienced several conflicts and contradictive actions that resulted in ineffective implementation of local CCA. This also reduced the possibility of reflecting on their experiences and to share lessons learned. The only mechanism through which feedback across levels is organized is through formal reporting, but the effectiveness of this mechanism in terms of policy orientated learning is questioned by local and provincial interviewees.

The hierarchical system has also resulted in 'silofication' where departments stick to their legally determined tasks and responsibilities and hardly share information or coordinate actions. As two interviewees note:

"Our department works following the principle: who has capacity and can find financial resources will implement CCA strategies. There is no need to coordinate as long as you do your job and I'll do mine", (interviewees of DONRE provincial level).

As a result, the sharing and updating of information about CCA between the agricultural and other sectors has not yet occurred, particularly not at provincial and district level. The lack of horizontal and vertical coordination is hampering the policy-oriented learning process among departments and staff in agricultural sectors. This means that upscaling of other initiatives is complicated:

"At province and district level there is recognition that small pilot projects, often led by NGOs, can result in valuable lessons for adaptation. But the lack of a mechanism for coordinating and sharing these lessons prevent up-scaled programming by the government. [...] The lack of horizontal coordination has lead in some cases to overlap in pilot projects between different departments", (interviewee of DAEC at district level).

\subsubsection{Policy capacity: Governing resources} Key enabling governing resources

Interviewees noted there are quite some financial resources available to start adapting to climate change. In recent years, the financial commitments by 
donor agencies to invest science, technology, and society have increased and climate change has become an important component of international funding. In total the budget allocated for climate change adaptation is $0.1 \%$ GDP of Vietnam, with two third of the funding from the Vietnamese government, and one third by international donors (MPI, 2015). In 2013, 79\% of the total climate finance budget is allocated to adaptation of the agricultural and rural development sector. Although this budget is still relatively small, these investments have grown rapidly in recent years (MPI, 2015). Interviewees argued that the large bureaucracy in Vietnam means that there are many civil servants working on agricultural issues. However, the number of people working on adaptation (rather than disaster risk reduction or sustainable development) is still relatively low, but slowly increasing.

\section{Key constraining governing resources}

Still policy actors considered the lack of financial resources a main governing resource constraint. Interviewees noted that there is a significant imbalance in the financial distribution across levels and sectors. The vast majority of financial resources is allocated to improving and building infrastructure at the national and provincial level, such as improving dykes. Investments in national infrastructure, for example, covered $93 \%$ of the total funding available for adaptation in the agricultural sector. In 2013, of the remaining budget, $4 \%$ was allocated for developing science and technology, $2 \%$ for enhancing governmental capacities, and a meagre $1 \%$ for developing adaptive capacity of communities and smallholder farmers (MPI, 2015). Interviewees reported that the unequal distribution and emphasis on technical measures prevented creating a social learning environment for smallholder farmers but also constrained civil servants for improving their policy analytical capacity.

In addition, whilst some funding for building adaptive capacity and stimulating social learning was available, this funding generally went to small scale pilot projects that were largely driven by donor funding. Currently, there is no systematic or continuous financial flow to ensure implementation of CCA in the long run. Interviewees reported that the existing policies and plans designed by the national government are far more ambitious than the available governing resources at the different levels. The disbalance in financial distribution is also reflected in the limited human resources for implementing CCA at local levels in terms of quantity and quality of staff. The limited number of staff that is knowledgeable about climate change adaptation is illustrated by one of the interviewees from DONRE:
"We work to mainstream CCA in all sectors for the Thua Thien Hue province. However, our department has only three staff members who are knowledgeable about climate change and none of them are knowledgeable about adaptation of the agricultural sector. Similarly, there is only one staff member for CCA at district and commune level but he is not knowledgeable about agriculture", (interviewee of DONRE at provincial level).

This can partly be attributed to institutional constraints as the tasks and responsibilities of the civil servants are not legally determined. This means it is up to the discretion of the Peoples' Committee to determine if, when and how governing resources are invested for adaptation:

"The Peoples' Committee at each level manages the human resource and finance of these departments. Moreover, agricultural departments at lower levels also are managed by agricultural departments at higher levels where emphasis is placed on management and steering of specialized technical agricultural activities. During the implementation of CCA strategies, there are overlapping and inefficient uses of human and financial resources", (interviewee of DARD at district level).

\subsubsection{Policy capacity: Individual policy actors}

\section{Key enablers of individual policy actors}

Although financial resources are limited, interviewees referred to several training courses to increase the policy analytical capacity of individual actors' working on climate change. These trainings are specifically designed for the implementation of the NTPRCC and NSCC. Most training follows the train-thetrainer principle, assuming that knowledge and expertise on CCA diffuses in the bureaucracy. Policy actors working on CCA at national level generally have high levels of education and are knowledgeable about CCA. There are also several opportunities to access updated climate change and CCA information in agriculture through national and international knowledge exchanges (e.g. conferences). Similarly, at the provincial level, several of the staff of DONRE and DARD are knowledgeable about climate change. These actors play a crucial role to enhance awareness about climate change for farming communities in their province.

\section{Key constraints of individual policy actors}

However all interviewees agreed that policy analytical capacity at district and commune level is very limited particularly due to the limited knowledge and 
skills about CCA in the agricultural sector. This can be attributed to some extent to the type of Vietnamese bureaucracy where generalists generally prevail over specialists and where civil servants rotate throughout the bureaucracy frequently. This means the very few civil servants knowledgeable about adaptation also change jobs and since there are no institutional mechanisms in place, this critically influences the organizational expertise and lowers the motivation of civil servants to become very knowledgeable about CCA. This is illustrated by one interviewee:

"I am trained in environmental inspections and I have worked for DONRE. From 2013 to 2014 I was moved to another department to support the provincial adaptation strategy development team. After that I returned to my old position. Since the beginning of 2016, however, DONRE has established the CCA department and I have worked as staff for this department for a while. However, I do not know whether I will continue to work here or if I will be moved to another department the future", (interviewee of DONRE at provincial level).

A second key constraint is that knowledge and information about CCA is lacking and no substantive trainings are offered for individual policy actors at local levels. Even if they were offered, interviewees mentioned that they would attend, but only when it was mandatory. Consequently, the knowledge level at district and commune level remains relatively low with very limited comprehensive knowledge on the consequences of climate change. This again comes back to the institutional characteristics, as mentioned by one of the interviewees:

"Some staff participated in training courses or CCA pilot projects. They have the opportunities to access knowledge and information but they did not share it to other staff because they do not consider this to be their responsibility" (interviewees DAEC at provincial and district levels).

Interviewees also mentioned that the train-the-trainer principles did not work simply because the person trained did not have the time, nor made it a priority to share the knowledge to others in the department. Whilst CCA is considered an important task by all civil servants interviewed, it is clear that individual civil servants already have a lot of tasks that are mandatory. As CCA is currently an integrating rather than a legal mandatory task, it is not considered the primary task of civil servants working at district and community level. The motivation to learn and acquire new knowledge about CCA and to improve skills to support the social learning of smallholder farmers is not considered a priority

"In our community there is only one staff in charge of agricultural, extensional, and economic development for the whole commune. Therefore, I do not have enough time to learn or update new climate change and CCA knowledge. Although I work closely with smallholder farmers, I know very little about CCA in agriculture. I think that this is also true for the leader of community, staff of the agricultural cooperative, and other people in the community", (interviewee agricultural staff at commune level).

\subsection{Discussion}

Our findings show that like any governance system, the hierarchical multilevel governance setting of Vietnam creates several enabling and constraining conditions that influence if, when and how smallholder farmers build adaptive capacity and create a social learning environment to adapt to climate change impacts. Although often critiqued in the literature, our findings suggest that the hierarchical governance system can offer some benefits, especially when it comes to vertical coordination and mainstreaming of CCA across departments. Vietnam is rapidly developing its CCA policies and measures and several successful examples of adaptation have been reported in the literature. The mainstreaming strategy seems well suited for such a governance context since it places CCA on a broader development pathway and can be implemented at all levels (Ward et al., 2013)

However, as this study also shows, this potential is not fully used and policy actors experienced various key constraints, including unclear institutions in terms of structure, roles, and accountability mechanisms, a lack of clarity with regards to the coordination within and across levels, a lack of human, financial, and legal governing resources, and limited individual policy actors' understanding of climate change and its impacts. These are mostly manifested at district and community level, but the very nature of the hierarchical system means that many of the constraints are shared across the different levels of the governance system.

The nature and design of institutional arrangements determine both the manoeuvring space and policy capacity of civil servants working on adaptation. Institutions are therefore portrayed as playing a crucial role in CCA processes (Dovers \& Hezri, 2010). Our study shows that in Vietnam the 
institutionalized collaboration between national and local levels for implementing CCA currently is problematic. Especially considering that there is no coordinative mechanism amongst the agencies. Consequently, some responsibilities may be either taken up by more than one agency or overlooked altogether because each agency assumes another one is responsible. Although some would argue that this opens up the possibility for polycentric governance to emerge (Jordan et al., 2015) in hierarchical governance systems this tends to lead to policy paralysis where no policy actor is feeling responsible to take action. Whilst this void is sometimes filled by non-governmental organizations, this remains a patchy and ad-hoc answer to a structural and systemic institutional problem.

Our findings contribute to the ongoing debates about the pros and cons of institutional hierarchies (McNeeley, 2012) or complex and inflexible institutional frameworks (Craig, 2010) which are said to reduce adaptive capacity and exacerbate vulnerability to climate change (Ahammad, 2011). Studies show that the bureaucratic characteristics in hierarchical systems constrain the ability of managers and staff to develop plans and projects that cross agency jurisdictions (Rutherford, 2005; Thomas, 2003). Recent changes of institutions and organizational structures towards more flexible and robust systems allow for more efficient CCA governance, as can be observed in countries like the Netherlands (Ward et al., 2013), Finland (Juhola \& Westerhoff, 2011), or Canada (Burch, 2010b). Authors have argued that a flexible institutional arrangement and organizational structure is needed to deal with the complex contextual conditions and combination top-down and bottom-up approach. Whilst we agree with the general line of reasoning, studies in public administration show that routinized practices and traditions are not easily changed, let alone transformed. Although the governing system in Vietnam is clearly opening-up there is still a long way to go before fundamental changes in the institutional system can be expected. This means that governance arrangements specifically for adaptation need to be aligned to the administrative traditions of Vietnam to prevent institutional misfits that lead to inefficiencies and ineffective policy processes on adaptation.

One of the most important policy approaches that plays a crucial role in CCA in agriculture in Vietnam is the mainstreaming strategy adopted in the so-called 'socio-economic development plans' (SEDPs). Reported benefits from the SEDPs at local levels include the increased coherence among policies and the reduced chances of duplication and policies that contradict each other (Rauken et al., 2015). These benefits of the mainstreaming are recognized by Vietnamese government (Knaepen, 2014), but how to do so still needs to be determined. Importantly, vertical forms of mainstreaming without interactions between different administrative levels may prove to be insufficient in the long-term. Addressing this requires reforms of the CCA organizational structure and associated institutions to help accelerate and deepen the development of the policy capacity needed to implement CCA at local levels.

The two other components of policy capacity - governing resources and policy analytical capacity - are directly influenced by the limitations of the institutional setting. We find that it is not necessarily the amount of money that is a constraint, but rather the way in which the money is allocated for developing and implementing CCA at local levels. In line with the work of Burch we argue that finding more financial resources is not more important than facilitating the effective use of existing resources (Burch, 2010b). In addition, the analytical capacity of civil servants plays decisive roles in performing key functions in policy processes (Brown et al., 2010; Sietz et al., 2011). This capacity was found to be limited at the local levels as no clear institutional arrangements have been made to enable civil servants to build such capacity. Existing training programs have yet to allow for learning, transferring and co-creating knowledge about CCA by policy actors and local farmers. This is in line with an earlier study that demonstrates that smallholder farmers in this region perceived their key constraints predominantly as a lack of information on climate change characteristics and CCA strategies (Phuong et al., 2017).

Understanding the interactions of the three dimensions of policy capacity that enable and constrain policy actors at different levels of government is important to consider when designing policy interventions to overcome some of these constraints. It requires comprehensive assessment that aims to understand the intricacy of the different causes that constrain CCA (Biesbroek et al., 2015). A key recommendation is, therefore, to enhance local policy capacities in Vietnam by establishing a clear legal mandate for adaptation that makes it a primary concern instead of a criterion to be considered in SEDPs. Addressing this main cause would already address many related barriers, including those related to accountability and coordination. Educating and enhancing knowledge and skills for agricultural staff at local levels will be crucial to further advance local adaptations, but this will require institutional 
mandates. Finally, it is important to consider the hierarchical context in which these processes take place. Solutions such as governance system transformations are not likely to emerge anytime soon nor will they be driven by climate change. Designing new institutions, building governance resources and increasing policy analytical capacity should therefore consider the existing hierarchical governing system.

\subsection{Conclusion}

This paper investigated how different levels of government enable or constrain the process of building adaptive capacity and social learning of smallholder farmers to adapt to impacts of climate change in a hierarchical governance system. We conclude that in Vietnam, the current hierarchical multilevel governance setting enables implementing CCA at national level but it creates several interdependent constraints at local levels. Whilst several constraints have been reported by policy actors, we find that the institutional setting and lacking legal mandatory are crucial to explain current progress on CCA in Vietnam across different administrative levels. Creating a social learning environment and increase adaptive capacity of smallholder farmers therefore does not only require investing in farmers, but also in the policy capacity of local governments to ensure the uptake and diffusion of CCA experiences across levels and scales. This requires overcoming institutional, resource, and policy analytical capacity constraints and to some extent accepting that the hierarchical governing system in Vietnam has both advantages and disadvantages for governing CCA.

\section{Acknowledgement}

This research is funded through the Nuffic project (NICHE/VNM/105). We acknowledge the helpful support by the staff in Department of Agriculture and Rural Development in Quang Dien district. We especially thank Mr Tan and $\mathrm{Mr}$ Lanh who supported us during data collection in community. We would like to thank the supporting of staff in Ministry of Natural Resource and Management, Ministry of Agriculture and Rural Development, National Agricultural Extension Centre, Thua Thien Hue provincial authorities, Quang Dien district authorities, and Quang Loi commune authorities, their staff, agricultural cooperatives and all farmers who provide invaluable information for this research.

\section{Chapter 6 General conclusions and reflections}




\subsection{Introduction}

This dissertation is borne out of the concern that climate change is fundamentally impacting vulnerable groups in society that are hardly to blame for what they are now facing. Smallholder farmers in rural areas are among those groups (Harvey et al., 2014). Although there is exponentially growing attention from all corners (e.g. scientific community, governments, the private sector and civil society organizations) there is no comprehensive and coordinated response to help increase the adaptive capacity of smallholder farmers to respond to climate change. Social learning emerges as a promising mechanism that is expected to work well in contexts where multi-stakeholder groups need to work together in order to respond to wicked problems that are characterized by complexity, ambiguity and uncertainty. However, as I have argued in chapter 1 , most of the evidence showing that social learning indeed works well is lacking and where it exists evidence tends to be anecdotal. Furthermore, little is known about the relationship between social learning and adaptive capacity building in the context of hierarchical governance systems.

Starting from the above observations, this dissertation conceptualized climate change as a wicked problem that, by definition, is hard to solve permanently. The central aim of this thesis was therefore to elicit and explore the ways through which social learning can increase the adaptive capacity of smallholder farmers in central coastal Vietnam to respond to climate change impacts. To address this aim four research questions were formulated:

RQ1 - What insights does the existing body of climate change adaptation literature provide into the interplay between social learning and adaptive capacity?

RQ2 - What do smallholder farmers in Vietnam perceive as their current adaptive capacity and what enables or constrains them in increasing it?

RQ3 - How can social learning configurations strengthen the adaptive capacity of farming communities?

RQ4 - How do different levels of government enable and constrain the process of building adaptive capacity and social learning of smallholder farmers to respond to the impacts of climate change in Vietnam?

By adopting pragmatism and eclecticism as methodological perspectives, I designed an explorative research project that adopted multiple methods to address these questions. The research started with a systematic literature review of the various conceptualizations of the interplay between social learning and adaptive capacity in the context of climate change (RQ1). Subsequently three empirical chapters of this dissertation addressed RQs 2, 3, and 4 .

This chapter is structured as follows. Section 6.2 will provide answers to each of these questions and how these answers help realize the central aim of this dissertation. Following from the ambition to also re-visit and influence the theoretical underpinnings of this research, section 6.3 reflects on the main contributions of this dissertation to current academic literature. Section 6.4 critically reflects on the research methodology used in the dissertation. Section 6.5 provides some directions for future research. Section 6.6 offers recommendations for shaping future climate change adaptation policies. This chapter ends with section 6.7 where I draw the overall conclusions.

\subsection{Synthesis of the research}

\subsubsection{The interplay between social learning and adaptive capacity}

RQ1 - What insights does the existing body of climate change adaptation literature provide into the interplay between social learning and adaptive capacity?

To understand the mechanisms needed for developing the adaptive capacity of smallholder farmers to respond adequately to climate change impacts, it was necessary to first critically examine the interplay between social learning and adaptive capacity on the one hand and to identify the conditions that favour a particular type of interplay, on the other. Chapter 2 addressed RQ1 by reviewing the fragmented literature on this interplay. The main finding of the review is the emergence of three distinct conceptualizations of interplay between social learning and adaptive capacity: 1) adaptive capacity-focused perspective, 2) social learning perspective, and 3) hybrid perspective.

First, the adaptive capacity-focused perspective emphasizes the process of increasing adaptive capacity by developing social learning processes. This perspective seems most appropriate in developing or low-income countries where people have limited adaptive capacity to respond to climate change impacts. Second, the social learning-focused perspective emphasizes that adaptive capacity is one of the conditions for enabling social learning to take place. This perspective seems most appropriate in situations where individuals or communities have enough adaptive capacity but where climate change 
governance or institutions are weak. Third, the hybrid perspective emphasises the interdependency between social learning and adaptive capacity. This mode seems most appropriate in cases in which climate change adaptation is already implemented, particularly in polycentric systems. Understanding these three perspectives of interplay has significant consequences for the design of learning-based interventions and for the identification of appropriate intervention strategies in a particular context.

My research shows that developing adaptive capacity of smallholder farmers to respond to climate change impacts is closely connected to the social learning process. The climate change literature can be characterized as adhering to a dominant optimistic understanding of social learning as a main factor and problem-solving mechanism for complex problems (Ha et al., 2016; PahlWostl, 2009; Rodela, 2013; Shaw \& Kristjanson, 2014). However, when using social learning as an approach to improve adaptive capacity it is critical to examine how the social and political context determines patterns of power, authority, accountability, stakeholder participation and policy coherence (Ensor \& Harvey, 2015; Ensor et al., 2015). In chapter 2 it was argued that planned adaptations should therefore focus on developing social learning to increase and engage stakeholder participation to increase adaptive capacity, particularly in low income countries. Chapters $4 \& 5$ provided some evidence of the benefits of applying a comprehensive social learning configuration and understanding barriers and enablers of climate change governance. These findings strengthen the need for an integrated frame for understanding the current and future adaptive capacity and is critical for designing, implementing, and evaluating context sensitive social learning configuration to increase the adaptive capacity of smallholder farmers in the context of climate change.

\subsubsection{Understanding smallholder farmers' capacity to respond to climate change impact}

RQ2 - What do smallholder farmers in Vietnam perceive as their current adaptive capacity and what enables or constrains them in increasing it?

Chapter 3 addressed RQ2 following the model developed by Grothmann and Patt (2005), combined with three critical important determinants of adaptive capacity (capacity to learn, decision, and act) (Bettini et al., 2015) and bearing in mind farmers' needs to cope with climate change impacts. The research revealed that farmers' in the Thua Thien Hue region perceive an increase in extreme climate variability in the past years which seriously impacts the agricultural production of farming communities. Several adaptation measures are already applied both in crop and livestock production; however these measures mainly consist of autonomous shortterm adaptation measures without considering long term consequences. Farmers adopt these adaptation measures because they are familiar with crop production techniques and because they need to respond to changes in market prices for livestock production. There are several constraints to adopt adaptation measures that farmers identify: market price fluctuations, lack of skilled labour, and lack of climate change information and limited capacity to learn and to apply techniques in practice. These constraints impact the motivation of farmers to learn and prevent them from applying adaptation strategies that can help increase their adaptive capacity to respond to climate change impacts. Surveyed farmers therefore expressed that they lack the adaptive capacity needed to address climate change issues in agricultural production.

These findings confirm empirically the findings from the systematic review by Berrang-Ford et al. (2011) that adaptation measures in developing countries are characterized by so-called "reactive adaptations". Most adaptation measures of smallholder farmers in this study are adopted at the individual level as the involvement of government stakeholders is rather weak. Farmers' willingness to adapt to climate change depended mainly on their economic interests and the quality of their social networks (Below et al., 2010). Opportunities in the local market was found in other studies as a key driver of change in agriculture in developing countries (Ojha et al., 2014). This is in line with my findings in chapter 3 that farmers' motivations predominantly promote adaptation strategies that not only deal with climate change, but also with changes in the market prices and household related economic conditions. This also corresponds with several previous studies in developing countries that show that generating a stable income from agricultural production can enable households to accept risks that might be associated with adopting adaptation strategies (Asfaw et al., 2016; Panda et al., 2013; Tambo \& Abdoulaye, 2013).

Chapters 2 \& 3 suggest that developing and implementing adaptation strategies focusing on only climate change are not enough to motivate learning, adopting, and upscaling these strategies and to develop farmers' 
adaptive capacity in Vietnam. Knowledge of climate change impacts and possible adaptation strategies is important because planned adaptation efforts can build upon this knowledge which is critical to systematically remove constraints and create an enabling environment to facilitate autonomous and/or planned adaptation (Burnham \& Ma, 2016). Interventions to increase adaptive capacity of smallholder farmers should therefore encourage the formal and informal social networks to be more involved in promoting discussions on climate change in the community.

Hence, the design and implementation of a social learning configuration should consider various forms of participation of stakeholders in the different phases as well as the contextual factors and needs. As far as the latter is concerned, especially the market conditions are critically important in the adoption of adaptation strategies that can reduce the impact of climate change on agricultural activities (chapter 4). Overall, I found that increasing adaptive capacity of smallholder farmers via social learning configurations can improve interactions with the (local) government and other stakeholder groups, and that this, in turn, can help improve the quality of social learning.

Considering the results from chapter 2 , the findings of chapter 3 research also suggest that in order to increase the adaptive capacity of smallholder farmers, a comprehensive social learning configuration is needed (see chapter 4).

\subsubsection{Increasing smallholder farmers' adaptive capacity to respond to climate change}

RQ3 - How can social learning configurations strengthen the adaptive capacity of farming communities?

The third question concerns value of social learning configuration based interventions in addressing the climate change-related problems local smallholder farmers in Central Vietnam are facing. Chapter 4 addressed this question explicitly by applying a social learning configuration through several workshops. The findings from this chapter show that a social learning-based configuration can contribute to enhanced relationships and social cohesion, utilization of different perspectives, improved systems thinking, initiation of new knowledge, and optimization of existing actions in the farming community. All these outcomes are considered valuable for developing farmers' adaptive capacity.
The application of a social learning-based intervention in an attempt to increase the adaptive capacity of smallholder farmers also unveiled and confirmed some of the major constraints for developing adaptation strategies that have also been reported elsewhere (Antwi-Agyei et al., 2015; Biesbroek et al., 2013). The findings also demonstrated several principles to create an appropriate social learning configuration that can help increase adaptive capacity of smallholder farmers; integral design as opposed to sectoral design, multi-stakeholder negotiation as opposed to consensus seeking, and continual learning as opposed to ad-hoc training. In addition, diversification of stakeholders is also considered an important principle of implementing social learning configurations successfully in practice. This has been reported elsewhere as well (Aytur et al., 2015; Wibeck, 2014).

In chapter 4 it became clear that although working with these guiding principles is important, it is certainly not enough. Researchers and facilitators (e.g. extension workers) also need to adjust their roles within the interventions and enhance their own policy capacity. Local governments and farmers' organizations as well as their institutions are critical in facilitating multistakeholder learning (Spielman et al., 2009), enhancing adaptive capacity in communities (Rodima-Taylor, 2012; Sterrett, 2011), and implementing or strengthening the adaptive strategies used (Eriksen \& Selboe, 2012). The findings of this chapter showed that the adjustments in institutions and participation of agricultural departments at different levels and in agricultural cooperatives at the local level can contribute to the effectiveness of the social learning configuration, improve farmers' adaptive capacity, and upscale adaptation measures beyond the farming community. This finding supports the findings of chapter 2 that from an adaptive capacity-focused perspective, it is vital that trust and relationships are recognised as critically important factors for designing and implementing social learning configurations. In addition, in a hierarchical governance system, as can be found in Vietnam, a social learningbased intervention should not just focus on the farmers but also on institutional innovation and multilevel governance. This also emerged from the analysis of barriers and enablers to climate change adaptation (chapter 5), which showed that the roles of the institutional setting and legal mandates are important for creating space for social learning and adaptive capacity building but, although not investigated here, it is likely that this may also work the other way around: improved social learning and adaptive capacity can enable institutional innovation and improve multilevel governance. 


\subsubsection{Barriers and enablers to climate change adaptation of hierarchical} governance system

RQ4 - How do different levels of government enable and constrain the process of building adaptive capacity and social learning of smallholder farmers to respond to the impacts of climate change in Vietnam?

Building on the observation in chapters 2 and 3 of the importance of governments in social learning and adaptation, the fourth research question aims to unravel the constraining and enabling factors of different levels of governments in building adaptive capacity and strengthening social learning among smallholder farmers to respond to climate change impacts. This question builds on but goes beyond the social learning configuration principles for increasing adaptive capacity (chapter 4). Applying the multilevel governance perspective, this question considered the policy capacity governments have to help farmers to adapt: institutional characteristics, governing resources, and policy analytical capacity of civil servants. In chapter 5, I show that although overall climate change adaptation governance in a hierarchical system create enablers in implementing adaptation strategies at national level, substantive policy capacity remains limited, particular due to a lack of institutional backing and the absence of a legal mandate at local levels.

Governmental institutions play a crucial role in enhancing the capacity of local communities to cope with climate vulnerability and providing mechanisms that help shape the interactions between society and the state (Burch, 2010a; Sietz et al., 2011). Therefore, social learning is not only important for increasing adaptive capacity of smallholder farmers, but could also remove constraints and create catalytic enablers of climate change governance in a hierarchical governmental system (chapters $2 \& 4$ ). There are currently major changes in the Vietnamese society, mainly as a result of economic globalization and digitalisation, but also as result of climate change impacts that call for a rethinking of government structures and policies (Christoplos et al., 2017). What is lacking within this new dynamic are adequate mechanisms that allow for collaboration between different types of actors and sectors as well as across spatial and temporal levels of governments in Vietnam. This re-affirms the observation made in chapter 1 that it is not easy to develop effective climate change adaptation governance in a hierarchical governmental system characterised by traditional systems, centralised structures and rigid bureaucracies. It seems that the push for learning-based approaches, such as social learning, that seek to link both different levels of government and different stakeholders, can increase the adaptive capacity of participants at project level, but not at the *inter)organisational and institutional level while the latter is needed for dealing with climate change impact more systemically. In order to upscale adaptation strategies and maintain continual learning, governance structures at each level and between different levels of government require some transformations too (Nyanga et al., 2011).

\subsubsection{Answering the main question}

How does social learning increase the adaptive capacity of smallholder farmers in Vietnam to respond to climate change impacts?

Taken together, the framing intervention (chapter 2), the analysis of smallholder farmers' adaptive capacity (chapter 3 ), the social learning configuration (chapter 4), and the study of policy capacity in hierarchical government system (chapter 5 ) results in a mixed view of how social learning can increase adaptive capacity to respond to climate change impacts. Although all these chapters combined illustrate that, in principle, a well-designed social learning configuration can be very useful for increasing the adaptive capacity of smallholder farmers, they also show that focusing on the capacity of individual farmers alone is not enough for responding to climate change impacts. An effective learning-based response to climate change is only possible when the policy capacity of multilevel governments is increased simultaneously. This demands particularly that attention is paid to enhancing roles and responsibilities of the local government. This is critical as it provides smallholder farmers with the support needed to improve their technical, social, human, and market conditions to implement autonomous and planned adaptation strategies. This is synthesized in figure 6.1 .

Summing up, the main findings of chapters $2 \& 4$ show that social learning can be useful in dealing with the wicked nature of climate change impacts. In the context of developing countries as Vietnam where smallholder farmers have low adaptive capacity, the findings of chapters $2 \& 4$ also reveal that, although the main components of social learning are crucial, they are not sufficient to ensure sustainable climate change adaptation. Additional institutional changes are needed as well. Mytelka et al. (2001) argue that such changes or innovations must be seen as the joint outcome of interaction among individual decision-makers, sociocultural context, institutional frameworks, regulatory systems and other conditions. In the context of a hierarchical government 
system, the changes or innovations in institutions is difficult and generally happen very slowly. The combined findings of chapters $2,4, \& 5$ suggest that creating an environment conducive to developing social learning and building adaptive capacity requires clear legal mandates, available financing for implementing policies, and training of governmental staff, particularly at local levels. This dissertation shows that institutions and governance processes can become catalysts for creating a generative social learning environment that allows for implementing different types of social learning configurations. This creates favourable conditions for increasing adaptive capacity for both smallholder farmers and civil servants.

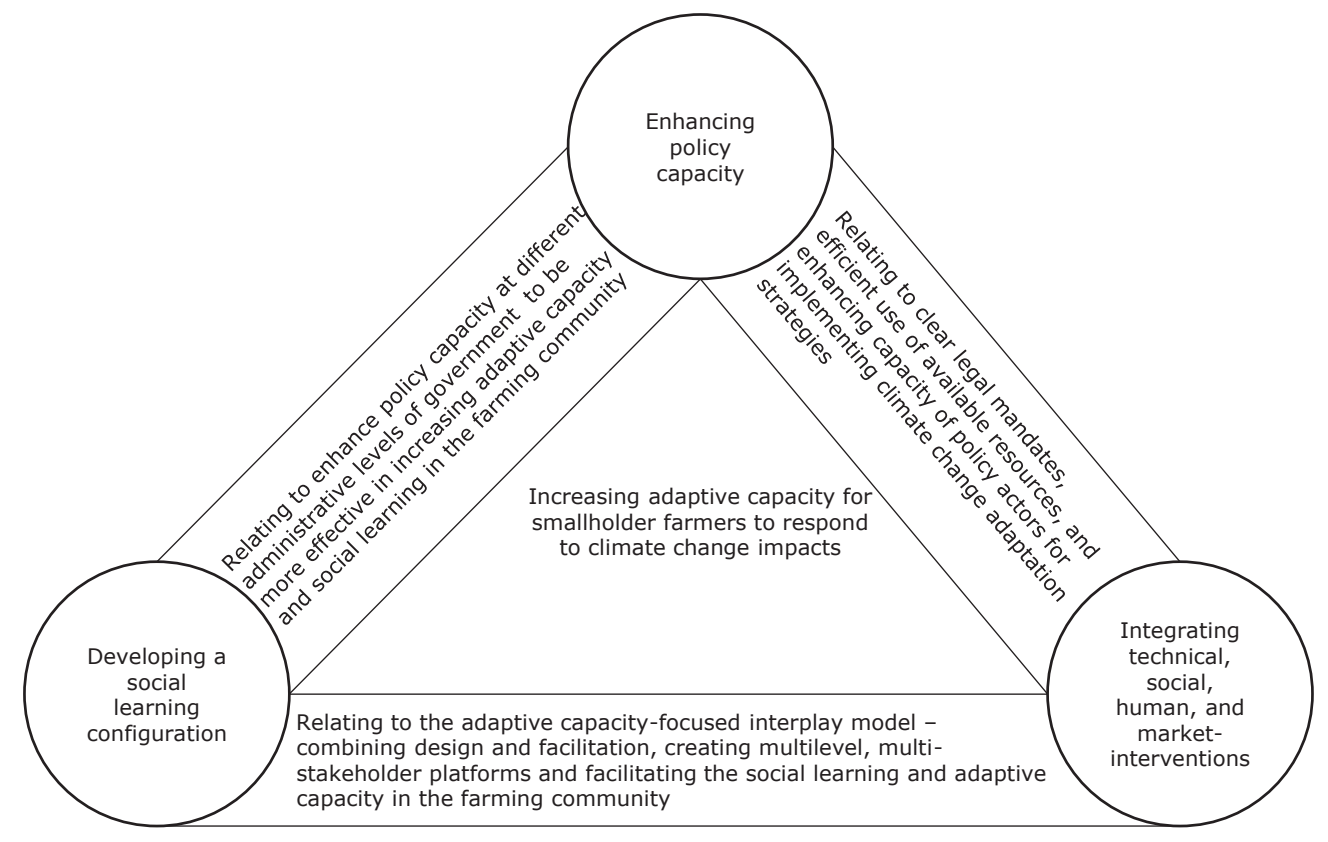

Figure 6.1. Increasing adaptive capacity for smallholder farmers to respond to climate change

At the same time, it was shown that the current implementation of adaptation measures in agricultural production to respond to climate change impacts depends on several factors. This leads to the more general question of why, although climate change adaptation concerns were pervasive and interventions were developed to address climate change impacts, the adaptive capacity of smallholder farmers remains limited. The research findings suggest that in addition to investing in smallholder farmer-orientated learning it is necessary to also invest in policy capacity to increase the ability of governments to facilitate and upscale learning processes and improve non-climate related conditions, such as local markets.

Agricultural adaptation to climate change emerges both at micro and macrolevels (Bhatta et al., 2017; Christoplos et al., 2017). The insights of chapters 3 $\& 5$ reveal differences in the barriers perceived by farmers and government to increase adaptive capacity and create a generative social learning environment. The main reason for this appears to be the disconnect between levels; on the one hand smallholder farmers and local institutions apply adaptation strategies, and on the other hand the formulation of climate change adaptation policy by the government, NGOs or private institutions at higher levels (Clemens et al., 2016). These two are hardly in sync. Eliciting farmers' understanding of the barriers created by government and of how government itself perceives and recognizes these barriers, is a critical step in overcoming these barriers and creating enabling conditions for dealing with climate change impacts in vulnerable rural communities. Better understanding of the societystate dynamics therefore, is a prerequisite to support farmers to adapt to climate change.

\subsection{Theoretical contributions}

Theoretically this dissertation contributes to the development of an innovative framework to develop adaptive capacity via social learning to respond to climate change impacts. Although some previous empirical studies showed a link between social learning and adaptive capacity already (e.g. Fazey et al., 2007; Leys \& Vanclay, 2011; Shaw \& Kristjanson, 2014; Yuen et al., 2013), this was rather fragmented and understudied. Previous research hardly focussed on the development of adaptive capacity through social learning for implementing climate change adaptation strategies, particularly in the context of smallholder farmers operating in developing countries. The three conceptualizations of the interplay between social learning and adaptive capacity described in chapter 2 provide the building blocks for such a comprehensive framework to help understand the asynchronous and multifaceted learning and capacity-building process that can increase community level adaptive capacity. Social learning plays varying roles in increasing adaptive capacity in the context of responding to climate change, but there are three constitutive elements: 1) the relationships between and level of engagement of stakeholders; 2) the design and facilitation of the learning 
configuration, and 3) the adaptability of the configuration by the agricultural institutions. The framework provides a tool for systematically building adaptive capacity by smallholder farmers.

In addition, the framework can help map the motivation of the stakeholders involved and the factors that influence community based adaptation. Most of the existing capacity frameworks and approaches used to study adaptive capacity focus on the five livelihood capacities (human, social, financial, physical, and natural capital) (see for instance: Jones et al., 2010; Tinch et al., 2015; Warrick et al., 2017), or on other capacities to reduce vulnerability or increase resilience of individuals and the community (Engle, 2011; Gallopín, 2006; Smit \& Wandel, 2006). However, these frameworks have concentrated on generic capacities, while in the context of climate change adaptation, the specific capacities are also important but are poorly understood (Eakin et al., 2014). Other frameworks to analyse adaptive capacity at the local level, particularly for smallholder farmers, are based on the MPPACC model developed by Grothman and Patt (2005). These frameworks seem more tailored to use in the context of smallholder farmers, but so far have not been implemented frequently. Chapters $3 \& 4$ contribute to this body of literature by implicitly and explicitly considering the motivations of smallholder farmers for engaging in decision-making and adopting adaptation strategies and by proposing the development of specific capacities.

This dissertation also contributes to theories on social learning in the context of climate change adaptation. There are some early scholarly debates around the design of social learning configurations in order to help in increasing the adaptive capacity needed to implement adaptation strategies (e.g. Bardsley, 2015; Clemens et al., 2016; Ensor \& Harvey, 2015; McCrum et al., 2009; Pelling et al., 2008). But these studies have not looked comprehensively at how to create and evaluate social learning configurations (Bartels et al., 2013; Bloch et al., 2016; Cooper \& Wheeler, 2015; Mapfumo et al., 2013; Mishra et al., 2013). For example, some studies lack a clear link between the design and evaluation phase of a social learning configuration and some studies are lacking an upscaling phase. This research shows that an effective social learning configuration must include, a responsive design, implementation, and evaluation component. Multiple actors need to be involved in the design of these components. Furthermore, the research in chapter 4 shows that an effective social learning configuration in the context of vulnerable rural coastal Vietnam communities must consider the interface between climatic, socio- economic conditions, market drivers, and institutional and policy frameworks. In addition, creating a 'dialogical space' that also takes into account the sociohistorical context of a community is important to facilitate the co-creation with different stakeholders in the different phases of a social learning configuration. As shown in chapter 4 , this can help increase participation and motivation of different stakeholders.

A final theoretical contribution of this dissertation is that a focus on policy capacity is important to consider in the context of designing and implementing a social learning configuration. In climate change adaptation literature, the main constraints in realizing adequate climate change governance are related to the institutional and social dimension of adaptation as well as to a lack of information and resources (Biesbroek et al., 2013; Measham et al., 2011). Several previous studies have looked at barriers related to policies and legal requirements as factors which can either be constraining or enabling adaptation actions (Amundsen et al., 2010; Juhola, 2016; Rantala et al., 2014). In addition, most existing frameworks and approaches for analysing climate change adaptation governance in hierarchical systems focus solely on barriers and therefore it is difficult to identify the potential of a governance system's overall capability to govern climate change (Ahammad, 2011; AntwiAgyei et al., 2015; Kithiia, 2011; Koch et al., 2007; Lebel et al., 2011). So far, no policy capacity studies have looked at the policy capacity for climate change adaptation in developing countries. Chapter 5 underlines both the enablers and constraints created by the hierarchical multilevel governance setting of Vietnam for community based adaptation. I have discussed the constraints and enablers in terms of their institutional characteristics, governing resources, and the policy analytical capacity of civil servants. Major constraints that were found in this study were the unclear institutional setting and lack of a legal mandate. These constraints differ from those identified in previous studies, that have emphasized the need for developing elements of 'soft' policy capacity, rather 'hard' policy capacity (i.e. laws and regulations). Understanding the constraints and enablers of multilevel governance in climate change adaptation can also provide indications for evaluating the effectiveness of different levels of government agencies in responding to climate change impacts. Insights gained from this dissertation can be useful in building adaptive capacity for policy workers who are considered instrumental in improving the decision-making functions in government agencies (Wellstead et al., 2011) 


\subsection{Methodological reflections}

\subsubsection{Reflecting on the exploratory approach design and the multiple} methods

Given the context and the multiple perspectives I adopted in this dissertation, I have used a mixed methods research design that is sensitive to the various ways of studying social learning and adaptive capacity. Following the perspectives of pragmatism and eclecticism, different theoretical strands and methods of design and analysis were implemented. I started with the assumption that the validity of this dissertation was increased by inviting, when feasible, smallholder farmers and governmental actors for feedback on my interpretations of the findings and adjusting them when needed. I also assumed that the learning process underlying the development of agricultural production brought to light in this dissertation, must be understood as a workrelated and situated phenomenon. This means that farmers' learning is embedded in daily practices. In this dissertation, I selected an exploratory approach to design the social learning configuration and used multiple methods to collect data and analyse social learning and adaptive capacity in the context of climate change adaptation. In this section I look back on the main research strategies used which require some reflection to further increase the legitimacy of my research findings.

First, the pragmatism and eclecticism perspectives can provide meaningful insights into multidisciplinary research as they operate at the intersection of different philosophical perspectives. This dissertation ideally uses "triangulation", combining exploratory research and a multiple method research approach so as to generate more robust and trustworthy answers to the research questions. The pragmatic and eclectic perspectives suggest that we can borrow different theories and methods to better understand how to develop adaptive capacity for smallholder farmers to respond to climate change impacts. I have done so extensively in this research and ontological purists might argue that I have been too flexible in adopting different theories. However, I would argue that this has allowed me to ask the questions that were developed throughout the study and, in doing so, to provide a contribution to different theories.

Second, the choice of multiple methods for data collecting and analysing contributed to the validity of the research. It served as a triangulation tool and resulted in drawing more balanced conclusions that take different types of knowledge into account. Methods worth mentioning in this respect are (1) the systematic reviews which strongly shaped my view of how good scientific research ought to be conducted and presented, (2) the survey method which provided a comprehensive view and allowed me to diversify data sources and data analysis methods, and (3) the pilot design where several stakeholders participated in different phases and itself too was evaluated via multiple methods, increasing the confidence in the findings of my research. I have also taken several steps to increase data reliability, for example by combining indepth interviews with the experiences gained in the social learning configuration, while informal discussions with smallholder farmers allowed me to reflect more critically on the data. Though any one measure or method might be legitimately questioned in terms of its validity, reliability, or generalizability, the weight of the combined methods increases the credibility of my findings. Although there is always a chance of interpretation bias, I have taken some measures to reduce this bias. For example, I have invited surveyed participants, particularly agricultural staff and local authorities, to participate in a feedback session where the survey results were presented and discussed with the participants. Triangulation of data proved challenging at times, as time constraints, the discontinuities in my personal life - having to juggle multiple roles in professional and personal life, but also being in Vietnam and in The Netherlands - made going back to the community, mirroring/checking of findings, and paying equal amounts of attention to different stakeholders and to the different administrative levels, sometimes was difficult.

Third, adopting the exploratory design allowed me to follow where the research findings led me. New empirical insights on how social learning builds adaptive capacity of smallholder farmers informed the next research steps. My exploratory design allowed me to build upon the insights or results from previous findings. For example, the findings of chapter 2 provided both the theoretical inputs and findings of chapter 3 but also provided the input for designing the configuration implemented in chapter 4 . Findings of chapters 2, 3 , and 4 confirmed the need for studying the role of the government in chapter 5. The choice of such an exploratory research design enabled identification and study of the most pressing issues. It is difficult, if not impossible, to adopt an explanatory, evaluative, or other type of research design to study a phenomenon about which so little initial knowledge exists. There needs to be some flexibility to accommodate for unexpected insights and to make them 
functional to the research. An exploratory design in a sense requires that the researcher him or herself has the capacity to adapt the research to what emerges. In my research, the focus successively shifted from increasing adaptive capacity to respond to climate change impacts of smallholder farmers, to the ability to address the wickedness of climate change via a social learning configuration, to the actual levels of building adaptive capacity across different levels of government. This adaptive and eclectic approach meant that I identified the direction and key steps for the research process, without knowing the details in advance.

Four, I have developed a specific type of intervention as well as a mechanism to evaluate the process and outcomes of the intervention. There are two main points of reflection I wish to share here. First, trust and a good relationship between interviewers, researchers, extension workers, policy workers, and respondents, is needed to ensure successful implementation of this type of research. By focusing on one case region, I was able to gain trust and get detailed information that would not have been possible if I conducted this study at multiple sites where I would have had to spread my personal attention over too many people. To gain this trust and build the relationship in the community, it helps when a researcher is actively involved in sharing their knowledge and experiences about climate change and climate change adaptation in agricultural sector through local community activities, e.g. during informal meetings, farm visit, pilot demonstrations, community-based organization meetings or agricultural cooperative meetings. Second it is critical to establish a core group with local stakeholders early on in the research. These stakeholders participated throughout all steps of the research, and have proven to be very important in identifying and supporting interviewers, researchers, extension workers, and policy workers and in building the trust and relationships needed to increase adaptive capacity of smallholder farmers in the community to respond to climate change impacts. In a way the design of the research can positively influence the phenomena under investigation which gives the research a kind of pedagogical aim: it seeks not to just extract data from a community to generate findings to be published in a peer-reviewed journal, it also seeks to provide some immediate benefit to those involved.

\subsubsection{Limitations of methodology}

Despite the methodological considerations and limitations mentioned in each chapter, some overarching dissertation limitations should be considered that can also guide future research. The first limitation is that the social learning configuration discussed in chapters 3-5 has been tested in only one case area. This makes it difficult to upscale the findings, particularly given that Vietnam is diverse in its culture, geography, climate, and its agricultural production systems. For example, the surveys conducted in chapters 3 and 5 to understand farmers' adaptive capacity and to explore the barriers and enablers in the hierarchical multilevel governance setting, focussed on data collection across different administrative levels focussed only on one province, district and commune. Another example is that the empirical chapters focused on farming communities in the coastal areas of Vietnam. However, the diversity across Vietnam means that the findings are not representative for all household groups and farming communities in Vietnam. To generalize and upscale the findings requires further testing of different social learning configurations in different farming communities and regions in Vietnam. This will allow for stronger claims about the scientific and practical value of the social learning configuration compared to the learning configuration used in this dissertation. This is not to say that this research does not have relevance for other contexts. It can still have impact elsewhere as the case holds elements that will likely speak to other situations, but exactly what these elements are will depend on what those working in other situations draw from this research. This research cannot authoritatively and confidently prescribe what is relevant and how it could be used elsewhere but could sensitize others to what might be relevant, what might matter and what one might do, bearing in mind the unique features of their own case. Wals \& Alblas (1997) refer to this as "case-inspired self-generalization".

The second limitation is that studying the social learning outcomes and influencing adaptive capacity through a social learning configuration was only conducted at one moment in time (chapters $3 \& 4$ ). Although I have taken a somewhat longitudinal perspective in chapter 4 to evaluate the social learning configuration, most of this dissertation's insights are based on "snapshots" gained through interviews and survey data. This can be problematic in researching social learning according to Eraut (2004). Most respondents see learning not as something related to their work environment but rather occurring in other more formal educational/learning settings such as in courses and trainings. Adopting new techniques and learning are thus often seen as separate activities by farmers. These challenges were taken into account in the design of the projects on which this dissertation draws. However, due to the above reasons, this research was constrained in time and resources preventing a truly longitudinal perspective which would have allowed it to assess, for 
example, how the social learning configuration implemented in chapter 4 actually altered practices of farmers to respond to climate change. Although I attempted to partly overcome this by observing and exploring the learning process as well as discussing learning with the respondents, it was still found to be quite difficult to make inferences based on the findings.

\subsection{Directions for future research}

For each of the chapters in this dissertation I made specific suggestions for future research. Based on these findings, this section reflects on the overarching directions for further research.

First, the most obvious recommendation is to conduct more comparative studies that could provide further insights into whether the social learning configuration designed and implemented in this dissertation could also be applied to other farming communities or household groups in different regions in Vietnam, or perhaps other countries. Further empirical testing of the social learning configuration could refine the different phases and conditions to support successful and sustainable learning processes and allow us to compare insights across different contexts. This would increase our understanding of the value of the configuration, not only in terms of its empirical contribution but also in terms of advancing theories on social learning and adaptive capacity, and enabling new interventions in climate change adaptation policies and governance. This could be combined with longitudinal research to generate an even better understanding of how the social learning process proceeds and how it influences farm-level production and increases adaptive capacity over longer periods of time.

Second, and linked to the above, the findings of this research are based on a single case region. I argue that a large-n study that combines quantitative and qualitative research would allow to test and compare more cases in different contexts to better understand adaptive capacity (chapter 3 ) as well as barriers and enablers of climate change adaptation in the hierarchical governance system of Vietnam (chapter 5). By increasing number of survey respondents and cases, it would allow for a more advanced statistical analysis in search for other possible explanatory variables than identified in this study. Using quantitative and large-n comparative studies would be a valuable approach, for example, to investigate the meaning farmers attribute to their adaptive capacity and the barriers and enablers they experience in practice and how this influences their actions.
Third, in order to extend and support the process of implementing climate change adaptation strategies, future studies could focus more explicitly on the relation between the policy capacity for climate change adaptation governance and adaptive capacity for smallholder farmers. As noted in chapters $4 \& 5$, it would be useful to extend social interventions and upscale social learning if there are strong connections of both supply and demand between the state and the society to start this learning. The findings of chapter 4 provided the initial evidence that suggested the need for adjusting policy capacity of governmental institutions and policy staff as this influences the process of implementing measures to adapt to climate change impacts. However, whether increasing policy capacity for climate change adaptation leads to an increase of adaptive capacity of smallholder farmers to respond to climate change impacts remains to be explored further.

Fourth and finally, further research could consider the influence of market conditions and how stable market access increases the social learning process and the adaptive capacity of smallholder farmers. The survey (chapter 3 ) and pilot design (chapter 4) indicated that market conditions critically influenced farmers' motivations to consider adopting adaptation measures. However, it remains to be explored whether and under which conditions increased to access markets could result in better social learning outcomes and increased adaptive capacity for smallholder farmers.

\subsection{Policy implications and recommendations}

Although the findings of this dissertation cannot be easily generalised due to the nature of the research design, I argue that there are some findings which can be applied on broader scale.

Despite their contextual specificities, the core elements of the social learning process brought to light in this dissertation can have positive implications for supporting climate change adaptation. My dissertation suggests that regardless of its specific context, the development of social learning involves similar processes, including the development of new identities and processes of social participation and deliberation. These insights can be used to design new social learning configurations by local governments in order to increase the adaptive capacity of smallholder farmers throughout Vietnam.

The findings of my dissertation also suggest that building smallholder farmers adaptive capacity to respond to climate change impacts should not only focus on single interventions, e.g. crop production or livestock production, but should 
aim to integrate interventions, especially combining emerging technologybased and market-oriented production of crops and livestock. This is because the motivations of farmers to participate in social learning processes are not necessarily linked to climate change but mostly to the stability of market prices of agricultural products. Future designing of new adaptation policies therefore needs to include the technical, social and human aspects, as well as economy-related market conditions that influence farmers' engagement in adaptation strategies. Such policy should ensure not only the dissemination of appropriate technologies but also the existence of a stable and fair market for farm products. This also requires creating the space for social learning and having examples of good practices in rural farming communities as this is found to increase their adaptive capacity.

The findings of this dissertation implicate that the roles and responsibilities of agricultural staff at local levels are very important to create learning environments as well as to increase adaptive capacity of smallholder farmers. However, the policy capacity of this staff was found to be very low. If the government wants to develop the adaptive capacity of smallholder farmers, they should not only focus on developing adaptive capacity of farmers, but also invest considerable efforts in increasing the policy capacity of agricultural staff and their departments. One important step is to make adaptation a legal responsibility and give policy makers a clear mandate for implementing climate change adaptation policy. This is also the case for extension workers and agricultural staff who need to increase their skills in facilitating and encouraging the participation of smallholder farmers in the social learning process. Likewise, this dissertation recommends that the Vietnamese government, particularly through the Ministry of Agriculture and Rural Development develops new and flexible adaptation policies and reforms existing institutions to increase responsibilities of agricultural departments and authorities at local levels in implementing climate change adaptation. It will be of critical importance to support staff at local agricultural departments with the training needed so as to remove some barriers farmers experience and to create an enabling learning environment.

The concept of a social learning configuration and the understanding of enablers and constraints of hierarchical multilevel governance presented in this dissertation, provide a good point of reference for the government and the agricultural sector for implementing effective adaptation strategies. There are many calls to increase adaptive capacity of smallholder farmers to respond to climate change impacts in Vietnam, but until now, there have been very few efforts by agricultural institutions and staff to support farmers' learning and training for developing adaptation strategies. It is hereby suggested that as a strategy to increase the adaptive capacity of smallholder farmers in Vietnam, the government (e.g. Ministry of Natural Resource and Environment and Ministry of Agriculture and Rural Development) should consider prioritizing the human aspects of climate change adaptation in the agricultural sector: creating social learning and increasing adaptive capacity for farmers as well as building policy capacity for agricultural sector. This will be helpful in ensuring the quality of policy in supporting smallholder farmers to implement adaptation strategies.

Through the use of multiple data sources, this dissertation has demonstrated that social learning configurations can support increasing the adaptive capacity of smallholder farmers. The outcomes of the social learning configuration implemented in chapter 4 have already adjusted some institutions and practices in the agricultural departments at district and commune level

In the current framework for training and interventions of agricultura departments in Quang Dien district and Thua Thien Hue province, farmers have not participated in the design and implementation of climate change trainings and therefore face several constraints. Department of Natural Resource and Environment and Department of Agriculture and Rural Development at the provincial level should consider more explicitly that farmers are the main stakeholders in the intervention process. It is crucial therefore that the design and implementation process, outcomes of interventions, knowledge and facilitation skills of facilitators/extension workers, as well as changes in the adaptive capacity of smallholder farmers, are regularly evaluated by both governmental actors and the farmers themselves. This is critical to understand the constraints farmers experience, which in turn informs where and how to enhance policy capacity of agricultural departments.

Finally, extending and capturing learning how to adapt through implementing multiple learning configurations will be crucial to upscale the building of adaptive capacity and will be critical to transform some governmental institutions in a more emancipatory way rather than in the more traditional hierarchical way. Such deviation from the traditional ways of working might be challenging at first, but this dissertation suggests that it might significantly increase the participation of smallholder farmers in Vietnam in building their adaptive capacity. 


\subsection{Overall conclusion}

This dissertation aimed to explore and elicit the ways through which social learning can increase the adaptive capacity of smallholder farmers in central coastal areas to respond to climate change impacts. It adopted a learning perspective and an exploratory research design that included multiple methods to answer the questions. The overall conclusion of this dissertation is that social learning offers valuable openings to increase the adaptive capacity of smallholder farmers to respond to climate change impacts in developing countries, but that careful responsive design, implementation, and evaluation is necessary. It also requires a favourable and enabling institutional environment where governmental support is crucial to overcome key challenges farmers experience. An active contribution by governments will be crucial in the implementation and upscaling of the learning outcomes. Implementing climate change adaptation strategies across different levels of government and ensuring the building of adaptive capacity, requires that investments need to be made in enhancing the policy capacity at different administrative levels.

This conclusion is followed by four final remarks. First, adopting an adaptive capacity-focused perspective is most appropriate to create social learning environment and increase adaptive capacity for smallholder farmers in a developing countries context. Second, increasing adaptive capacity to adapt to climate change impacts should not only focus on technical or social and human interventions, but also consider market interventions to generate sufficient market access and fair and stable price for products. Third, context specific and well-designed social learning configurations are needed to address challenges to climate change adaptation. Several principles to create an appropriate social learning configuration include integral design, multistakeholder negotiation, and continuous learning. These configurations have much to contribute to the process of increasing adaptive capacity of smallholder farmers to implement climate change adaptation measures. Fourth, large scale implementation of such learning requires clear legal institutions, available financing for implementing policies, and the training of governmental staff, particularly at the district and commune levels where the policy capacities are generally low. Any efforts of social learning and increasing adaptive capacity for smallholder farmers should therefore include investments in policy capacity to ensure uptake and upscaling of adaptation actions in the short and long term

\section{References}

Adger, W.N. 2010. Climate change, human well-being and insecurity. New Political Economy, 15(2), 275292.

Adger, W.N., Arnell, N.W., Tompkins, E.L. 2005. Successful adaptation to climate change across scales. Global environmental change, 15(2), 77-86

Ahammad, R. 2011. Constraints of pro-poor climate change adaptation in Chittagong city. Environment and Urbanization, 23(2), 503-515.

Akpo, E., Crane, T.A., Vissoh, P.V., Tossou, R.C. 2015. Co-production of Knowledge in Multi-stakeholder Processes: Analyzing Joint Experimentation as Social Learning. The Journal of Agricultural Education and Extension, 21(4), 369-388.

Albert, C., Zimmermann, T., Knieling, J., Haaren, C.v. 2012. Social learning can benefit decision-making in landscape planning: Gartow case study on climate change adaptation, Elbe valley biosphere reserve. Landscape and Urban Planning, 105(4), 347-360.

Alcantara, C., Nelles, J. 2014. Indigenous peoples and the state in settler societies: Toward a more robust definition of multilevel governance. Publius: The Journal of Federalism, 44(1), 183-204.

Alford, J., Head, B. 2016. Wicked and less wicked problems: A typology and a contingency framework. International Research Society for Public Management 20th Annual Conference, Hong Kong, China.

Amundsen, H., Berglund, F., Westskog, H. 2010. Overcoming barriers to climate change adaptation-a question of multilevel governance? Environment and Planning C: Government and Policy, 28(2), 276-289.

Antwi-Agyei, P., Dougill, A.J., Stringer, L.C. 2015. Barriers to climate change adaptation: evidence from northeast Ghana in the context of a systematic literature review. Climate and Development, $7(4)$, 297-309.

Apata, T.G., Samuel, K., Adeola, A. 2009. Analysis of climate change perception and adaptation among arable food crop farmers in South Western Nigeria. Contributed paper prepared for presentation at the international association of agricultural economists' 2009 conference, Beijing, China, August 16.

Araos, M., Ford, J., Berrang-Ford, L., Biesbroek, R., Moser, S. 2016. Climate change adaptation planning for Global South megacities: the case of Dhaka. Journal of Environmental Policy \& Planning, 1-15.
.

Argyris, C., Schon, D.A. 1974. Theory in practice: Increasing professional effectiveness. Jossey-Bass.

Argyris, C., Schon, D.A. 1974. Theory in practice: Increasing professional effectiveness. Jossey-Bass.
Armitage, D., Berkes, F., Dale, A., Kocho-Schellenberg, E., Patton, E. 2011. Co-management and the coproduction of knowledge: Learning to adapt in Canada's Arctic. Global Environmental Change,
proment 21(3), 995-1004.

Armitage, D., Plummer, R. 2010. Adapting and transforming: governance for navigating change. in: Adaptive capacity and environmental governance, Springer, pp. 287-302.

Armitage, D.R. 2005. Community-based Narwhal management in Nunavut, Canada: Change, uncertainty, and adaptation. Society and Natural Resources, 18(8), 715-731.

Asfaw, S., McCarthy, N., Lipper, L., Arslan, A., Cattaneo, A. 2016. What determines farmers' adaptive capacity? Empirical evidence from Malawi. Food Security, 8(3), 643-664.

Asian Management and Development Institute. 2011. Climate Change and Disaster Management Policy in Viet Nam. Retrieved 28th June 2014, from Webside: http://sv.care.dk/files/RC Assessment Reports/Vietnam CAR CCWG and DMWG.pdf.

Awokuse, T.O., Xie, R. 2015. Does agriculture really matter for economic growth in developing countries? Canadian Journal of Agricultural Economics, 63(1), 77-99.

Aytur, S.A., Hecht, J.S., Kirshen, P. 2015. Aligning climate change adaptation planning with adaptive governance: Lessons from Exeter, NH. Journal of Contemporary Water Research \& Education, governance: Less

Baird, J., Plummer, R., Haug, C., Huitema, D. 2014. Learning effects of interactive decision-making processes
(1) for climate change adaptation. Global Environmental Change, 27(1), 51-63.

Bandura, A. 1977. Social learning theory Englewood Cliffs, NJ: Prentice-Hall. Mew Jersey, USA. 
Bardsley, D.K. 2015. Navigating the Roles of the Social Learning Researcher: a critical analysis of a learning approach to guide climate change adaptation. Australian Geographer, 46(1), 33-50.

Bartels, W.-L., Furman, C.A., Diehl, D.C., Royce, F.S., Dourte, D.R., Ortiz, B.V., Zierden, D.F., Irani, T.A., Fraisse, C.W., Jones, J.W. 2013. Warming up to climate change: A participatory approach to engaging with agricultural stakeholders in the Southeast US. Regional Environmental Change, 13(1), 45-55.

Bauer, A., Steurer, R. 2014. Multi-level governance of climate change adaptation through regional partnerships in Canada and England. Geoforum, 51, 121-129.

Bayard, B., Jolly, C.M., Shannon, D.A. 2007. The economics of adoption and management of alley cropping in Haiti. Journal of environmental management, 84(1), 62-70.

Beckman M.2010. Converging and conflicting interests in adaptation to environmental change in centra Vietnam. Climate and Development, 3(1), 31-41.

Below, T., Artner, A., Siebert, R., Sieber, S. 2010. Micro-level practices to adapt to climate change for African small-scale farmers. International Food Policy Research Institute Discussion Paper, 953.

Below, T.B., Mutabazi, K.D., Kirschke, D., Franke, C., Sieber, S., Siebert, R., Tscherning, K. 2012. Can farmers' adaptation to climate change be explained by socio-economic household-level variables? Global Environmental Change, 22(1), 223-235.

Berkes, F. 2009. Evolution of co-management: role of knowledge generation, bridging organizations and social learning. Journal of environmental management, 90(5), 1692-1702.

Berrang-Ford, L., Ford, J.D., Paterson, J. 2011. Are we adapting to climate change? Global environmental change, 21(1), 25-33.

Berrang-Ford, L., Pearce, T., Ford, J.D. 2015. Systematic review approaches for climate change adaptation research. Regional Environmental Change, 15(5), 755-769.

Bettini, Y., Brown, R.R., de Haan, F.J. 2015. Exploring institutional adaptive capacity in practice: Examining water governance adaptation in Australia. Ecology and Society, 20(1).

Bhatta, G.D., Ojha, H.R., Aggarwal, P.K., Sulaiman, V.R., Sultana, P., Thapa, D., Mittal, N., Dahal, K., Thomson, P., Ghimire, L. 2017. Agricultural innovation and adaptation to climate change: empirical evidence from diverse agro-ecologies in South Asia. Environment, Development and Sustainability, 19(2), 497-525

Biesbroek, G.R., Klostermann, J.E., Termeer, C.J., Kabat, P. 2013. On the nature of barriers to climate change adaptation. Regional Environmental Change, 13(5), 1119-1129.

Biesbroek, R., Dupuis, J., Jordan, A., Wellstead, A., Howlett, M., Cairney, P., Rayner, J., Davidson, D. 2015. Opening up the black box of adaptation decision-making. Nature Climate Change, 5(6), 493-494.

Blackmore, C., van Bommel, S., de Bruin, A., de Vries, J., Westberg, L., Powell, N., Foster, N., Collins, K., Roggero, P.P., Seddaiu, G. 2016. Learning for transformation of water governance: reflections on design from the climate change adaptation and water governance (CADWAGO) project. Water (Switzerland), 8(11).

Blackstock, K., Dunglinson, J., Dilley, R., Matthews, K., Futter, M., Marshall, K. 2009. Climate proofing scottish river basin planning - A future challenge. Environmental Policy and Governance, 19(6), 374387.

Bloch, R., Knierim, A., Häring, A.-M., Bachinger, J. 2016. Increasing the adaptive capacity of organic farming systems in the face of climate change using action research methods. Organic Agriculture, 6(2), 139-151.

Bos, J., Brown, R., Farrelly, M. 2013. A design framework for creating social learning situations. Global Environmental Change, 23(2), 398-412.

Bosch, O., Nguyen, N.C., Ha, T.M., Banson, K.E. 2015. Using a systemic approach to improve the quality of life for women in small-scale agriculture: Empirical evidence from Southeast Asia and Sub-Saharan Africa. in: Advance in business management towards systemic approach, (Ed.) Dominici et al. perugia, Italy, pp. 280-285.

Bosma, R.H., Ngo, A.T., Huynh, C.V., Le, H.T., Dang, N.K., Van, T.P., Halsema, G.V. 2016. Seven steps in identifying local climate change responses for agriculture in Vietnam. Tropicultura, 34(Specialissue), 31-49.

Boyd, E., Ensor, J., Broto, V.C., Juhola, S. 2014. Environmentalities of urban climate governance in Maputo, Mozambique. Global environmental change, 26, 140-151.
Bradbury, S., Middlemiss, L. 2015. The role of learning in sustainable communities of practice. Local Environment, 20(7), 796-810

Brooks, N., Adger, W.N. 2005. Assessing and enhancing adaptive capacity. in: Adaptation policy frameworks for climate change: Developing strategies, policies and measures, (Eds.) B. Lim, E. Spanger-Siegfried, Cambridge University Press. Cambridge, pp. 165-182.

Brown, H.C.P., Nkem, J.N., Sonwa, D.J., Bele, Y. 2010. Institutional adaptive capacity and climate change response in the Congo Basin forests of Cameroon. Mitigation and Adaptation Strategies for Global Change, 15(3), 263-282.

Bruun, O. 2012. Sending the Right Bill to the Right People: Climate Change, Environmental Degradation, and Social Vulnerabilities in Central Vietnam. Weather, Climate and Society, 4(4), 250-262.

Bryan, E., Deressa, T.T., Gbetibouo, G.A., Ringler, C. 2009. Adaptation to climate change in Ethiopia and South Africa: options and constraints. environmental science \& policy, 12(4), 413-426.

Brydon-Miller, M., Greenwood, D., Maguire, P. 2003. Why action research? Action research, 1(1), 9-28. Burch, S. 2010 In pursuit of resilient low carbon communities: an examination of barriers to action in three Canadian cities. Energy Policy, 38(12), 7575-7585.

Burch, S. 2010b. Transforming barriers into enablers of action on climate change: insights from three municipal case studies in British Columbia, Canada. Global Environmental Change, 20(2), 287-297.

Burck, J., Marten, F., Bals, C. 2016. The Climate Change Performance Index Results 2016 (https://germanwatch.org/en/download/13626.pdf). Germanwatch - Bonn Office.

Burnham, M., Ma, Z. 2017. Climate change adaptation: factors influencing Chinese smallholder farmers' perceived self-efficacy and adaptation intent. Regional Environmental Change, 1-16.

Burnham, M., Ma, Z. 2016. Linking smallholder farmer climate change adaptation decisions to development. Climate and Development, 8(4), 289-311.

Butler, J.R.A., Wise, R.M., Skewes, T.D., Bohensky, E.L., Peterson, N., Suadnya, W., Yanuartati, Y., Handayani, T., Habibi, P., Puspadi, K., Bou, N., Vaghelo, D., Rochester, W. 2015. Integrating TopDown and Bottom-Up Adaptation Planning to Build Adaptive Capacity: A Structured Learning Approach. Coastal Management, 43(4), 346-364.

Campbell, B., Mann, W., Melendez-Ortiz, R. 2011. Agriculture and climate change: A scoping report. Campbell, B., Mann, W, Melendez-Ortiz, R. 2011 . Agriculture and Climate change: A scoping report. Cantrell, D.C. 1993. Alternative paradigms in environmental education research: The interpretive perspective. in: Alternative paradigms in environmental education research, (Ed.) R. Mrazek, pp. 81 104.

Carien De Villiers, A., Esler, K.J., Knight, A.T. 2014. Social processes promoting the adaptive capacity of rangeland managers to achieve resilience in the karoo, South Africa. Journal of Environmental Management, 146, 276-283.

Chaffin, B.C., Garmestani, A.S., Gosnell, H., Craig, R.K. 2016. Institutional networks and adaptive wate governance in the Klamath River Basin, USA. Environmental Science \& Policy, 57, 112-121.

Chambers, R. 1994. The origins and practice of participatory rural appraisal. World development, 22(7), 953 969.

Charmaz, K. 2006. Constructing grounded theory: A practical guide through qualitative analysis. Sage, London.

Christmann, S., Aw-Hassan, A., Rajabov, T., Rabbimov, A. 2015. Collective action for common rangelands improvement: a climate change adaptation strategy in Uzbekistan. Society \& Natural Resources, 28(3), 280-295.

Christmann, S., Aw-Hassan, A.A. 2015. A participatory method to enhance the collective ability to adapt to rapid glacier loss: the case of mountain communities in Tajikistan. Climatic Change, 133(2), 267282.

Christoplos, I., Ngoan, L.D., Sen, L.T.H., Huong, N.T.T., Nguyen, H. 2017. Changing arenas for agricultural climate change adaptation in Vietnam. Development in Practice, 27(2), 132-142.

Clemens, M., Rijke, J., Pathirana, A., Evers, J., Quan, N.H. 2016. Social learning for adaptation to climate change in developing countries: insights from Vietnam. Journal of Water and Climate Change, 7(2), 365-378.

Collins, K., Ison, R. 2009. Jumping off Arnstein's ladder: Social learning as a new policy paradigm for climate change adaptation. Environmental Policy and Governance, 19(6), 358-373. 
Cooper, S.J., Wheeler, T. 2015. Adaptive governance: livelihood innovation for climate resilience in Uganda. Geoforum, 65, 96-107.

Craft, J., Howlett, M. 2012. Subsystem Structures, Shifting Mandates and Policy Capacity: Assessing Canada's Ability to Adapt to Climate Change. Canadian Political Science Review, 6(1).

Craft, J., Howlett, M., Crawford, M., McNutt, K. 2013. Assessing policy capacity for climate change adaptation: Governance arrangements, resource deployments, and analytical skills in Canadian infrastructure policy making. Review of Policy Research, 30(1), 42-65.

Craig, R.K. 2010. Stationarity is Dead: Long Live Transformation: Five Principles for Climate Change Adaptation Law Harvard Environmental Law Review, 31, 9-75.

Crane, T.A., Delaney, A., Tamás, P.A., Chesterman, S., Ericksen, P. 2017. A systematic review of local vulnerability to climate change in developing country agriculture: In search of transparency, coherence and comparability. Wiley Interdisciplinary Reviews: Climate Change.

Creswell, J.W. 2009. Research Design: Qualitative, Quantative, and Mixed Methods, Approaches Sage, London.

Cundill, G., Rodela, R. 2012. A review of assertions about the processes and outcomes of social learning in natural resource management. Journal of environmental management, 113, 7-14.

Dale, A., Newman, L.L. 2007. E-dialogues: a role in interactive sustainable development? Integrated Assessment, 6(4), 31-141.

Dana, G.V., Nelson, K.C. 2012. Social learning through environmental risk analysis of biodiversity and GM maize in South Africa. Environmental Policy and Governance, 22(4), 238-252.

Daniels, S.E., Walker, G.B. 2001. Working through environmental conflict: The collaborative learning approach.

Dasgupta, S., Laplante, B., Murray, S., Wheeler, D. 2011. Exposure of developing countries to sea-level rise and storm surges. Climatic Change, 106(4), 567-579.

Defoer, T., Wopereis, M., Idinoba, P., Kadisha, T., Diack, S., Gaye, M. 2009. Curriculum for Participatory Learning and Action Research (PLAR) for Integrated Rice Management (IRM) in Inland Valleys of Learning and Action Research (PLAR) for Integrated Rice Management (IRM) in Inland Valleys of
Sub-Saharan Africa: Facilitator's Manual. Global Rice Science Partnership (GRiSP), International Rice Research Institute partership with AfricaRice, Cotonou, Benin. Muscle Shoals, USA.

Deressa, T.T., Hassan, R.M., Ringler, C., Alemu, T., Yesuf, M. 2009. Determinants of farmers' choice of adaptation methods to climate change in the Nile Basin of Ethiopia. Global environmental change, $9(2), 248-255$

Desbarats, J. 1987. Population redistribution in the Socialist Republic of Vietnam. Population and Development Review, 43-76.

Dhanya, P., Ramachandran, A. 2015. Farmers' perceptions of climate change and the proposed agriculture adaptation strategies in a semi arid region of south India. Journal of Integrative Environmental Sciences.

Doelle, M., Henschel, C., Smith, J., Tollefson, C., Wellstead, A. 2012. New governance arrangements at the intersection of climate change and forest policy: Institutional, political and regulatory dimensions. Public Administration, 90(1), 37-55.

Dousa, T.M. 2010. Classical Pragmatism and its Varieties: On a Pluriform Metatheoretical Perspective for Knowledge Organization. Knowledge organization, 37(1).

Dovers, S.R., Hezri, A.A. 2010. Institutions and policy processes: the means to the ends of adaptation. Wiley Interdisciplinary Reviews: Climate Change, 1(2), 212-231.

Dupuis, J., Biesbroek, R. 2013. Comparing apples and oranges: the dependent variable problem in comparing and evaluating climate change adaptation policies. Global Environmental Change, 23(6), 1476-1487.

Duru, M., Felten, B., Theau, J.P., Martin, G. 2012. A modelling and participatory approach for enhancin learning about adaptation of grassland-based livestock systems to climate change. Regional environmental change, 12(4), 739-750.

Eakin, H., Eriksen, S., Eikeland, P.-O., Øyen, C. 2011. Public sector reform and governance for adaptation: implications of new public management for adaptive capacity in Mexico and Norway. Environmental management, 47(3), 338-351.
Eakin, H., Lemos, M.C. 2006. Adaptation and the state: Latin America and the challenge of capacity-building under globalization. Global environmental change, 16(1), 7-18.

Eakin, H.C., Lemos, M.C., Nelson, D.R. 2014. Differentiating capacities as a means to sustainable climate change adaptation. Global Environmental Change, 27, 1-8.

EEA. 2017. Climate change, impacts, and vulnerability in Europe 2016: An indicator-based report. Publications Office of the European Union.

Egunyu, F., Reed, M. 2015. Social learning by whom? Assessing gendered opportunities for participation and social learning in collaborative forest governance. Ecology and Society, 20(4).

Emerson, K., Gerlak, A.K. 2014. Adaptation in Collaborative Governance Regimes. Environmental Management, 54(4), 768-781.

Engle, N.L. 2012. Adaptation Bridges and Barriers in Water Planning and Management: Insight from Recent Extreme Droughts in Arizona and Georgia. Journal of the American Water Resources Association, 48(6), 1139-1150.

Engle, N.L. 2011. Adaptive capacity and its assessment. Global Environmental Change, 21(2), 647-656.

Ensor, J., Harvey, B. 2015. Social learning and climate change adaptation: evidence for internationa development practice. Wiley Interdisciplinary Reviews: Climate Change, 6(5), 509-522.

Ensor, J.E., Park, S.E., Hoddy, E.T., Ratner, B.D. 2015. A rights-based perspective on adaptive capacity. Global Environmental Change, 31, 38-49.

Eriksen, S., Selboe, E. 2012. The social organisation of adaptation to climate variability and global change: The case of a mountain farming community in Norway. Applied Geography, 33, 159-167.

Faysse, N., Errahj, M., Imache, A., Kemmoun, H., Labbaci, T. 2014. Paving the Way for Social Learning When Governance Is Weak: Supporting Dialogue Between Stakeholders to Face a Groundwater Crisis in Morocco. Society and Natural Resources, 27(3), 249-264.

Fazey, I., Fazey, J.A., Fischer, J., Sherren, K., Warren, J., Noss, R.F., Dovers, S.R. 2007. Adaptive capacity and learning to learn as leverage for social-ecological resilience. Frontiers in Ecology and the Environment, 5(7), 375-380.

FitzGibbon, J., Mensah, K.O. 2012. Climate change as a wicked problem: an evaluation of the institutional context for rural water management in Ghana. Sage Open, 2(2), 2158244012448487.

Folke, C., Hahn, T., Olsson, P., Norberg, J. 2005. Adaptive governance of social-ecological systems. Annu. Rev. Environ. Resour., 30, 441-473.

Förch, W., Kristjanson, P., Cramer, L., Barahona, C., Thornton, P.K. 2014. Back to baselines: measuring change and sharing data. Agriculture \& Food Security, $3(1), 13$

Ford, J.D., Berrang-Ford, L., Paterson, J. 2011. A systematic review of observed climate change adaptation in developed nations. Climatic change, 106(2), 327-336.

Fortier, F.o. 2010. Taking a climate chance: A procedural critique of Vietnam's climate change strategy. Asia Pacific Viewpoint, 51(3), 229-247.

Frank, E., Eakin, H., López-Carr, D. 2011. Social identity, perception and motivation in adaptation to climate risk in the coffee sector of Chiapas, Mexico. Global environmental change, 21(1), 66-76.

Fröhlich, J., Knieling, J. 2013. Conceptualising climate change governance. in: Climate Change Governance, Springer, pp. 9-26.

Gallego-Ayala, J. 2013. Trends in integrated water resources management research: a literature review. Water Policy, 15(4), 628-647.

Gallopín G.C. 2006. Linkages between vulnerability, resilience, and adaptive capacity. Global environmenta change, 16(3), 293-303.

Gbetibouo, G.A. 2009. Understanding farmers' perceptions and adaptations to climate change and variability: The case of the Limpopo Basin, South Africa. Intl Food Policy Res Inst.

Georgopoulou, E., Mirasgedis, S., Sarafidis, Y., Vitaliotou, M., Lalas, D.P., Theloudis, I., Giannoulaki, K.D., Dimopoulos, D., Zavras, V. 2017. Climate change impacts and adaptation options for the Greek agriculture in 2021-2050: A monetary assessment. Climate Risk Management.

Glaser, B., Strauss, A. 1967. Grounded theory: The discovery of grounded theory. Sociology The Journal of The British Sociological Association, 12, 27-49.

GOS. 2016. General Statistic Office, Vietnam.

Gough, D., Oliver, S., Thomas, J. 2012. An introduction to systematic reviews. Sage. 
Government of Vietnam. 2011. National strategy on climate change (issued together with decision on No.2139/QD-TTg 05/12/2011 of the Prime Minister), (Ed.) MONRE.

Greene, J.C., Caracelli, V.J., Graham, W.F. 1989. Toward a conceptual framework for mixed-method evaluation designs. Educational evaluation and policy analysis, 11(3), 255-274.

Grothmann, T., Patt, A. 2005. Adaptive capacity and human cognition: the process of individual adaptation to climate change. Global Environmental Change, 15(3), 199-213.

Gupta, J. 2007. The multi-level governance challenge of climate change.

Gupta, J, Termeer C., Klostermann, Meijerink, S, van den Brink, M, Jong, P., Nooteboom, S, Bergsma, E. 2010. The adaptive capacity wheel: a method to assess the inherent characteristics of institution to enable the adaptive capacity of society. Environmental Science \& Policy, 13(6), 459-471.

Ha, T.M. 2014. Establishing a transformative learning framework for promoting organic farming in Northern Vietnam: a case study on organic tea production in Thai Nguyen province. Asian Journal of Business and Management (ISSN: 2321-2802), 2(03).

Ha, T.M., Bosch, O.J.H., Nguyen, N.C. 2016. Establishing an Evolutionary Learning Laboratory for Improvin the Quality of Life of Vietnamese Women in Small-scale Agriculture: Part I-The Current Situation. Systems Research and Behavioral Science, 33(4), 532-543.

Ha, T.M., Bosch, O.J.H., Nguyen, N.C., Trinh, C.T. 2017. System dynamics modelling for defining livelihood strategies for women smallholder farmers in lowland and upland regions of northern Vietnam: A comparative analysis. Agricultural Systems, 150, 12-20.

Hagemeier-Klose, M., Beichler, S.A., Davidse, B.J., Deppisch, S. 2014. The Dynamic Knowledge Loop: Interand Transdisciplinary Cooperation and Adaptation of Climate Change Knowledge. International Journal of Disaster Risk Science, $\mathbf{5}(1), 21-32$

Hanh, T.T.H. 2010. Income diversification in fishing and aquaculture in the Tam Giang lagoon - adaptation to climate change or not?, Vol. Msc, Swedish University of Agricultural Sciences. Sweden.

Harmer, N., Rahman, S. 2014. Climate change response at the farm level: a review of farmers' awareness and adaptation strategies in developing countries. Geography Compass, 8(11), 808-822.

Harvey, B., Ensor, J., Carlile, L., Garside, B., Patterson, Z., Naess, L.O. 2012. Climate change communication and social learning-Review and strategy development for CCAFS. in: CGIAR Research Program on Climate Change, Agriculture and Food Security (CCAFS). Copenhagen, Denmark.

Harvey, C.A., Rakotobe, Z.L., Rao, N.S., Dave, R., Razafimahatratra, H., Rabarijohn, R.H., Rajaofara, H. Mackinnon, J.L. 2014. Extreme vulnerability of smallholder farmers to agricultural risks and climate change in Madagascar. Philosophical Transactions of the Royal Society B: Biological Sciences, 369(1639).

Hassan, R., Nhemachena, C. 2008. Determinants of African farmers' strategies for adapting to climate change: Multinomial choice analysis. African Journal of Agricultural and Resource Economics, 2(1) 83-104.

Hazell, P.B., Rahman, A. 2014. New directions for smallholder agriculture. OUP Oxford.

Henly-Shepard, S., Gray, S.A., Cox, L.J. 2015. The use of participatory modeling to promote social learning and facilitate community disaster planning. Environmental Science \& Policy, 45, 109-122.

Henstra, D. 2016. The tools of climate adaptation policy: analysing instruments and instrument selection. Climate Policy, 16(4), 496-521.

Ho, T.V.T., Cottrell, A., Valentine, P., Woodley, S. 2012. Perceived barriers to effective multilevel governance of human-natural systems: an analysis of Marine Protected Areas in Vietnam. Journal of Political Ecology, 19, 17-35.

Hoang, M., Namirembe, S., van Noordwijk, M., Catacutan, D., Öborn, I., Perez-Teran, A., Nguyen, H. Dumas-Johansen, M. 2014. Farmer portfolios, strategic diversity management and climate-chang adaptation-implications for policy in Vietnam and Kenya. Climate and Development, 6(3), 216-225.

Hoffmann, V., Probst, K., Christinck, A. 2007. Farmers and researchers: How can collaborative advantages be created in participatory research and technology development? Agriculture and human values, 24(3), 355-368.

Hooghe, L. 1996. Cohesion policy and European integration: building multi-level governance. Oxford University Press Oxford.
Hooghe, L., Marks, G. 2003. Unraveling the Central State, But How? Types of Multi-Level Governance"(2003) 97. Am. Pol. Sci. Rev., 2, 233.

Howden, S.M., Soussana, J.-F., Tubiello, F.N., Chhetri, N., Dunlop, M., Meinke, H. 2007. Adapting agriculture to climate change. Proceedings of the national academy of sciences, 104(50), 19691-19696.

Howlett, M. 2009. Governance modes, policy regimes and operational plans: A multi-level nested model of policy instrument choice and policy design. Policy Sciences, 42(1), 73-89.

Howlett, M. 2015. Policy analytical capacity: The supply and demand for policy analysis in government. Policy and Society, 34(3), 173-182.

Hughes, A., Gleeson, D., Legge, D., Lin, V. 2015. Governance and policy capacity in health development and implementation in Australia. Policy and Society, 34(3), 229-245.

Huntjens, P., Lebel, L., Pahl-Wostl, C., Camkin, J., Schulze, R., Kranz, N. 2012. Institutional design propositions for the governance of adaptation to climate change in the water sector. Global Environmental Change, 22(1), 67-81.

Huntjens, P., Pahl-Wostl, C., Rihoux, B., Schluter, M., Flachner, Z., Neto, S., Koskova, R., Dickens, C., Kiti, I.N. 2011. Adaptive Water Management and Policy Learning in a Changing Climate: a Formal Comparative Analysis of Eight Water Management Regimes in Europe, Africa and Asia. Environmental Policy and Governance, 21(3), 145-163.

Hurlbert, M. 2015. Learning, participation, and adaptation: exploring agri-environmental programmes. Journal of Environmental Planning and Management, 58(1), 113-134.

Hurlbert, M.A., Diaz, H. 2013. Water Governance in Chile and Canada: a Comparison of Adaptive Characteristics. Ecology and Society, 18(4), 15

IFAD. 2014. Comprehensive environmental and climate change assessment in Vietnam. International Fund for Agricultural Development.

Igodan, C.O., Ohaji, P.E., Ekpere, J.A. 1988. Factors associated with the adoption of recommended practices for maize production in the Kainji Lake Basin of Nigeria. Agricultural Administration and Extension, 29(2), $149-156$.

IPCC. 2014. WG II AR5 Glossary in: Climate change 2014: Impacts. Adaptation, adn Vulnerability. part A: Global and Sectoral Aspects. Contribution of Working Group II to the Fifth Assessment Report of the Intergovernmental Panel on Climate change, (Eds.) J. Agard, L. Schipper, Cambridge Universtiy Press. Cambridge, UK.

son, R. 2010. System Practice: How to Act in a Climate Change World. Springer, London, UK.

Ison, R., Watson, D. 2007. Illuminating the possibilities for social learning in the management of Scotland's water. Ecology and society, 12(1), Art. 21.

Jakku, E., Thorburn, P. 2010. A conceptual framework for guiding the participatory development of agricultural decision support systems. Agricultural Systems, 103(9), 675-682.

Janjua, S., Thomas, I., McEvoy, D. 2010. Framing climate change adaptation learning and action: the case of Lahore, Pakistan. International Journal of Climate Change Strategies and Management, 2(3), 281296.

Johannessen, Å., Hahn, T. 2013. Social learning towards a more adaptive paradigm? Reducing flood risk in Kristianstad municipality, Sweden. Global Environmental Change, 23(1), 372-381.

Johnson, K.A., Dana, G., Jordan, N.R., Draeger, K.J., Kapuscinski, A., Olabisi, L.K.S., Reich, P.B. 2012. Using Participatory Scenarios to Stimulate Social Learning for Collaborative Sustainable Development. Ecology and Society, 17(2)

Jones, L., Ludi, E., Levine, S. 2010. Towards a characterisation of adaptive capacity: a framework for analysing adaptive capacity at the local level.

Jordan, A.J., Huitema, D. Hildén, M., Van Asselt, H., Rayner, T.J., Schoenefeld, J.J., Tosun, J., Forster, J., Boasson, E.L. 2015. Emergence of polycentric climate governance and its future prospects. Nature Climate Change, 5(11), 977-982.

Juhola, S. 2016. Barriers to the implementation of climate change adaptation in land use planning: A multilevel governance problem? International Journal of Climate Change Strategies and Management, 8(3), 338-355 
Juhola, S., Westerhoff, L. 2011. Challenges of adaptation to climate change across multiple scales: a case study of network governance in two European countries. Environmental science \& policy, 14(3) 239-247.

Kandlikar, M., Risbey, J. 2000. Agricultural impacts of climate change: if adaptation is the answer, what is the question? Climatic change, 45(3-4), 529-539.

Keen, M., Brown, V.A., Dyball, R. 2005. Social learning in environmental management: towards a sustainable future. Routledge.

Keessen, A., Vink, M., Wiering, M., Boezeman, D., Ernst, W., Mees, H., Van Broekhoven, S., Van Eerd, M. 2016. Solidarity in water management. Ecology and Society, 21(4).

Keys, N., Bussey, M., Thomsen, D.C., Lynam, T., Smith, T.F. 2014. Building adaptive capacity in South East Queensland, Australia. Regional Environmental Change, 14(2), 501-512.

Kilelu, C.W., Klerkx, L., Leeuwis, C. 2014. How dynamics of learning are linked to innovation support services: insights from a smallholder commercialization project in Kenya. The Journal of Agricultural Education and Extension, 20(2), 213-232.

Kithiia, J. 2011. Climate change risk responses in East African cities: need, barriers and opportunities. Current Opinion in Environmental Sustainability, 3(3), 176-180.

Knaepen, H.L. 2014. Mainstreaming climate change adaptation into Vietnamese development as a new policy arrangement. Coastal Disasters and Climate Change in Vietnam, 355-377.

Koch, I.C., Vogel, C., Patel, Z. 2007. Institutional dynamics and climate change adaptation in South Africa. Mitigation and Adaptation Strategies for Global Change, 12(8), 1323-1339.

Kolb, D.A. 1984. Experiential learning: experience as the source of learning and development. Prentice Hall, Englewood Cliffs, NJ.

Kooiman, J., Jentoft, S. 2009. Meta-governance: values, norms and principles, and the making of hard choices. Public administration, 87(4), 818-836.

Kristjanson, P., Neufeldt, H., Gassner, A., Mango, J., Kyazze, F.B., Desta, S., Sayula, G., Thiede, B., Förch, W., Thornton, P.K. 2012. Are food insecure smallholder households making changes in their farming practices? Evidence from East Africa. Food Security, 4(3), 381-397.

Kummar, R. 2011. Research methodology: A step-by-step guide for beginners. SAGE, Los Angles.

Kuruppu, N., Liverman, D. 2011. Mental preparation for climate adaptation: The role of cognition and culture in enhancing adaptive capacity of water management in Kiribati. Global Environmental Change, 21(2), 657-669.

Le Dang, H., Li, E., Bruwer, J., Nuberg, I. 2014a. Farmers' perceptions of climate variability and barriers to adaptation: lessons learned from an exploratory study in Vietnam. Mitigation and adaptation strategies for global change, 19(5), 531-548.

Le Dang, H., Li, E., Nuberg, I., Bruwer, J. 2014b. Farmers' assessments of private adaptive measures to climate change and influential factors: A study in the Mekong Delta, Vietnam. Natural Hazards, 71(1), 385-401.

Le Dang, H., Li, E., Nuberg, I., Bruwer, J. 2014c. Farmers' perceived risks of climate change and influencing factors: a study in the Mekong Delta, Vietnam. Environmental management, 54(2), 331-345.

Le Dang, H., Li, E., Nuberg, I., Bruwer, J. 2014d. Understanding farmers' adaptation intention to climate change: A structural equation modelling study in the Mekong Delta, Vietnam. Environmental Science and Policy, 41, 11-22.

Le, D.N., Le, T.H.S., Nguyen, T.T.H., Christoplos, I., Lindegaard, L.S. 2013. Climate Change and Rural Institutions in Central Viet Nam. Danish Institute for International Studies, DIIS, Working Paper

Le, T.A. 2010. Impacts of Climate Change and Sea Level Rise to the Agriculture-Aquaculture System in the Mekong River Basin - A case study in the Lower Mekong River Delta in Vietnam. in: The International Workshop on the "Climate Change Responses for Asia International Rivers: Opportunities and Challenges, China, 26-28 February, 2010. China.

Lebel, L., Grothmann, T., Siebenhüner, B. 2010. The role of social learning in adaptiveness: insights from water management. International Environmental Agreements: Politics, Law and Economics, 10, 333-353.

Lebel, L., Manuta, J.B., Garden, P. 2011. Institutional traps and vulnerability to changes in climate and flood regimes in Thailand. Regional Environmental Change, 11(1), 45-58.
Leeuwis, C., Pyburn, R. 2002. Wheelbarrows full of frogs. Assen, The Netherlands: Koninklijke Van Gorcum Lemos, M.C. 2015. Usable climate knowledge for adaptive and co-managed water governance. Current Opinion in Environmental Sustainability, 12, 48-52.

Lemos, M.C., Agrawal, A., Eakin, H., Nelson, D.R., Engle, N.L., Johns, O. 2013. Building adaptive capacity to climate $c$

Lemos, M.C, Lo, Y. Nelson, D. R, Eakin, H., Bedran-Martins, A.M. 2016. Linking development to climate adaptation: leveraging generic and specific capacities to reduce vulnerability to drought in NE Brazil. Global Environmental Change, 39, 170-179.

Leys, A.J., Vanclay, J.K. 2011. Social learning: A knowledge and capacity building approach for adaptive comanagement of contested landscapes. Land Use Policy, 28(3), 574-584.

Lien, T.T. 2015. Exploring adaptation measures to drought in agricultural production, case study in Quang Loi, Quang Dien, TTHue, Vietnam, Vol. Bsc, Hue University of Agriculture and Forestry. Vietnam.

Lobell, D.B., Burke, M.B., Tebaldi, C., Mastrandrea, M.D., Falcon, W.P., Naylor, R.L. 2008. Prioritizing climate change adaptation needs for food security in 2030. Science, 319(5863), 607-610.

Lodge, M., Wegrich, K. 2014. The problem-solving capacity of the modern state: governance challenges and administrative capacities. Oxford University Press, USA.

Maddison, D.J. 2007. The perception of and adaptation to climate change in Africa. World Bank Policy Research Working Paper(4308).

Mapfumo, P., Adjei-Nsiah, S., Mtambanengwe, F., Chikowo, R., Giller, K.E. 2013. Participatory action research (PAR) as an entry point for supporting climate change adaptation by smallholder farmers in Africa. Environmental Development, 5, 6-22.

Maplecroft. 2011. Climate change vulnerability map 2011. Climate change vulnerability Index. Webside: http://maplecroft.com/about/news/ccvi.html.

MARD. 2008. Action Plan Framework for Adaptation to Climate Change of the Agriculture and Rural Development in Period 2008-2020 (Implemeting the Government's Decision No.2730/QĐ-BNNKHCN dated 5 th September 2008)

MARD. 2011. Action Plan Framework for Adaptation to Climate Change of the Agriculture and Rural Development in Period 2011-2015 and a Vision to 2050 (Implemeting the Government's Decision No.543/QD-BNN-KHCN dated 23rd March 2011).

Marks, G. 1993. Structural policy and multilevel governance in the EC. in: The state of the European Community, (Ed.) A.C.a.G. Rosenthal, Vol. 2, CO: Lynne Rienner. Boulder, pp. 391-410.

Marx, S.M., Weber, E.U., Orlove, B.S., Leiserowitz, A., Krantz, D.H., Roncoli, C., Phillips, J. 2007. Communication and mental processes: Experiential and analytic processing of uncertain climate information. Global Environmental Change, 17(1), 47-58.

Mattner, M. 2004. Power to the people? Local governance and politics in Vietnam. Environment and Urbanization, 16(1), 121-128.

McKendrick, J.H. 1999. Multi-Method Research: An Introduction to Its Application in PopulationGeography. The Professional Geographer, 51(1), 40-50.

McNeeley, S.M. 2012. Examining barriers and opportunities for sustainable adaptation to climate change in Interior Alaska. Climatic Change, 111(3-4), 835-857.

Measham, T.G., Preston, B.L., Smith, T.F., Brooke, C., Gorddard, R., Withycombe, G., Morrison, C. 2011 Adapting to climate change through local municipal planning: barriers and challenges. Mitigation and Adaptation Strategies for Global Change, 16(8), 889-909.

Medema, W., Wals, A., Adamowski, J. 2014. Multi-loop social learning for sustainable land and water governance: towards a research agenda on the potential of virtual learning platforms. NJASWageningen Journal of Life Sciences, 69, 23-38.

Mendelsohn, R. 2014. The impact of climate change on agriculture in Asia. Journal of Integrative Agriculture, 13(4), 660-665.

Mengistu, D.K. 2011. Farmers' perception and knowledge on climate change and their coping strategies to the related hazards: case study from Adiha, central Tigray, Ethiopia. Agricultural Sciences, 2(02), 138. 
Mertz, O., Mbow, C., Reenberg, A., Diouf, A. 2009. Farmers' perceptions of climate change and agricultural adaptation strategies in rural Sahel. Environmental management, 43(5), 804-816.

Mezirow, J. 1996. Contemporary paradigms of learning. Adult education quarterly, 46(3), 158-172.

Mezirow, J. 1997. Transformative Learning: Theory to Practice. New Directions for Adult and Continuing Education, 74.

Mickwitz, P., Aix, F., Beck, S., Carss, D., Ferrand, N., Görg, C., Jensen, A., Kivimaa, P., Kuhlicke, C., Kuindersma, W. 2009. Climate policy integration, coherence and governance.

Milestad, R., Dedieu, B., Darnhofer, I., Bellon, S. 2012. Farms and farmers facing change: The adaptive approach. in: Farming Systems Research into the 21st century: The new dynamic, Springer, pp. 365-

Minh Chau, D. 1997. Administrative reform in Vietnam: need and strategy. Asian Journal of Public Administration, 19(2), 303-320.

Minh, T.T., Larsen, C.E.S., Neef, A. 2010. Challenges to institutionalizing participatory extension: The case of farmer livestock schools in Vietnam. Journal of Agricultural Education and Extension, 16(2), 179194

Mishra, A., Kumar, P., Noble, A. 2013. Assessing the potential of SRI management principles and the FFS approach in Northeast Thailand for sustainable rice intensification in the context of climate change. International Journal of Agricultural Sustainability, 11(1), 4-22.

Mohabbat, K.M., Shahriar, I.M. 2015. Climate change adaptation in developing countries: does globalization act as facilitator? Journal of Globalization Studies, $6(2)$

MOLISA. 2016. Annual Report.

MONRE. 2012. Climate change, sea level rise scenarios for Vietnam, Narenca. Ha Noi, Vietnam.

MONRE. 2016. Climate change, sea level rise scenarios for Vietnam, Narenca. Ha Noi, Vietnam. . 2011. National Strategies on Climate change (Implementing the Government's Decision No.2139/QĐ-TTg dated 5th December, 2011).

MONRE. 2008. National Target Program to Respond to Climate Change (Implementing the Government's Decision No.158/QD-TTg dated 2nd December, 2008).

Moon, K., Blackman, D. 2014. A guide to understanding social science research for natural scientists. Conservation Biology, 28(5), 1167-1177.

Morse, J.M., Swanson, J.M., Kuzel, A.J. 2001. The Nature of Qualitative Evidence Sage Publications, America.

Moser, S.C., Ekstrom, J.A. 2010. A framework to diagnose barriers to climate change adaptation. Proceedings of the National Academy of Sciences, 107(51), 22026-22031.

Mostert, E., Pahl-Wostl, C., Rees, Y., Searle, B., Tàbara, D., Tippett, J. 2007. Social learning in European riverbasin management: barriers and fostering mechanisms from 10 river basins. Ecology and Society, $12(1), 2007$.

MPI. 2015. Finance for climate change adaptation in Vietnam: Intelligent investments for sustainability in the future (consutants from UNDP and WB). , (Ed.) M.o.P.a.I. (MPI).

Mtambanengwe, F., Mapfumo, P., Chikowo, R., Chamboko, T. 2012. Climate change and variability: smallholder farming communities in Zimbabwe portray a varied understanding. African Crop Science Journal, 20(2), 227-241.

Munaretto, S., Klostermann, J.E.M. 2011. Assessing adaptive capacity of institutions to climate change: A comparative case study of the Dutch Wadden Sea and the Venice Lagoon. Climate Law, 2(2), 219250.

Muro, M., Jeffrey, P. 2008. A critical review of the theory and application of social learning in participatory natural resource management processes. Journal of environmental planning and management, 51(3), 325-344

Mytelka, L.K., Smith, K., Karelplein, K. 2001. Innovation theory and innovation policy: Bridging the gap. Social sciences and innovation, 125.

Nguyen, Q., Hoang, M.H., Oborn, I., Noordwijk, M.v. 2013. Multipurpose agroforestry as a climate change resiliency option for farmers: an example of local adaptation in Vietnam. Climate change(117), 241257.
Nguyen, Q.A., Miller, F., Bowen, K., Tan Sinh, B. 2017. Evaluating capacity for climate change adaptation in the health and water sectors in Vietnam: constraints and opportunities. Climate and Development, 9(3), 258-273.

Nhemachena, C., Hassan, R. 2007. Micro-level analysis of farmers adaption to climate change in Southern Africa. Intl Food Policy Res Inst.

Nilsson, A.E., Gerger Swartling, Å., Eckerberg, K. 2012. Knowledge for local climate change adaptation in Sweden: Challenges of multilevel governance. Local Environment, 17(6-7), 751-767.

Nyanga, P.H., Johnsen, F.H., Aune, J.B. 2011. Smallholder farmers' perceptions of climate change and conservation agriculture: evidence from Zambia. Journal of Sustainable Development, 4(4), 73-85.

Nykvist, B. 2014. Does Social Learning Lead to Better Natural Resource Management? A Case Study of the Modern Farming Community of Practice in Sweden. Society and Natural Resources, 27(4), 436-450. Obayelu, O.A., Adepoju, A.O., Idowu, T. 2014. Factors influencing farmers' choices of adaptation to climate change in Ekiti State, Nigeria. Journal of Agriculture and Environment for International Development, 108(1), 3-16.

Oberlack, C. 2016. Diagnosing institutional barriers and opportunities for adaptation to climate change. Mitigation and Adaptation Strategies for Global Change, 1-34.

Office of Migrant Education. 2001. Comprehensive needs assessment: Materials adapted from "Planning and Conducting Needs Assessments: A Practical Guide".

Ojha, H.R., Sulaiman V, R., Sultana, P., Dahal, K., Thapa, D., Mittal, N., Thompson, P., Bhatta, G.D., Ghimire, L., Aggarwal, P. 2014. Is South Asian agriculture adapting to climate change? Evidence from the Indo-Gangetic Plains. Agroecology and sustainable food systems, 38(5), 505-531.

Oliphant, S., Howlett, M. 2010. Assessing policy analytical capacity: Comparative insights from a study of the Canadian environmental policy advice system. Journal of Comparative Policy Analysis, 12(4), 439-445.

Orderud, G.I., Winsvold, M. 2012. The role of learning and knowledge in adapting to climate change: a case study of Norwegian municipalities. International Journal of Environmental Studies, 69(6), 946-961.

Osborne, D., Gaebler, T. 1992. Reinventing government: How the entrepreneurial spirit is transforming government. Reading Mass. Adison Wesley Public Comp.

Ostrom, E. 2007. A diagnostic approach for going beyond panaceas. Proceedings of the national Academy of sciences, 104(39), 15181-15187.

Oyekale, A., Ibadan, N. 2009. Climatic variability and its impacts on agriculture income and household' welfare in the Souhtern and Northern Nigeira. Institute of Physics Publishing. pp. 322004.

Pahl-Wostl, C. 2009. A conceptual framework for analysing adaptive capacity and multi-level learning processes in resource governance regimes. Global Environmental Change, 19(3), 354-365.

Pahl-Wostl, C. 2006. The importance of social learning in restoring the multifunctionality of rivers and floodplains. Ecology and society, 11(1).

Pahl-Wostl, C. 2007. Transitions towards adaptive management of water facing climate and global change. Water resources management, 21(1), 49-62.

Pahl-Wostl, C., Craps, M., Dewulf, A., Mostert, E., Tabara, D., Taillieu, T. 2007a. Social learning and water resources management. Ecology and society, 12(2).

Pahl-Wostl, C., Sendzimir, J., Jeffrey, P., Aerts, J., Berkamp, G., Cross, K. 2007b. Managing change toward adaptive water management through social learning. Ecology and society, 12(2).

Pahl-Wostl, C., Tabara, D., Bouwen, R., Craps, M., Dewulf, A., Mostert, E., Ridder, D., Taillieu, T. 2008. The importance of social learning and culture for sustainable water management. Ecological Economics, 64(3), 484-495.

Painter, M. 2003. Public administration reform in Vietnam: problems and prospects. Public Administration and Development, 23(3), 259-271.

Painter, M., Peters, B. 2010. Tradition and public administration. Springer

Painter, M., Pierre, J. 2004. Challenges to state policy capacity: Global trends and comparative perspectives. Springer.

Panda, A., Sharma, U., Ninan, K., Patt, A. 2013. Adaptive capacity contributing to improved agricultura productivity at the household level: empirical findings highlighting the importance of crop insurance. Global Environmental Change, 23(4), 782-790. 
Paris, T.R., Chi, T.T.N. 2005. The impact of row seeder technology on women labor: a case study in the Mekong Delta, Vietnam. Gender, Technology and Development, 9(2), 157-184.

Pelling, M., High, C., Dearing, J., Smith, D. 2008. Shadow spaces for social learning: A relational understanding of adaptive capacity to climate change within organisations. Environment and Planning A, 40(4), 867-884.

Pettengell, C. 2010. Climate Change Adaptation: Enabling people living in poverty to adapt. Oxfam Policy and Practice: Climate Change and Resilience, 6(2), 1-48.

Petticrew, M., Roberts, H. 2006. Systematic reviews in the social sciences: A practical guide. Blackwell Publishing, Malden USA

Phuong, L.T.H. 2010. Climate change and farmers' adaptation. A case study of mixed-farming systems in Quang Tri province, Vietnam, Vol. Msc, Swedish University of Agricultural Sciences. Sweden.

Phuong, L.T.H., Biesbroek, G.R., Wals, A.E.J. 2017. The interplay between social learning and adaptive capacity in climate change adaptation: A systematic review. NJAS - Wageningen Journal of Life Sciences, 82, 1-9.

Phuong, L.T.H., Biesbroek, R., Sen, L.T.H., Wals, A. under review. Understanding smallholder farmers' capacity to respond climate change: A case study in coastal community, Central-Vietnam. Climate and Development.

Plummer, R., Armitage, D. 2010. Adaptive capacity and environmental governance, Springer Berlin, Germany.

Prager, K., Posthumus, H. 2010. Socio-economic factors influencing farmers' adoption of soil conservation practices in Europe. Human Dimensions of Soil and Water Conservation, 203-223.

Pringle, P., Conway, D. 2012. Voices from the frontline: The role of community-generated information in delivering climate adaptation and development objectives at project level. Climate and Development, 4(2), 104-113.

QD District People Committee. 2014. Report on the Socio-Economic Development Plan of Quang Loi commune (hard copy).

QL Commune People Committee. 2012. Report on the Socio-Economic Development Plan of Quang Lo commune (hard copy).

QL Commune People Committee. 2014. Report on the Socio-Economic Development Plan of Quang Lo commune (hard copy).

Rantala, S., Hajjar, R., Skutsch, M. 2014. Multilevel governance for forests and climate change: Learning from Southern Mexico. Forests, 5(12), 3147-3168

Rauken, T., Mydske, P.K., Winsvold, M. 2015. Mainstreaming climate change adaptation at the local level. Local Environment, 20(4), 408-423.

Raymond, C.M., Cleary, J. 2013. A tool and process that facilitate community capacity building and social learning for natural resource management. Ecology and Society, 18(1), 25

Reed, M., Evely, A., Cundill, G., Fazey, I., Glass, J., Laing, A., Newig, J., Parrish, B., Prell, C., Raymond, C. 2010 What is social learning? Ecology and Society, 15(4).

Reidsma, P., Ewert, F., Lansink, A.O., Leemans, R. 2010. Adaptation to climate change and climate variability in European agriculture: the importance of farm level responses. European journal of agronomy, 32(1), 91-102.

Rist, S., Chiddambanathan, M., Escobar, C., Wiesmann, U. 2006. "It was hard to come to mutual understanding...."-The multidimensionality of social learning processes concerned with sustainable natural resource use in India, Africa and Latin America. Systemic Practice and Action Research, 19(3), 219-237.

Rodela, R. 2013. The social learning discourse: Trends, themes and interdisciplinary influences in current research. Environmental science \& policy, 25, 157-166.

Rodela, R., Cundill, G., Wals, A.E. 2012. An analysis of the methodological underpinnings of social learning research in natural resource management. Ecological economics, 77, 16-26.

Rodima-Taylor, D. 2012. Social innovation and climate adaptation: Local collective action in diversifying Tanzania. Applied Geography, 33, 128-134.
Rogers, R.W. 1983. Cognitive and physiological processes in fear appeals and attitude change: a revised theory of protection motivation. in: Social Psychophysiology: A Sourcebook, (Eds.) B.L. Cacioppo, L.L. Petty, Guilford. London, UK, pp. 135-176.

Rubin, O. 2014. Social vulnerability to climate-induced natural disasters: Cross-provincial evidence from Vietnam. Asia Pacific Viewpoint, 55(1), 67-80.

Rutherford, S.M.B. 2005. Bureaucratic landscapes: Interagency cooperation and the preservation of biodiversity. Policy Sciences, 38(2), 195-200.

Saljo, R. 1979. Learning in the Learner's Perspective. I. Some Common-Sense Conceptions. . Reports from the Institute of Education, No. 76

Saunders, M., Lewis, P., Thornhill, A. 2012. Research Methods for Business Students. Pearson Education Limited.

Schreurs, M.A. 2010. Multi-level Governance and Global Climate Change in East Asia. Asian Economic Policy Review, 5(1), 88-105

T.M., Decker, D.J., Pfeffer, M.J. 2003. Social learning for collaborative natural resource management. Society \& Natural Resources, 16(4), 309-326.

Sen, L.T.H. 2014. Agricultrual Extension Methods. Hue University Publisher, Hue.

Sen, L.T.H. 2016. Methods for selection climate change adaptation in agricultural production. Hue University Publisher, Hue.

Sen, L.T.H., Phuong, L.T.H. 2011. Climate change and adaptation of farmers in Trieu Van commune, Quang Tri province, Vietnam. in: Issues and Challenges in Rural Development, Vol. 126, Germany. Margraf Publishers.

Serrat-Capdevila, A., Browning-Aiken, A., Lansey, K., Finan, T., Valdes, J.B. 2009. Increasing Social-Ecologica Resilience by Placing Science at the Decision Table: the Role of the San Pedro Basin (Arizona) Decision-Support System Model. Ecology and Society, 14(1).

Shaw, A. 2005. Imbued Meaning: Science-policy interactions in the Intergovernmental Panel on Climate Change, Vol. PhD Thesus, University of British Columbia. Vancouver, BC, Cananda.

Shaw, A., Kristjanson, P. 2014. A catalyst toward sustainability? Exploring social learning and social differentiation approaches with the agricultural poor. Sustainability, 6(5), 2685-2717.

Shields, P.M., Rangarajan, N. 2013. A playbook for research methods: Integrating conceptual frameworks and project management. New Forums Press.

Shisanya, C., Khayesi, M. 2007. How is climate change perceived in relation to other socic environmental threats in Nairobi, Kenya? Climatic Change, 85(3-4), 271-284.

Sietz, D., Boschütz, M., Klein, R.J. 2011. Mainstreaming climate adaptation into development assistance: rationale, institutional barriers and opportunities in Mozambique. Environmental Science \& Policy, 14(4), 493-502.

Smit, B., McNabb, D., Smithers, J. 1996. Agricultural adaptation to climatic variation. Climatic change, 33(1), 7-29.

Smit, B., Pilifosova, O. 2003. Adaptation to climate change in the context of sustainable development and equity. Sustainable Development, 8(9), 9.

Smit, B., Pilifosova, O., Burton, I., Challenger, B., Huq, S., Klein, R.JT., Yohe, G., Adger, N., Downing, T. Harvey, E., Kane, S., Parry, M., Skinner, M., Smith, J., andel, J. 2001. Adaptation to climate change in the context of sustainable development and equity. in: Climate Change 2001: Impacts, Adaptation and Vulnerability. Contribution of Working Group II to the Third Assessment Report of the Intergovernmental Panel on Climate Change, (Eds.) J.J. McCarthy, O.F. Canziani, N.A. Leary, D.J. Dokken, K.S. White, Cambridge University Press. Cambridge, UK.

Smit, B., Wandel, J. 2006. Adaptation, adaptive capacity and vulnerability. Global environmental change, $16(3), 282-292$

Sol, J., Beers, p.J., Wals, A.E.J. 2013. Social learning in regional innovation networks: trust, commitment and reframing as emergent properties of interaction. Cleaner Production 49, 35-43.

Solaymani, S. 2017. Impacts of climate change on food security and agriculture sector in Malaysia. Environment, Development and Sustainability, 1-22. 
Spielman, D.J., Ekboir, J., Davis, K., Sanginga, P. 2009. Developing the art and science of innovation systems enquiry: alternative tools and methods, and applications to sub-Saharan African agriculture. Innovation Africa. Enriching farmers' livelihoods.

Sterrett, C. 2011. Review of climate change adaptation practices in South Asia. Oxfam Policy and Practice: Climate Change and Resilience, 7(4), 65-164.

Storbjork, S. 2010. 'It Takes More to Get a Ship to Change Course': Barriers for Organizational Learning and Local Climate Adaptation in Sweden. Journal of Environmental Policy \& Planning 12(3), 235-254.

Suong, N.T.H. 2011. Impact of climate change and farmer's adaptation in agriculutral production in TTHue, Vietnam, Vol. Bsc, Hue University of Agriculture and Forestry. Vietnam.

Swart, R., Biesbroek, R., Lourenço, T.C. 2014. Science of adaptation to climate change and science for adaptation. Frontiers in environmental science, $\mathbf{2}, 29$

Tambo, J.A., Abdoulaye, T. 2013. Smallholder farmers' perceptions of and adaptations to climate change in the Nigerian savanna. Regional Environmental Change, 13(2), 375-388.

Termeer, C., Dewulf, A., Breeman, G. 2013. Governance of wicked climate adaptation problems. in: Climate change governance, Springer, pp. 27-39.

Termeer, C.J., Dewulf, A., Lieshout, M.v. 2010. Disentangling scale approaches in governance research comparing monocentric, multilevel, and adaptive governance. Ecology and Society, 14(4).

Thomas, C.W. 2003. Bureaucratic Landscapes: Interagency Cooperation and the Preservation of Biodiversity (Politics, Science, and the Environment).

Thompson, G. 1991. Markets, hierarchies and networks: the coordination of social life. Sage.

Thomsen, D.C. 2008. Community-based research: Facilitating sustainability learning. Australasian Journal of Environmental Management, 15(4), 222-230.

Tiernan, A. 2011. Advising Australian federal governments: Assessing the evolving capacity and role of the Australian public service. Australian Journal of Public Administration, 70(4), 335-346.

Tinch, R., Jäger, J., Omann, I., Harrison, P.A., Wesely, J., Dunford, R. 2015. Applying a capitals framework to measuring coping and adaptive capacity in integrated assessment models. Climatic Change, 128(34), 323-337.

Togbé, C.E., Haagsma, R., Aoudji, A.K., Vodouhê, S.D. 2015. Effect of Participatory Research on Farmers' Knowledge and Practice of IPM: The Case of Cotton in Benin. The Journal of Agricultural Education and Extension, 21(5), 421-440.

Tompkins, E.L., Adger, W.N. 2004. Does adaptive management of natural resources enhance resilience to climate change? Ecology and Society, 9(2).

Tompkins, E.L., Adger, W.N., Boyd, E., Nicholson-Cole, S., Weatherhead, K., Arnell, N. 2010. Observed adaptation to climate change: UK evidence of transition to a well-adapting society. Global Environmental Change, 20(4), 627-635.

Tortola, P.D. 2017. Clarifying multilevel governance. European Journal of Political Research, 56, 234-250.

Tran, V.S. 2016. Towards successful implementation of Vietnamese national government climate change policy at the provincial and local farmer level. in: School of Environment, Science and Engineering Vol. PhD, Southern Cross University. Lismore, NSW.

Tschakert, P. 2007. Views from the vulnerable: Understanding climatic and other stressors in the Sahel. Global Environmental Change, 17(3-4), 381-396.

TH Provincial People Committee. 2014. Report on the Socio-Economic Development Plan of Thua Thien Hue province. www.thuathienhue.gov.vn.

UNFCCC. 2015. Paris Agreement

Van der Brugge, R., Rotmans, J. 2007. Towards transition management of European water resources. Water Resources Management, 21(1), 249-267.

van Noordwijk, M., Hoang, M.H., Neufeldt, H., Öborn, I., Yatich, T. 2011. How trees and people can co-adap to climate change: reducing vulnerability through multifunctional agroforestry landscapes. World Agroforestry Centre (ICRAF), Nairobi, 155

Vedwan, N. 2006. Culture, climate and the environment: Local knowledge and perception of climate change among apple growers in northwestern India. Journal of Ecological Anthropology, 10(1), 4-18.
Vermeulen, S.J., Challinor, A.J., Thornton, P.K., Campbell, B.M., Eriyagama, N., Vervoort, J.M., Kinyangi, J., Jarvis, A., Läderach, P., Ramirez-Villegas, J. 2013. Addressing uncertainty in adaptation planning for agriculture. Proceedings of the National Academy of Sciences, 110(21), 8357-8362.

Vien, T.D., Leisz, S.J., Lam, N.T., Rambo, A.T. 2006. Using traditional swidden agriculture to enhance rural livelihoods in Vietnam's uplands. Mountain Research and Development, 26(3), 192-196.

Vinning, G. Chỉnh, N.Q. 2008. Safe vegetables, fruit and tea in Vietnam: A marketing perspective (In Investment Options for the Proposal Loan Project: Quality and Safety Improvement of Agricultural Products, Asian Development Bank"Project Number: PPTA 4927-VIE). Ministry of Agriculture \& Rura Development, Hanoi.

Waibel, M. 2008. Implications and challenges of climate change for Vietnam. Pacific News, 29(1), 26-27.

Walker, B.J., Adger, W.N., Russel, D. 2015. Institutional barriers to climate change adaptation in decentralised governance structures: Transport planning in England. Urban Studies, 52(12), 22502266.

Wals, A.E. 2007. Social learning towards a sustainable world: Principles, perspectives, and praxis. Wageningen Academic Pub.

Wals, A.E., Alblas, A.H. 1997. School-based Research and Development of Environmental Education: a case study. Environmental Education Research, 3(3), 253-267.

Wals, A.E., Jickling, B. 2002. "Sustainability" in higher education: from doublethink and newspeak to critical thinking and meaningful learning. International Journal of Sustainability in Higher Education, 3(3), 221-232.

Wals, A.E., Rodela, R. 2014. Social learning towards sustainability: Problematic, perspectives and promise. NJAS-Wageningen Journal of Life Sciences, 69, 1-3.

Wals, A.E., Van der Hoeven, N., Blanken, H. 2007. The acoustics of social learning. Design learning processes that contribute to a more sustainable world, Wageningen Academic Publishers. Wageningen, the Netherlands.

Wals, A.E.J., Lans, T., Kupper, H. 2012. Blurring the boundaries between vocational education, business and research in the agri-food domain. Journal of Vocational Education \& Training, 64(1), 3-23.

Ward, P.J., Pauw, W., Van Buuren, M., Marfai, M.A. 2013. Governance of flood risk management in a time of climate change: the cases of Jakarta and Rotterdam. Environmental Politics, 22(3), 518-536.

Warrick, O., Aalbersberg, W., Dumaru, P., McNaught, R., Teperman, K. 2017. The 'Pacific Adaptive Capacity Analysis Framework': guiding the assessment of adaptive capacity in Pacific island communities. Regional Environmental Change, 17(4), 1039-1051.

Weber, E.U. 2010. What shapes perceptions of climate change? Climate Change, 1(3), 332-342.

Webler, T., Tuler, S., Dow, K., Whitehead, J., Kettle, N. 2016. Design and evaluation of a local analyticdeliberative process for climate adaptation planning. Local Environment, 21(2), 166-188.

Wellstead, A., Stedman, R. 2015. Mainstreaming and beyond: Policy capacity and climate change decisionmaking. Michigan Journal of Sustainability, 3.

Wellstead, A.M., Stedman, R.C., Howlett, M. 2011. Policy analytical capacity in changing governance contexts: A structural equation model (SEM) study of contemporary Canadian policy work. Public Policy and Administration, 26(3), 353-373.

Wheatley, M., Frieze, D. 2015. Lifecycle of Emergence: Using Emergence to Take Social Innovation to Scale. KOSMOS-Global Transformation in Harmony with All Life, 14(2).

Wibeck, V. 2014. Enhancing learning, communication and public engagement about climate change-some lessons from recent literature. Environmental Education Research, 20(3), 387-411.

Wilder, M., Scott, C.A., Pablos, N.P., Varady, R.G., Garfin, G.M., McEvoy, J. 2010. Adapting across boundaries: Climate change, social learning, and resilience in the U.S.-Mexico border region. Annals of the Association of American Geographers, 100(4), 917-928.

Williams, C., Fenton, A., Huq, S. 2015. Knowledge and adaptive capacity. Nature climate change, 5, 82-83. Wilson, J. 2010. Essentials of Business Research: A guide to doing your research project. Sage.

Wolf, J., Allice, I., Bell, T. 2013. Values, climate change, and implications for adaptation: evidence from two communities in Labrador, Canada. Global Environmental Change, 23(2), 548-562. 
Woodhill, J. 2010. Sustainability, social learning and the democratic imperative: Lessons from the Australian landcare movement. in: Social learning systems and communities of practice, (Ed.) C. Blackmore, Springer. London, UK., pp. 57-72.

Wu, X., Ramesh, M., Howlett, M. 2015. Policy capacity: A conceptual framework for understanding policy competences and capabilities. Policy and Society, 34(3), 165-171.

Xuan, M.T.T., Hien, D.T.T. 2013. Kinh tế nông hộ gia đình ở Việt Nam. Tap chí Khoa học, Đai học Quốc gia Hà Nội, 29(3), 1-9.

Yohannes, H. 2016. A review on relationship between climate change and agriculture. Earth Science \& Climate Change, 7(2), 1-8.

Yohe, G., Tol, R.S. 2002. Indicators for social and economic coping capacity - moving toward a working definition of adaptive capacity. Global Environmental Change, 12(1), 25-40.

Yu, B., Zhu, T., Breisinger, C., Hai, N.M. 2010. Impacts of climate change on agriculture and policy options for adaptation. International Food Policy Research Institute (IFPRI).

Yuen, E., Jovicich, S.S., Preston, B.L. 2013. Climate change vulnerability assessments as catalysts for social learning: four case studies in south-eastern Australia. Mitigation and Adaptation Strategies for Global Change, 18(5), 567-590.

\section{Supplementary material A}

Supplementary material A belonging to the chapter $\mathbf{2}$ "The interplay between social learning and adaptive capacity in climate change

SM A1. The keywords for searching strategies

\begin{tabular}{|c|c|c|c|}
\hline & & & \\
\hline $\begin{array}{l}\text { Collective learn* } \\
\text { Collaborative learn* } \\
\text { Policy learn* } \\
\text { Configuration learn* }\end{array}$ & 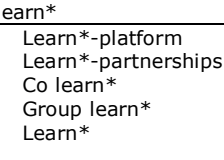 & $\begin{array}{l}\text { Adaptive-capacity } \\
\text { Capabilit** } \\
\text { Abilit**tial } \\
\text { Potential }\end{array}$ & 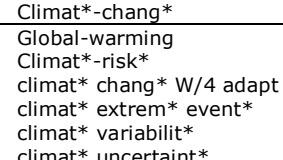 \\
\hline
\end{tabular}

SMA2. The categories for analysis

\begin{tabular}{ll} 
Categories & Interpretation \\
\hline Regional focus & A country is deemed to be developing or developed mainly on the basis of economics, per capita \\
income, industrialization, literacy rate, living standards etc. A developed country has a highly
\end{tabular} Ancome, industrialization, literacy rate, living standards etc. A developed country has a highly
developed economy and advanced technological infrastructure relative to other less developed
nations. We use GDP (gross domestic product) to distinction between Developed (1) and Developing
countries (2) We use the UN database and definition of developed countries that have a GDP. countries (2). We use the UN database and definition of developed countries that have a GDP.
To differentiate between different developing countries, we make the distinction between south

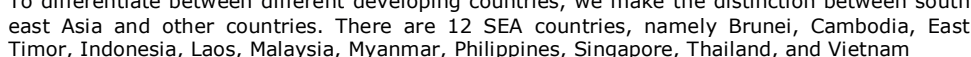
Timor, Indonesia, Laos, Malaysia, Myanmar, Philippines, singapore, Thailand, and Vietnam
The reporting year in this article was selected from 1997-9/2016.
The adaptation with three perspectives: development, resilience, and vulnerability. To understan the conceptal starting point Therefore, social learning/adantive capacity will e into account the conceptual starting point. Therefore, social learning/adaptive capacity will be understood
following three categories of theoretical orientation: development (1), resilience (2), and

$\frac{\text { Reporting year }}{\text { Adaptation }}$ Suctor of research is understood as the research discipline or, e.g. agriculture; water//Iand/forest//coastal zone management; natural resource management; risk management;
governance in community/farming community; conservation; ecosystem-based agriculture; Level(s) of research is understood as the location, size, or scale of a research. Social learning and adaptive capacity in climate change adaptation can study in all levels. It
distinguishes researches by different levels: international, regional, national, commune/community levels. Type of articles is understood as Indicates what kind of article this is e.g. empirical articles including case study or comparative case study, theory articles or synthesis articles
Definition of social learning is understood as the collective action and reflection that occurs among different individuals and groups as they work to improve the management of human and

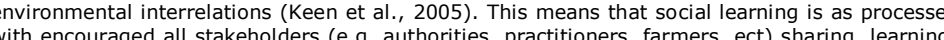
doing and reflection/feedback together or each other. Two types of social learning exist: passive
social learning (1) and active social learning (2). Three learning cycles often mention in social

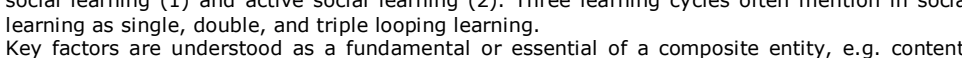
context, and process and individual attributes. Key factors/characteristics of adaptive capacity can include: variety, learning capacity, room for autonomous change, leadership, and resources (applying Adaptive capacity wheel to identify
components)
Conceptual link is understood as the connection or interaction between social learning and Adaptive capacity
Key factors

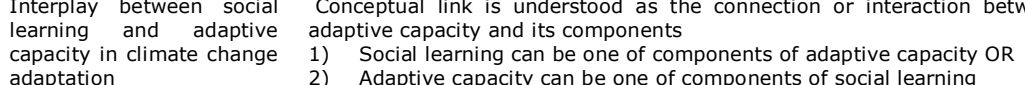

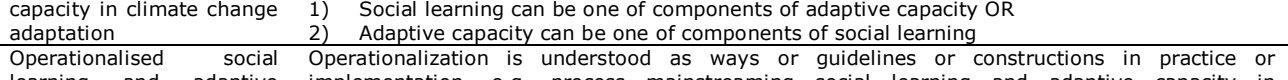

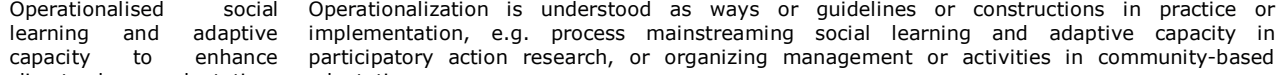
capacity to enhance
climate change adaptation Internal
influence $\stackrel{\text { and }}{\text { on }} \begin{gathered}\text { external } \\ \text { social }\end{gathered}$ adaptation.
1) Internal components of social learning: internal refers to the factors and conditions that are
atributed to the functioning of social learning that can be designed or controlled, eas presence of individual leadership or policy.
2) External factors condiditions of social learning, e.g. institutional conditions that enable or
constran social learning These factors are beyond the control of these that are learning

$\begin{array}{lll}\text { Internal and external } & \text { 1) Internal components of adaptive capacity: internal refers to the factors and conditions that } \\ \text { influence on } & \text { adaptive } & \text { are attributed to the functioning of adaptive capacity, }\end{array}$ 2) External factors/conditions of adaptive capacity, e.g. shocks, risks, subside that enable or
constrain adaptive capacity. These factors are beyond the control of human (e.g. 


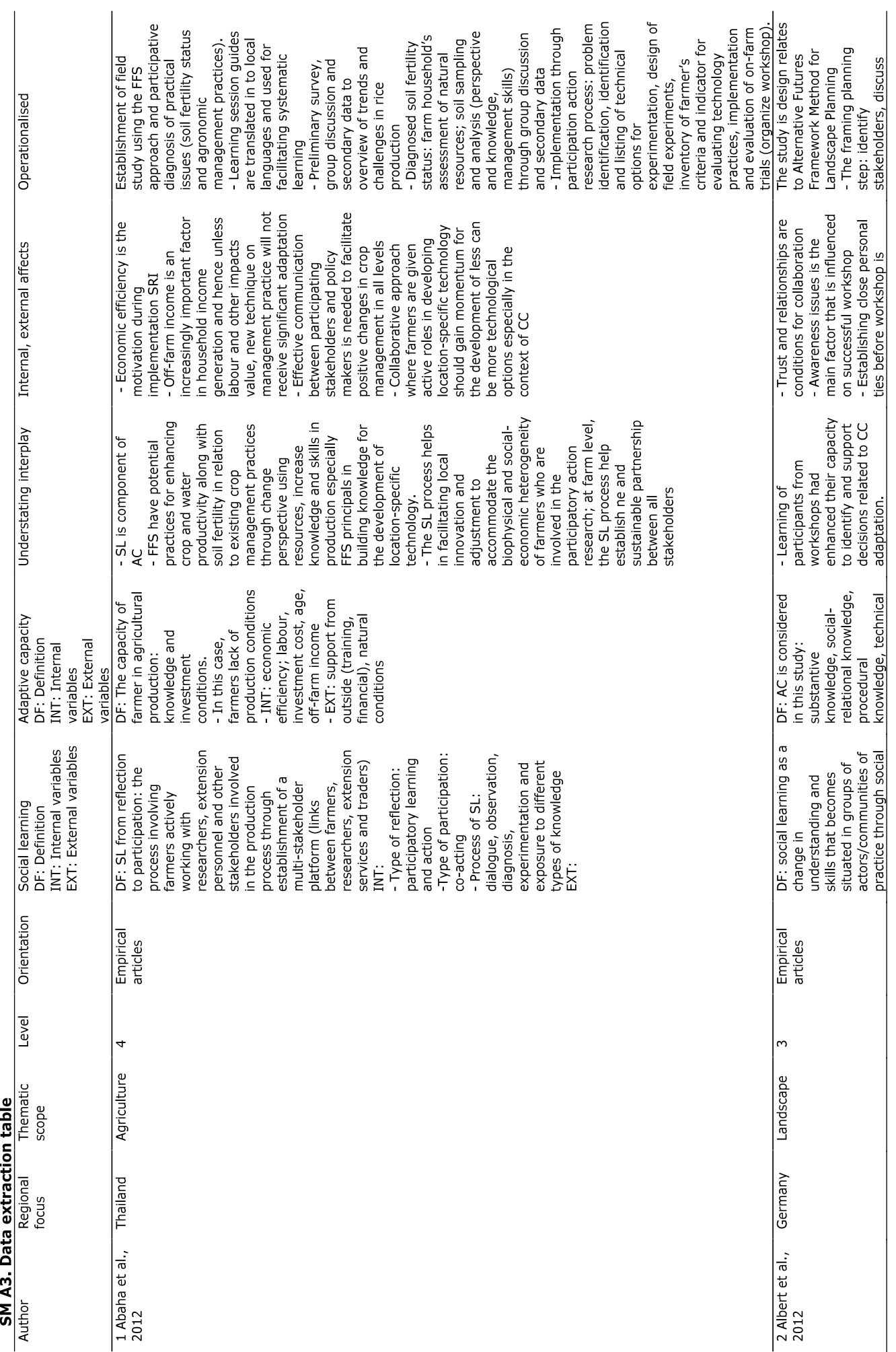

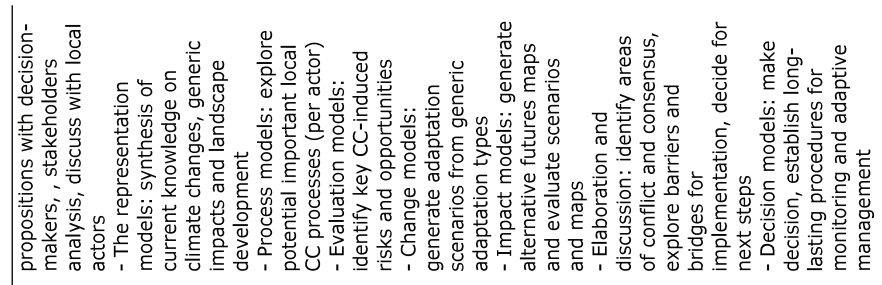

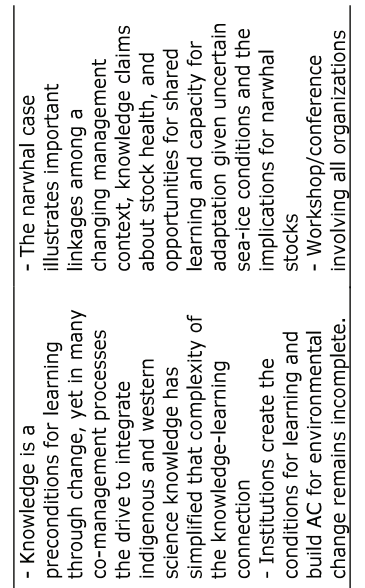

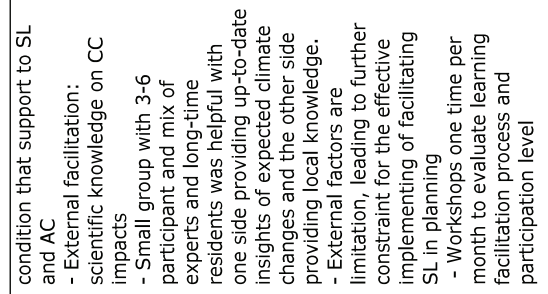

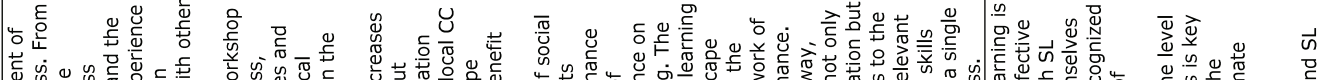

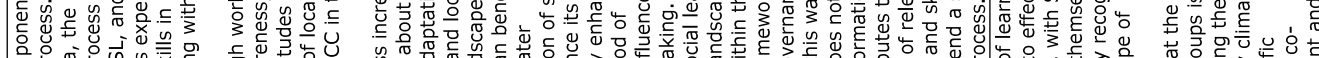

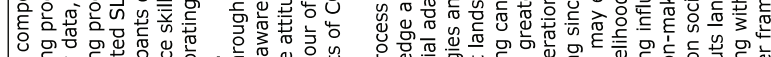

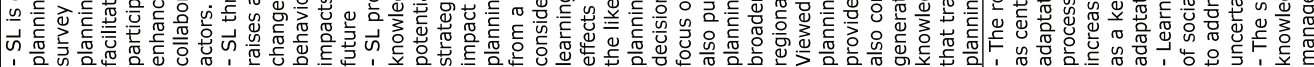

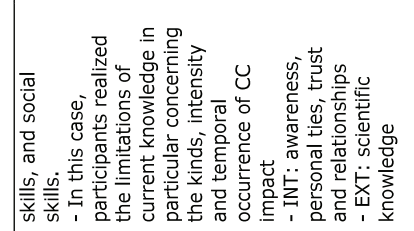

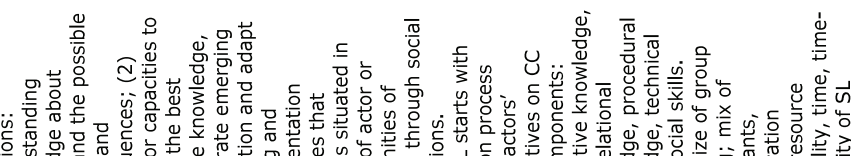

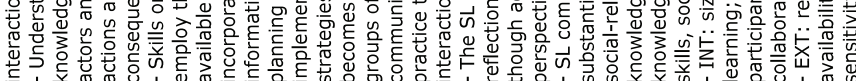

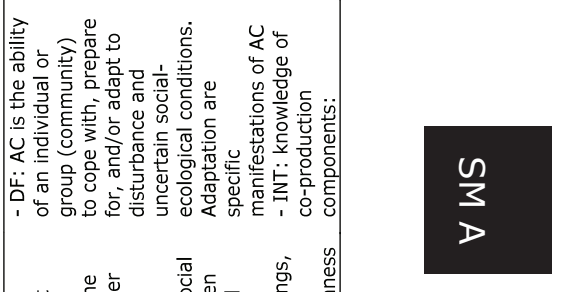




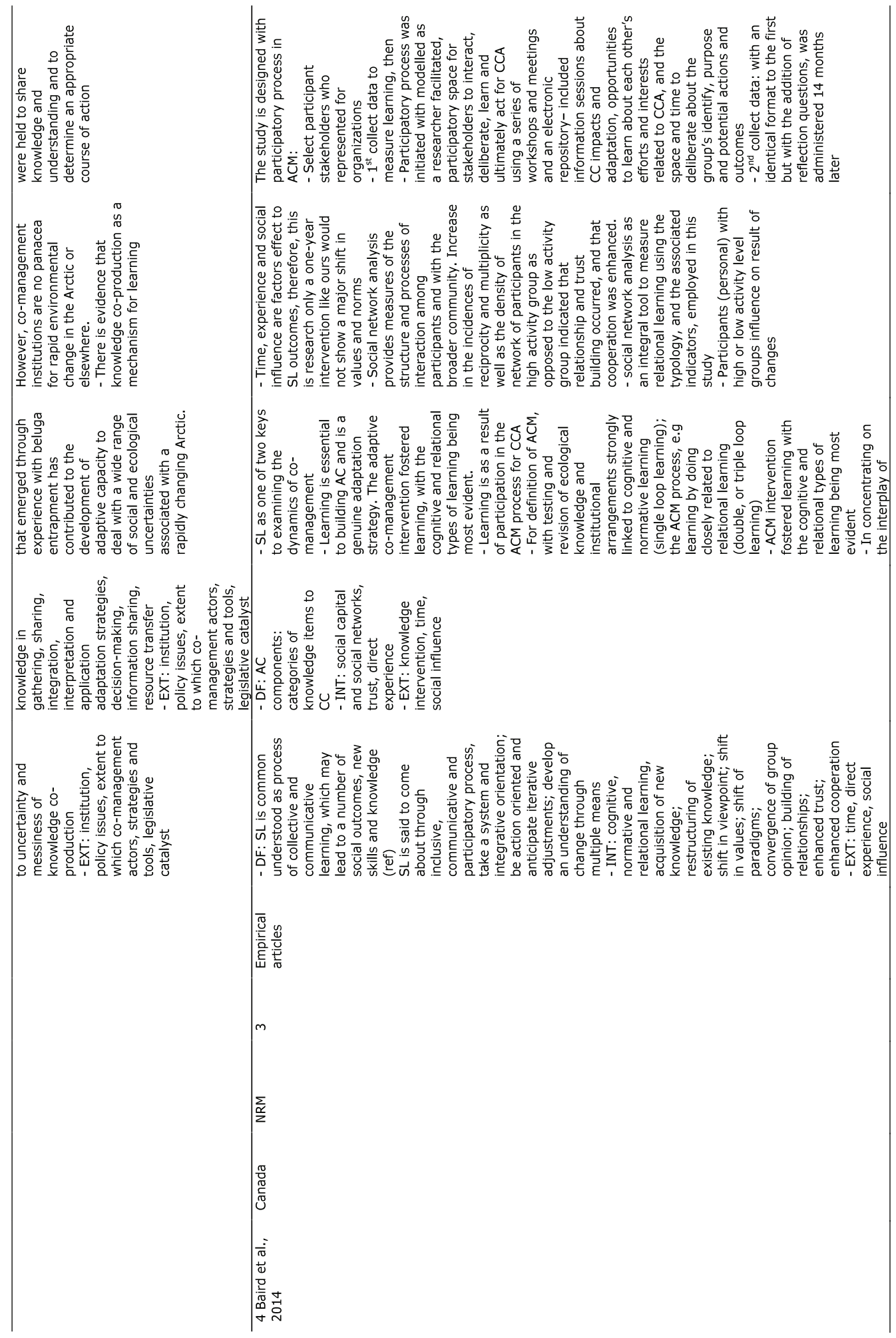

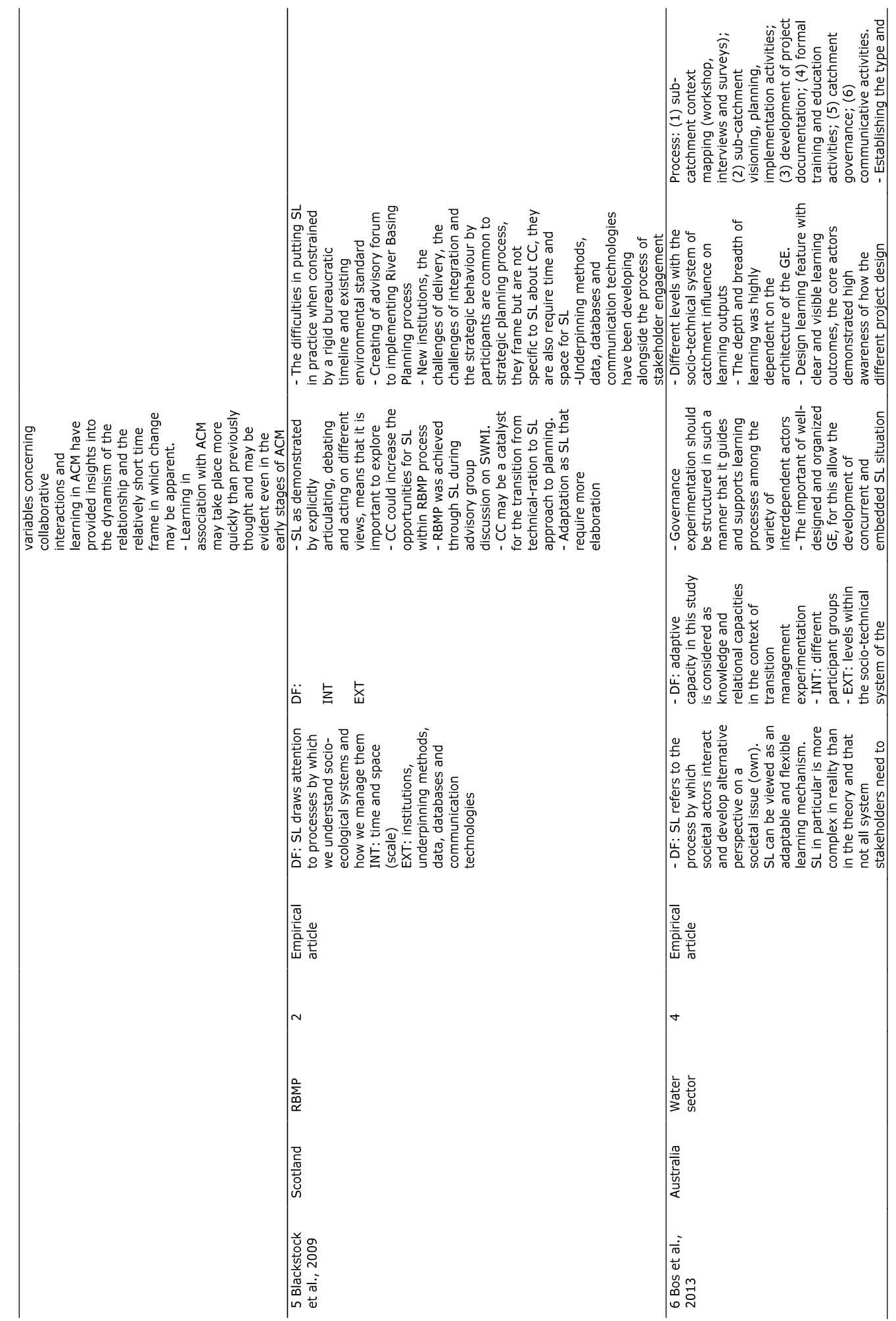




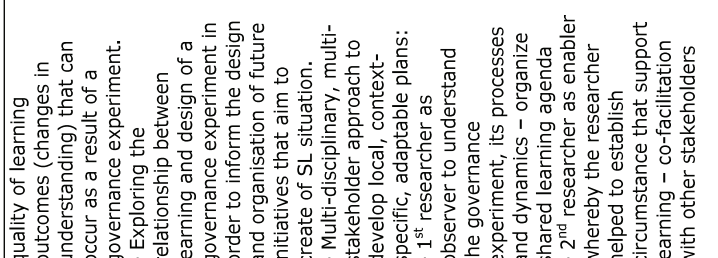

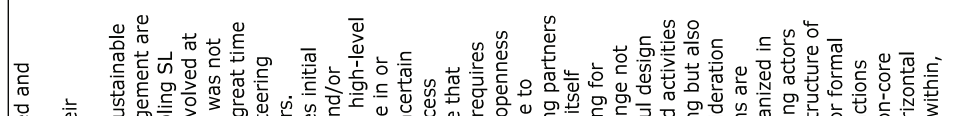

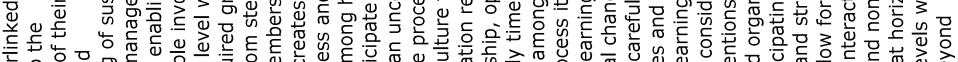

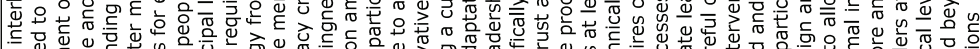

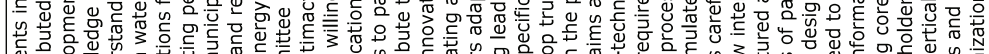

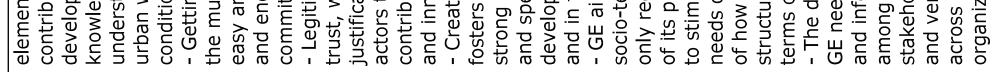

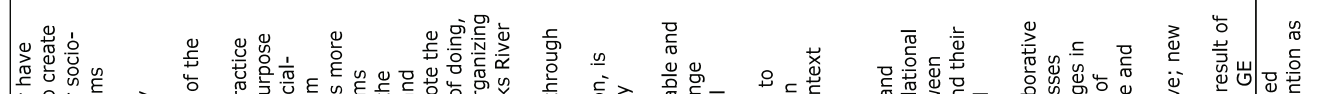

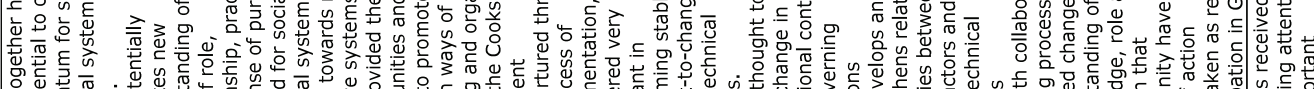

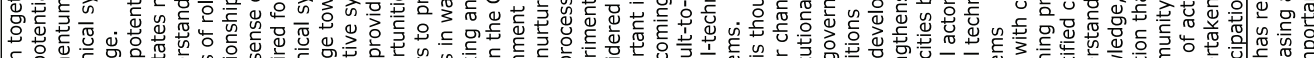

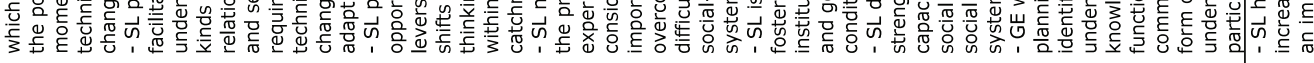

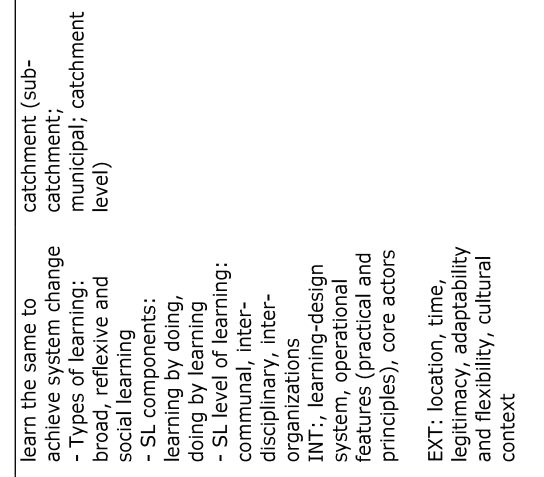

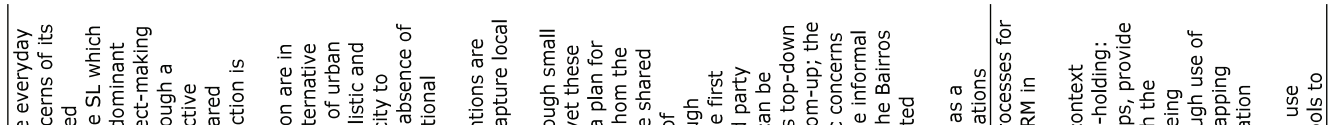

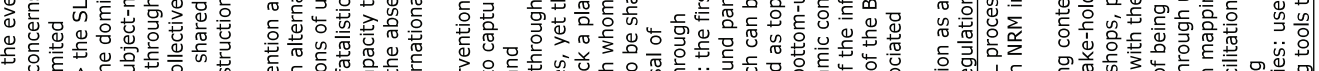

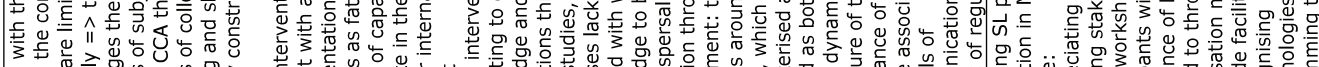
Bittim 足

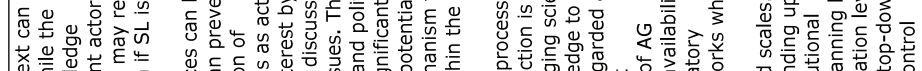

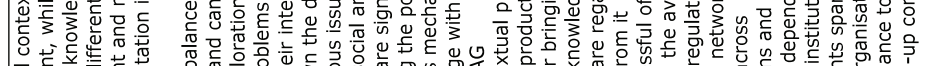

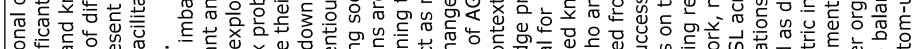

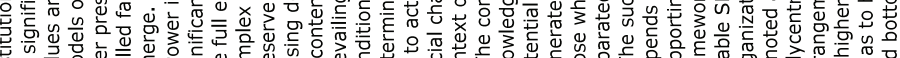

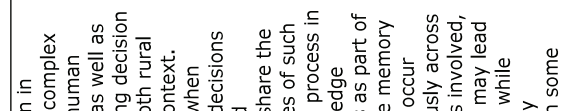
然 $\begin{array}{ll} & \\ 0 & \end{array}$

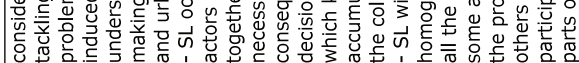

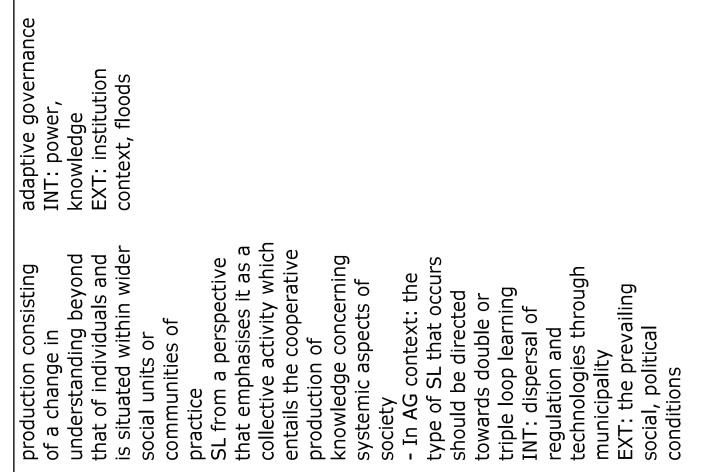

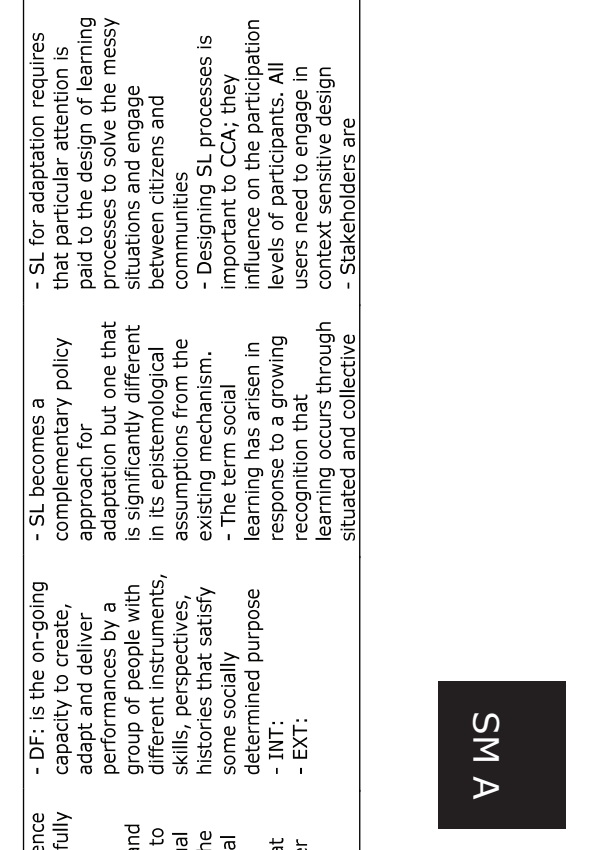

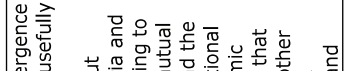

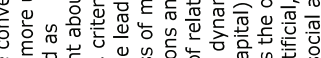

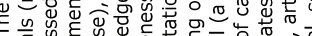

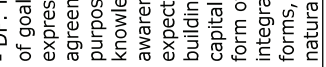




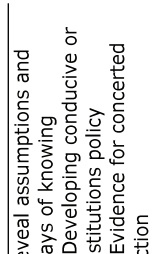

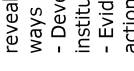

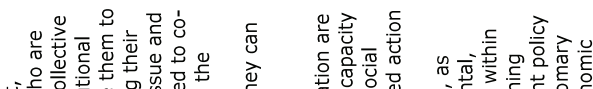

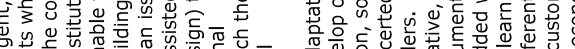

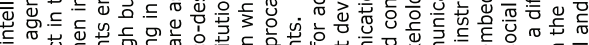
等

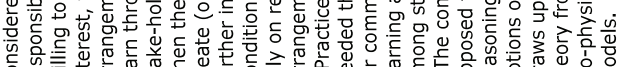

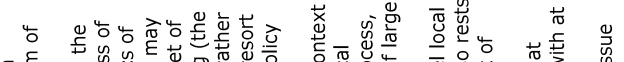

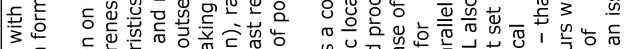

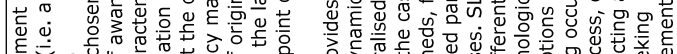

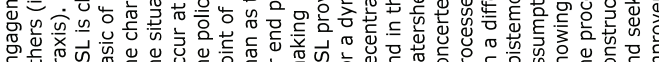

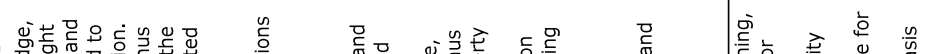

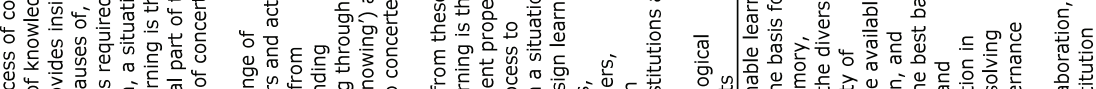

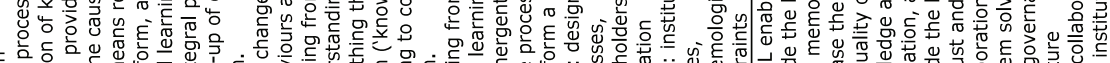

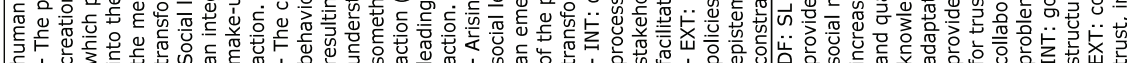

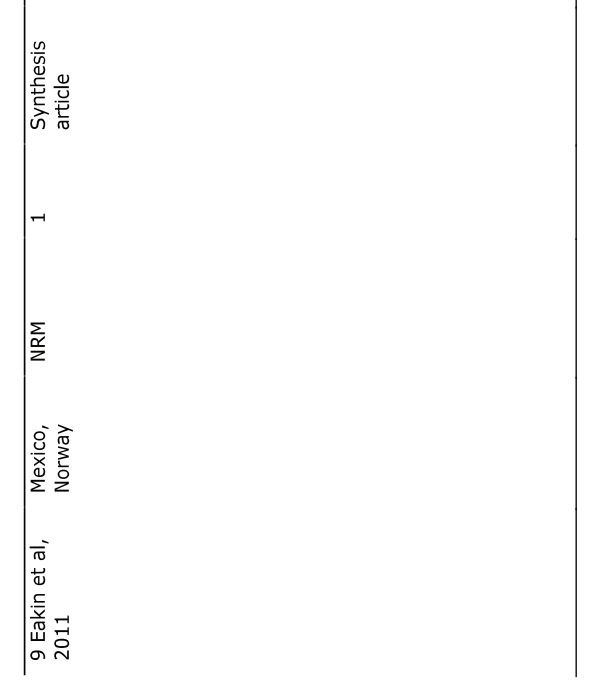

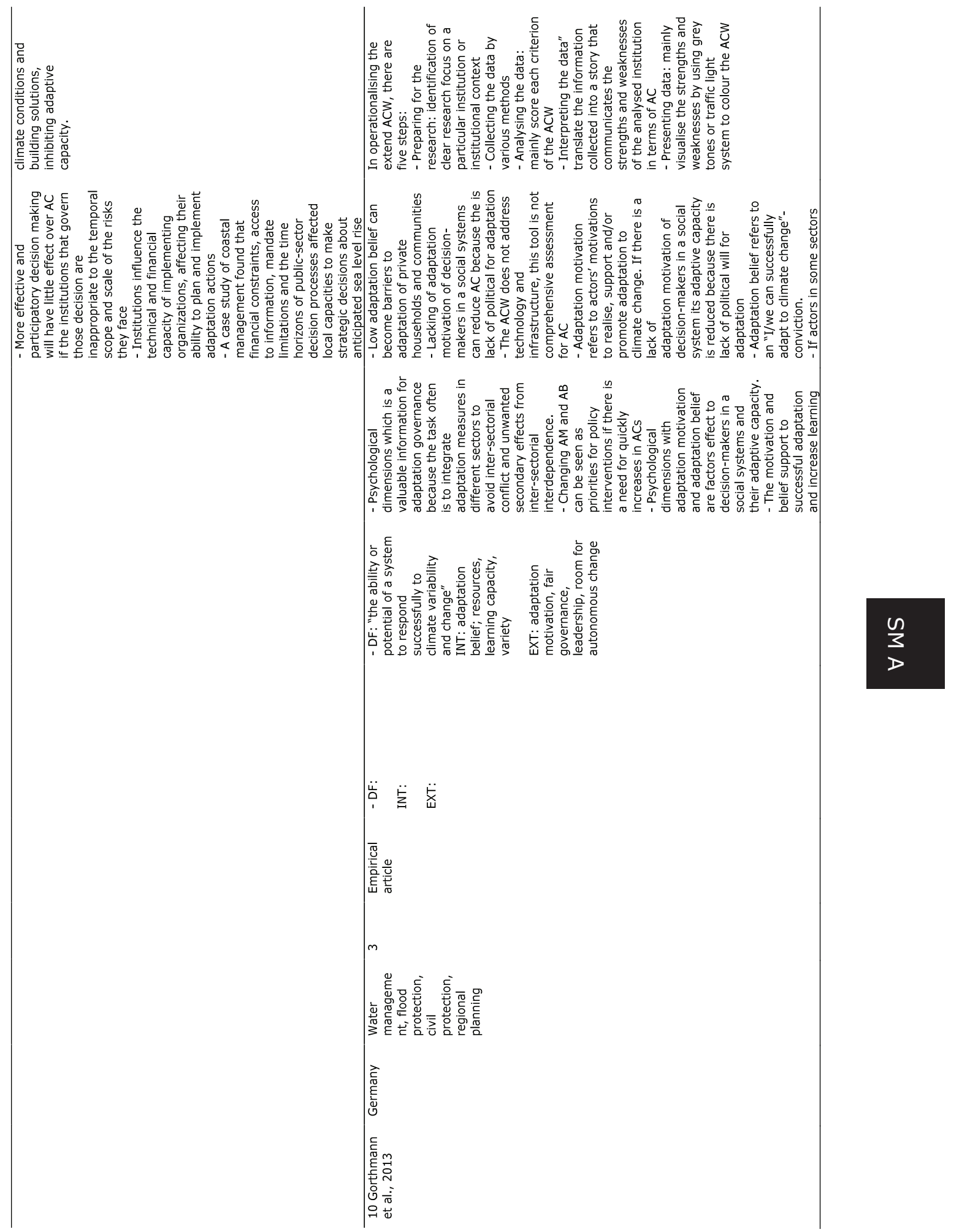




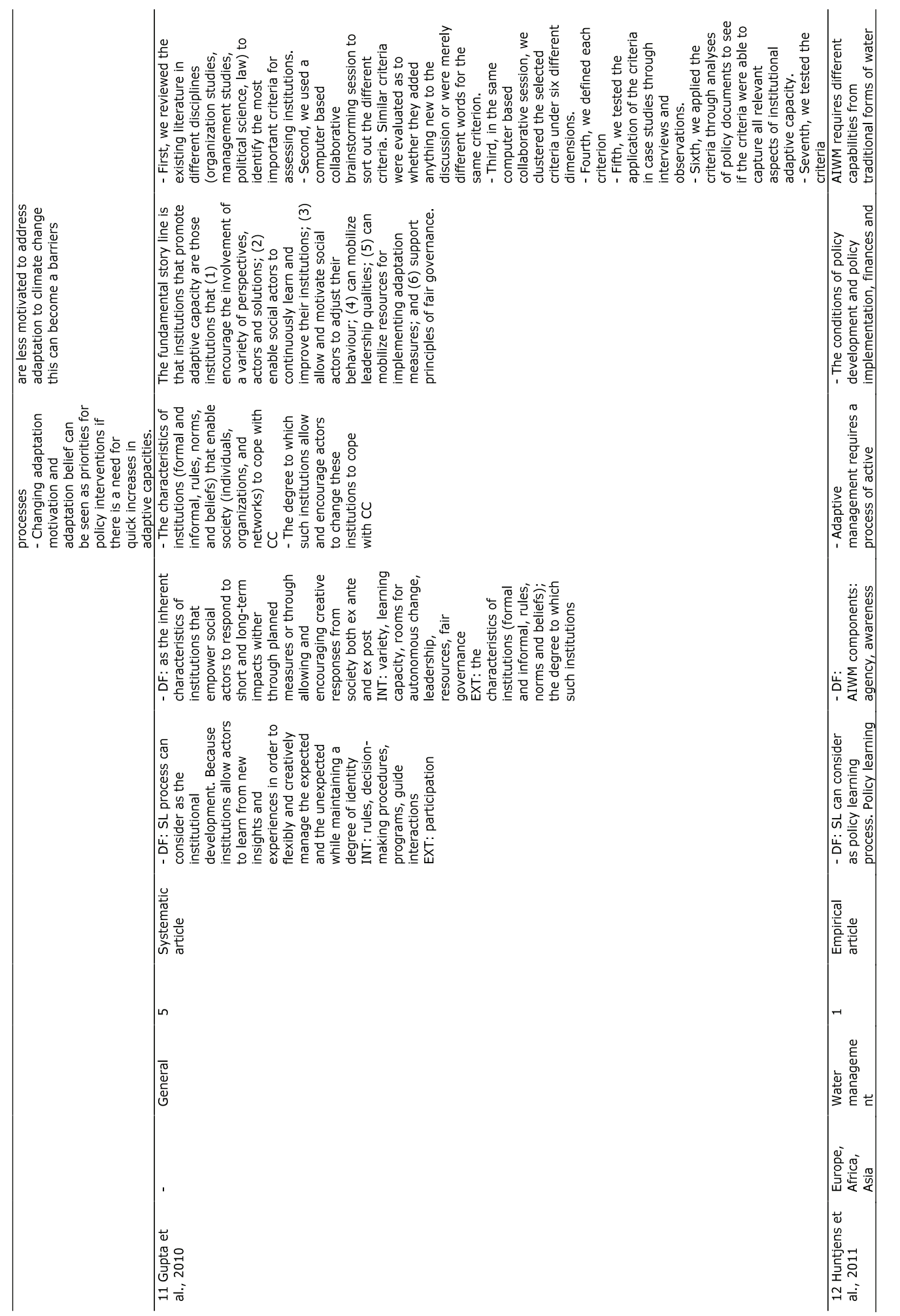

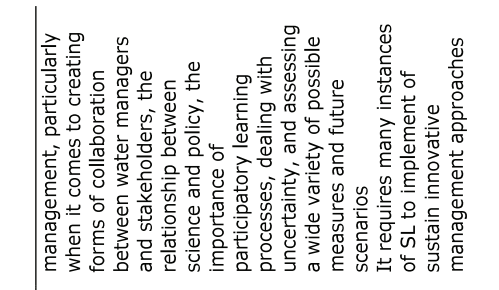
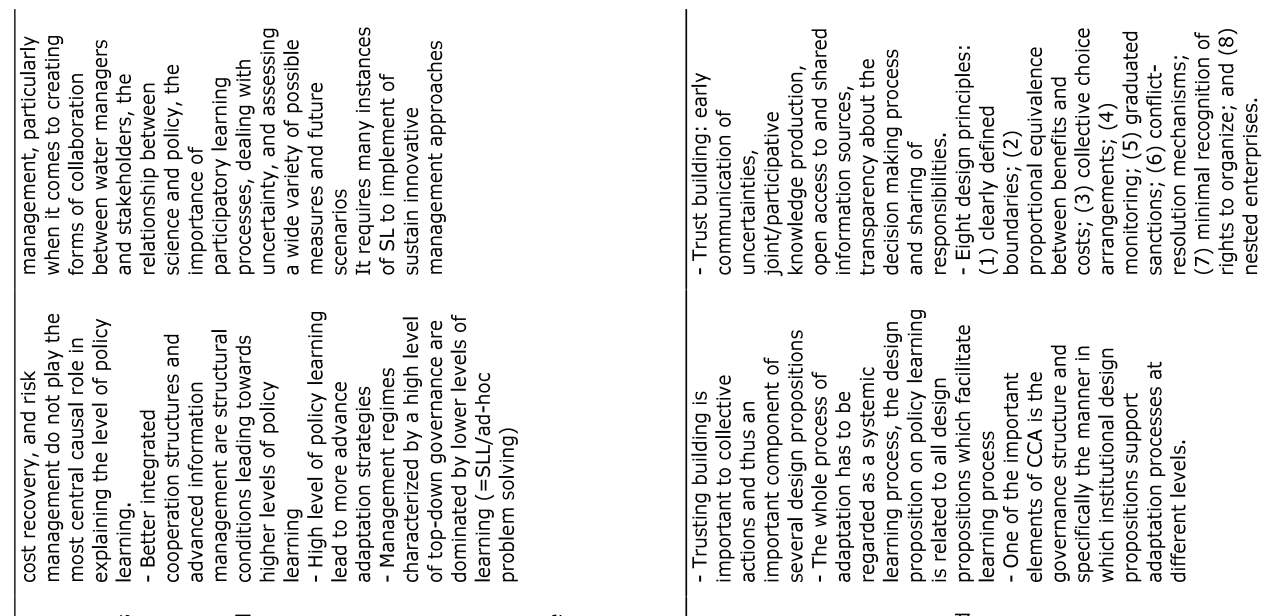

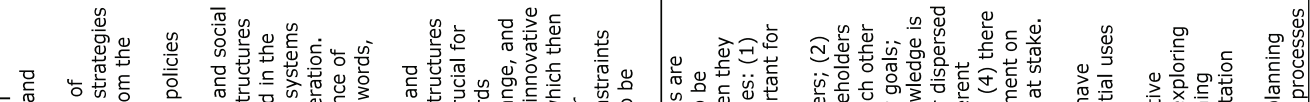

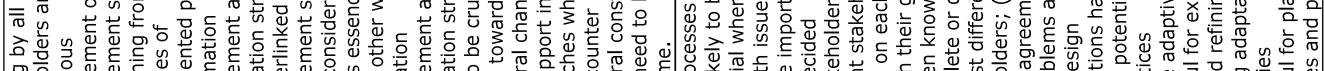

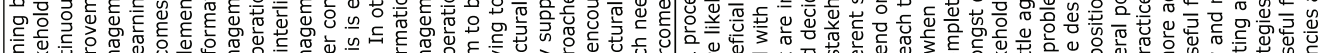

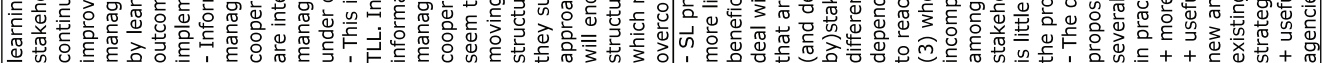
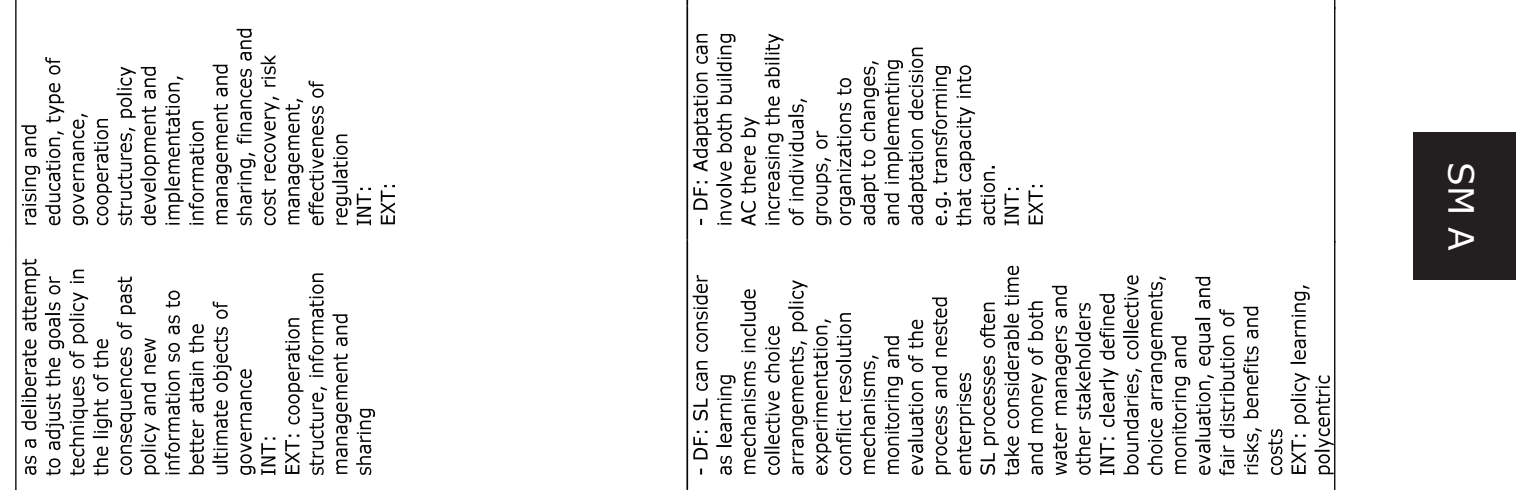

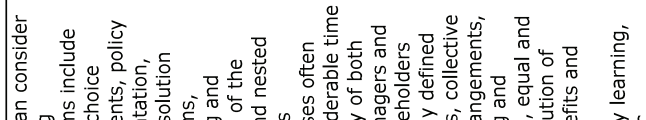

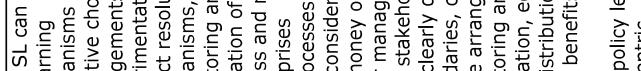

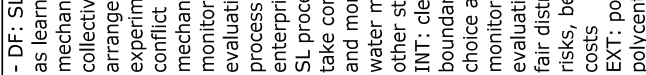

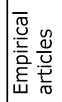

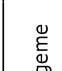

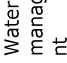

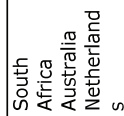

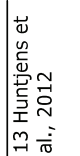



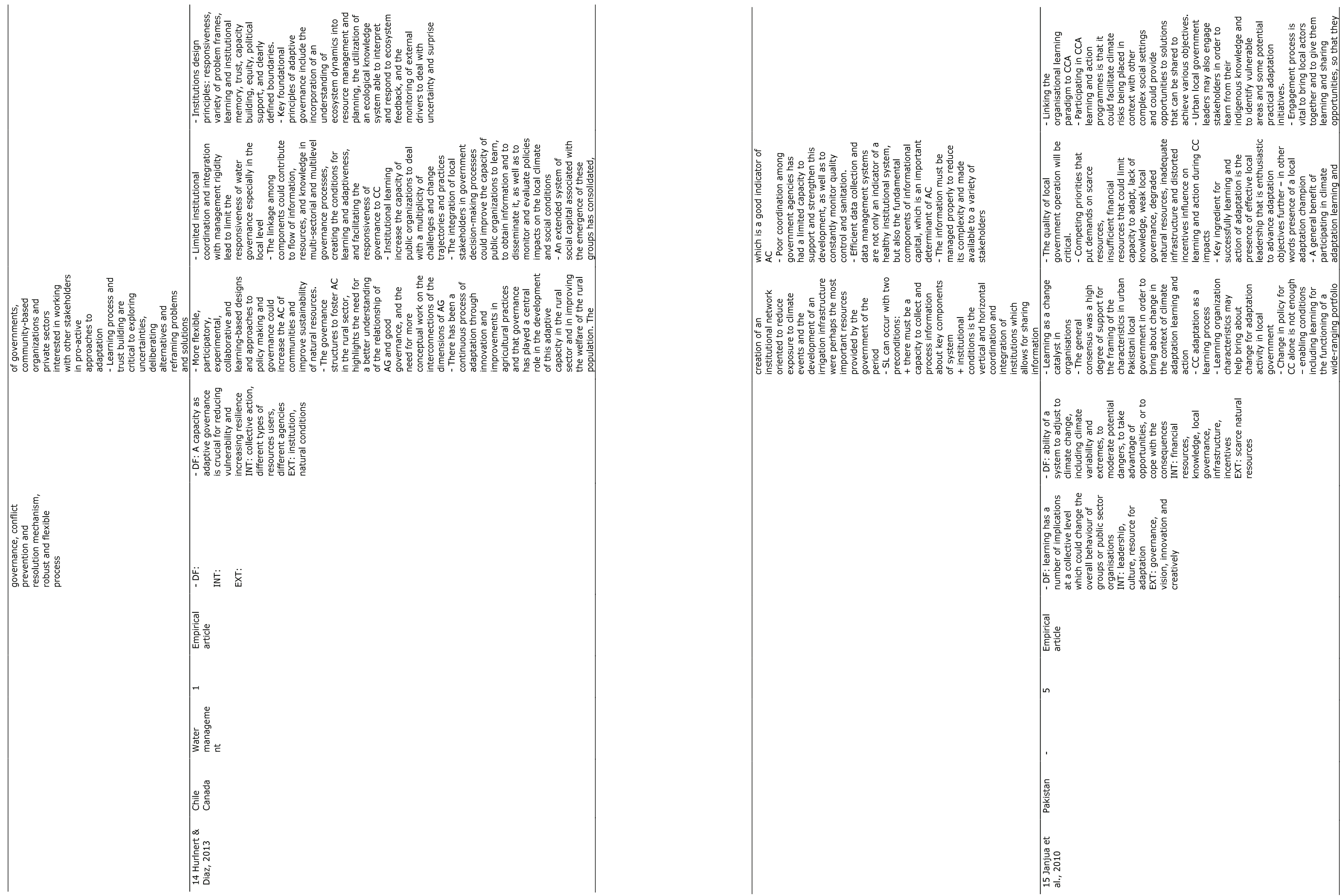


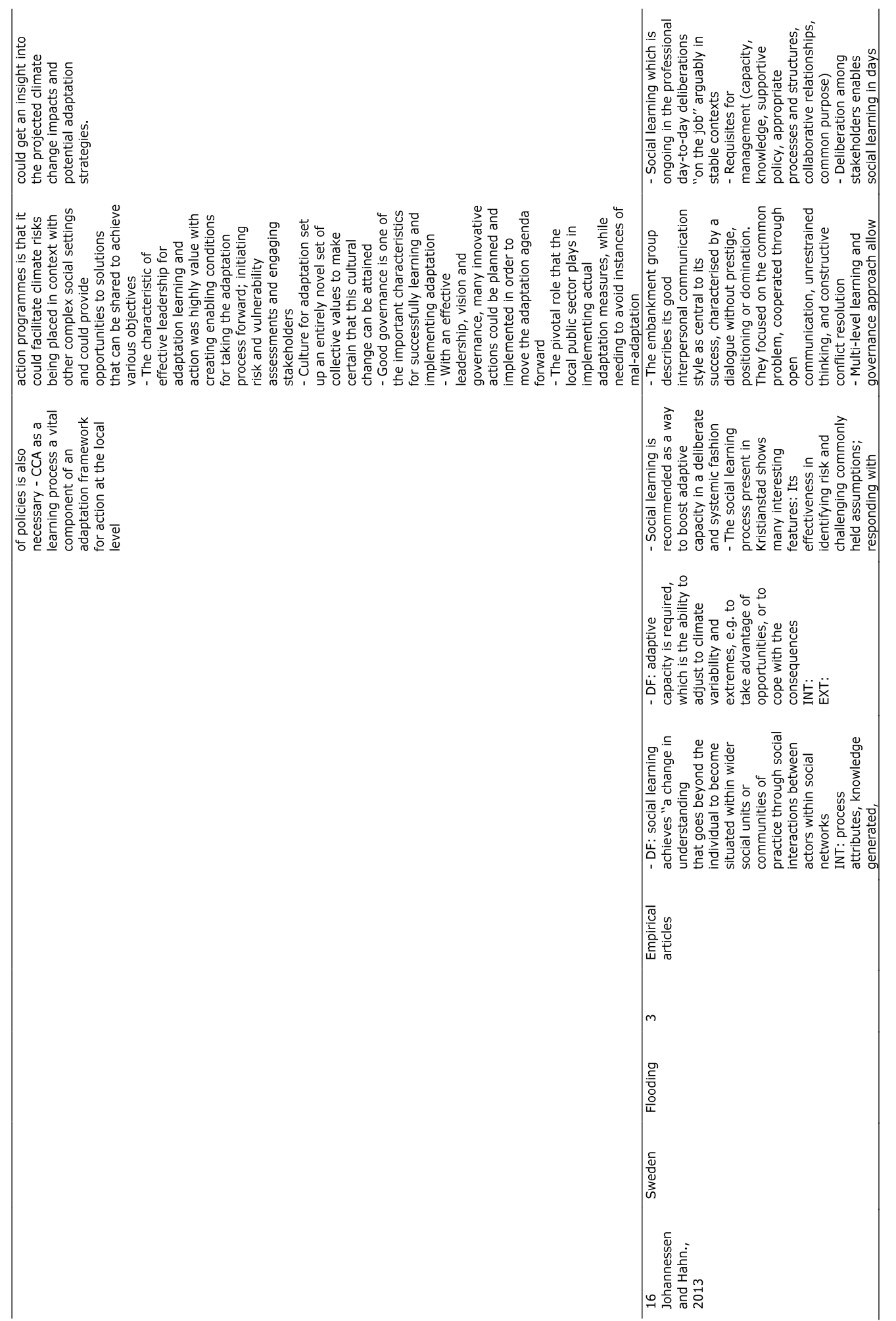

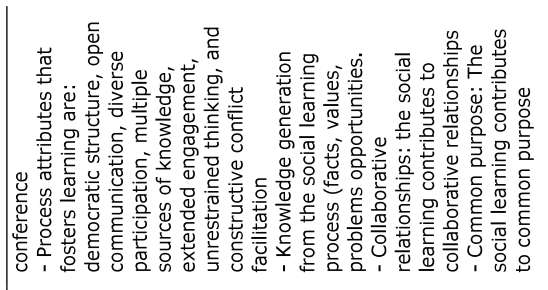

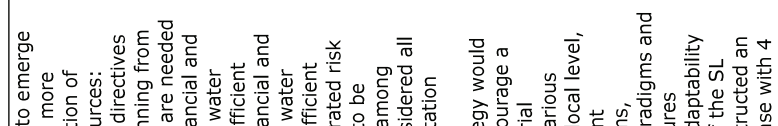

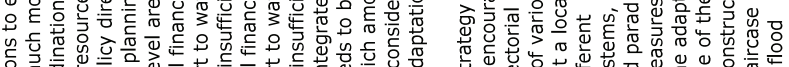

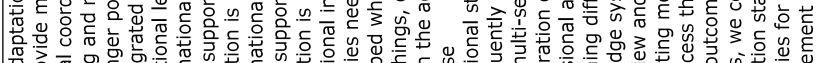

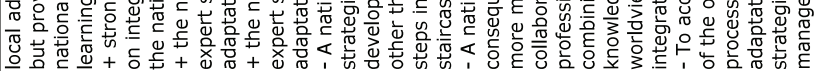

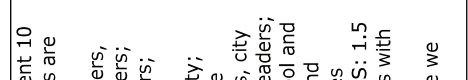

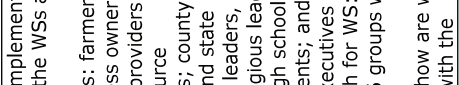

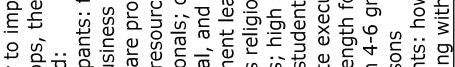

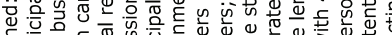

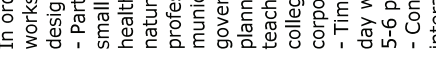

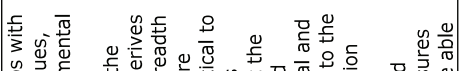
岁产产

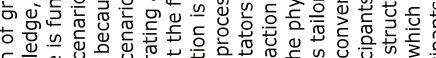
然 等

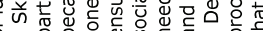

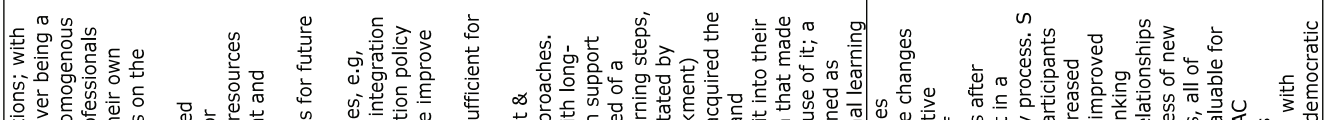

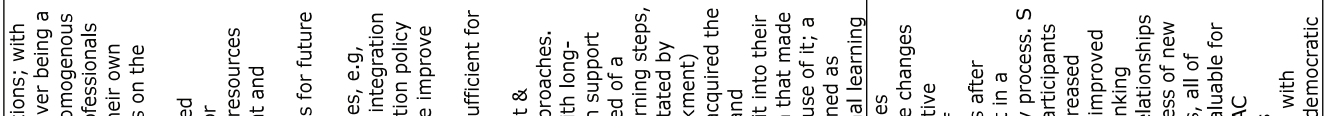

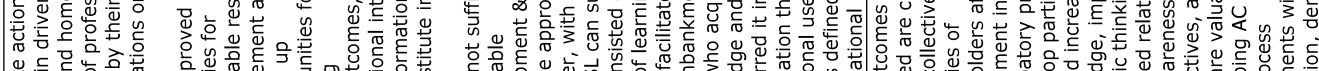

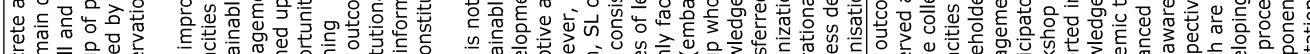

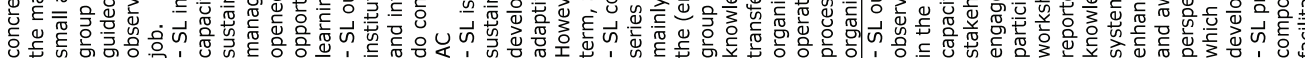

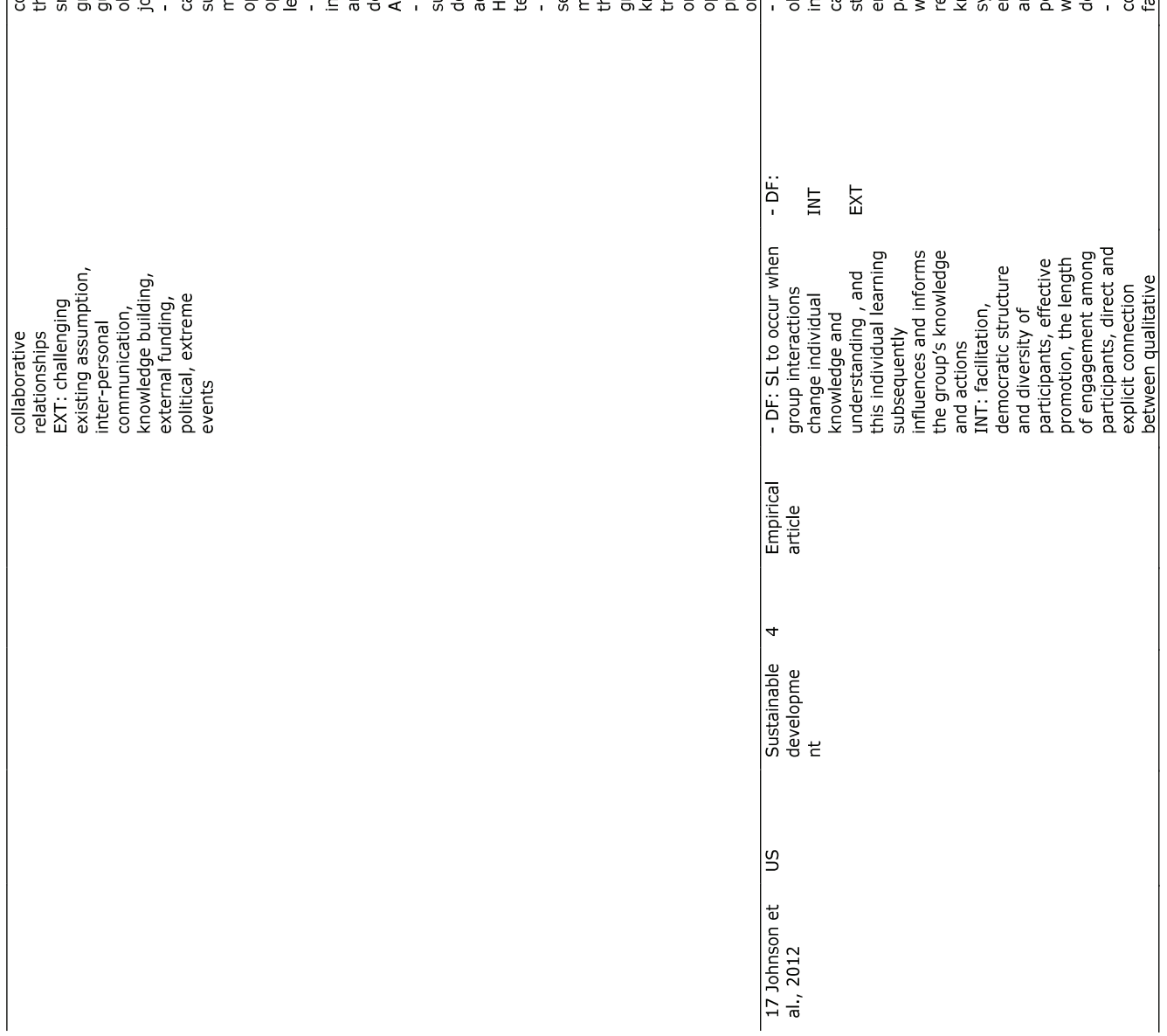



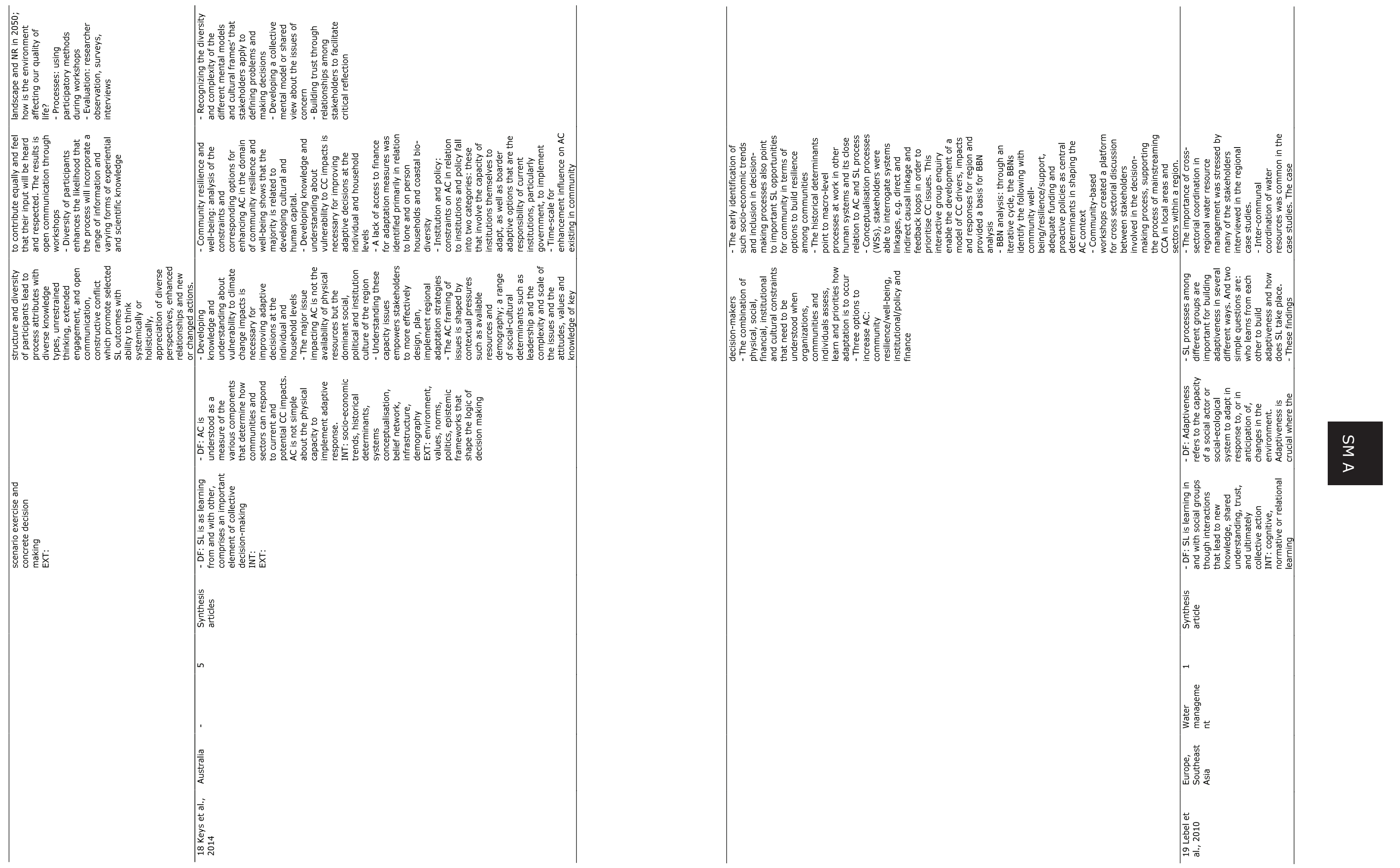


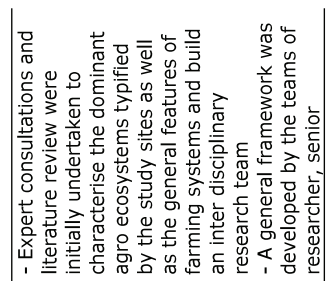

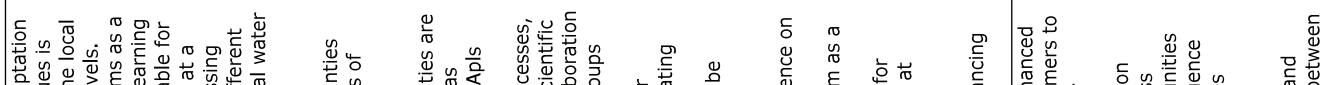

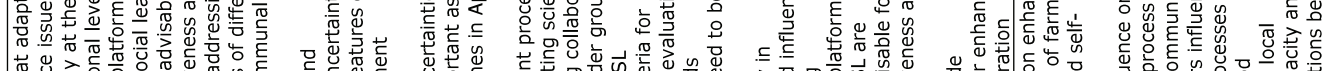

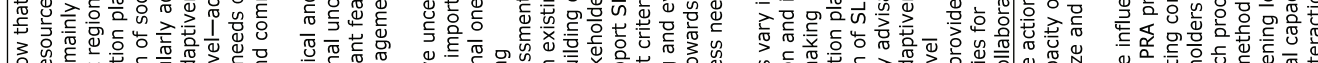
等

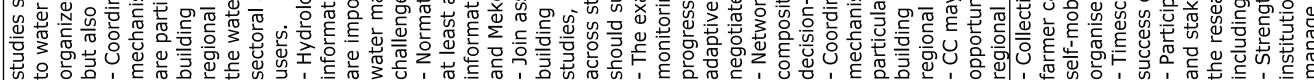

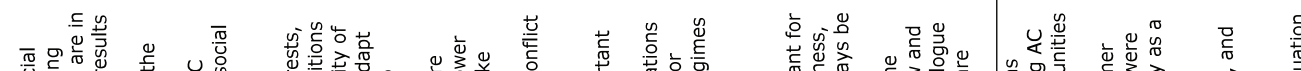

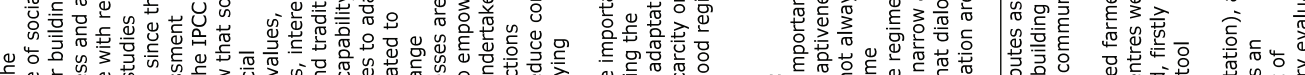

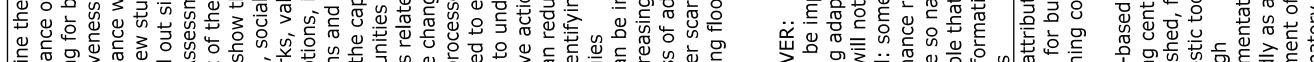

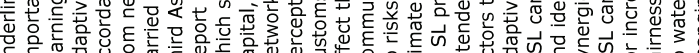
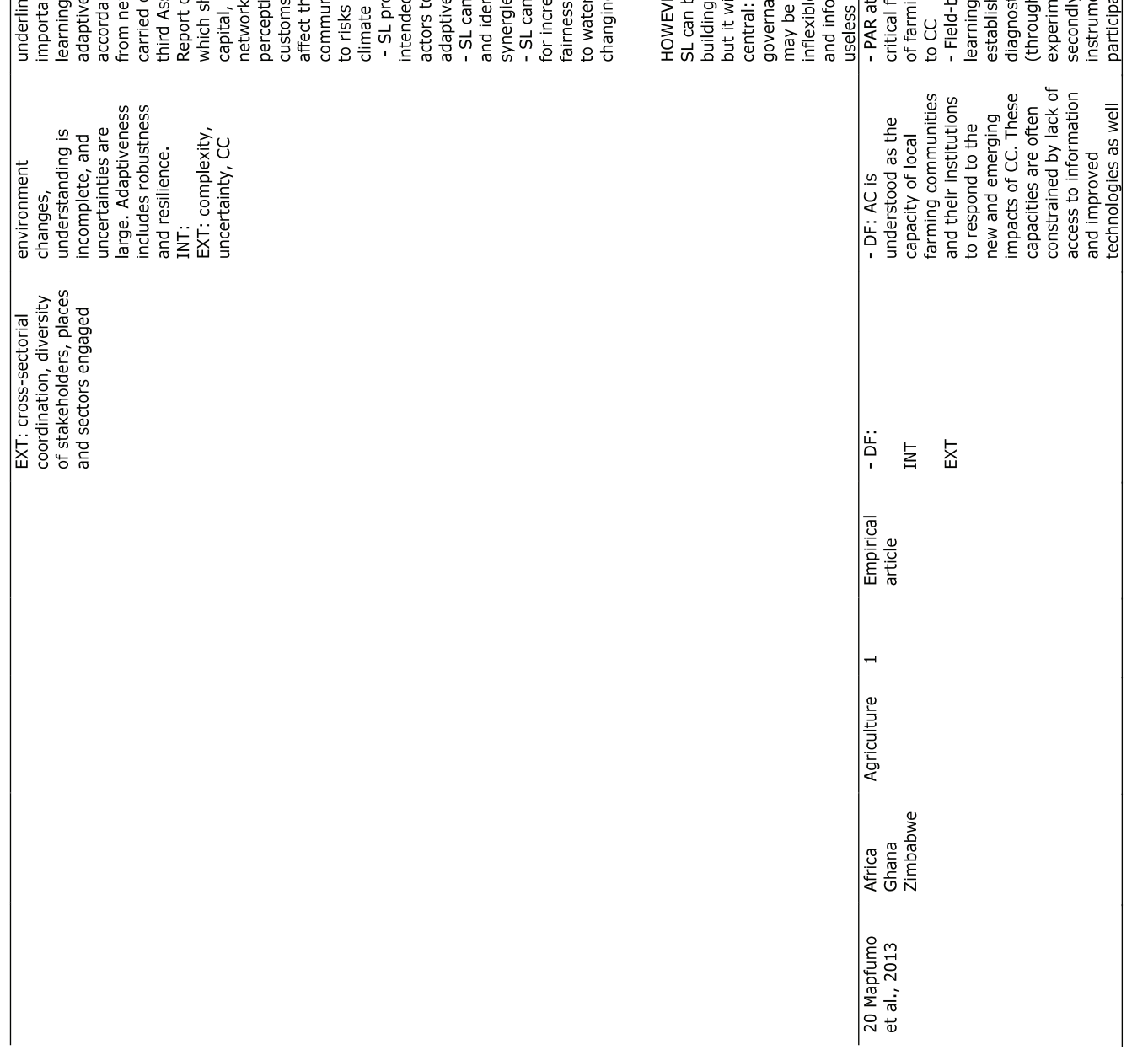
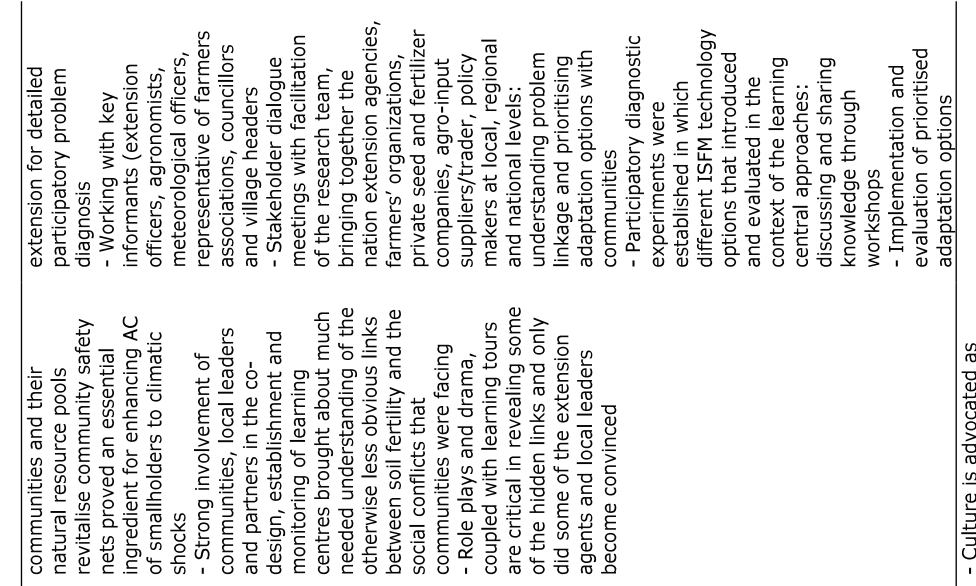

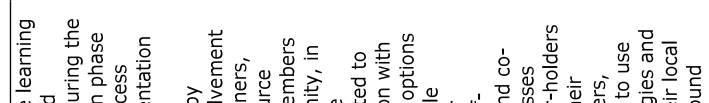
等

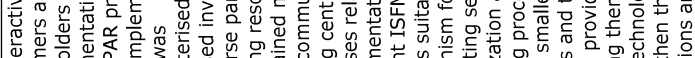

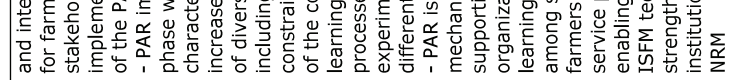

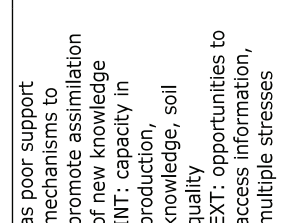
学
蒿点

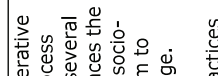
等

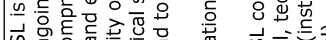

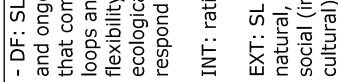
势

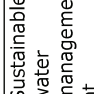

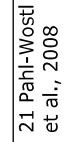

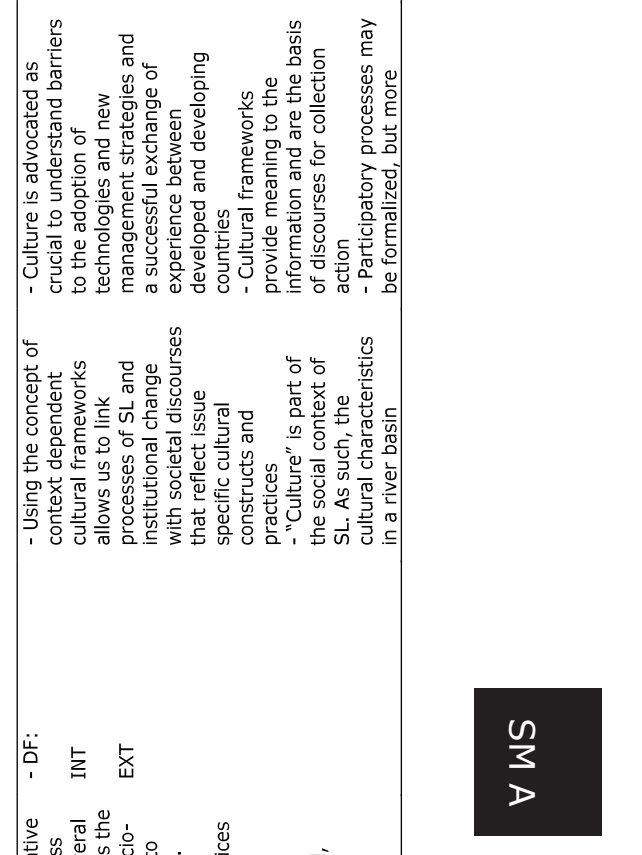



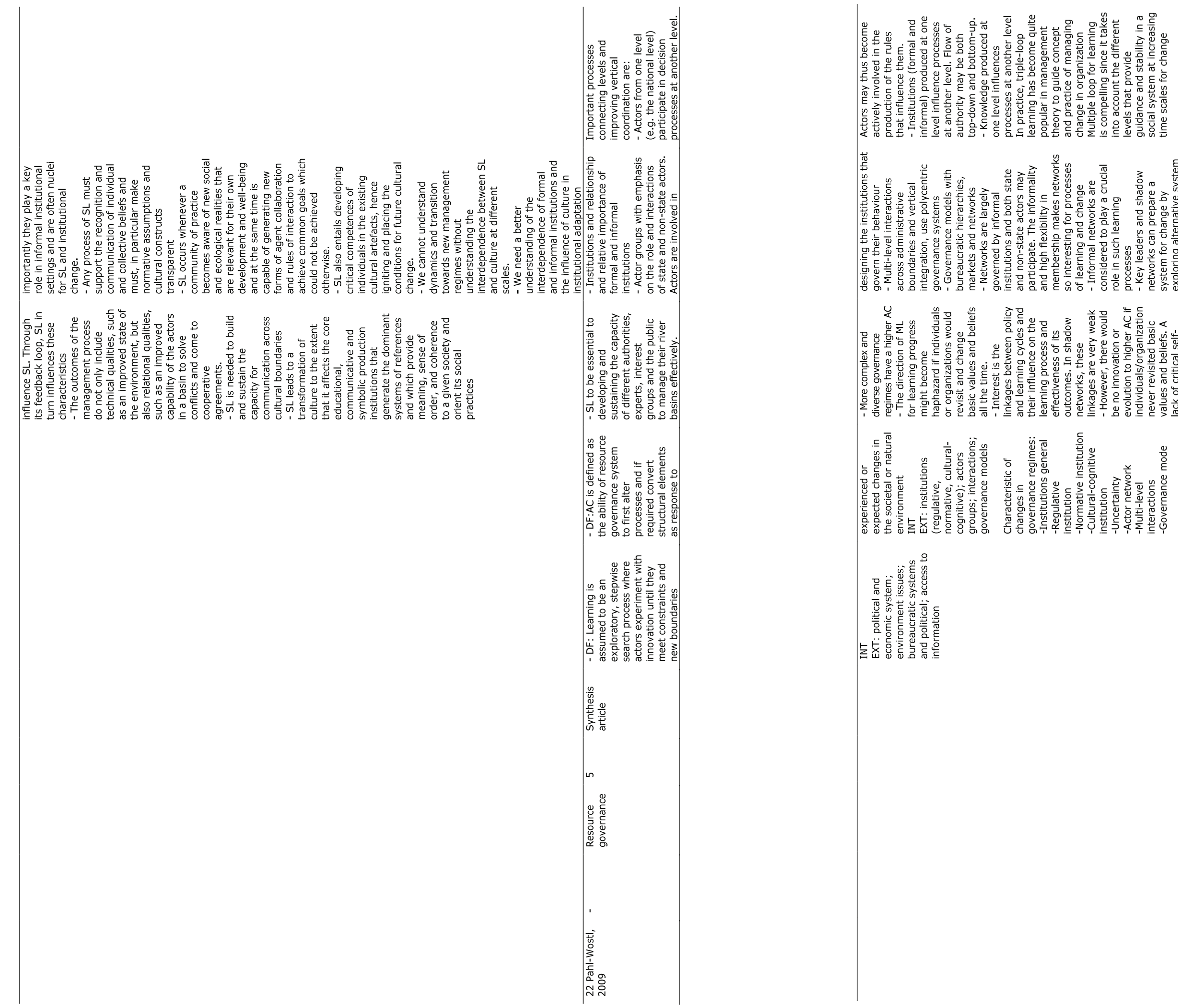

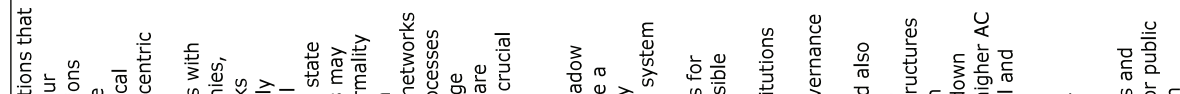

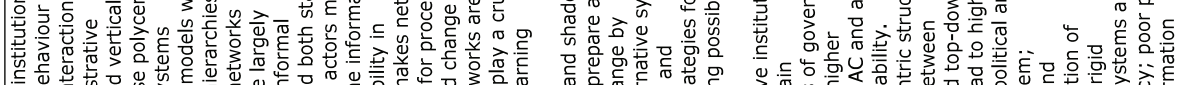

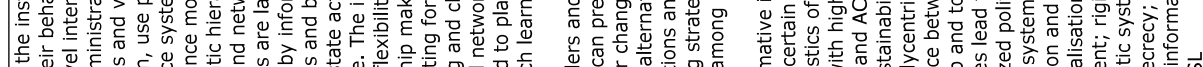

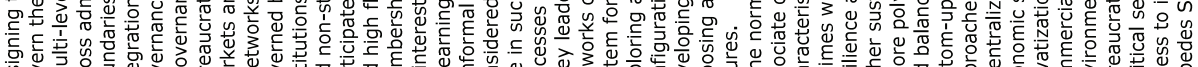

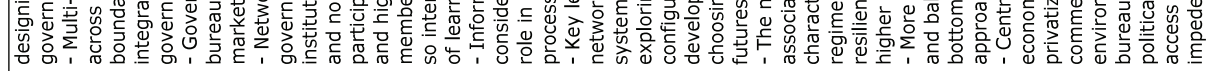

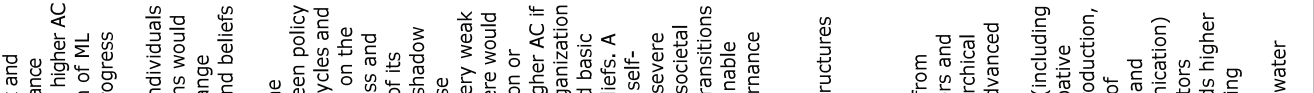

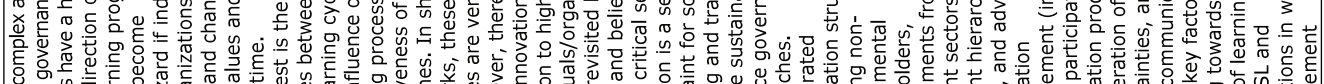
$\begin{array}{ll} & \\ 0 & \end{array}$

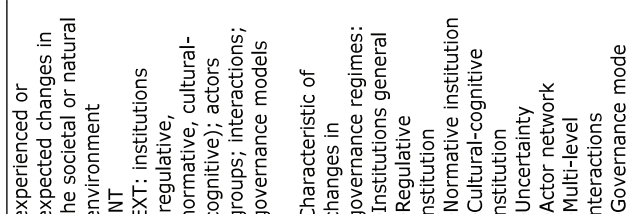

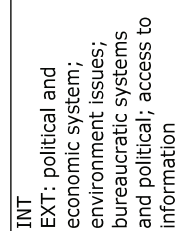




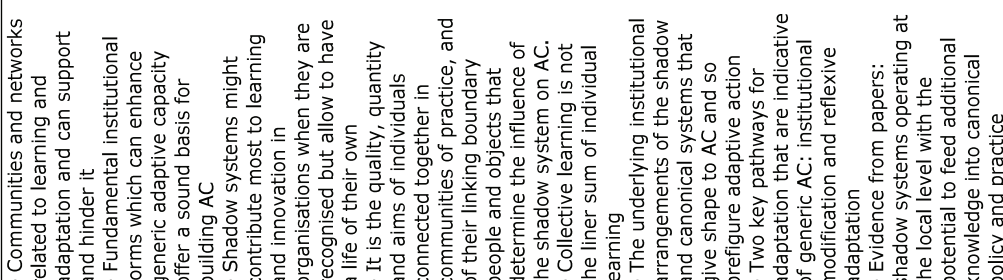

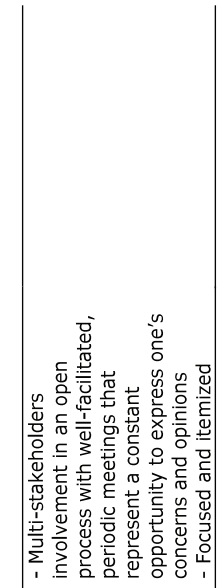

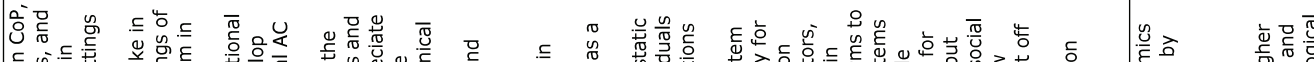

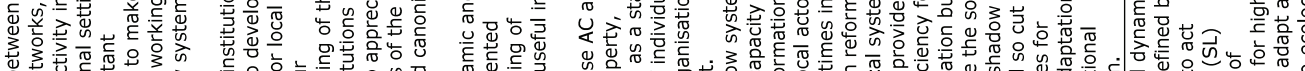

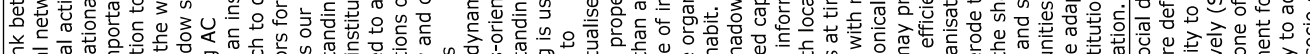

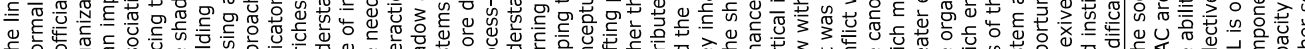
等

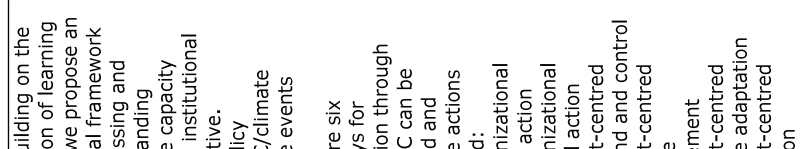

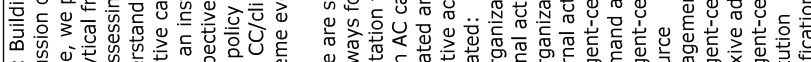

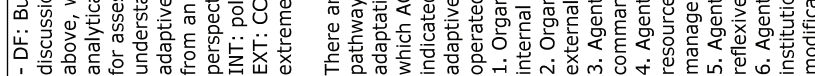

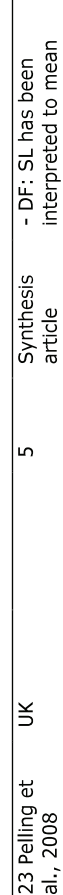

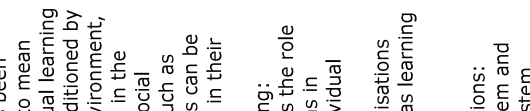
$\begin{array}{ll} & \\ 0 & \end{array}$

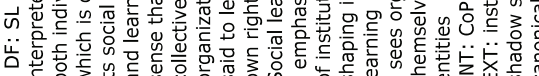

紊紊

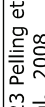

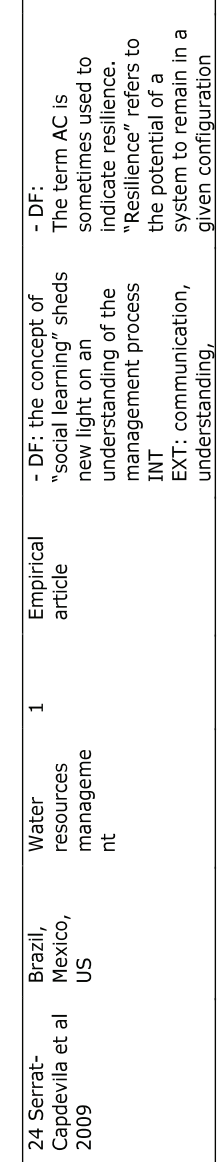

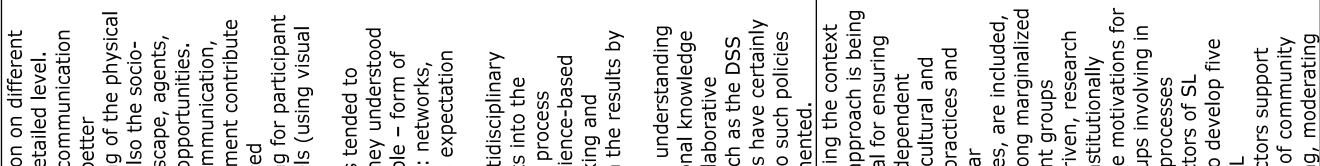

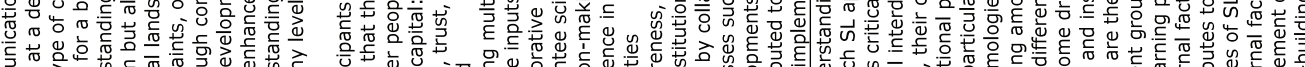

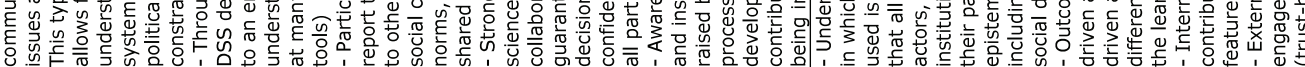

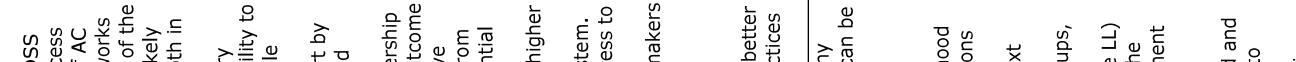

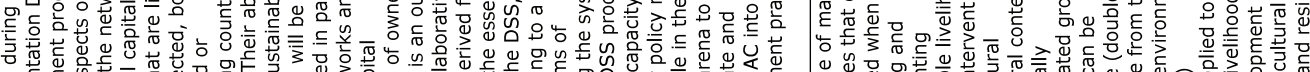

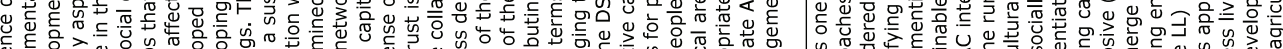
等

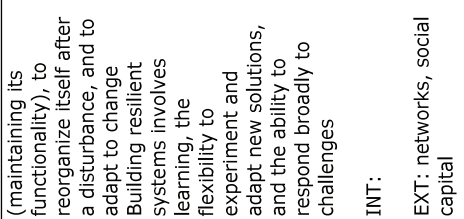

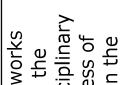

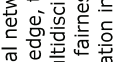

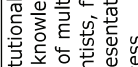

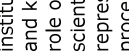

㟥点

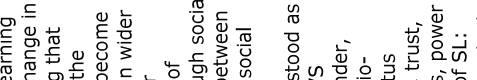

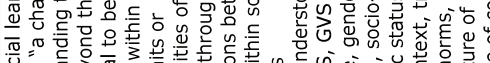

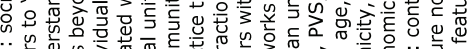

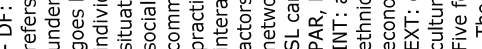

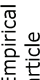

产

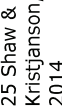



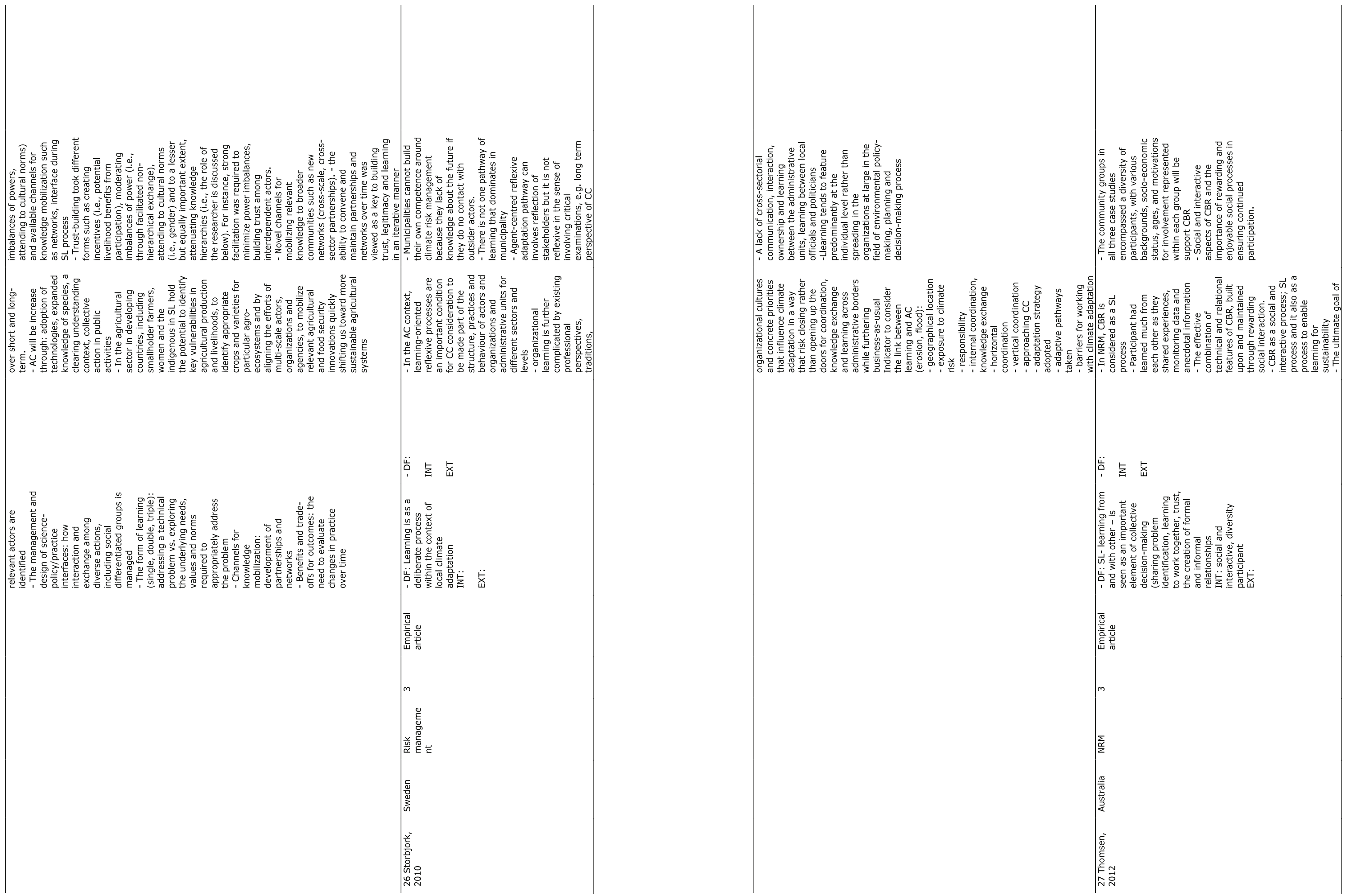


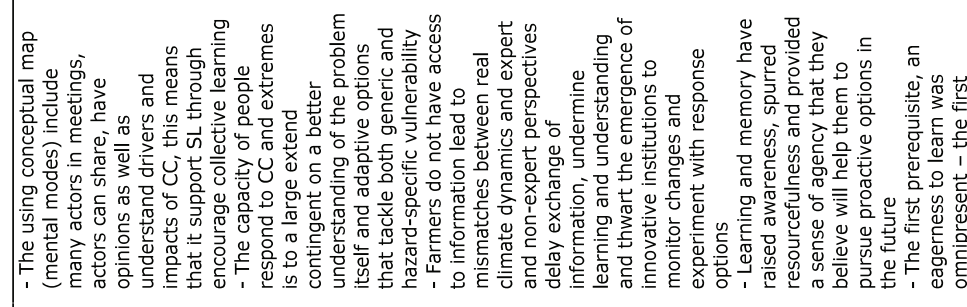

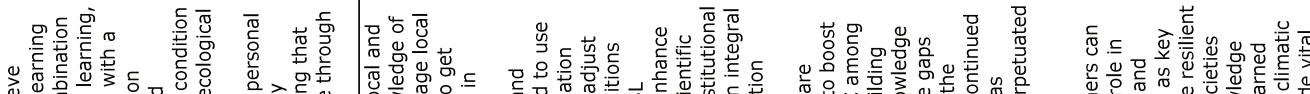
$\begin{array}{llll} & \\ 0 & & \\ 0\end{array}$

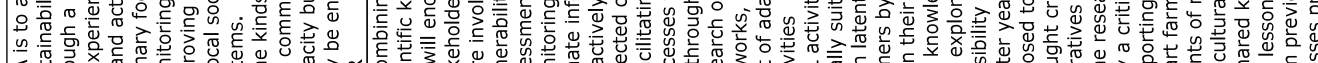

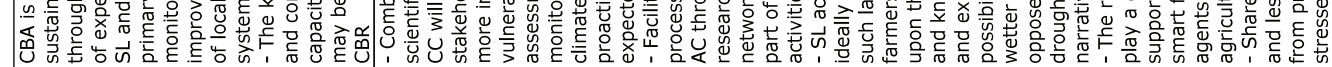

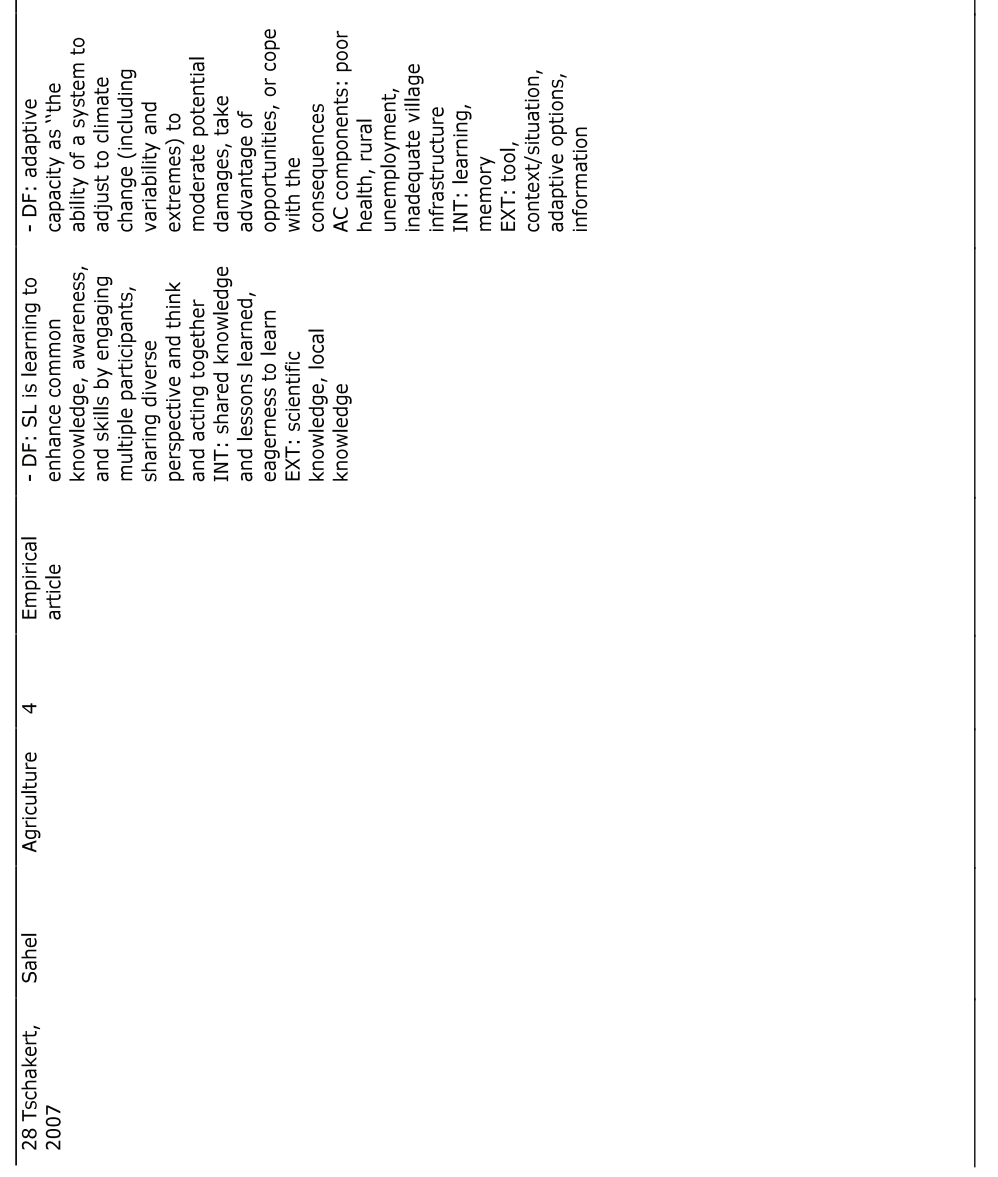

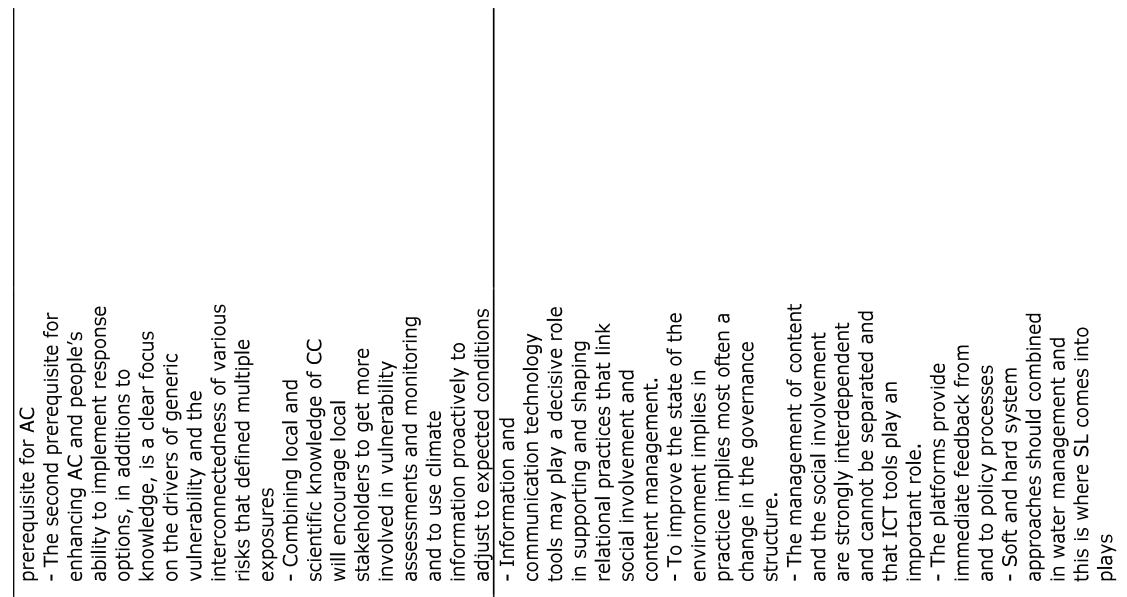

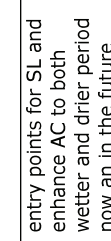

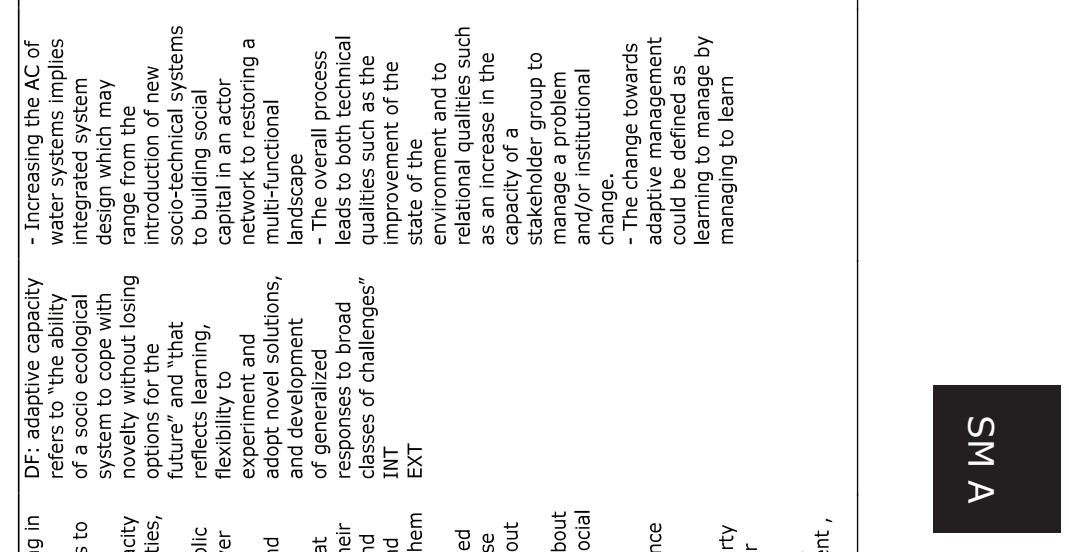

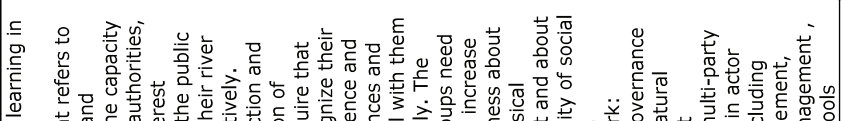

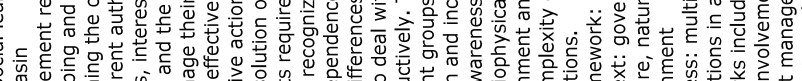

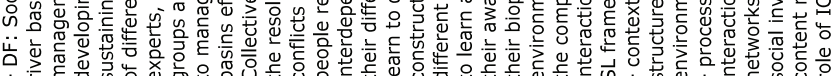




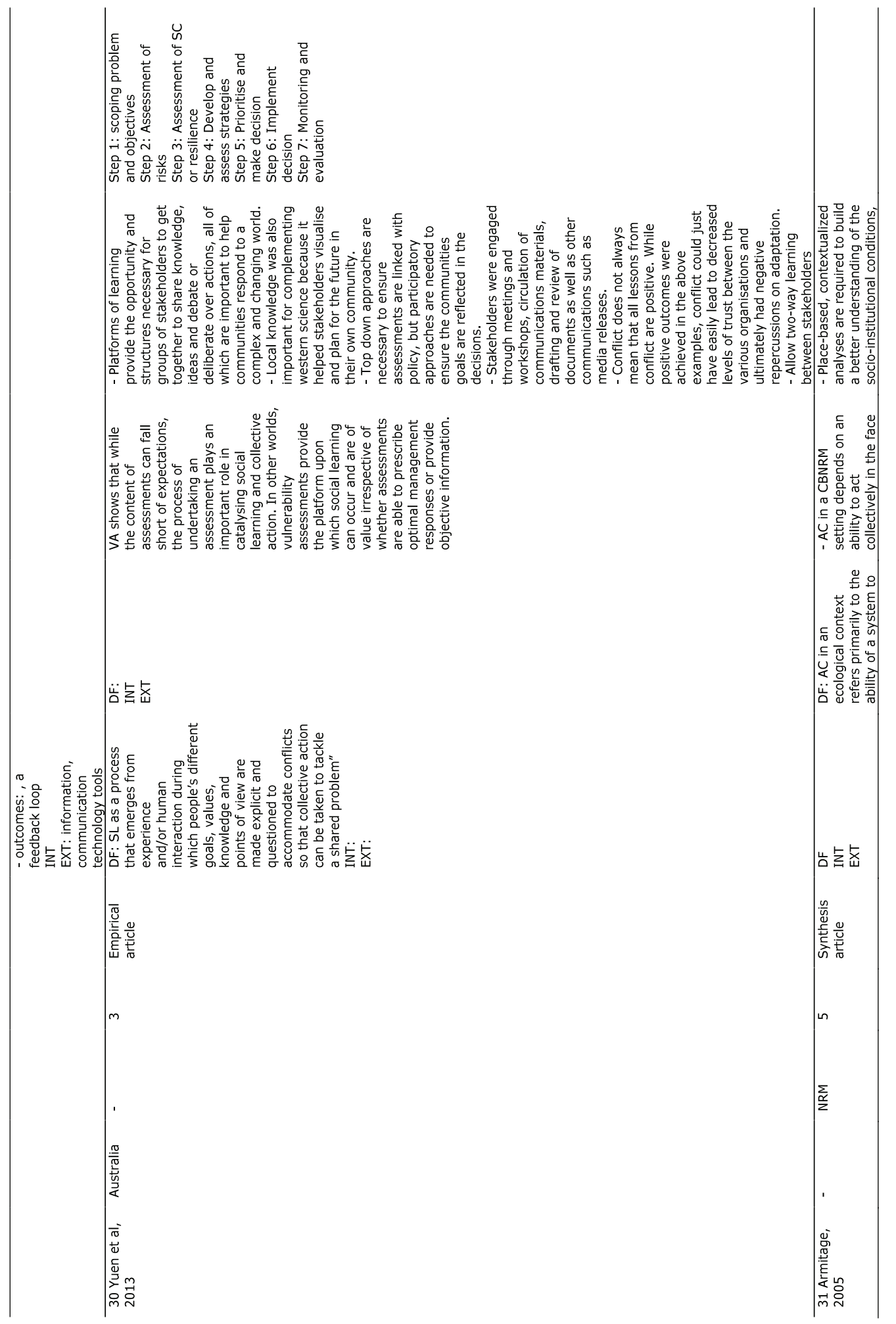

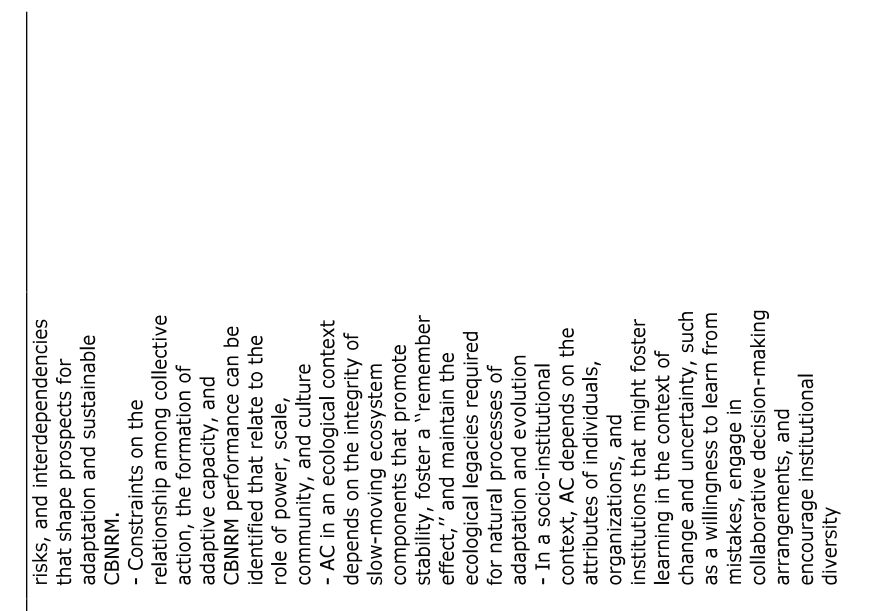

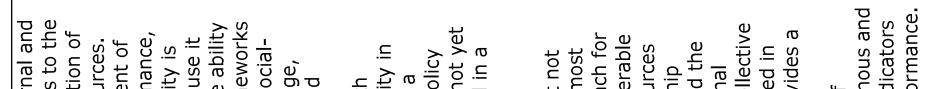

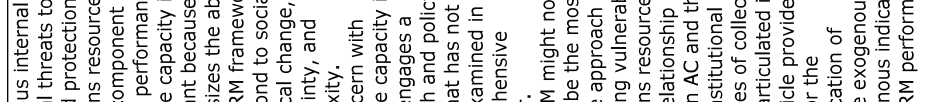

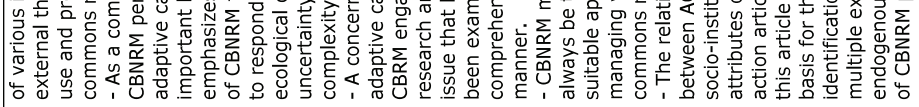

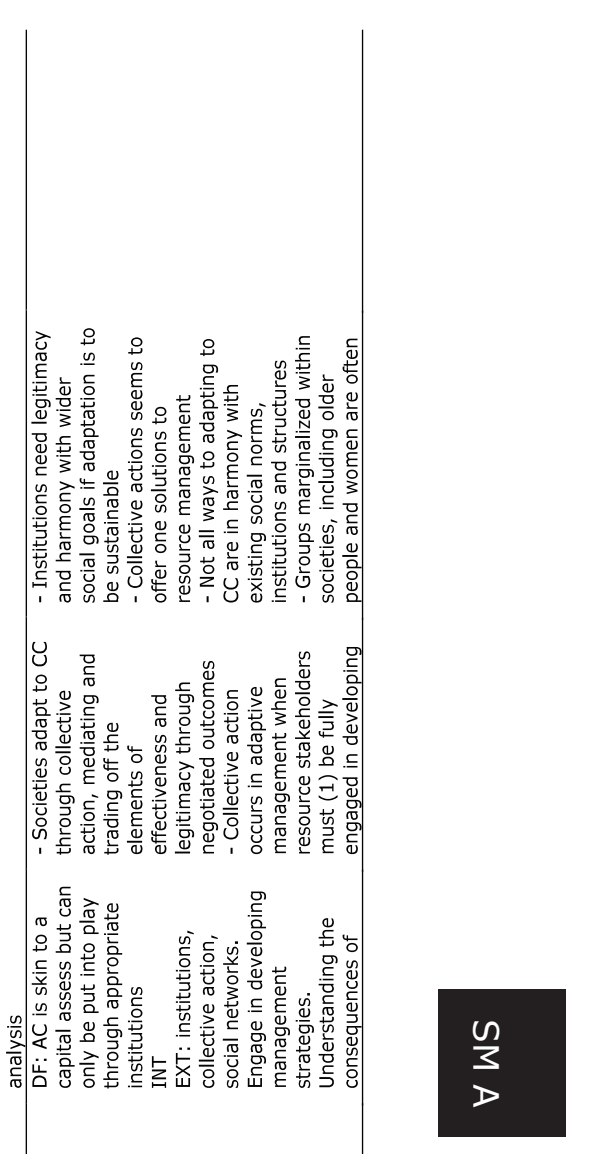

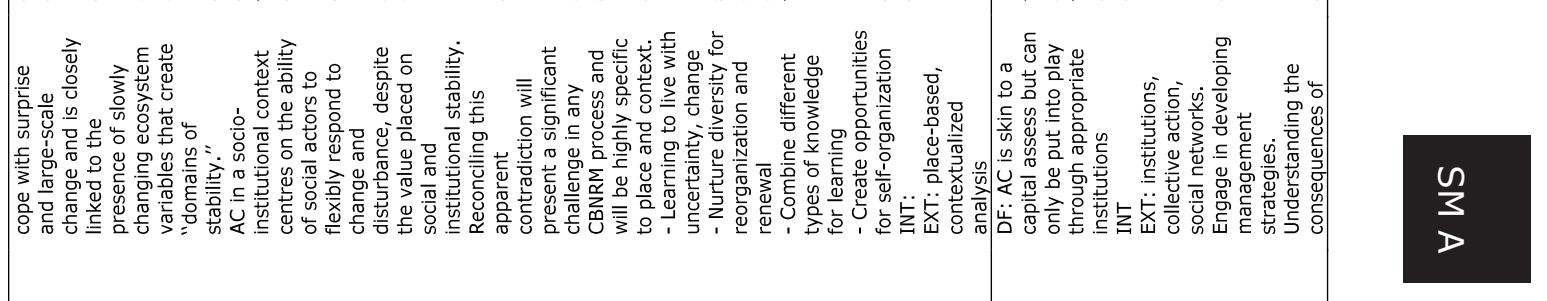






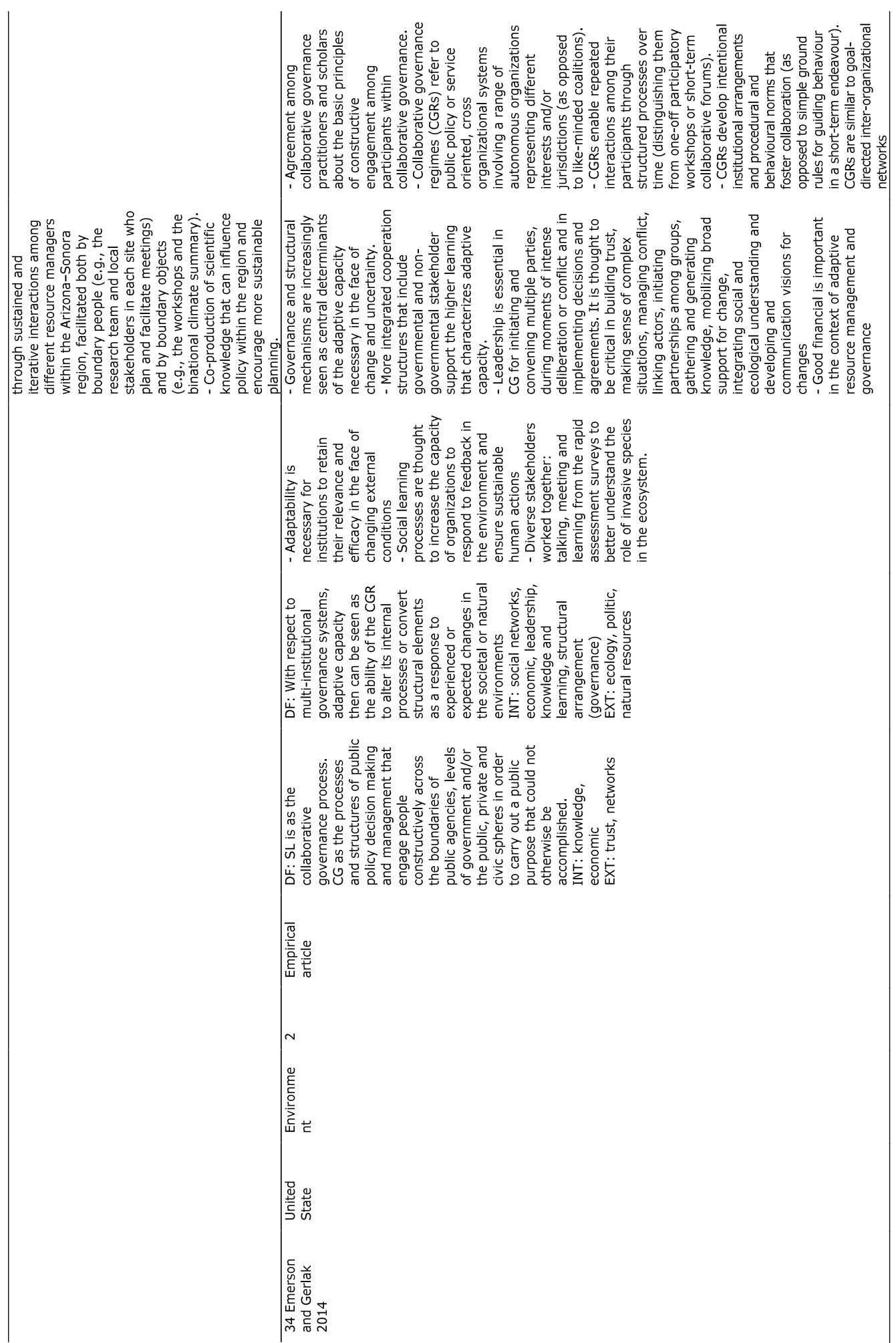




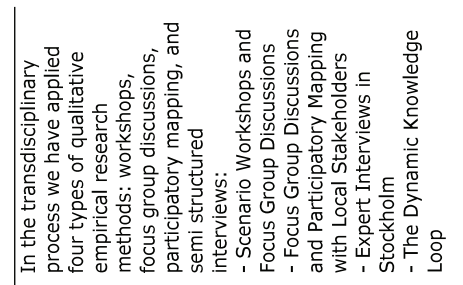

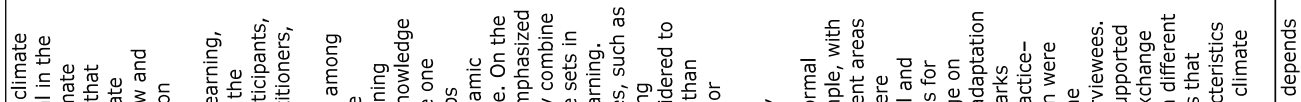

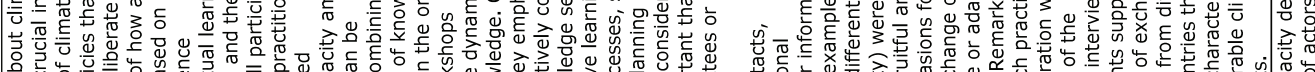
$\begin{array}{ll} & \\ 0 & \end{array}$ 等

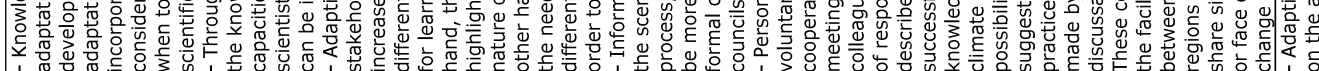

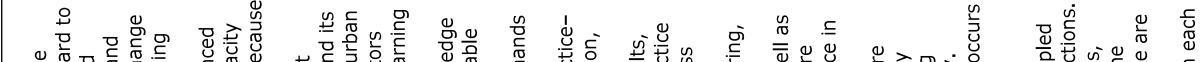

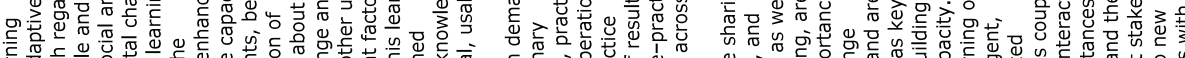

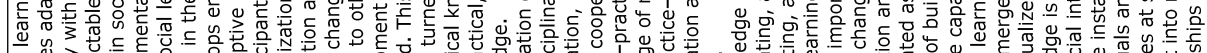

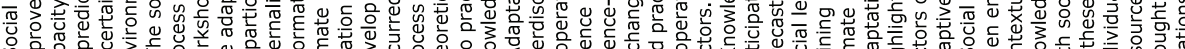

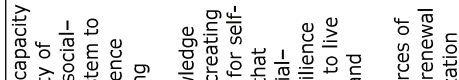

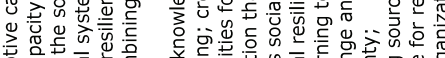

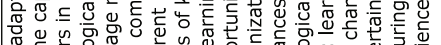

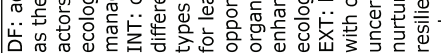

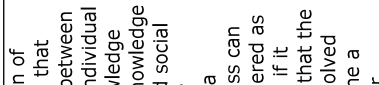

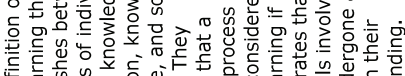

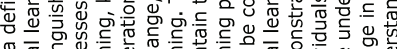

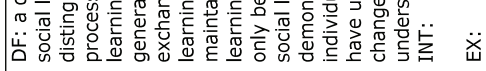

氶

言茊

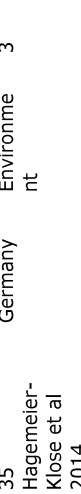

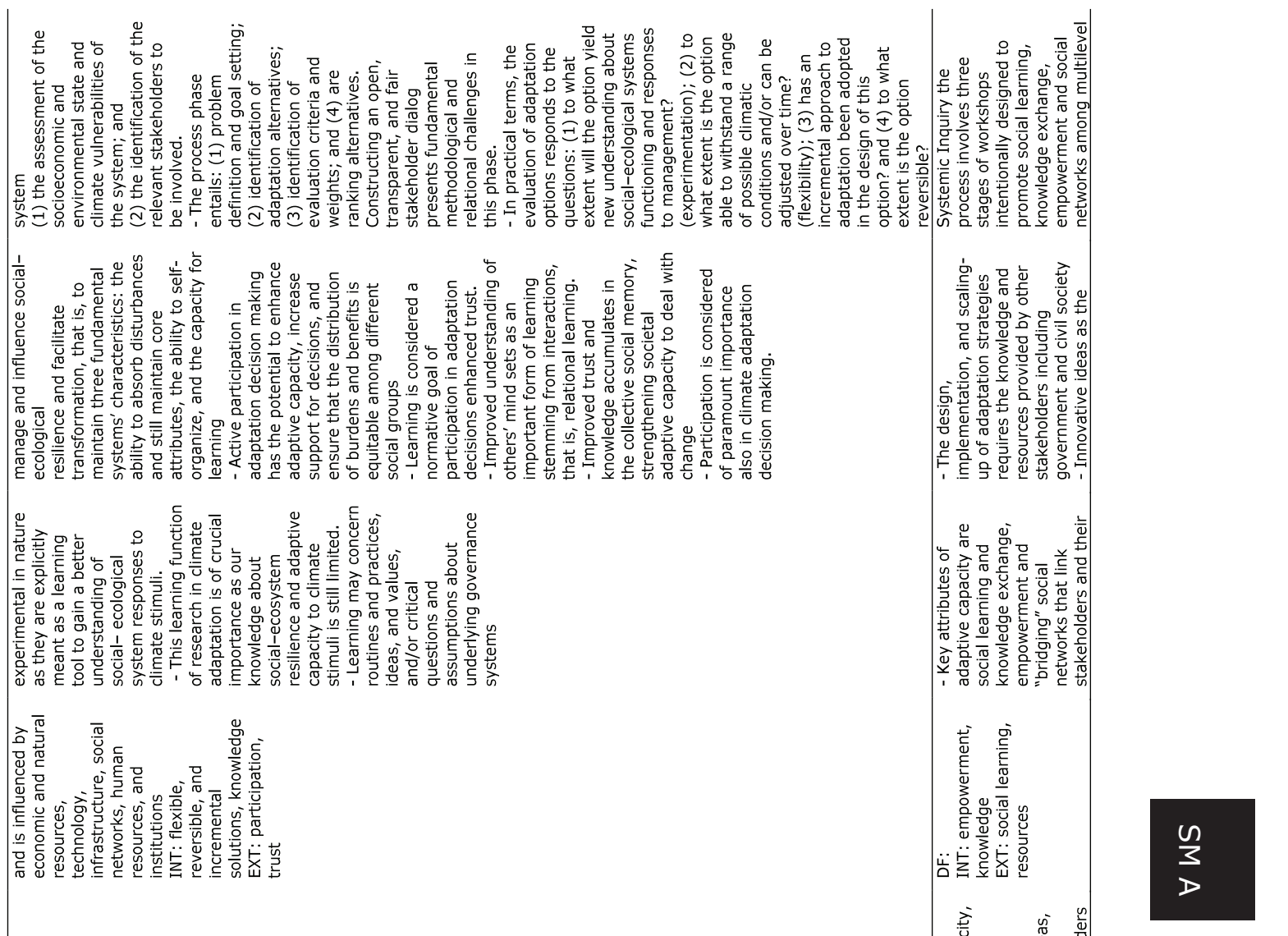




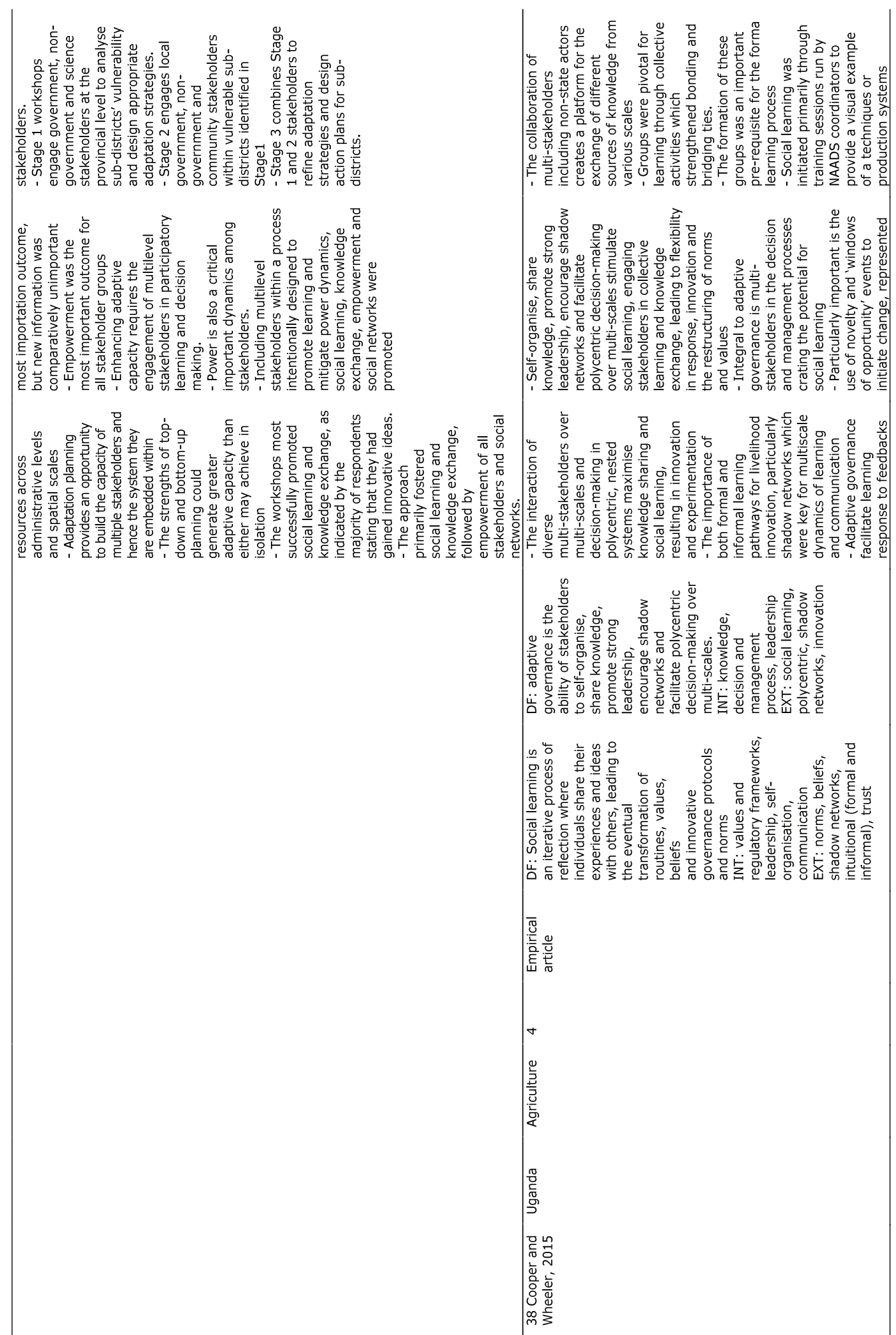

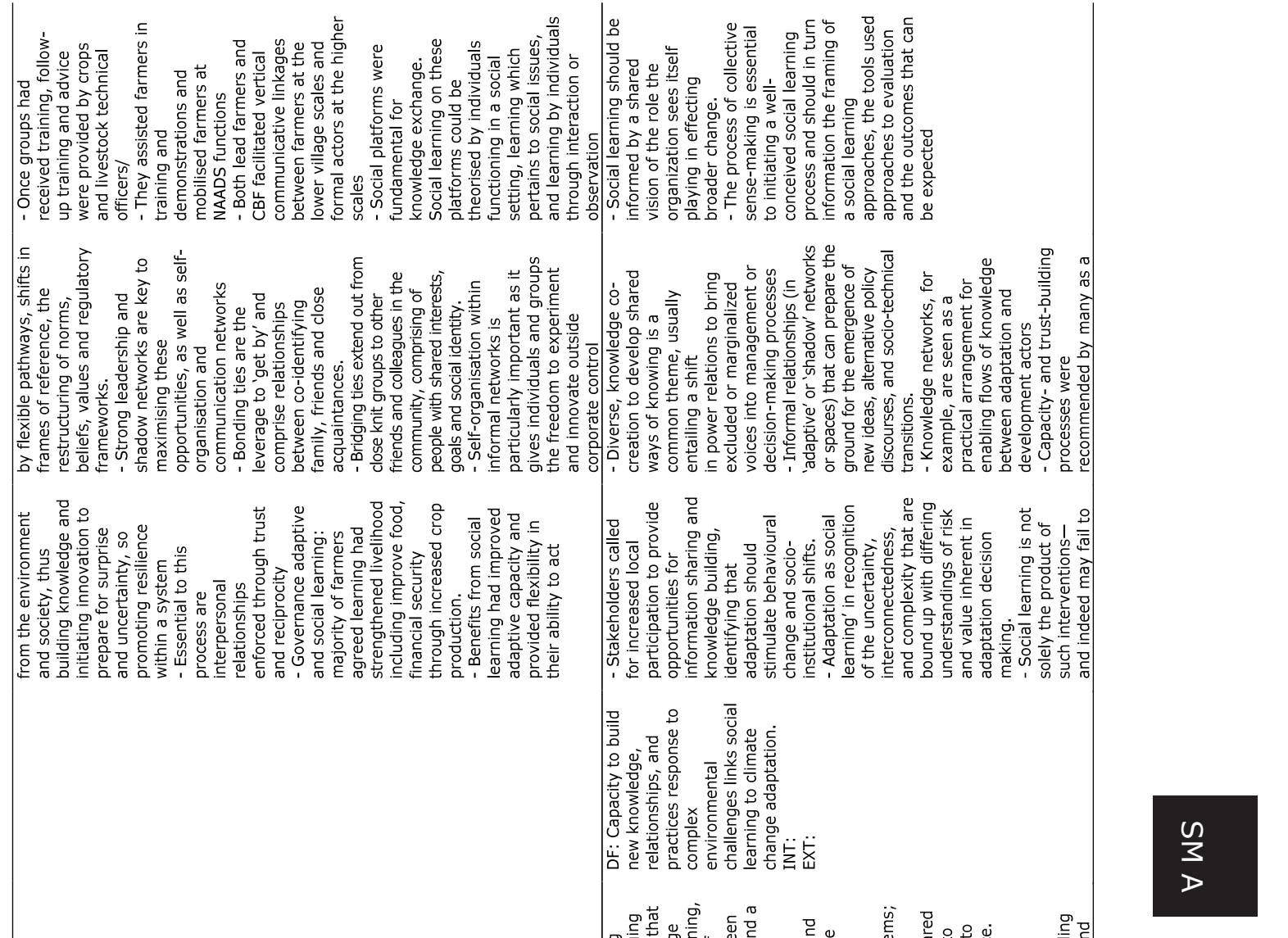

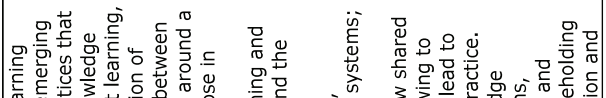

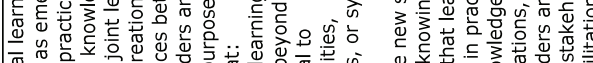

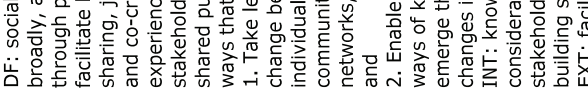

量

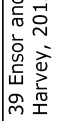



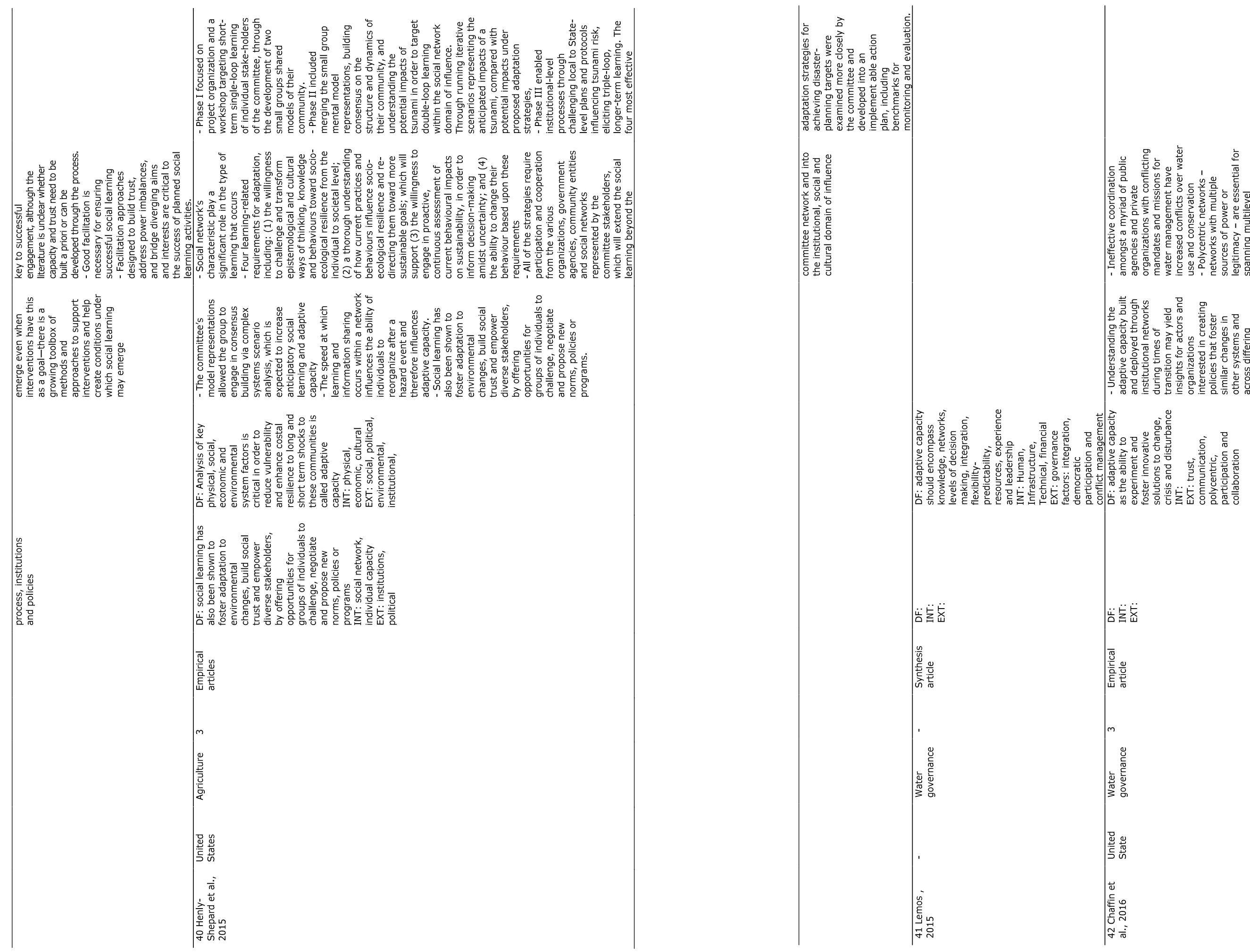


\section{Supplementary material B}
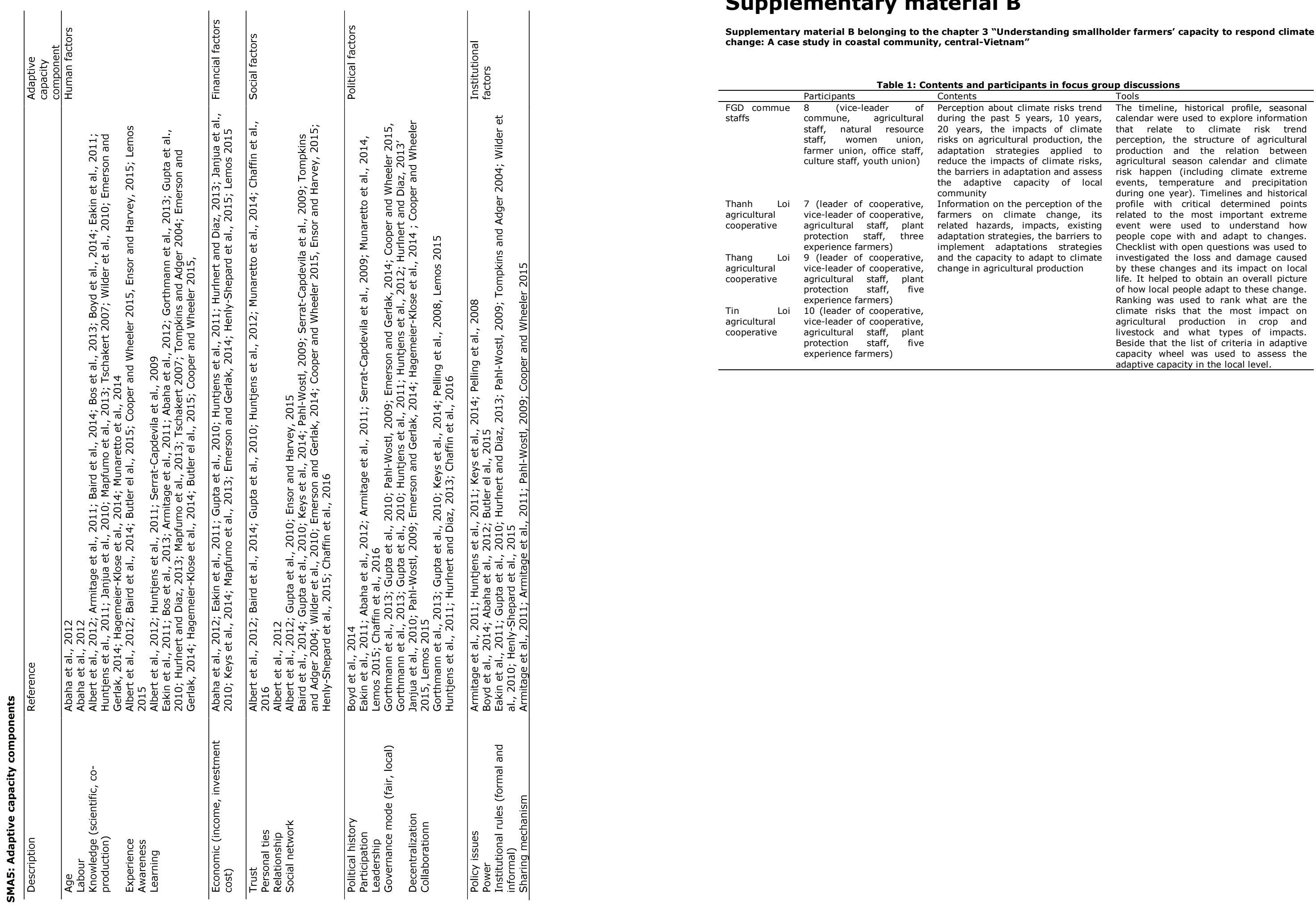
Table 2: Adaptation strategies to drought of farmers in crop production

\begin{tabular}{|c|c|c|c|c|}
\hline Adaptation option & Option & Option 2 & $\begin{array}{l}\text { Option } \\
3\end{array}$ & $\begin{array}{l}\text { Option } \\
4\end{array}$ \\
\hline $\begin{array}{l}\text { Change the seasonal calendar: shortening growing seasons to avoid insect attack and } \\
\text { drought seasons, and to allow the maximum number of crops cultivated annually } \\
\text { (AM)) }\end{array}$ & 100 & & & \\
\hline Change chemical fertilizer and pesticide: change time and quantity during drought & 91.2 & 0 & 6.1 & \\
\hline $\begin{array}{l}\text { Use more manure: the main } \\
\text { capacity for keeping water an }\end{array}$ & 90.4 & 0.9 & 8.8 & \\
\hline was reduce to save water and reduce & 87.7 & 0 & 10.5 & 1.8 \\
\hline 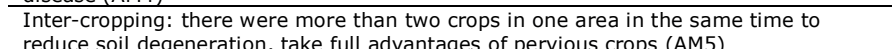 & 76.3 & 4.4 & 18.4 & \\
\hline $\begin{array}{l}\text { Use mulching: use straw, water hyac } \\
\text { vegetable, water melon, local onion } \\
\text { which can keep soil moisture and ret }\end{array}$ & 73.7 & 1.8 & 23.7 & 1.9 \\
\hline 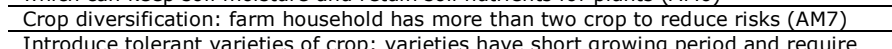 & 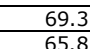 & $\frac{6.1}{25.4}$ & $\frac{24.6}{3.5}$ & 5 \\
\hline & & & & \\
\hline $\begin{array}{l}\text { Crop rotation: in the same area, farmers change different crops per season to reduce } \\
\text { pest and disease (AM9) }\end{array}$ & 51.8 & 28.9 & 18.4 & \\
\hline $\begin{array}{l}\text { Improve irrigation system t } \\
\text { Improve road in the field to }\end{array}$ & & & & \\
\hline
\end{tabular}

Table 3: Adaptation strategies to drought of farmers in livestock production

\begin{tabular}{|c|c|c|c|c|}
\hline Adaptation option & $\begin{array}{l}\text { Option } \\
1\end{array}$ & $\begin{array}{l}\text { Option } \\
2\end{array}$ & ${ }_{3}^{\text {Option }}$ & $\begin{array}{l}\text { Option } \\
4\end{array}$ \\
\hline $\begin{array}{l}\text { Livestock vaccination: vaccination is the use of vaccines to prevent and control animal } \\
\text { disisases, increase livestock resilience to uncertainty climate and erratic seasons } \\
\text { (AM13) }\end{array}$ & 99.1 & & & \\
\hline $\begin{array}{l}\text { Utilising supplementary feeds: most of supplementary feeds are industrial feeds and } \\
\text { ther farmer store rice, sweet potato, cassava for livestock during storage feeds } \\
\text { (AM14) }\end{array}$ & 99.1 & 0 & 0.9 & \\
\hline $\begin{array}{l}\text { Planting trees around the pigsty and cattle-shed: to create "artificial" environmental } \\
\text { and create shape were the sustainable options for long time and the increasing } \\
\text { temperature (AM15) }\end{array}$ & 97.2 & 0 & 2.8 & \\
\hline $\begin{array}{l}\text { Change the edesign in building house for livestock: To moderate the impacts of high } \\
\text { temperature and southern - Western wind in the summer season, farmers designed } \\
\text { imstr with high foundation, more windows and hiah roof to provent heat (AM16) }\end{array}$ & 89.6 & 6.6 & 0.9 & 2.8 \\
\hline 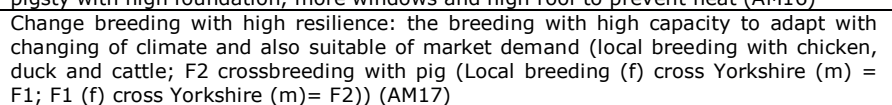 & 78.3 & 9.4 & 6.6 & \\
\hline $\begin{array}{l}\text { ement techniques: Including breeding selection, } \\
\text { increase resilience (AM18) bn }\end{array}$ & 38.7 & 2.8 & 0 & 8.5 \\
\hline e, roster, check ana eval & 37.7 & 1.9 & 0 & 0.4 \\
\hline $\begin{array}{l}\text { Livestock diversification: farm househ } \\
\text { (AM20) }\end{array}$ & 32.1 & 16 & 48.1 & 3.8 \\
\hline hange seasonal calendar (AM21) & & & & \\
\hline
\end{tabular}

Change seasonal calendar (AM21)
Ootion 1: Yes, I have adototed this adaptation option; Option 2: No, I have not, but it I will consider it for the future; Option 3: No, I
have not and I probably will not: Option 4: Don't know/refuse to answer

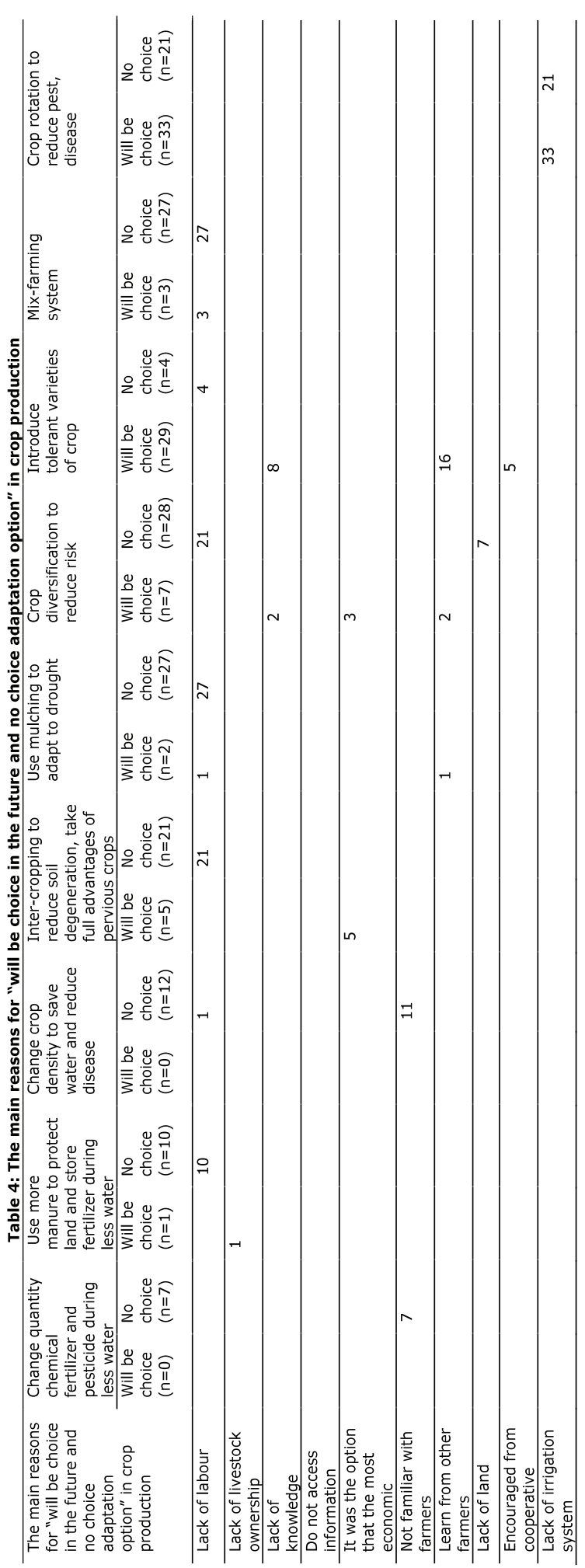


Level Table 6: The level to know climate change information in the current and future \begin{tabular}{l}
\hline Level \\
Very well informed (I know everything about current and future climate change) \\
Informed (I know the basics of current and future climate change)
\end{tabular} Informed (I know the basics of current and future climate change)
Not very well informed (I have heard about current and future climate change before) $1.8 \%(n=2)$
$17.5 \%(n=20)$
$73.7 \%(n=84)$ $\begin{array}{ll}\text { Not informed at all (I have no idea what climate change entails) } & 73.7 \%(n=84) \\ 8.0 \%(n=8)\end{array}$

\begin{tabular}{|c|c|c|c|c|}
\hline Explanatory variables & Mean & Std. Devia & $\mathrm{N}$ & Description \\
\hline $\begin{array}{l}\text { Primary school (grade from 1-5) } \\
\end{array}$ & 1,38 & ,487 & 114 & $\begin{array}{l}\text { Dummy, take the values } 1 \text { if no } \\
\text { study and } 2 \text { otherwise }\end{array}$ \\
\hline Secondary school (grade from 6-9) & 1,43 & ,497 & 114 & $\begin{array}{l}\text { Dummy, take the values } 1 \text { if no } \\
\text { study in and } 2 \text { otherwise }\end{array}$ \\
\hline High school (grade from 10-12) & 1,18 &, 382 & 114 & $\begin{array}{l}\text { Dummy, take the values } 1 \text { if no } \\
\text { study in and } 2 \text { otherwise }\end{array}$ \\
\hline Number of member of household (person) & 4,5088 & 1,67884 & 114 & $\begin{array}{l}\text { Continuous, number of member in } \\
\text { the household }\end{array}$ \\
\hline Number of workers (person) & 3,1228 & 1,30445 & 114 & $\begin{array}{l}\text { Continuous, number of labour in } \\
\text { the household }\end{array}$ \\
\hline Number of workers on the farm (person) & 1,8860 & ,43637 & 114 & $\begin{array}{l}\text { Continuous, number of agriculture } \\
\text { labour in the household }\end{array}$ \\
\hline 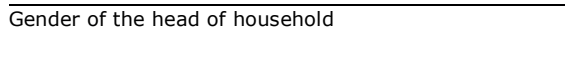 & 1,84 & ,366 & 114 & $\begin{array}{l}\text { Dummy, take the values } 1 \text { if } \\
\text { female and } 2 \text { otherwise }\end{array}$ \\
\hline Age of the head of household (age) & 57,921 & 9,8242 & 114 & Continuous \\
\hline Farmable land available in winter season (sao $=500 \mathrm{~m} 2)$ & 14,9140 & 8,83266 & 114 & Continuous \\
\hline 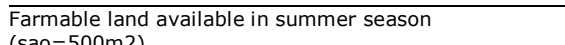 & 8,4535 & 6,30525 & 114 & Continuous \\
\hline $\begin{array}{l}\text { Lan-5nom3) (million, VND) } \\
\text { Farm income (illo }\end{array}$ & 56,1750 & 33,85420 & 114 & Continuous \\
\hline Non-farm income (million, VND) & 22,7281 & 23,13084 & 114 & Continuous \\
\hline Number of available information sources & 4,92 & 1,761 & 114 & Continuous \\
\hline Training participation & 1,80 & , 403 & 114 & $\begin{array}{l}\text { Dummy, take the values } 1 \text { if no } \\
\text { participation and } 2 \text { otherwise }\end{array}$ \\
\hline$\overline{\text { Accessing much information }}$ & 1,02 & ,132 & 114 & $\begin{array}{l}\text { Dummy, take the values } 1 \text { if no } \\
\text { accessing and } 2 \text { otherwise }\end{array}$ \\
\hline$\overline{\text { Accessing average information }}$ & 1,18 & ,382 & 114 & $\begin{array}{l}\text { Dummy, take the values } 1 \text { if no } \\
\text { accessing and } 2 \text { otherwise }\end{array}$ \\
\hline $\begin{array}{l}\text { Accessing little information } \\
\end{array}$ & 1,74 & ,442 & 114 & $\begin{array}{l}\text { Dummy, take the values } 1 \text { if no } \\
\text { accessing and } 2 \text { otherwise }\end{array}$ \\
\hline
\end{tabular}

Table 8: Pearson product moment correlation between the number of adaptation strategies in agriculture and selected variables

\begin{tabular}{lrr}
\hline Explanatory variables & Correlation & \multicolumn{1}{c}{ Sig. } \\
\hline Primary school (grade from 1-5) & -0.167 & $0.038^{* *}$ \\
\hline Secondary school (grade from 6-9) & 0.128 & $0.087^{*}$ \\
\hline High school (grade from 10-12) & 0.134 & $0.078^{*}$ \\
\hline Number of member of household (person) & 0.148 & $0.057^{*}$ \\
\hline Number of workers (person) & 0.011 & 0.445 \\
\hline Number of workers on the farm (person) & 0.353 & $0.000^{* * *}$ \\
\hline Gender of the head of household & 0.270 & $0.002^{* * *}$ \\
\hline Age of the head of household (age) & -0.138 & $0.071^{*}$ \\
\hline Farmable land available in winter season (sao=500m2) & 0.201 & $0.016^{* *}$ \\
\hline Farmable land available in summer season (sao=500m2) & -0.021 & 0.414 \\
\hline Farm income (million, VND) & 0.417 & $0.000^{* * *}$ \\
\hline Non-farm income (million, VND) & -0.004 & 0.428 \\
\hline Number of available information sources & 0.338 & $0.000^{* * *}$ \\
\hline Training participation & 0.195 & $0.019^{* *}$ \\
\hline Accessing much information & 0.135 & $0.076^{*}$ \\
\hline Accessing average information & 0.070 & 0.228 \\
\hline Accessing little information & 0.097 & 0.151
\end{tabular}

Accessing little information
Variables significant correlated with the number of adaptation in agriculture at the $10 \%, 5 \%, 1 \%$ level with $*, * * * * * 1.151$
, respectively
Table 9: The coefficients between the explanatory variables and the number of adaptation measures Standardized
Coefficients

\begin{tabular}{|c|c|c|c|c|c|}
\hline \multirow{2}{*}{ Explanatory variables } & \multicolumn{2}{|c|}{$\begin{array}{l}\text { Unstandardized } \\
\text { Coefficients }\end{array}$} & \multirow{2}{*}{$\begin{array}{c}\begin{array}{c}\text { Standardized } \\
\text { Coefficients }\end{array} \\
\text { Beta } \\
\end{array}$} & \multirow[b]{2}{*}{$\mathrm{t}$} & \multirow[b]{2}{*}{ Sig. } \\
\hline & B & $\begin{array}{l}\text { Std. } \\
\text { Error }\end{array}$ & & & \\
\hline (Constant) & -4.293 & 6.941 & & -.619 & .538 \\
\hline Primary school (grade from 1-5) & 2.056 & 1.131 & .305 & 1.817 & .072 \\
\hline Secondary school (grade from 6-9) & 1.806 & 1.090 & 274 & 1.656 & 101 \\
\hline High school (grade from 10-12) & .524 & 1.145 & .061 & .458 & .648 \\
\hline Number of member of household (person) & .100 & .250 & .051 & .399 & .691 \\
\hline Number of workers (person) & -.240 & 277 & -.096 & -.865 & .389 \\
\hline Number of workers on the farm (person) & 1.859 & .690 & .248 & 2.693 & $.008^{* *}$ \\
\hline Gender of the head of household & .897 & .923 & .100 & .971 & .334 \\
\hline Age of the head of household (age) &,- 051 & .040 & -.152 & -1.277 & .205 \\
\hline $\begin{array}{l}\begin{array}{l}\text { armable land available during winter season } \\
(\text { sao }=500 \mathrm{~m} 2)\end{array} \\
\text { (a) }\end{array}$ & .006 & .042 & .015 & .132 & .895 \\
\hline $\begin{array}{l}\text { Farmable land available during summer season } \\
\text { (sao }=500 \mathrm{~m} 2 \text { ) }\end{array}$ & -.118 & .053 & -.226 & -2.229 & $.028^{*}$ \\
\hline Farm income (million, VND) & .042 & .010 & .431 & 3.989 & $.000^{* *}$ \\
\hline Non-farm income (million, VND) & -.004 & .013 & -.027 & -.295 & .768 \\
\hline Number of available information sources & .435 & 157 & .234 & 2.769 & $.007^{* *}$ \\
\hline Training participation & -.021 & .700 & -.003 & -.030 & .976 \\
\hline Accessing much information & 4.497 & 2.338 & .181 & 1.924 & .057 \\
\hline Accessing average information & .372 & 1.259 & .043 & .295 & .768 \\
\hline Accessing little information & .340 & 1.083 & .046 & .314 & .754 \\
\hline
\end{tabular}

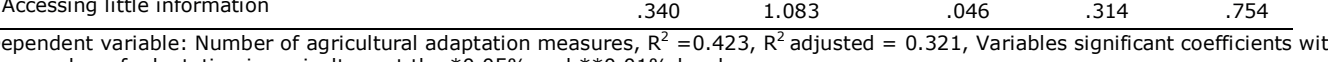

Table 10: The channels that farmers are informed climate change impacts and adaptation

\begin{tabular}{lrrr}
\hline Information source & $N$ & Percent & Percent of cases \\
\hline Via media & 107 & $18.9 \%$ & $93.9 \%$ \\
Via farmer in region & 94 & $16.6 \%$ & $82.5 \%$ \\
Via training & 86 & $15.2 \%$ & $75.4 \%$ \\
Via cooperative & 84 & $14.8 \%$ & $73.7 \%$ \\
Via family & 53 & $9.4 \%$ & $46.5 \%$ \\
Via CBOs & 52 & $9.2 \%$ & $45.6 \%$ \\
Via local government & 30 & $5.3 \%$ & $26.3 \%$ \\
Via extension staff & 20 & $3.5 \%$ & $17.5 \%$ \\
Via agency & 20 & $3.5 \%$ & $17.5 \%$ \\
Via education & 8 & $1.4 \%$ & $7.0 \%$ \\
Via farmer out region & 6 & $1.1 \%$ & $5.3 \%$ \\
Via lecturer & 5 & $.9 \%$ & $4.4 \%$ \\
Via NGO & 1 & $.2 \%$ & $.9 \%$ \\
& 566 & $100.0 \%$ & $496.5 \%$ \\
\hline
\end{tabular}


Semi-questionnaire form

\section{Quang Loi commune committee Socialist Republic of Vietnam \\ ........................ Co-operative Independence - Freedom - Happiness}

LETTER OF INVITATION

Dear Sir/Madam...

We would be grateful to invite you attention an interview of students from Hue university of Agriculture and Forestry. Each interviewee contents: Understanding farmer's experience in agricultural production to adapt to climate change

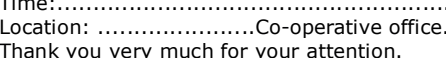

We look forward to meeting you for interview.

Chairman of commune
Adaptive capacity to climate change of Agriculture in Vietnam: Perception of farmers in the Quang Dien district

Thank you for agreeing to participate in this survey. The aim of this survey is to better understand the adaptive capacities of local
farmers in Vietnam, particularly the in Quang Dien district. Understanding the capacity to adapt to climate change is an issue of ncreasing concern as communities will have to adapt to the impacts of changing weather extremes and long tem ats ate changes. conditions allows us to assist local farmers to build their adaptive capacity so as to be better prepared for climate change. You

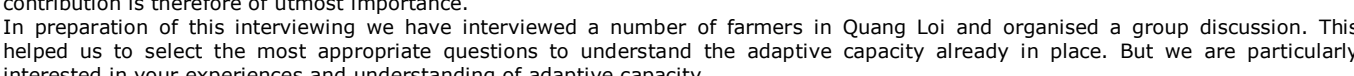
We kindly like to ask you to address the questions raised by the interviewer and/or complete some of the questions on the survey form. The survey is structured in four parts. Each part will have a number of open questions and closed questions. We expect the survey to

If you require additional information, please contact Mrs Le Thi Hong Phuong by email or post

Thank you again for taking the time to answer the questions.

Mrs Le Thi Hong Phuong: Hue University of Agriculture and Forestry, 102 Phung Hung street. Tel: +84 943726267 or email: Dr. Sen Le Thi Hoa (Hue University of Agriculture and Forestry, Vietnam)

Dr. Robbert Biesbroek (Wageningen University, the Netherlands)

\section{General information}

Q1.2. What is the name of head of household:

Gender:

Q1.3. Could you please indicate the highest level of education you completed?

Q1.5. How many year do you work in agricultural production?

Q1.6. What is the type of your household? 1-poor 2-near poor 3-average 4-better 5-rich

II. Characteristic of agricultural production

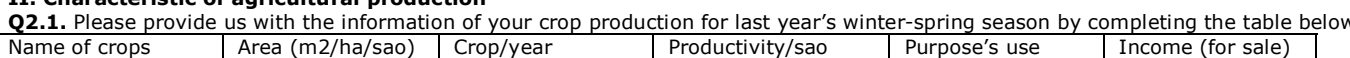

\begin{tabular}{|l|l|l|l|l|l|}
\hline $\begin{array}{l}\text { Name of crops } \\
\text { Winter-spring }\end{array}$ & Area (m2/ha/sao) & Crop/year & Productivity/sao & Purpose's use & Income (for sale) \\
\hline Summer-autumn & & & & & \\
\hline
\end{tabular}

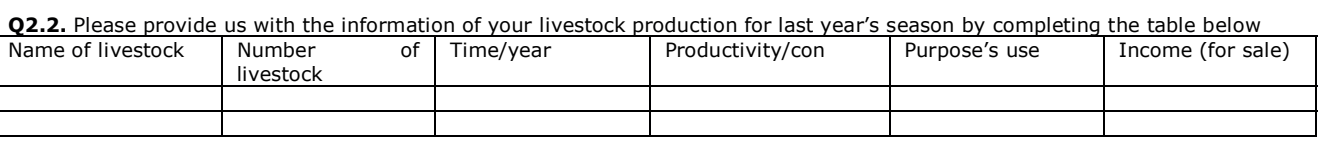

Q2.3. Does your family have other income sources (in 2014)?
1-Yes (continuous question 2.4)

\begin{tabular}{l} 
Q2.4. Please list ther income sources \\
$\begin{array}{ll}\text { Type of income sources } & \text { Income (1,000 VND) }\end{array}$ \\
\hline
\end{tabular}

\begin{tabular}{|l|l|l|}
\hline ype of income sources & Income (1,000 VND) & Time \\
\hline & & \\
\hline
\end{tabular}

Q2.5. How many members in your family do you have?

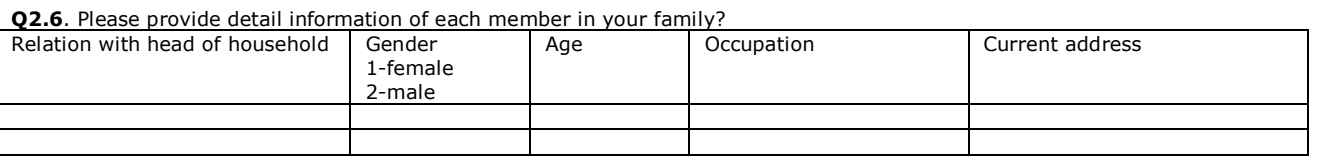

III. Perception of farmers on climate variability

Q3.1. Climate change is likely to impact your region. If you have answered the question above with "yes" could you share your
experience for each of the following climate effects by completing the table below? Please place a " $X$ ' for each of the climate effects at the most appropriate answer.
Intensity of climate ext

\begin{tabular}{|c|c|c|c|c|c|c|}
\hline & $\begin{array}{l}\text { Significant } \\
\text { increase }\end{array}$ & Increase & $\begin{array}{l}\text { Stayed more or } \\
\text { less the same }\end{array}$ & Decrease & $\begin{array}{l}\text { Significant } \\
\text { decrease }\end{array}$ & $\begin{array}{l}\text { Don't know/refuse } \\
\text { to answer }\end{array}$ \\
\hline \multicolumn{7}{|l|}{$\begin{array}{l}\text { Rainfall } \\
\text { Storms } \\
\end{array}$} \\
\hline \\
\hline \multirow{2}{*}{\multicolumn{7}{|c|}{$\begin{array}{l}\text { Droughts } \\
\text { Cold weather }\end{array}$}} \\
\hline \multirow{2}{*}{\multicolumn{7}{|c|}{$\begin{array}{l}\text { Cold weather } \\
\text { Saltwater intrusion } \\
\text { Freng }\end{array}$}} \\
\hline & & & & & & \\
\hline Frequency of climate ex & $\begin{array}{l}\text { Significant } \\
\text { increase }\end{array}$ & Increase & $\begin{array}{l}\text { Stayed more or } \\
\text { less the same }\end{array}$ & Decrease & $\begin{array}{l}\text { Significant } \\
\text { decrease }\end{array}$ & $\begin{array}{l}\text { Don't know/refuse } \\
\text { to answer }\end{array}$ \\
\hline $\begin{array}{l}\text { Temperature } \\
\text { Rainfall }\end{array}$ & & & & & & \\
\hline $\begin{array}{l}\text { Rainfail } \\
\text { Storms }\end{array}$ & & & & & & \\
\hline $\begin{array}{l}\text { Floods } \\
\text { Droughts }\end{array}$ & & & & & & \\
\hline $\begin{array}{l}\text { Cold weather } \\
\text { Soltwotan }\end{array}$ & & & & & & \\
\hline Saltwater intru & & & & & & \\
\hline
\end{tabular}

Q3.2. How would you describe the impacts of climate change on your commune?

ANSWER:

Q3.3. Have you been impacted by climate change or weather related impacts in the last 5 years?
5-very major impact 4-major impact 3-minor impact 2 -very minor impact 0 -no impact

Q3.4. Looking at your own agricultural production, could you identify which climate extreme event has affected your agricultura production? Please specify between crop or livestock and How these climate extreme event affected your agricultural production? Crop:

Q3.5. What do you think will be the most important climate extreme events for your agricultural business in the future (between now and 2020)?
ANSWER: 

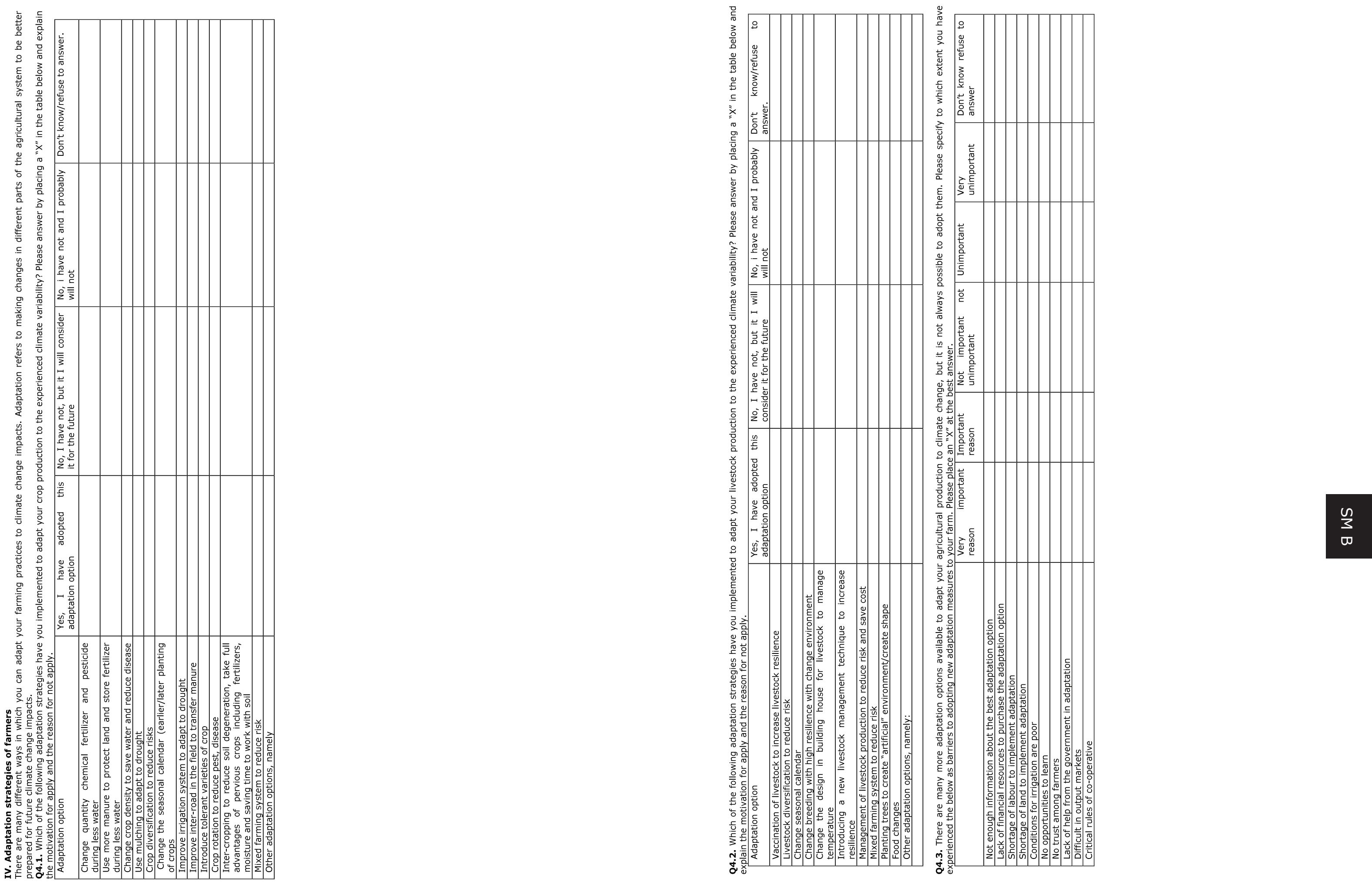


\section{Adaptive capacity of household}

(n) climate change?

A. Very well informed ("iknow everything about future climate change")

D. Informed ("i know the basics of future climate change")
C. Not very well informed ("i have heart about future climate change before")
D. Not informed at all ("no idea what climate change entails")

Q5.2. Through which ways are you informed about future climate change impacts and adaptation? Please circle one of the answers
below Multiple ontions possible.

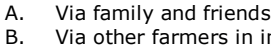

A. Via family and friends
B. Via other farmers in inside the region
C. Via other farmers in outside the region

D. Via the government

E. Via media (radio, television, internet)

G. Via education (middle school, etc)

H. Via agricultural coope sho
I. Via extension staffs
V.

3. Via NGO organization
K. Via lecturer in HUAF

L.. Via traders

Q5.3. Are you aware of long term plans for adapting to climate change in your agricultural production?
$1-$ yes (namely)

$2-10$
2.3
0.3

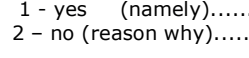

Q5.4. How do you feel the quality of cooperative services in community?

5-very good 4-good 3 -average 2 -bad 1 -very bad 0 -do not know
05.5. How do you feel the quality of extension services in community?

5-very good 4-good 3 -average 2 -bad 1 -very bad 0 -do not know
0.5.6. How do

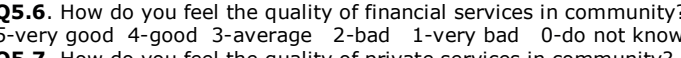

the quality of private services in community?

5-very good 4-good 3-average 2-bad 1-very bad 0 -do not know
Q.5.8. To what extent do you consider the following to be present in your household? Please indicate by placing an $\mathrm{X}$ at the

\begin{tabular}{|c|c|c|c|c|c|c|}
\hline Question & Very good & Good & Average & Bad & Very bad & $\begin{array}{l}\text { Don't } \\
\text { know/refuse } \\
\text { to answer }\end{array}$ \\
\hline $\begin{array}{l}\text { Learn from others } \\
\text { Access to information and technology about climate } \\
\text { change impacts and adaptation }\end{array}$ & & & & & & \\
\hline $\begin{array}{l}\text { Have strong social network with other actors to solve } \\
\text { any problems during weather extremes } \\
\text { Participate or be involved in collective actions of co- }\end{array}$ & & & & & & \\
\hline
\end{tabular}

implement climate change adaptation

25.9. How important do you consider the following to be present in your household to adapt to climate change? Please indicate

"high", "medium" or "low". Please explain why this is the case.
5-very important 4-important 3-average 2-less important 1-very less important 0-no important

5-very important 4-important 3-average 2-less important 1-very less important 0-no important
Question Importance Please explain why is this case Learn from others
Access to information and technology about climate change impacts and adaptation any problems during weather extremes
Participate or be involved in collective actions of co-

Participate or be involved in collective actions of $\mathrm{co}$
operative to implement climate change adaptation

5.10. Have you participated climate change or climate change adaptation tin general and agricultural production in particult 1 -yes, (go to question 5.11)

2-no (go to question 5.12$)$
25.11. What are the trainings and when? Please list the place, date and name of training(s)

Q5.11.
$1-$
$2-$

Q5.12. In your opinion, what kind of additional training would you like to have to be better prepared for climate change?
ANSWER:

VI. Local authorities and commune leaders

Q6.1. Local authorities can play an important role in helping you adapt to climate change. To which of the following statements do you

A. local authorities have done nothing yet to prepare local farmers
B. local authorities have just started to implement measures to increse

ess of climate change

C. local authorities have started to implement concrete adaptation measures
D. local authorities have started to implement measures to increase awareness and skills of climate change and implement
Q6.2 Are you aware of any governmental policies or laws with regards to climate change adaptation?

A. Yes, namely:
B. No

C. Don't know / refuse to answer

Q6.3. Do community leaders/agricultural staffs introduce innovative techniques for agriculture? Please explain why you think so B. no:
C. Don
Don

Q6.4 Are you actively involved in planning agricultural production in your commune? If yes, please explain how you are involved
A $\begin{array}{ll}\text { A. } & \text { yes } \\ \text { B. no } & \text { no }\end{array}$

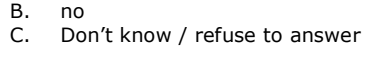

Q6.5 How well to you trust the following actors when it comes to preparing your agricultural business for climate change. Please select \begin{tabular}{|l|l|l|l|l|l|l|l|} 
by placing an " $x "$ in the table for each of the following actors & I have very high & I have trust in & I have no trust in & I have no & Don't know \\
\hline
\end{tabular}

\begin{tabular}{|c|c|c|c|c|c|}
\hline & $\begin{array}{l}\text { I have very high } \\
\text { trust in them }\end{array}$ & $\begin{array}{l}\text { I have trust in } \\
\text { them }\end{array}$ & $\begin{array}{l}\text { I have no trust in } \\
\text { them }\end{array}$ & $\begin{array}{l}\text { I have no } \\
\text { trust at all } \\
\text { in them }\end{array}$ & $\begin{array}{l}\text { Don't know } \\
\text { refuse to } \\
\text { answer to }\end{array}$ \\
\hline Via family and friends & & & & & \\
\hline Via other farmers in inside the region & & & & & \\
\hline $\begin{array}{l}\text { Via other farmers in outside the region } \\
\text { Via the government }\end{array}$ & & & & & \\
\hline Via media (radio, television, internet) & & & & & \\
\hline $\begin{array}{l}\text { Via a raining courses } \\
\text { Via education (middle school) }\end{array}$ & & & & & \\
\hline $\begin{array}{l}\text { Via agricultural cooperative } \\
\text { Viativesposf }\end{array}$ & & & & & \\
\hline $\begin{array}{l}\text { Via extension staffs } \\
\text { Via NGO organization }\end{array}$ & & & & & \\
\hline $\begin{array}{l}\text { Via lecturer in HUAF } \\
\text { Via traders }\end{array}$ & & & & & \\
\hline $\begin{array}{l}\text { Via agency } \\
\end{array}$ & & & & & \\
\hline
\end{tabular}

Q6.6 For those who have children: Yes, because...
No, because

Thank you for completing the survey. 


\section{Supplementary material C}

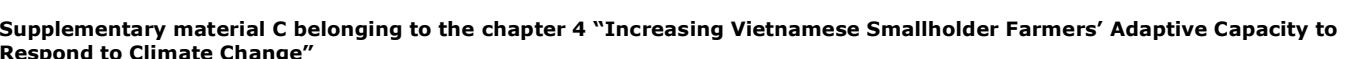
Form 1. The background information of participants

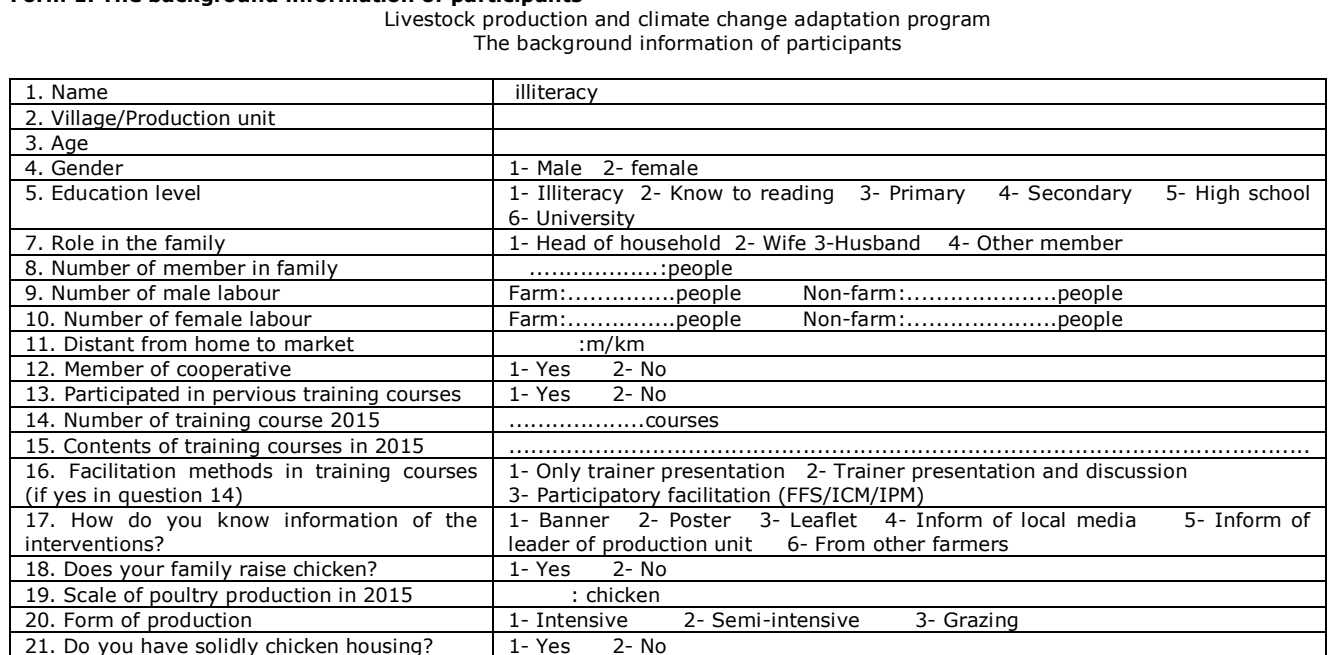

Form 2. Evaluation social learning configuration design

Workshop-based interk rronduction and climate change adaptation program
Whe poultry production using biological bedding material

I. Evaluation the contents of the intervention
1 . How do you feel about the quantity of knowledge that provide in the interventions?

a-Extreme sufficient knowledge b-Sufficient knowledge c-Just enough c-Little knowledge e-Extreme little knowledge

2. How do you feel about the contents of the interventions that provide relevant the present needs in terms of information and

techniques of poultry production to adapt to climate change?
a- - very relevant b- Relevant c- Fairly relevant c- Not so relevant e- Not relevant at all

a- Very relevant $\quad b$ - Relevant $\quad c-$ Fairly relevant
Do you have any suggestions about other contents?........

3. How do you think about the relevant of group discussion topics to your experience/knowledge?
a- Very relevant b-Relevant c- Fairly relevant c- cot so relevant e- Not relevant at all

Do you have any suggestions abros

4. How do you think these group discussions that were fruitful and the ideas useful for your work?

a- Very productive b-Productive c-Fairly productive c-Not so productive e- Not productive

5. How do you think about the appropriate of the intervention contents with the local conditions?
5......

\begin{tabular}{|c|c|c|c|c|c|}
\hline 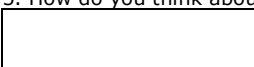 & $\begin{array}{l}\text { Very } \\
\text { appropriate }\end{array}$ & Appropriate & \begin{tabular}{|l|}
$\begin{array}{l}\text { Fairly } \\
\text { appropriate }\end{array}$ \\
\end{tabular} & $\begin{array}{ll}\text { Not } \\
\text { appropriate }\end{array}$ & Not appropriate at all \\
\hline \multicolumn{6}{|l|}{ Climate conditions } \\
\hline \multicolumn{6}{|l|}{ Economic conditions } \\
\hline \multicolumn{6}{|l|}{ Labour conditions } \\
\hline \multicolumn{6}{|l|}{ Education conditions } \\
\hline Local market conditions & & & & & \\
\hline
\end{tabular}

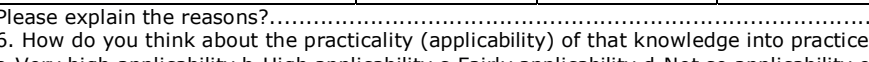

6. How do you think about the practicality (applicability) of that knowledge into practice?
a-very high applicabilitit b-ligh applicability c-Fairly applicability d-Not so applicability e-Not applicability at all

II. Evaluation the organization of the intervention

7. How do you think about the appropriate of the time for propaganda? (one week before interventions)
a-Very appropriate b- Appropriate c-Fairly appropriate d-Not so appropriate

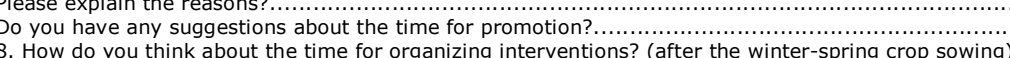

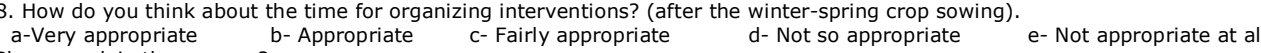

Please explain the reasons?
Does the time for organizing interventions "after the winter-spring crop sowing" affect learning efficiency?

a- Yes, why
b- No, why

(1)

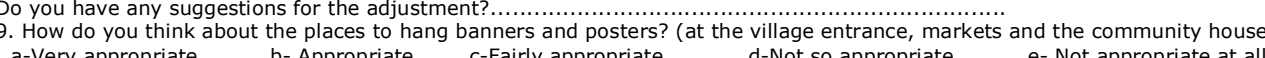

a-Very appropriate b- Approp
Please explain the reasons?

Do you have any suggestions to adjust?..............

(1)

(two times in the morning, one time at noon and two time in the afternoon)
a- Very appropriate
b- Appropriate - Fairly appropriate $\quad$ - Not so appropriate e- Not appropriate at all

Please expl

Do you have any suggostions to adjust?
11 . How do you think about the time r.

o bulletin notices? (After the weather predict news)?

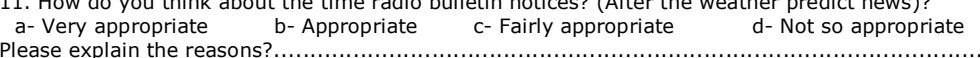

Do you have any suggestions to adjust?

a- Very appropriate b- Appropriate c- Fairly appropriate d- Not so appropriate

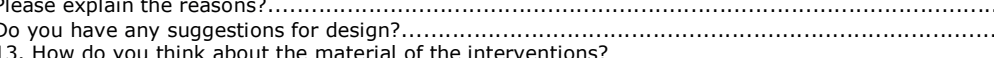

a- Very appropriate b-Appropriate c- Fairly appropriate d- Not so appropriate

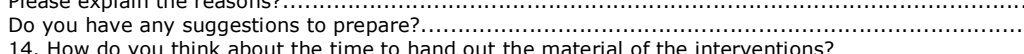

14. How do you think about the time to hand out the material of the interventions?

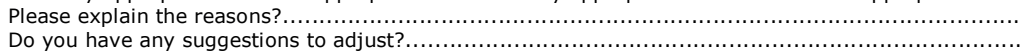

III. Evaluation the location of the intervention

15. How do you think about the location where organized the interventions?
a- Very appropriate b-Apropriate c-Fairly appropriate d- Not so appropriate

Do you have any suggestions to adjust? 


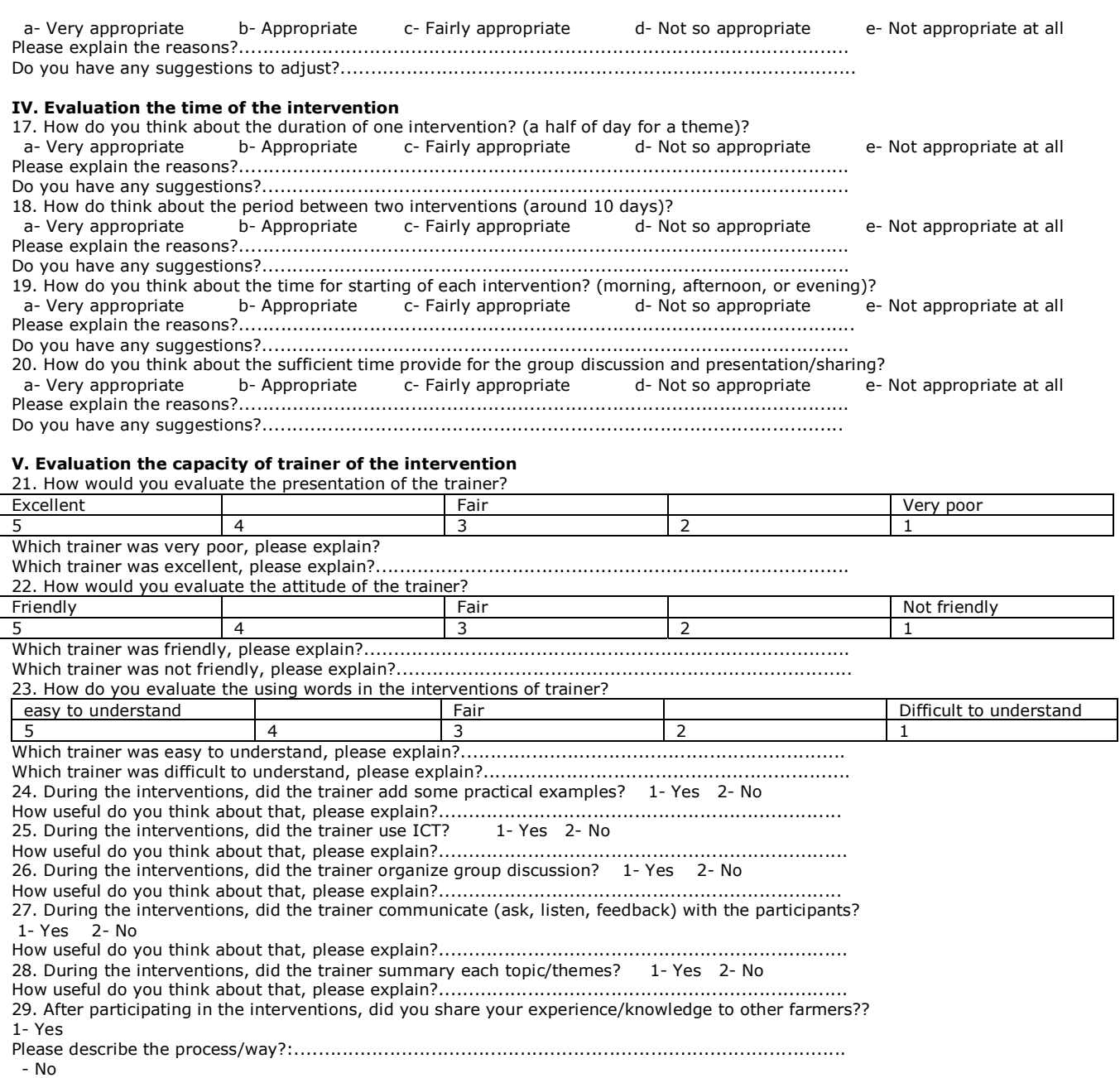

Form 3: Evaluation social learning outcomes (after 1 day interventions)

Livestock production and climate change adaptation program
Workshop-based intervention: The poultry production using biological bedding materia

Workshop-based interventions int poultry production using biological bed
1. Relationship and appreciation of others' perspectives: The intervention workshop has:

1.1. Strengthened my relationships with ofher participants
a- strongly agree
b-agree $c$ - no difference d- disagree e- strongly disagree

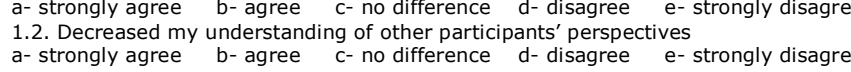

a- strongly agree b- agree c-no difference d- disagree e- strongly disagree
2. Systems thinking : The intervention workshop has:

2.1. Increased $\mathrm{my}$ understanding of the connections between climate change scenario and human decisions in implementation a- strongly agree $\quad b$ - agree $c$ - no difference $d$ - disagree e- strongly disagree
2.2. Weakened my ability to think systemically about connections between climate change scenario and decisions in implementation d- no difference d-disagree e- strongly disagre 3. New or changed actions: The intervention workshop has: a- strongly agree b-agree c-no difference d- disagree e- strongly disagree a- strongly agree $\quad$ b-agree $\quad c$ - no difference d- disagree e- strongly disagree 4. Individual learning new knowledge about livestock adaptation to climate a- strongly agree b- agree c c no difference d- disagree e- strongly disagree
4.2. The intervention and participation in the meetings led to deeper change in the a- strongly agree b-agree c-no difference d- disagree e- strongly disagree

5.1. The intervention and participation in the meetings supported development of
decision making a- strongly agree $\quad b$-agree $\quad c$ - no difference d-disagree e- strongly disagree

5.2. The intervention and participation in the meetings supported development of community network connections on
strongly agree 5.3. The intervention and participation in the meetings supported development collective agreement on livestock management decision
making a- strongly argee b- agree c-no difference d- disagree e- strongly disagree community preferences in livestock managemen a- strongly agree $\underset{b}{b}$ - agree $\quad \mathrm{c}$ - no difference d- disagree e- strongly disagree 


\section{Form 4: Evaluation social learning and adaptive capacity}

Intervention: The poultry production using biological bedding material

With participants participated in three interventions and implementing plot model:
1. After three interventions and implementing the plot model, how do feel about your general climate change knowledge? What After three interventions and implementing the plot model, how do feel about your general climate change knowledge? What
did you learn that you did not know before, if anything?
How about your knowledge, specifically, about climate change adaptation? What did you learn about CCA that you did not 3. Anow before, if anything?

4. Can this knowledge solve the current issues in your poultry production? If so, in what way? If no, why not?
5. During the implementation of the plot model do you share your knowledge that you have learnt from the intervention During the implementation of the plot model, do you share your knowledge that you have learnt from three interventions
with other farmers? If yes, at what moments did you share your knowledge? How? If no, what kept you from sharing your If you remember, with how many farmers you have shared your knowledge? Which group farmers you shared your
knowledge most? Why with this particular group? (question only relevant when farmers responded that they did share Thowledge, if not then it can be skipped)

8. During the implementation the plot model, have any farmers asked you to tell them about how to apply the
techniques/knowledge in the poultry production using biological bedding material? (how many farmers if you remember)

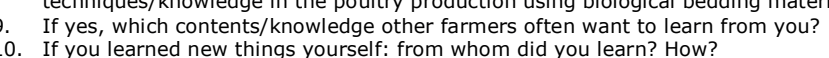

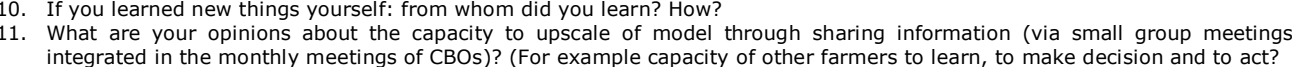

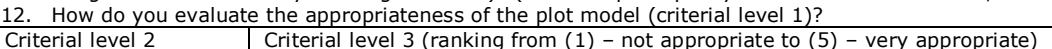
Appropriate with the Appropriate with area of land in the garden Appropriate with the
natural conditions

Appropriate with the
capacity of community

Appropriate with climate conditions (high temperature and uncertainty weather)

Apropiate with shill and knowied of

Appropriate with skills and knowledge of farmers in community new knowledge and also not too modern knowledge
Appropriate with financial capacity and investment capacity of farmers in community
Appropriate with local policies

Appropriate with the
culture-society and

Appropriate with farmer' needs

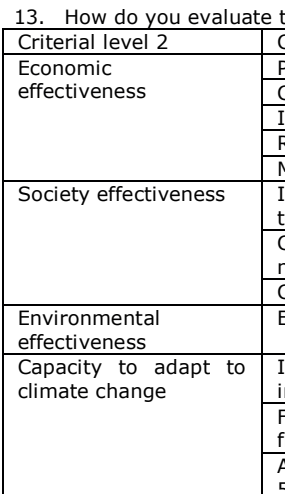

he effectiveness of the plot model (criterial level 1)?

Productivity (ranking from 1-very low to 5 - very high)

\section{come (ranking from 1- very low to 5 - very high)}

Market (ranking from 1- not good, not stabilization to 5-very good)

Improve farmers' capacity - skills and knowledge (ranking from 1 - capacity does not improve Colnctive and community) cohesion (ranking from 1- no cohesion/maybe have conflict to 5 Change practices in livestock production (ranking from 1 - no change to 5 - changes a lot)

Increase income and diversify income (ranking from 1 - do not increase income and diversify
crome to 5 - increase a lot income and more diversify income) (texibility in seasonal adjustments to avoid the impact of extreme weather events (ranking flexibility in seasonal adjustments to avoid the impact of extreme weather events (ranking
remm 1 - 0 o flexibilit to $5-$ very flexibility)
Adaptation with high temperature and uncertainty of climate (ranking from 1 - no adaptation to

14. How do you see the potential to upscale of the plot model to other areas and other farmers (1- very little potential to 5 - very
potential to unscale? 15. Wotential to upscale)? ? think influence on the poussibility to upscale model?
16. What are difficulties/barriers during for implementing the plot model?

16. What are difficulties/barkers dhe difficlities/barriers?
17. Do you have any solutions for these dimplementation of the plot mode 2
18. How do evaluate the support of agricultural staff during you impleme

1. During the implementation of the plot model, did you receive any support from the local authorities? If yes, by whom? In
19.

20. What way? If If no, why not?
21. When the mode intention to continuously develop and improve your poultry production?
further implementation? upscaled, which conditions you think the agricultural staffs or local authorities should provide for

With participant participated in three interventions but have not yet applied
1. After three interventions, how do feel about your general climate

climate change knowledge? What did you learn that you did not How about your knowledge, specifically, about climate change adaptation? What did you learn about CCA that you did not
know hefore, if anything? Anow before, if anything?
Atan three interventions, what is your opinion about your poultry production using biological bedding material?
Can this knowledge solve the current issues in your poultry production? If so, in what way? If no, why not?

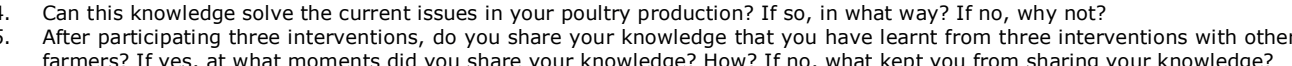
farmers? If yes, at what moments did you share your knowledge? How? If no, what kept you from sharing your knowledge?
6. If you remember, with how many farmers you have shared your knowledge? Which group farmers you shared your
knowledge most? Why with this particular group? (question only relevant when farmers responded that they did share

knowledge, if not then it can be skipped)
Through which channels/way you have shared your knowledge with other farmers?
3. After participating three interventions, have any farmers asked you to tell them about how to apply the techniques/knowledge in the poultry production using biological bedding mater
If yes, which contents/knowledge other farmers often want to learn from you?

10. If you learned new things yourself: from whom did you learn? How?
11. What are your opinions about the capacity to uspcale of model through sharing information (via small group meetings,
integrated in the monthly meetings of CBics)? (For example capacity of other farmers to leatn, to make decision and to act?

12. Do you have the minthiln to continuously develop and improve your poultry production?

When the model will be ups
further implementation?

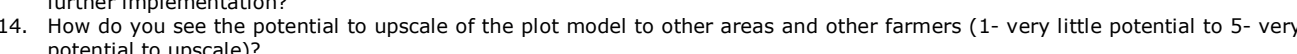

15. Which factors do you think influence on the possibility to upscale model?

16. What are difficultitis/barriers if farmers upscale the plot model
17. Do you have any solutions for these difficulties/barriers?

With participants did not participate in three interventions
1 . Do you hear or know about the interventions

作 your community?
If you hear or rnow, how do you know this information?

In the future, do you have the planning to apply this technique in your poultry production?

And when?
When you apply, which conditions you think the agricultural staffs or local authorities should support for implementation?

\section{Table 1. Participants' evaluation the contents of the interventions (number of resonds)}

\begin{tabular}{lccccc}
\hline 1: Participants evaluation the contents of the interventions (number or respondents) & Fairly appropriate & \\
\hline Local conditions & Very appropriate & Appropriate & 22 & 4 \\
\hline Climate conditions & 10 & 5 & 26 & 5 \\
\hline Economic conditions & 5 & 23 & 6 \\
\hline Labour conditions & 7 & 23 & 8 \\
\hline Educational conditions & 5 & 23 & 8 \\
\hline Local market conditions & 5 & &
\end{tabular}

Table 2: Participants' evaluation the process of the interventions (number of respondents)

\begin{tabular}{lll} 
Intervention design & Very & Appropriate \\
\hline
\end{tabular}

The time for promotion: one week before interventions

The design of the banner, poster and leafle

The places to hang banners and posters: at the village entrance, markets and the community

The contents of the leaflet

The structure and information of the newsletter

\begin{tabular}{lll} 
The repeat quantity of the newsletter in the local media for informing the information of the & 20 & 16 \\
\hline
\end{tabular}

\begin{tabular}{lll}
\hline The time radio bulletin notices: after the weather predict news & 20 & 16 \\
\hline
\end{tabular}

The tize for or maizing interventions: after three weeks the winter-spring crop sowing

\begin{tabular}{llll}
\hline The time for organizing interventions: after three weeks the winter-spring crop sowing & 13 & 23 \\
\hline The duration of one intervention: a half of day for a theme & 12 & 24 \\
\hline
\end{tabular}

The period between two interventions: around 7-10 days

The location where organized the interventions

The seating arrangement for learning and group discussion

ICT supporting

The time provide for the group discussion and presentation/sharing

The contents of materia

\begin{tabular}{lll} 
The design of material & 11 & 25 \\
\hline
\end{tabular}

The time to hand out the material of the interventions 
Table 3: Participants' evaluation facilitators' skills (number of respondents)

Table 3: Participants' evaluation facilitators' skills (number of respondents)
\begin{tabular}{llr} 
Facilitator's skills & & \\
\hline The skills of facilitators to present and share & 20 & 16 \\
\hline The skills of facilitators to use words in the interventions & 30 & 6 \\
\hline The skills of facilitators to add some practical examples & 21 & 15 \\
\hline The skills of facilitators to use ICT & 36 & 0 \\
\hline The skills of facilitators to organize group discussions & 30 & 6 \\
\hline The skills of the facilitators to communicate (ask, listen, feedback) with the participants & 20 & 16 \\
\hline The skills of the facilitators to summary each topic/themes & 26 & 11 \\
\hline The attitude of the facilitators & 36 & 0 \\
\hline
\end{tabular}

\section{Summary}

Climate change already affects Vietnam in every sector and region, and the impacts are projected to increase under the pressing future socio-economic developments. The Vietnamese agricultural sector is particularly vulnerable to current and future climate risks because of the low capacities of local farming communities to respond to climate change impacts. These local farming communities play an integral part in ensuring food security and creating sustainable livelihoods across Vietnam. Social learning is increasingly considered to be an important mechanism to develop the adaptive capacity of these farming communities. However, the challenge is how to ensure that social learning will increase the adaptive capacity of smallholder farmers to manage climate impacts on their farming practices. So far studies on the adaptive capacity of smallholder farmers have been limited in scope and hardly considered the multiple dimensions that impact social learning and adaptive capacity building, particularly in low income countries such as Vietnam. The aim of this thesis is therefore to explore and elicit the ways through which social learning can increase the adaptive capacity of smallholder farmers in central coastal Vietnam to respond to climate change impacts. The four research questions central to this thesis are:

- What insights does the existing body of climate change adaptation literature provide into the interplay between social learning and adaptive capacity?

- What do smallholder farmers in Vietnam perceive as their current adaptive capacity and what enables or constrains them in increasing it?

- How can social learning configurations strengthen the adaptive capacity of farming communities?

- How do different levels of government enable and constrain the process of building adaptive capacity and social learning of smallholder farmers to respond to impacts of climate change in Vietnam?

These questions are addressed using pragmatism and eclecticism as methodological perspectives in designing a reasoned exploratory research project that combines multiple methods and theories. These perspectives yielded complementary insights and helped ensure the validity of findings. This thesis consists of four publications that conjointly address the four research questions. 
Chapter 2 addresses the research question of what insights the existing body of climate change adaptation literature provide about the interplay between social learning and adaptive capacity. Systematic review methods are used to identify and assess 43 carefully selected scientific publications. By reviewing the literature, this chapter distilled three perspectives of the interplay between social learning and adaptive capacity. First, the adaptive capacity-focused perspective emphasises the process of increasing adaptive capacity by developing the social learning process. This perspective seems most appropriate in developing or low-income countries where people have limited adaptive capacity to respond to climate change impacts. Second, the social learning-focused perspective emphasises that adaptive capacity is one of the crucial conditions for creating an enabling social learning environment. This perspective was found to be most appropriate in situations where individuals or communities have enough adaptive capacity but where existing climate change governance or institutions are weak. Third, the hybrid perspective emphasises the interdependency between social learning and adaptive capacity. This perspective seems most appropriate in cases in polycentric governance systems where climate change adaptation is implemented in conditions where there are self-organizing decision authorities that are loosely connected to each other. Understanding these three perspectives results in more refined understanding for the design of learning-based interventions and for the identification of appropriate intervention strategies in a particular context.

Chapter 3 investigates what smallholder farmers in Vietnam perceive as their current adaptive capacity and what enables or constrains them in further increasing their adaptive capacity. The model of private proactive adaptation to climate change and three critically important determinants of adaptive capacity are adopted to answer this question. The findings of chapter 3 showed that farmers in the Thua Thien Hue region experience an increase in extreme climate variability which seriously impacts the agricultural production of farming communities. Several adaptation measures are already applied in both crop and livestock production; however these measures represents forms of autonomous adaptation that have limited forward looking dimensions. Farmers adopt these adaptation measures mostly because they are familiar with certain crop production techniques or because of changes in the market price for livestock. The study found that there are several constraints in adopting adaptation measures that farmers perceive: market price fluctuations, lack of skilled labour, and lack of climate change information and limited capacity to learn and to apply techniques in practice. These constraints have influenced the motivations of farmers to master and apply adaptation strategies. Overall, farmers perceive that they lack adaptive capacity to manage climate change issues in agricultural production and this is particularly that case for farmers in livestock production.

Chapter 4 starts from the findings from chapters $2 \& 3$, to address the research question how social learning configurations could strengthen the adaptive capacity of farming communities. Adopting the adaptive-capacity focused perspective developed in chapter 2 , the findings from this chapter show that a social learning configuration through workshop-based interventions offers important ways to increase adaptive capacity of smallholder farmers. The specific social learning configuration adopted leads to enhanced relationships and improved social cohesion, better utilisation of different perspectives, improved systems thinking, initiation of new knowledge, and to the optimisation of existing adaptation actions in the farming community. These outcomes are considered valuable for developing farmers' adaptive capacity as they increased their knowledge exchange, changed their farming practices, improved their social networks, resulted in higher and more stable farmers' income, and improved overall environmental quality. However, chapter 4 also indicated that enhancing adaptive capacity does not only rely on designing, facilitating and monitoring a responsive learning configuration, but also on the available policy capacity of governments to ensure successful implementation of the configuration and upscaling of the findings.

Chapter 5 builds on this observation by asking how different levels of governments enable and constrain the process of building adaptive capacity and social learning of smallholder farmers in Vietnam. Using policy capacity theory, the findings from chapter 5 showed that in the hierarchical multilevel governance setting of Vietnam, there were several enablers and several constraints that have an influence on developing adaptive capacity and creating an optimal social learning environment for smallholder farmers to respond to climate change impacts. Crucial enabling factors included funding from international organizations for the most vulnerable countries, dedicated climate change adaptation policies, and clear responsibilities for climate change adaptation at national level. However, several institutional, resource, and policy analytical capacity constraints were observed: unclear institutional structures and absence of a clear legal mandate, limited available resources at local levels, limited knowledge and skills of individual policy actors to implement adaptation at local levels. The constraints outlined do not act in 
isolation but rather interact at different levels and were found to significantly constrain the building of adaptive capacity through social learning. Chapter 5 concludes that systematically building up policy capacities at different levels, especially in lower local levels should be considered to create a learning environment to increase the adaptive capacity of smallholder farmers.

Chapter 6 brings the most important finding together in a synthesis, reflects on the findings ad methods, and proposes several steps forward for research and policy. Based on the previous chapters, it is argued that this dissertation has shown that even though climate change continues to impact farmers in Vietnam, a well-designed responsive social learning configuration offers possibilities to enhance adaptive capacity of smallholder farmers to respond to climate change impacts. In order to implement such a learning configuration successfully, consideration of local (market) conditions is critical in the design of the configuration. Moreover, efforts are needed to enhance the policy capacity of government at different administrative levels as this creates the enabling environment for farmers to start learning, and to implement adaptation measures, and to upscale the lessons learned. The chapter provides various suggestions for strengthening adaptive capacity for smallholder farmers, including creating specific adaptation responsibilities at local and district levels. At the same time the chapter notes that strengthening adaptive capacity of farmers will remain challenging given the sparse resources, competition with other pressing societal issues and the difficulties, if not impossibility of changing the hierarchical governance system in Vietnam.

\section{About the author}

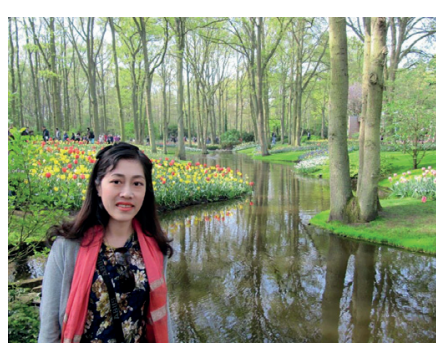

Le Thi Hong Phuong was born on $16^{\text {th }}$ of November 1983 in Nghe An, Vietnam. She obtained her Bachelor of Science in Agronomy at University of Agriculture and Forestry (HUAF), Hue University, Vietnam (2001-2005). Since 2005 she has worked as a lecturer at the Faculty of Extension and Rural Development, HUAF. She continued her Master of Science studies in Rural Development (with Specialization in Livelihood and Natural Resource Management) at the Swedish University of Agricultural Sciences (SLU), Uppsala, Sweden (2008-2010). Her Master thesis focused on climate change adaptation in agricultural production in Central coastal, Vietnam.

In March 2014, she started her Ph.D. study at the Education and Competence Studies group, Wageningen University. Her Ph.D. research focused on the development of adaptive capacity of smallholder farmers in the coastal areas in Vietnam to respond to climate change impacts by exploring stallholders' learning and governance. The research was financed under the Ministry of Education and Training, Vietnam (the 911 program) and NUFFIC/NICHE/VNM/105 project, the Netherlands. During her Ph.D. research, she followed the education program at the Wageningen School of Social Sciences (WASS). She followed various courses in the field social learning and climate change adaptation as well as climate change governance. After graduation, she will continue to work at HUAF as a lecturer and researcher in Vietnam.

Le Thi Hong Phuong,

Wageningen, 22 November 2017 


\section{List of publications}

Published and accepted

Phuong, L.T.H., Biesbroek, G.R., Wals, A.E.J., (2017). The interplay between social learning and adaptive capacity in climate change adaptation: A systematic review. NJAS - Wageningen Journal of Life Sciences, 82, 1-9.

Phuong, L.T.H., Biesbroek, G.R., Sen, L.T.H., Wals, A.E.J. (accepted, 2017). Understanding smallholder farmers' capacity to respond climate change: A case study in coastal community, Central-Vietnam. Climate and Development

Under review

Phuong, L.T.H., Biesbroek, G.R., Sen, L.T.H., Hoa, N.Q., Lu, P.V., Wals, A.E.J (under review). Increasing Vietnamese smallholder farmers' adaptive capacity to respond to climate change. Local Environment

Phuong, L.T.H., Biesbroek, G.R., Wals, A.E.J. (under review). Barriers and enablers to climate change adaptation in the hierarchical governance system of Vietnam. Journal of Environmental Policy and Planning

Presentations

Phuong, L.T.H., Biesbroek, G.R., Sen, L.T.H., Hoa, N.Q., Lu, P.V., Wals, A.E.J. (2016). Increasing the smallholders farmers' adaptive capacity to climate change impacts through social learning intervention in central Vietnam. International Conference: University Curricula and Research on Water Management and Agriculture for Climate Change Responses, Hanoi, August, Vietnam

Phuong L.T.H. (2014). The use of indigenous knowledge in developing climate change adaptation strategies. International Conference: Deltas in Time of Climate change II, Rotterdam, September, Netherlands

Other

Hoa. B.T, Phuong. L.T.H., Loi. T.H., Tuan. T.V. (2017). Factors affecting the adoption of adaptation measures to climate change: A case study in Huong Phong commune, Huong Tra town, Thua Thien Hue province. Hue University Journal of science, 126(5b)

Tuyen. T.V., Phuong. L.T.H., Khanh. H.L.P., Sen. L.T.H., Hoang. T.Q., Tuan, N.V., Nhung. P.T., Nhung. N.B.T., Hung. H.G. (2013). Building Extension Club cited in Community development skills in Extension - Agricultural Publisher

Sen. L.T.H., \& Phuong. L.T.H. (2011). Climate change and adaptation of farmers in Trieu Van commune, Quang Tri province, Vietnam, Issues and Challenges in Rural Development, Vol II, Volume 126, page 239-257, Margraf Publishers

Phuong. L.T.H., Ha. H.M, Sen. L.T.H. (2010). Farmer's Adaptation to Drought: A case study of mixed-farming systems in the coastal area in Trieu Van commune, Trieu Phong district, Quang Tri province, in Rural change: research on livelihoods, rural institutions and household adaptation strategies Proceeding, Hue University Publisher

Sen. L.T.H., \& Phuong. L.T.H. (2009). Literature review: Climate change and adaptation in agricultural production in coastal area, Hue university Publisher

Phuong. L.T.H. \& Sau. T.Q. (2009). Property rights practice in aquatic exploitation for fish corral activity in Vinh Giang commune, Phu Loc district, Thua Thien Hue provice, Vietnam, Agricultural Publisher

\section{Le Thi Hong Phuong}

Wageningen School of Social Sciences (WASS)

Completed Training and Supervision Plan

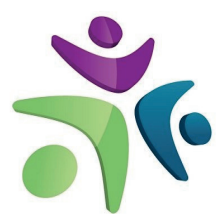

Wageningen School of Social Sciences

Name of the learning activity

A) Project related competences

Research Methodology: From Topic to Proposal WASS
Systematic Approaches to Reviewing Literature WASS

Critical Perspectives on Social Theory

WASS

Climate Change Governance: Adaptation and

Mitigation as Institutional Change Processes

Writing Research Proposal

CDI

WASS

WASS

B) General research related competences

WASS Introduction Course

Efficient Writing Strategies

Techniques for Writing and Presenting a Scientific Paper

Data managemen

Competence theory, Research and Practice

Project and Time Management

C) Career related competences/personal development

Effective Behaviour in Your Professional

Surroundings (Part 1)

Effective Behaviour in Your Professional

Surroundings (Part 2)

PhD Competence Assessment

PhD meeting

The fourth Annual WPC PhD Symposium

The use of indigenous knowledge in developin

climate change adaptation strategies

Increasing the smallholders farmers' adaptive capacity to climate change impacts through

WASS

WGS

WGS

WGS
ICO

WGS

WGS

WGS

ECS

WGS

Year

$2014 \quad 4$

$2014 \quad 4$

$2014 \quad 3.5$

$2014 \quad 4$

$2016 \quad 0.5$

20146

8.2

$2014 \quad 1$

$2014 \quad 1.2$

$2014 \quad 1.2$

$2015 \quad 0.3$

$2014 \quad 3.0$

$2014 \quad 1.5$

8.9
0.7

$2015 \quad 0.6$

$2014 \quad 0.3$

2014- $\quad 1$

$2017 \quad 0.3$

International Conference: Deltas in Time of Climate change II, Rotterdam

$2014 \quad 1$

International Conference: University Curricula and

Teaching and Supervision

One Bachelor class: Agricultural Extension

Supervision one Bachelor student: Assessing

farmers' adaptive

Total

*One credit according to ECTS is on average equivalent to 28 hours of study load 


\section{Colophon}

This research described in this thesis was financially supported by the Ministry of Education and Training, Vietnam and NUFFIC/NICHE/VNM/105 project, The Netherlands.

Cover design by Le Nguyen Cong Phuc \& Le Thi Hong Phuong

Printed by Digiforce B.V. || Proefschriftmaken.nl 